\title{
Attentional Dysfunctions and its Pharmacological Modulation in Childhood Psychiatric Disorders: Evidence from Neuropsychological Studies
}

\section{Proefschrift}

Ter verkrijging van de graad van doctor aan de universiteit Maastricht.

Door

Thomas Günther

Aken (D), juli 2005

Promotores:

Prof. dr. J. Jolles

Prof. dr. B. Herpertz-Dahlmann

Co-Promotor:

Dr. K. Konrad 

Chapter 1: Attention in child and adolescent psychiatry disorders - Background and goals of the thesis

Chapter 2: Verbal memory and aspects of attentional control in children and adolescents with anxiety disorders or depressive disorders Günther, Holtkamp, Jolles, Herpertz Dahlmann, Konrad (2004). Journal of Affective Disorders. 82: 265.269

Chapter 3: The impact of age differences on impulsivity and sustained attention deficits in attention deficit/ hyperactivity disorder with and without disruptive behavior disorder: a cross-sectional study

Günther, Konrad, Jolles, Herpertz-Dahlmann (in progress).

Chapter 4: Age- dependent neuropsychological deficits and effects of methylphenidate in children with attention-deficit/ hyperactivity disorder: a comparison of pre- and grade-school children

Hanisch, Konrad, Günther, Herpertz-Dahlmann (2004). Journal of Neural Transmission. 111: 865-881

Chapter 5: Differential effects of methylphenidate on attentional functions in children with attention-deficit / hyperactivity disorder Konrad, Günther, Hanisch, Herpertz-Dahlmann (2004). Journal of the American Academy of Child and Adolescent Psychiatry. 43: 191.198

Chapter 6: Clinical evaluation of subjective and objective changes in motor activity and attention in children with attention-deficit / hyperactivity disorder in a double-blind methylphenidate trial Konrad, Günther, Heinzel-Gutenbrenner, Herpertz-Dahlmann (2005). Journal of Child and Adolescent Psychopharmacology. 15: 180-190 
4 | Contents

Chapter 7: The influence of sertraline on attention and verbal memory in children and adolescents with anxiety disorders

Günther, Holtkamp, Jolles, Herpertz-Dahlmann, Konrad (in press). Journal of

Child and Adolescent Psychopharmacology

Chapter 8: The influence of risperidone on attentional functions in children and adolescents with attention deficit/ hyperactivity disorder and comorbid disruptive behavior disorder

Günther, Konrad, Jolles, Herpertz-Dahlmann (in progress)

Chapter 9: Concluding Remarks

Appendix: Reliability of attention and verbal memory tests for children and adolescents

Günther, Herpertz-Dahlmann, Konrad (2005). Zeitschrift für Kinder- und Jugendpsychiatrie. 33: 169-179 
Chapter 1:

Attention in child and adolescent psychiatry disorders - Background and goals of the thesis 


\section{6 | Chapter 1}

\section{Introduction}

It is estimated that 3\% - 5\% of all school-age children suffer from an attention-deficit/ hyperactivity disorder (ADHD) (DSM-IV; American Psychiatric Association, 1994). More boys than girls are affected before and after puberty. $30 \%$ of those children suffering from ADHD will continue to be plagued by it as adults. The areas of dysfunction highlighted by diagnostic tests include executive and attention-related abilities, increased motor activity, and cognitive and behavioral impulsivity. Some of the related behavioral and cognitive problems are, e.g., poor concentration, restlessness, impulsivity and not well thought-out responses. Often ADHD leads to behavioral problems, such as disruptive and aggressive behavior, and there is a high overlap rate between ADHD and disruptive behavior disorders (DBD) (Biederman, Newcorn, \& Sprich, 1991; August, Realmuto, MacDonald, Nugent, \& Crosby, 1996). These comorbid disorders are also associated with cognitive problems. Children with ADHD and comorbid DBD, for example, are described as being more impulsive than children that only suffer from ADHD, whereas children with ADHD have more attentional problems (e.g. Halperin et al., 1990). Other frequently observed comorbid disorders are affective disorders such as depression or anxiety disorders. Also, anxiety disorders and affective disorders are associated with different cognitive impairments such as lowered cognitive flexibility (Toren et al., 2000) or deficits in attention and executive function (Porter, Gallagher, Thompson, \& Young, 2003).

In summary, psychiatric disorders can be associated with cognitive impairments, whereas different psychiatric disorders, e.g. ADHD and DBD, often occur together. The fact that there is comorbidity of different psychiatric childhood disorders raises the question which cognitive impairments characterize these children with comorbidity. ADHD, for example, is associated with attentional impairments and is, in general, treated with methylphenidate (MPH) to enhance the associated attentional impairments. However, the comorbidity of ADHD with severe DBD may result in a combination treatment of MPH and a neuroleptic agent (e.g. risperidone) to treat the aggressive behavior. It is possible that children with a combination of ADHD and DBD differ in their attentional impairment profile from children with ADHD only.

In addition, it is important to know to what extent the cognitive profile changes as a result of a combination treatment of MPH and a neuroleptic agent. However, in general, the psychopharmacology literature about children and adolescents is limited and knowledge about the medication's effect on the children's cognition scarce or controversial. Therefore, it is necessary to know which cognitive impairments are associated with psychiatric disorders or 
comorbidity. Results in this area make it easier to examine the possible cognition changes resulting from psychotropic treatment.

The present thesis examines the problem of the possible comorbidiy of ADHD and DBD and evaluates the nature of cognitive dysfunctions in these conditions. This is done especially in relation to the effects of various behaviorally active drugs. In order to describe the aims of this thesis in more detail, some background information is needed. This will be provided in the next paragraphs. The following sections give a short background summary about cognitive dysfunctions - notably attention and attentional deficits - in children with psychiatric disorders. It mainly focuses on attention deficits in children with ADHD or ADHD + DBD. It also introduces cognitive deficits in depression and anxiety disorders. Finally, it gives a short introduction about the psychopharmacological agents used in this thesis and their impact on attentional functions.

\section{Attention Deficits in Attention Deficit/ Hyperactivity Disorders, Disruptive Behavior Disorders and Emotional Disorders}

Attention is a cognitive function which is indispensable for the everyday life of children and adults. With respect to children and adolescents, this is true especially in relation to school or vocational training. Deficits in this area could affect the schooling or vocational education. Attention is, however, a higher cognitive function and involves various functions or processes (Van Zomeren \& Brouwer, 1994). Current concepts of attention generally distinguish between selectivity (focused and divided attention) and intensity (alertness and sustained attention) of attention. Impairments can be divided into four subcategories: (a) difficulty in maintaining attentional focus on a single stimulus in the presence of distractors (focused attention), (b) difficulty in dividing attention between two or more stimuli (divided attention), (c) difficulty in orienting oneself and reacting to a stimulus (alertness), and (d) difficulty in remaining alert for extended periods of time (sustained attention). In addition, deficits in attentional functions are also explained by problems in inhibitory processes, which are dependent upon the prefrontal areas of the brain. The different components of the attentional system are considered to be autonomous to each other and selectively susceptible to interference (Sturm \& Zimmermann, 2000). 


\section{8 | Chapter 1}

\section{$\underline{\text { Attention and ADHD }}$}

The first ADHD symptoms can usually be identified before a child is 6 years old. An attention disorder, beside hyperactivity and impulsivity, is one of the main symptoms of ADHD (American Psychiatric Association, 1994). Some of the behavioral and cognitive problems related to ADHD are poor concentration, restlessness, impulsivity and not well thought-out responses. Some other problems that are frequently associated with ADHD are low selfesteem, emotional outbreaks and difficulties with delayed gratification (Faraone \& Doyle, 2001). The stop-signal task is a frequently used neuropsychological paradigm to examine attentional functions in children and adolescent with ADHD. A recent meta-analytic review of stopping performance concluded that children with ADHD had both, an attention deficit and an inhibitory deficit (Lijffijt, Kenemans, \& van Engeland, 2005). In this study, the adults did not have any more attention deficits, whereas the inhibitory problems remained. This suggests that an impairment of inhibitory motor control might be the core deficit in ADHD (Barkley, 1999; Quay, 1997). However, when testing for neuropsychological functions model oriented, children and adolescents with ADHD had no deficits in divided or focused attention but showed deficits in alertness (Van der Meere, Wekking, \& Sergant, 1991). Moreover, they had more unspecified attention problems, like slower, fluctuating and more faulty attention reactions in comparison to healthy controls (Földényi, Imhof, \& Steinhausen, 2000). In addition, Swaab-Barneveld et al. (2000) examined the sustained attention performance in six different clinical groups (among others ADHD, conduct disorder (CD), anxiety and affective disorders). Thereby, the authors demonstrate that all clinical samples made more errors and showed increased speed fluctuations. Altogether, this study could prove an attention deficit in children with ADHD, but there was no specific profile in comparison to other clinical groups.

\section{$\underline{\text { Attention and DBD }}$}

Neuropsychological deficits in the attentional system and/or executive function (EF) and behavioral deficits (e.g. impulsivity) are also related to DBD. Several studies of children with ADHD generally failed to find a deficit in motivational inhibition (Nigg, 1999; Jaboni, Douglas, \& Baker, 1995), whereas the notion that there is a motivational disinhibition in CD is well supported by behavioral and physiological data (Finn, Mazas, Justus, \& Steinmetz, 2002; O'Brian \& Frick, 1996). One of the most important points is that children with ADHD and associated DBD have a more serious clinical course and poorer outcome than children with ADHD without DBD (Biederman et al., 1991; Fischer, Barkley, Smallish, \& Fletcher, 2002). Overall, children with ADHD+DBD have more varied, severe, and stable antisocial behaviors 
(Fischer et al., 2002) and perform more poorly on tests regarding neuropsychological functioning (Lynam, 1996). Furthermore, there is consistent and robust evidence that children with ADHD and children with ADHD+DBD have a deficit in attentional and executive functions (Pennington \& Ozonoff, 1996; Oosterlaan, Logan, \& Sergeant, 1998). A review of research in the EF for ADHD, oppositional defiant disorder (ODD), CD, higher functioning autism and Tourette syndrome makes clear that there are distinct differences between these groups and normal controls in EF (Sergeant, Geurts, \& Oosterlaan, 2002). ADHD children have performance deficits in some EF tasks, but performance on EF tests in these children were also deficient in other clinical groups such as ODD or CD. However, these deficits do not distinguish children with ADHD from children with ADHD+DBD or other psychiatric disorders such as emotional disorders.

\section{Other Childhood Psychiatric Disorders and Cognitive Function}

Emotional disorders are common in children and adolescents with psychiatric conditions, and approximately $5 \%$ of all school-aged children are diagnosed with anxiety disorders and depression. There are high levels of comorbidity between the two disorders (Angold, Costello, \& Erkanli, 1999). It has been suggested that emotional disorders may be associated with impaired neurocognitive functions (e.g., Porter et al., 2003). This is based on teacher and parent reports stating that children with an anxiety disorder or depression suffer from concentration and memory problems and usually have a lot of problems in school (Benjamin, Costello, \& Warren, 1990). However, until now, it is not clear whether the child's neurocognitive abilities are disturbed even when taking an objective test regarding attention and memory and, if so, which cognitive impairments are specifically associated with either anxiety disorders or childhood depression. Several studies have examined the neurocognitive performance of adults with depressive disorders (e.g., Austin et al., 1999); however, findings to date have been contradictory, with many factors potentially contributing to inconsistencies between studies. A recent study sought to address these previous limitations by testing a well characterized group of medication-free patients with major depressive disorders with a comprehensive neurocognitive test battery (Porter et al., 2003). There were no differences regarding verbal memory processes; however, the most robust effects were found in tests regarding attention and executive function. In summary, adult studies have provided inconsistent results which might especially be due to inhomogeneous patient groups in terms of age, symptom severity, time since symptom onset, or psychotropic medication history. 


\section{Cognitive Neuropharmacology}

Cognitive neuropharmacology is a specialty within the broad domain of psychopharmacology, which deals with the study of mechanisms underlying the action of drugs on psychological functioning and the development of drugs that help modify psychological functions (Le Merrer \& Noguès, 2000). Psychotropic drugs are subdivided into three groups, based on their effect on cognition: psycholeptics (depress central nervous system activity), psychoanaleptics (increase central nervous system activity), and psychodysleptics (perturb brain functioning). Different psychotropics are used to treat psychiatric disorders in children and adolescents, but, to date, pediatric psychopharmacology only has substantial empirical evidence that supports stimulant medications for ADHD (Taylor et al., 2004), and selective serotonin reuptake inhibitors (SSRI) for obsessive compulsive disorder (for a review see McClellan \& Werry, 2003). Some well designed multi-centric trials also support SSRIs for major depression (e.g. Emslie et al., 2002) and childhood anxiety disorders (e.g. The Research Units on Pediatric Psychopharmacology Anxiety Study Group, 2001), and risperidone for behavioral disturbances (e.g. Snyder et al., 2002; Turgay, Binder, Snyder, \& Fisman, 2002). Over the past few years, more and more children have been given prescriptions for psychotropics. Over the past 10 years, the overall prescription of $\mathrm{MPH}$, for example, has tripled for preschoolers (Connor, 2002) and increased eightfold for grade-schoolers (American Academy of Child and Adolescent Psychiatry, 2002). The effects of psychotropics on cognition can either be desired or unwanted side effects. However, the psychopharmacology literature for children and adolescents is limited and there is very little and only controversial knowledge about its effect on cognition. Therefore, it is important to examine the influence of psychotropics on cognition in children and adolescents (Riddle, Kastelic, \& Frosch, 2001).

\section{Methylphenidate (MPH)}

Stimulants, especially methylphenidate (MPH), are the most widely prescribed psychotropic medications for children, primarily in the treatment of ADHD (Greenhill et al., 2002). More than 150 randomized control studies in school-age children have demonstrated the benefits and efficacy of MPH. A sufficient number of studies have confirmed that stimulant medications reduce the occurrence of the three cardinal ADHD symptoms: inattention, impulsivity and hyperactivity (Greenhill, Halperin, \& Abikoff, 1999). These studies do not, however, clearly describe the effects of MPH on cognitive functions. Although some empirical results report increased attention functions (Van der Meere et al., 1991; Tannock, Ickowicz, \& Schachar, 1995; Tannock, Schachar, \& Logan, 1995), other studies did not find that the medi- 
cation had any positive effects regarding selective attention paradigms in children with ADHD (Van der Meere, Gunning, \& Stemerdink, 1999) or even report that the children had less cognitive flexibility under stimulant medication (Solanto, 1984). With regard to dosagedependent effects, again, divergent findings have been reported with several studies failing to show a MPH dosage effect on cognitive functions (Rapport \& Kelly, 1991 for a review). When dosage effects were found, unlike behavioral changes, only a few attentional functions seem to show linear improvements. This seems to be true for simple tasks such as target detection, in particular regarding the variability of simple reaction times or sustained attention (Denney \& Rapport, 2001). However, there are also studies, e.g. on inhibition, which have shown U-shaped improvements, with reduced performance on higher dosages of MPH (Tannock et al., 1995). To summarize, little is known about the sensitivity and specificity of levels of MPH with regards to attention tasks and only a limited number of studies are available so far.

\section{Selective Serotonin Reuptake Inhibitors (SSRI)}

Selective serotonin reuptake inhibitors (SSRI) have become the second most prescribed psychotropic agents and represent an important therapeutic modality in the treatment of childhood psychiatric disorders (Jensen et al., 1999). Prescription rates are not only increasing among late adolescents but also among children between the ages of 10 and 14 (Zito et al., 2002). Behavioral side effects include motor restlessness and behavioral disinhibition (Damsa et al., 2004). The neuropsychological side effects of SSRI in childhood psychiatric disorders have never been systematically assessed, although animal and human studies indicate that these drugs may influence cognitive performance (Buhot, Martin, \& Segu, 2000).

Impulsive behavior may be modified by serotonergic (5-HT) activity, with underactivity in 5HT neurotransmission increasing impulsivity and vice versa (Bizot \& Thiebot, 1996). By contrast, animal data and lesion studies suggest that acute increases in central serotonin concentrations may impair learning abilities (Santucci, Knott, \& Haroutunian, 1996). Moreover, a single dose study with healthy adults showed that paroxetine could improve motor performance through practice, but that it decreased the ability to inhibit automatisms (Loubinoux, Pariente, Rascol, Celsis, \& Chollet, 2002). Other studies with healthy middle-aged subjects confirmed paroxetine's impairment of vigilance performance, whereas this effect was not found for sertraline (Schmitt et al., 2002).

Taken together, the results for the influence of SSRI on cognitive functions such attention and memory remain contradictory. In fact, different study designs (single application, various 


\section{2 | Chapter 1}

dosages, short-term versus long-term applications, different SSRIs) make it difficult to draw a clear picture of the cognitive side effects. However, the effects of manipulations of serotonergic activity seem to depend on the nature of the responses required, the baseline regulation of the serotonergic system and the age of the subjects, thereby differentially influencing impaired and non-impaired cognitive functions in healthy subjects and patient groups of different ages.

\section{Risperidone}

Aggression is a common target symptom for which antipsychotics are prescribed to youths (Kaplan, Simms, \& Busner, 1994). The best evidence for the efficacy of risperidone treatment for aggression exists for autism (Arnold et al., 2003; McClellan et al., 2003). Particularly for children and adolescents, there is less evidence regarding any cognitive side effects of risperidone. There are only two studies with children between five and twelve years of age with an IQ beneath 84 and disruptive behavior (Turgay et al., 2002; Snyder et al., 2002). These studies did not find any changes or improvements of cognitive variables (Continuous Performance Test \& California Verbal Learning Test) and also no deterioration of cognitive function in participants that were being treated with risperidone. The participants did, however, experience sedative and amnestic effects of psychotropic drugs after the first administration (Nowakowska, Chodera, \& Kus, 1999; Holland, Wesnes, \& Dietrich, 1994) and, compared with adults, children are especially vulnerable to adverse effects such as sedation (McConville \& Sorter, 2004).

\section{Thesis Outline}

In summary, attention is one of the cognitive domains which is indispensable in the everyday life of children and adolescents (e.g. in school or vocational training). Deficits in this cognitive domain could affect their performance in school or during their vocational training. To treat children with disorders like ADHD, DBD or emotional disorders more appropriately, it is essential to understand the cognitive deficits that are linked to the different disorders. Furthermore, it is important to be aware of the influence of the used psychotropic agents on cognitive functions. There is a lot of published research about ADHD, and it is indisputable that children with ADHD have attentional deficits. Typically prescribed psychotropics such as methylphenidate are used to enhance the attention functions of children and adolescents. However, the literature is not unambiguous regarding the primary processes on which these substances act, and the precise effects of MPH on cognitive functions are less clear described. 
In addition, there are only a limited number of neuropsychological published studies about cognitive deficits in DBD or emotional disorders. Moreover, there is very little research regarding the impact that the typically used psychotropic agents have on attentional functions in children and adolescents. It is quite difficult to do so due to the high comorbidity between the disorders and possible interaction effects. Furthermore, double medications, like a combined treatment of ADHD+DBD with methylphenidate and risperidone, make the issue still more complex.

Therefore, the goal of this thesis is to learn more about the attentional dysfunctions in children and adolescents with psychiatric disorders and the changes in attention functions that are caused by psychotropics. If the diagnostic processes and objective tools to measure cognitive changes that are caused by psychotropics improve, it is possible to increase the efficacy of psychopharmacological treatment. Therefore, this study examines attentional dysfunctions in children and adolescents with ADHD, ADHD with comorbid DBD, anxiety disorder and depression. Furthermore, it investigates the influence of typically used psychotropic agents for the different disorders have on cognitive functions.

In line with the mentioned goals, the thesis consists of two parts. Part I (chapter $2-4$ ) evaluates neuropsychological deficits of children with ADHD, ADHD with comorbid DBD, anxiety disorder and depression. These chapters aim to examine basic performance results that children and adolescents with anxiety disorder or depressive disorders achieve on attention and memory tasks. Part I also takes a look at attention and inhibition differences between children and adolescent with ADHD and ADHD+DBD. Part II (chapter 4 - 8) addresses the influence of different psychopharmacological agents (methylphenidate, sertraline and risperidone) on attention, verbal memory and motor activity. The goal is to investigate effects of $\mathrm{MPH}$, sertraline and risperidone on different attention functions. Chapter 9 summarizes and discusses the results described in the various chapters of the thesis. Below, a short overview of the chapters of this thesis is given.

\section{Chapter 2 Verbal memory and aspects of attentional control in children and adolescents with anxiety disorders or depressive disorders}

It has been suggested that emotional disorders may be associated with impairments in neurocognitive functioning. However, until now, it remains unclear whether neurocognitive abilities are disturbed when ob- 
jective measures of attention and memory are evaluated and, if so, which cognitive impairments are specifically associated with either anxiety disorders or depression in childhood. Therefore, the goal of chapter 2 was to examine basic performance on attention and memory tests in treatment-naïve children and adolescents with anxiety disorder or depressive disorder under drug-free conditions.

\section{Chapter 3 The impact of age differences on impulsivity and sustained attention} deficits in attention deficit/ hyperactivity disorder with and without disruptive behavior disorder: a cross-sectional study

Attention and executive function deficits are a part of ADHD and ADHD +DBD. However, it seems that the described deficits are not specific to one clinical group. Furthermore, evidence from research about neuropsychological deficits in ADHD or ADHD+DBD is based on children under the age of 12 , but it is suggested that attention and executive function deficits in children with ADHD change based on the patient's age and development. Therefore, the goal of chapter 3 was to analyze attention and inhibition differences between children and adolescent with ADHD and ADHD+DBD. To examine developmental processes, the study compared two age groups within each clinical group: children between 8-11 years of age and adolescents between 1217 years of age.

Chapter 4 Age- dependent neuropsychological deficits and effects of methylphenidate in children with attention-deficit/ hyperactivity disorders: a comparison of pre- and grade-school children

The goal of chapter 4 was to compare neuropsychological performances of pre-school and grade-school children with ADHD. Attention deficits in both age groups were expected, especially in attention intensity and in the supervisory attention system. Brain maturation processes might result in differences in the distribution of cognitive subtypes across age groups. A second goal was to evaluate MPH effects on computerized attention tests and compare pre-school to grade-school children. 


\section{Chapter 5 Differential effects of methylphenidate on attentional functions in} children with attention deficit / hyperactivity disorders

Little is known about the sensitivity and specificity of levels of methylphenidate to attention tasks, and there are only a limited number of studies so far. Therefore, the goal of chapter 5 was to investigate dosagedependent effects on different attentional functions using a theoretically based selection of six attention paradigms.

Chapter 6 Clinical evaluation of subjective and objective changes in motor activity and attention in children with attention-deficit / hyperactivity disorder in a double-blind methylphenidate trial

Although several studies have examined drug effects on either subjective or objective measures of attentional and motor functioning in children with ADHD, little is known about the relationship between these two areas of outcome measures. Studying the convergences and divergences of change in these two measures might provide a useful basis for optimizing methylphenidate titration guidelines. Therefore, the aim of chapter 6 was to examine dosage-dependent effects of methylphenidate on motor activity and attention.

Chapter 7 The influence of sertraline on attention and verbal memory in children and adolescents with anxiety disorders

There were several studies demonstrating that sertraline was safe for the treatment of children and adolescents. However, the results for the influence of SSRI on cognitive functions, like attention and memory, remain contradictory. Thus, chapter 7 aimed to investigate the effect of a 6week course of sertraline treatment on verbal memory and attentional performance in children with anxiety disorders. The current study examines the influence of sertraline on non-impaired cognitive functions in children and adolescents treated with sertraline for clinical purposes.

Chapter 8 The influence of risperidone on attentional functions in children and adolescents with attention deficit/ hyperactivity disorder and co- 


\section{morbid disruptive behavior disorder}

Risperidone is a well tolerated neuroleptic agent and has a place in the management of children with ADHD with associated severe DBD, when other treatments have proved unsuccessful. However, little is known about cognitive side effects of risperidone in ADHD+DPD children with an average IQ. The goal of chapter 8 was to examine the influence of risperidone on different attentional systems in a sample of ADHD+DPD children with an average IQ, who had not benefited sufficiently from a previous stimulant treatment.

\section{Chapter 9 Concluding remarks}

The goal of chapter 9 is to discuss the value of the results in the various chapters of the thesis. It combines the research results, discusses them and indicates some directions for further research.

\section{Appendix Reliability of attention and verbal memory tests for children and adolescents}

The purpose of this appendix is to provide information on particular psychometric characteristics of tests used in this thesis in order to provide some relevant background information. More specifically, it describes the test-retest reliability for the attention- and verbal memory tests used in this thesis after six weeks.

\section{References}

American Academy of Child and Adolescent Psychiatry (2002). Practice parameters for the use of stimulant medication in the treatment of children, adolescents and adults with ADHD. Journal of the American Academy of Child and Adolescent Psychiatry, 41 Suppl, 2649.

American Psychiatric Association (1994). Diagnostic and Statistical Manual of Mental Disorders - DSM-IV. (4 ed.) Washington D.C.: American Psychiatric Association.

Angold, A., Costello, E. J., \& Erkanli, A. (1999). Comorbidity. Journal of Child Psychology and Psychiatry, 40, 57-87. 
Arnold, L. E., Vitello, B., McDougle, C., Scahill, L., Shah, B., Gonzalez, N. M. et al. (2003). Parent-Defined Target Symptoms Respond to Risperidone in RUPP Autism Study: Customer Approach to Clinical Trials. Journal of the American Academy of Child and Adolescent Psychiatry, 42, 1443-1450.

August, G. J., Realmuto, G. M., MacDonald, A. W., Nugent, S. M., \& Crosby, R. (1996). Prevalence of ADHD and Comorbid Disorders Among Elementary School Children Screened for Disruptive Behavior. Journal of Abnormal Child Psychology, 24, 571-595.

Austin, M. P., Mitchell, P., Wilhelm, G., Parker, G., Hickie, I., Brodaty, H. et al. (1999). Cognitive function in depression: a distinct pattern of frontal impairment in melancholia? Psychological Medicine, 29, 73-85.

Barkley, R. A. (1999). Response inhibition in attention-deficit hyperactivity disorder. Mental Retardation and Developmental Disabilities Research Reviews, 5, 177-184.

Benjamin, R., Costello, E. J., \& Warren, M. (1990). Anxiety disorder in a pediatric sample. Journal of Anxiety Disorders, 4, 293-316.

Biederman, J., Newcorn, J. H., \& Sprich, S. (1991). Comorbidity of Attention Deficit Hyperactivity Disorder With Conduct, Depressive, Anxiety, and Other Disorders. American Journal of Psychiatry, 148, 564-577.

Bizot, J. C. \& Thiebot, M. H. (1996). Impulsivity as a confounding factor in certain animal tests of cognitive function. Cognitive Brain Research, 3, 243-250.

Buhot, M. C., Martin, S., \& Segu, L. (2000). Role of serotonin in memory impairment. Annals of Medicine, 32, 210-221.

Connor, D. F. (2002). Preschool attention deficit hyperactivity disorder: A review of prevalence, diagnosis, neurobiology, and stimulant treatment. Journal of Developmental \& Behavioral Pediatrics, 23, 1-9.

Damsa, C., Bumb, A., Bianchi-Demicheli, F., Vidailhet, P., Sterck, R., Andreoli, A. et al. (2004). "Dopamine-dependent" side effects of selective serotonin reuptake inhibitors: a clinical review. Journal of Clinical Psychiatry, 65, 1064-1068.

Denney, C. \& Rapport, M. D. (2001). The cognitive pharmacology of stimulants in children with ADHD. In M.V.Solanto, A. F. Arnsten, \& F. X. Castellanos (Eds.), Stimulant Drugs and ADHD: Basic and Clinical Neuroscience (pp. 283-302). New York: Oxford University Press.

Emslie, G. J., Heiligenstein, J. H., Wagner, K. D., Hoog, S., Ernest, D., Brown, E. et al. (2002). Fluoxetine for Acute Treatment of Depression in Children and Adolescents: A Pla- 
cebo-Controlled, Randomized Clinical Trial. Journal of the Amarican Academy of Child and Adolescent Psychiatry, 41, 1205-1215.

Faraone, S. V. \& Doyle, A. E. (2001). The nature and heritability of attentiondeficit/hyperactivity disorder. Child and Adolescent Psychiatry Clinics of North America, 10, 299-316.

Finn, P. R., Mazas, C. A., Justus, A. N., \& Steinmetz, H. (2002). Early-onset alcoholism with conduct disorder: Go/No-Go learning deficits. working memory capacity, and personality. Alcoholism: Clinical and Experimental Research, 26, 186-206.

Fischer, M., Barkley, R. A., Smallish, L., \& Fletcher, K. (2002). Young Adult FollowUp of Hyperactive Children: Self-Reported Psychiatric Disorders, Comorbidity, and the Role of Childhood Conduct Problems and Teen CD. Journal of Abnormal Child Psychology, 30, 463-475.

Földényi, M., Imhof, K., \& Steinhausen, H. C. (2000). Klinische Validität der computergestützten TAP bei Kindern mit Aufmerksamkeits-/ Hyperaktivitätsstörung. Zeitschrift für Neuropsychologie, 11, 154-167.

Greenhill, L. L., Halperin, J. M., \& Abikoff, H. (1999). Stimulant Medications. Journal of the American Academy of Child and Adolescent Psychiatry, 38, 503-512.

Greenhill, L. L., Pliszka, S., Dulcan, M. K., Bernet, W., Arnold, V., Beitchman, J. et al. (2002). Practice Parameter for the Use of Stimulant Medications in the Treatment of Children, Adolescents, and Adults. Journal of the American Academy of Child and Adolescent Psychiatry, 41, 26S-49S.

Halperin, J. M., O’Brien, J. D., Newcorn, J. H., Healey, J. M., Pascualvaca, D. M., Wolf, L. E. et al. (1990). Validation of Hyperactive, Aggressive, and Mixed Hyperactive/Aggressive Childhood Disorders: A Research Note. Journal of Child Psychology and Psychiatry, 31, 455-459.

Holland, R. L., Wesnes, K., \& Dietrich, B. (1994). Single dose human pharmacology of umespirone. European Journal of Clinical Pharmacology, 46, 461-468.

Jaboni, F., Douglas, V. I., \& Baker, A. G. (1995). Effects of reward and response costs on inhibition in ADHD children. Journal of Abnormal Child Psychology, 104, 232-240.

Jensen, J. B., Jessop, D. S., Harbuz, M. S., Mork, A., Sanchez, C., \& Mikkelsen, J. D. (1999). Acute and long-term treatments with the selective serotonin reuptake inhibitor citalopram modulate the HPA axis activity at different levels in male rats. Journal of Neuroendocrinology, 11, 465-471. 
Kaplan, S. L., Simms, R. M., \& Busner, J. (1994). Prescribing practices of outpatient child psychiatrists. Journal of the Amarican Academy of Child and Adolescent Psychiatry, 32, $577-581$.

Le Merrer, J. \& Noguès, X. (2000). Cognitive Neuropharmacology: New Perspectives for the Pharmacology of Cognition. Pharmacological Research, 41, 503-514.

Lijffijt, M., Kenemans, J. L., \& van Engeland, H. (2005). A Meta-Analytic Review of Stopping Performance in Attention-Deficit/ Hyperactivity Disorder: Deficient Inhibitory Control? Journal of Abnormal Psychology, 114, 216-222.

Loubinoux, I., Pariente, J., Rascol, O., Celsis, P., \& Chollet, F. (2002). Selective serotonin reuptake inhibitor paroxetine modulates motor behavior through practice. A doubleblind, placebo-controlled, multi-dose study in healthy subjects. Neuropsycholigia, 40, 18151821.

Lynam, D. R. (1996). The early identification of chronic offenders: Who is the fledgling psychopath? Psychological Bulletin, 120, 209-234.

McClellan, J. M. \& Werry, J. S. (2003). Evidence-Based Treatments in Child and Adolescent Psychiatry: An Inventory. Journal of the American Academy of Child and Adolescent Psychiatry, 42, 1388-1400.

McConville, B. J. \& Sorter, M. T. (2004). Treatment challenges and safety considerations for antpsychotic use in children and adolescents with psychoses. Journal of Clinical Psychiatry, 65, S20-S29.

Nigg, J. T. (1999). The ADHD response inhibition deficit as measured by the Stop Task: replication with DSM-IV combined type, extension, and qualification. Journal of Abnormal Child Psychology, 27, 391-400.

Nowakowska, E., Chodera, A., \& Kus, K. (1999). Influence of olanzapine on cognitive functions and catalepsy in rats after single and chronic administration. Polish Journal of Pharmacology, 51, 295-300.

Oosterlaan, J., Logan, G. D., \& Sergeant, J. A. (1998). Response Inhibition in AD/HD, $\mathrm{CD}$, Comorbid AD/HD+CD, Anxious, and Control Children: A Meta-analysis of Studies with the Stop Task. Journal of Child Psychology and Psychiatry, 39, 411-425.

O’Brian, B. S. \& Frick, P. J. (1996). Reward dominance: associations with anxiety, conduct problems, and psychopathology in children. Journal of Abnormal Child Psychology, 24, 223-240.

Pennington, B. F. \& Ozonoff, S. (1996). Executive functions and developmental psychopathology. Journal of Child Psychology and Psychiatry and Allied Disciplines, 37, 51-87. 
Porter, R. J., Gallagher, P., Thompson, J. M., \& Young, A. H. (2003). Neurocognitive impairment in drug-free patients with major depression. British Journal of Psychiatry, 182, 214-220.

Quay, H. C. (1997). Inhibition in attention deficit hyperactivity disorder. Journal of Abnormal Child Psychology, 25, 7-13.

Rapport, M. D. \& Kelly, K. L. (1991). Psychostimulant effects on learning and cognitive function: Findings and implications with Attention Deficit Hyperactivity Disorder. Clinical Psychology Review, 11, 61-92.

Riddle, M., Kastelic, E. A., \& Frosch, E. (2001). Pediatric Psychopharmacology. Journal of Child Psychology and Psychiatry, 42, 73-90.

Santucci, A. C., Knott, P. J., \& Haroutunian, V. (1996). Excessive serotonin release, not depletion, leads to memory impairments in rats. European Journal of Pharmacology, 295, $7-17$.

Schmitt, J. A., Ramaekers, J. G., Kruizinga, M. J., van Boxtel, M. P., Vuurmann, E. F., \& Riedel, W. J. (2002). Additional dopamine reuptake inhibition attenuates vigilance impairment induced by serotonin reuptake inhibition in man. Journal of Psychopharmacology, 16, 207-214.

Sergeant, J. A., Geurts, H., \& Oosterlaan, J. (2002). How specific is a deficit of executive functioning for Attention-Deficit/Hyperactivity Disorder? Behavioural Brain Research, 130, 3-28.

Snyder, R., Turgay, A., Aman, M., Binder, C., Fisman, S., Carroll, A. et al. (2002). Effects of Risperidone on Conduct and Disruptive Behavior Disorders in Children With Subaverage IQs. Jornal of the American Academy of Child \& Adolescent Psychiatry, 41, 10261036.

Solanto, M. V. (1984). Neuropharmacological basis of stimulant drug action in attention deficit disorder with hyperactivity: a review and synthesis. Psychological Bulletin, 95, 387-409.

Sturm, W. \& Zimmermann, P. (2000). Aufmerksamkeitsstörungen. In W.Sturm, M. Herrmann, \& C. W. Wallesch (Eds.), Lehrbuch der Klinischen Neuropsychologie (pp. 345365). Lisse: Swets \& Zeitlinger.

Swaab-Barneveld, H., Sonneville-de, L., Cohen-Kettenis, P., Gielen, A., Buitelaar, J., \& Engeland-van, H. (2000). Visual Sustained Attention in a Child Psychiatric Population. Jornal of the American Academy of Child \& Adolescent Psychiatry, 39, 651-659. 
Tannock, R., Ickowicz, A., \& Schachar, R. (1995). Differential Effects of Methylphenidate on Working Memory in ADHD Children with and without Comorbid Anxiety. The American Academy of Child and Adolescent Psychiatry, 34, 886-895.

Tannock, R., Schachar, R., \& Logan, G. D. (1995). Methylphenidate and cognitive flexibility: dissociated dose effects in hyperactive children. Journal of Abnormal Child Psychology, 23, 235-266.

Taylor, E., Döpfner, M., Sergeant, J., Asherson, P., Banaschewski, T., Buitelaar, J. et al. (2004). European clinical guidelines for hyperkinetic disorder - first upgrade. European Child and Adolescent Psychiatry, 13 Supl. 1, i7-i30.

The Research Units on Pediatric Psychopharmacology Anxiety Study Group (2001). Fluvoxamine for the treatment of anxiety disorders in children and adolescents. New England Journal of Medicine, 344, 1279-1285.

Toren, P., Sadeh, M., Wolmer, L., Eldar, S., Koren, S., Weizman, R. et al. (2000). Neurocognitive Correlates of Anxiety Disorders in Children: A Preliminary Report. Journal of Anxiety Disorders, 14, 239-247.

Turgay, A., Binder, C., Snyder, R., \& Fisman, S. (2002). Long-Term Safety and Efficacy of Risperidone for the Treatment of Disruptive Behavior Disorders With Subaverage IQs. Pediatrics, 110, e34.

Van der Meere, J., Wekking, E., \& Sergant, J. (1991). Sustained Attention and Pervasive Hyperactivity. Journal of Child Psychology and Psychiatry, 32, 275-284.

Van der Meere, J., Gunning, B., \& Stemerdink, N. (1999). The Effect of Methylphenidate and Clonidine on Response Inhibition and State Regulation in Children with ADHD. Journal of Child Psychology and Psychiatry, 40, 291-298.

Van Zomeren, A. H. \& Brouwer, W. J. (1994). Clinical Neuropsychology of Attention. New York, Oxford: Oxford University Press.

Zito, J. M., Safer, D. J., dosReis, S., Gardner, J. F., Soeken, K., Boles, M. et al. (2002). Rising prevalence of antidepressants among US youths. Pediatrics, 109, 721-727. 

Chapter 2:

\title{
Verbal memory and aspects of attentional control in children and adolescents with anxiety disorders or depressive disorders
}

\author{
T. Günther, K. Holtkamp, J. Jolles, B. Herpertz-Dahlmann, K. Konrad *
}

\section{Summary}

Background: The aim was to examine basic performance on attention and memory tasks in treatment-naïve children and adolescents with anxiety disorder or depressive disorder and in healthy subjects under drug-free conditions. Methods: Basic neurocognitive performance on attention and verbal memory tasks was examined in children and adolescents with emotional disorders, between 6 and 17 years of age. A total of 34 children with an anxiety disorder, 31 children with a depressive disorder, and 33 healthy controls were assessed with a comprehensive neuropsychological test battery. All children were treatment naïve at the time of testing. Five different computerized attention tasks and the Rey Auditory-Verbal Learning Test were administered. Results: A significant effect of diagnosis was found for verbal memory but not for attention. Limitations: The large age range and inclusion of different diagnoses resulted in rather inhomogeneous groups. Conclusion: The present study provided evidence for an undisturbed attentional performance in both patient groups and a dissociation in memory functioning between anxious and depressed children. Memory impairment was found to be specifically associated with childhood depression. 


\section{Introduction}

Recently it has been suggested that emotional disorders may be associated with impairments in neurocognitive functioning (Porter et al. 2003). This is supported by teacher and parent reports stating that children with anxiety disorder or depression suffer from problems in concentration and memory and show increased school dysfunction (Benjamin, Costello, \& Warren 1990). Additionally, anxious children complain of frequent and intensive intrusive thoughts during cognitive tasks in self-report questionnaires (Kendall \& Chansky 1991). However, until now, it remains unclear whether neurocognitive abilities are disturbed when objective measures of attention and memory are applied and, if so, which cognitive impairments are specifically associated with either anxiety disorders or depression in childhood. This might be an important point for our understanding of the underlying cognitive impairment, as well as for the development and monitoring of a specific psychotherapeutic or psychopharmacological intervention in children with emotional disorders.

Therefore, the aim of the present study was to examine basic performance on attention and memory tasks in treatment-naïve children and adolescents with anxiety disorder or depressive disorder and in healthy subjects under drug-free conditions. In order to assess the specificity of neuropsychological processes that characterize children and adolescents with depression or anxiety disorders, only non-co-morbid patients were included in the study.

\section{Material and methods}

A total of 34 children with anxiety disorder (17 with social phobia and 17 with generalized anxiety disorder), 31 children with a depressive disorder (22 with major depressive disorder and 9 with dysthymic disorder) and 33 healthy controls between 8 and 17 years old, whose diagnoses had been assessed according to the DSM-IV (American Psychiatric Association 1994), were recruited. Classification was based on a semi-structured interview of the child (KDIPS; Unnewehr, Schneider, \& Margraf 1995) and on his or her developmental history. DSM-IV diagnoses were confirmed by an independent diagnosis of the clinicians. All patients were recruited from our inpatient or outpatient department of child and adolescent psychiatry. The two clinical groups differed significantly from the control group on the depression score of the German version of the Children's Depression Inventory (Kovacs 1985; StiensmeierPelster, Schürmann, \& Duda 2000). However, in line with the literature (Ambrose \& Rholes 1993; Stark \& Laurent 2001), no significant difference on CDI scores was found between the two clinical groups. Exclusion criteria were: a general IQ below 80 (WISC-III), any kind of medication, and a present or past diagnosis of ADHD, assessed with the K-DIPS as well as 
Verbal Memory and aspects of attentional control in anxiety and depressive disorders $\mid 25$

with the clinician's anamnesis. The three groups were not different with respect to age, IQ, or sex. Informed parental consent was obtained for all participants, and the study was approved by the Ethics Committee of the University Hospital of Aachen. Table 1 summarizes major demographic data.

\begin{tabular}{|c|c|c|c|c|}
\hline & $\begin{array}{l}\text { Controls } \\
(n=33)\end{array}$ & $\begin{array}{l}\text { Anxiety disorder } \\
\qquad(\mathrm{n}=34)\end{array}$ & $\begin{array}{l}\text { Depressive disorder } \\
\qquad(\mathrm{n}=31)\end{array}$ & Group difference \\
\hline Age (Mean/SD) & $12,8 / 2,5$ & $12,4 / 2,3$ & $13,5 / 2,6$ & $\mathrm{~ns}^{\mathrm{a})}$ \\
\hline IQ (Mean/SD) & $107 / 11$ & $102 / 11$ & $101 / 13$ & $\mathrm{~ns}^{\mathrm{b})}$ \\
\hline Sex (boy/girl) & $15 / 18$ & $19 / 15$ & $17 / 14$ & $\mathrm{~ns}^{\mathrm{c}}{ }^{\mathrm{c}}$ \\
\hline CDI (Mean/SD) & $7,9 / 4,2$ & $14,7 / 7,3$ & $13,3 / 7,3$ & $<0.001^{\mathrm{d})}$ \\
\hline
\end{tabular}

Table 1. Demographic data: ${ }^{\text {a) }}$ ANOVA: $\mathrm{F}_{(2,95)}=1,76 ; \mathrm{p}=\mathrm{ns} ;{ }^{\mathrm{b})} \operatorname{ANOVA}: \mathrm{F}_{(2,95)}=2,26 ; \mathrm{p}=$ $\mathrm{ns} ;{ }^{\mathrm{c})} \chi^{2}$ Pearson: $\chi^{2}=0,87 ; \mathrm{df}=2 ; \mathrm{p}=\mathrm{ns} ;{ }^{\mathrm{d})}$ ANOVA: $\mathrm{F}_{(2,95)}=21,39 ; \mathrm{p}<0.001$

All subjects received a neuropsychological assessment, and the order of the tests was randomized according to a standard protocol. Cognitive functions were assessed using the following tests:

The Rey Auditory-Verbal Learning Test (Helmstaedter, Lendt, \& Lux 2001; Lezak 1995) was applied with the following dependent measures:

- the score of the total words of trials 1-3 (free recall),

- trial 1 as a measure of working memory,

- the difference between trial 3 and trial 1 as a rate for acquisition (learning curve),

- $\quad$ trial 6, after learning a second word list, as a measure for interference,

- a 30-min delayed recall trial, and

- a recognition trial.

$\underline{\text { Alertness }}$ was assessed with a simple reaction time (RT) task, and Divided Attention was assessed with a dual task, which combined an optic and acoustic discrimination task (Fimm \& Zimmermann 2001). In the Go/NoGo Paradigm (Fimm \& Zimmermann 2001), a motor response with the dominant hand was either initiated or inhibited depending on the stimulus that appeared. The Sustained Attention Task involved the continuous and consecutive presentation of 50 series of twelve different dot patterns (600 signals) (de Sonneville 2000). The dependent measures were in each task the reaction time (RT) and its standard deviation (SD), the score of misses (MIS), and the score of false alarms (FA). 
The demographic characteristics were assessed by ANOVA and $\chi^{2}$-Pearson. The neuropsychological test variables were divided into two general content areas, namely verbal memory and attention. Group differences were evaluated using multivariate analysis of covariance (MANCOVA), with the diagnostic group as the independent variable, neuropsychological test scores as the dependent variables, and IQ and age as covariates since the neuropsychological data were correlated with both age and IQ $(\mathrm{p}<.05)$. Two MANCOVAs were performed, one for each content area. If necessary, follow-up one-tailed pairwise ANCOVAs by diagnoses were conducted to investigate specific group differences on tasks. A Bonferroni adjustment was made for inflated Type I error (Tabachnick \& Fidell 2000).

\section{Results}

There was no main effect of diagnosis on free recall $\left(\mathrm{F}_{(2,93)}=2.19 ; \mathrm{ns}\right)$, working memory $\left(\mathrm{F}_{(2}\right.$, 93) $=1.07 ; \mathrm{ns})$, or learning curve $\left(\mathrm{F}_{(2,93)}=1.23 ; \mathrm{ns}\right)$. A significant main effect was found in the number of free recalled words after learning an interference list of words $\left(\mathrm{F}_{(2,93)}=5.08 ; \mathrm{p}=\right.$ $0.008)$, in long delay free recall $\left(\mathrm{F}_{(2,93)}=5.07 ; \mathrm{p}=0.008\right)$, and in the recognition trial $\left(\mathrm{F}_{(2,93)}\right.$ $=5.257 ; \mathrm{p}=0.007)$. Separate analysis indicated that children with depressive disorder performed worse than the controls and the children with anxiety disorder. No significant difference was found between the controls and children with anxiety disorder (Table 3).

No main effect of diagnosis was found for any of the attention tasks. 


\begin{tabular}{lccccc}
\hline & $\begin{array}{c}\text { Controls } \\
(\mathrm{n}=33) \\
\mathrm{M}(\mathrm{SD})\end{array}$ & $\begin{array}{c}\text { Anxiety } \\
(\mathrm{n}=34)\end{array}$ & $\begin{array}{c}\text { Depression } \\
(\mathrm{n}=31)\end{array}$ & $\mathrm{F}^{\mathrm{a})}$ & $\mathrm{p}^{\mathrm{b})}$ \\
& & & & \\
& $31.5(6.9)$ & $28.6(4.8)$ & $28.3(5.2)$ & 2.19 & $\mathrm{~ns}$ \\
\hline Verbal memory & $7.7(2.8)$ & $6.6(1.9)$ & $6.8(1.8)$ & 1.07 & $\mathrm{~ns}$ \\
Free recall & $4.8(1.8)$ & $5.4(2.2)$ & $4.8(1.9)$ & 1.22 & $\mathrm{~ns}$ \\
Learking memory & $13.6(1.5)$ & $13.0(2.1)$ & $11.9(2.6)$ & 5.07 & 0.008 \\
Interference & $13.8(1.6)$ & $13.4(1.9)$ & $12.0(2.3)$ & 5.06 & 0.008 \\
Long delay free recall & $14.8(0,6)$ & $14.6(0,9)$ & $13.8(1,8)$ & 5.25 & 0.007 \\
Recognition & & & & &
\end{tabular}

Attention

Alertness

$\begin{array}{lccccc}\text { RT } & 247(25) & 250(51) & 256(52) & 0.85 & \text { ns } \\ \text { SD } & 55(28) & 53(32) & 57(32) & 0.76 & \text { ns }\end{array}$

Sustained attention

$\begin{array}{lccccc}\text { Tempo } & 11.7(3.5) & 12.6(4) & 10.1(3.3) & 3.99 & \text { ns } \\ \text { TempoFluc } & 2(1.2) & 2.4(1.6) & 1.9(1.3) & 0.13 & \text { ns } \\ \text { FA } & 19.1(12.6) & 23.5(22.4) & 19(15.8) & 0.49 & \text { ns } \\ \text { MIS } & 27.2(20) & 19.4(16.4) & 19.7(16.1) & 2.14 & \text { ns }\end{array}$

Divided attention

$\begin{array}{llllll}\text { RT } & 711(80) & 741(96) & 699(77) & 0.92 & \text { ns } \\ \text { SD } & 262(74) & 256(81) & 240(86) & 0.77 & \text { ns } \\ \text { FA } & 2.9(3.5) & 2.2(2.2) & 2.1(2.3) & 1.79 & \text { ns } \\ \text { MIS } & 3.9(2.8) & 3.2(2.4) & 3.8(3.5) & 3.03 & \text { ns }\end{array}$

Go/NoGo

$\begin{array}{lccccc}\text { RT } & 389(68) & 442(72) & 456(115) & 4.50 & \text { ns } \\ \text { SD } & 93(29) & 99(23) & 106(36) & 1.97 & \text { ns } \\ \text { FA } & 2.2(1.9) & 2.9(2.5) & 3.1(3.7) & 1.20 & \text { ns } \\ \text { MIS } & 0.8(1.1) & 0.5(1) & 0.5(0.9) & 1.87 & \text { ns }\end{array}$

Table 2. Neuropsychological test performance of anxiety disorder subjects, depressive disorder subjects, and normal control subjects: ${ }^{\text {a) }}$, Adjusted for IQ and age, ${ }^{\text {b) }}$ Corrected for multiple testing 


\begin{tabular}{lcc}
\hline & $\mathrm{F}^{\mathrm{a})}$ & $\mathrm{p}$ \\
\hline Interference & & $\mathrm{ns}$ \\
Controls / Anxiety disorder & 0.514 & 0.013 \\
Controls / Depressive disorder & 7.336 & 0.043 \\
Anxiety disorder / Depressive disorder & 4.28 & \\
Long delay free recall & & $\mathrm{ns}$ \\
Controls / Anxiety disorder & 0.113 & 0.017 \\
Controls / Depressive disorder & 5.991 & 0.033 \\
Anxiety disorder / Depressive disorder & 5.517 & \\
Recognition & & $\mathrm{ns}$ \\
Controls / Anxiety disorder & 0.785 & 0.01 \\
Controls / Depressive disorder & 5,543 & 0.03 \\
Anxiety disorder / Depressive disorder & 4.610 & \\
\hline
\end{tabular}

Table 3. Group comparison for the verbal memory aspects "interference", "long delay free recall", and "recognition": a), Adjusted for IQ and age;

\section{Discussion}

The present study provides evidence for a memory impairment which was specifically associated with childhood depression, while an undisturbed attentional performance was found in both paediatric patient groups. Our results are in line with some recent studies on adult patients showing that depressive adults tend to have more problems with verbal memory (Fennig et al. 2002; Goldberg et al. 1993) but do not show any deficits on attention tasks (Barch et al. 2003). Thus, our results contradict the hypothesis that memory deficits in mood disorders are the result of poor encoding caused by a deficit in attention (Sweeney et al. 1989). However, discrepant findings have also been reported by Porter et al. (2003) and Swaab-Barneveld et al. (2000), emphasizing that patients with major depressive disorder are impaired in a range of cognitive domains, including sustained attention and executive function. This discrepancy might be due to differences between paediatric and adult samples, regarding symptom severity, time since symptom onset, group composition, or comorbidity.

A possible neurobiological explaination of the specific memory impairment in children with depression might be as follows. Dysregulation in the hypothalamic-pituitary-adrenal axis associated with high cortisol levels has been linked to depressive disorders in adults and adolescents (Brooks-Gunn et al. 2001 for a review). Effects of cortisol hypersecretion on cognitive 
Verbal Memory and aspects of attentional control in anxiety and depressive disorders $\mid 29$

neuroendocrine functioning might explain memory dysfunctions in depressive children (Charmandari et al. 2003). Moreover, a continuous exposure of the brain to abnormal cortisol levels during development might contribute to the worsening of functioning in a greater range of cognitive domains from childhood to adulthood.

In concordance with the adult literature on neurocognitive performance in patients with different kinds of anxiety disorders (e.g. Gladsjo et al., 1998), our results provided evidence that children with social phobia or generalized anxiety disorder did not differ from normal controls with regard to attentional performance. Thus, the attentional difficulties described in selfreports or teacher and parental ratings of anxious children are more likely to be caused by a selective attentional bias for emotional material (Dalgleish et al. 2003) and not by basic attentional deficits. Anxious children also did not differ from normal controls with regard to memory functions. This is in line with some other studies examining adult patients under drug-free conditions (e.g. Gladsjo et al., 1998); however, it contradicts the recent findings of Toren et al. (2000). The authors reported significantly lower scores of memory tasks in a group of anxious children. However, the sample size was small $(n=19)$, and the children fulfilled DSM III$\mathrm{R}$ criteria for overanxiety (which might be equal to the GAD children in our study) or separation anxiety (which might be different from our study including patients with social phobia). Another methodological difference with our study was that age and IQ were not included as covariates in the analyses of the neuropsychological data, whereas this is recommended if IQ and age are correlated with the dependent variables (Bortz \& Döring 2002).

Our study had some methodological limitations which should be acknowledged. The different groups in this study were comparable for age, but the range from 8 to 17 years was too large to form homogeneous groups of children or adolescents. Another limitation was that the group of anxiety disorders consisted of children with social phobia or generalized anxiety disorder and the depression group consisted of children and adolescents with major depression or dysthymic disorder. Again, this resulted in inhomogeneous groups.

\section{References}

Ambrose, B. \& Rholes, W. S. (1993). Automatic Cognitions and the Symptoms of Depression and Anxiety in Children and Adolescents: An Examination of the ContentSpecific Hypothesis. Cognitive Therapy and Research, 17, 153-171.

American Psychiatric Association (1994). Diagnostic and Statistical Manual of Mental Disorders - DSM-IV. (4 ed.) Washington D.C.: American Psychiatric Association. 
Barch, D. M., Sheline, Y. I., Csernansky, J. G., \& Snyder, A. Z. (2003). Working Memory and Prefrontal Cortex Dysfunction: Specificity to Schizophrenia Compared with Major Depression. Biological Psychiatry, 53, 376-384.

Benjamin, R., Costello, E. J., \& Warren, M. (1990). Anxiety disorder in a pediatric sample. Journal of Anxiety Disorders, 4, 293-316.

Bortz, J. \& Döring, N. (2002). Forschungsmethoden und Evaluation für Human- und Sozialwissenschaftler. (3 ed.) Berlin: Springer.

Brooks-Gunn, J., Auth, J. J., Petersen, A. C., \& Compas, B. E. (2001). Physiological processes and the development of childhood and adolescent depression. In I.M.Goodyer (Ed.), The depressed child an adolescent (2 ed., pp. 79-118). Cambridge: Cambridge University Press.

Charmandari, E., Kino, T., Souvatzoglou, E., \& Chrousos, G. P. (2003). Pediatric stress: hormonal mediators and human development. Hormonal Research, 59, 161-179.

Dalgleish, T., Taghavi, R., Neshat-Doost, H., Moradi, A., Canterbury, R., \& Yule, W. (2003). Patterns of processing bias for emotional information across clinical disorders: a comparison of attention, memory, and prospective cognition in children and adolescents with depression, generalized anxiety, and posttraumatic stress disorder. Journal of Clinical Child Psychology, 32, 10-21.

de Sonneville, L. M. J. (2000). ANT 2.1 - Amsterdam Neuropsychological Tasks. Amstelveen: Sonar.

Fennig, S., Mottes, A., Ricter-Levin, G., Treves, I., \& Levkovitz, Y. (2002). Everydag Memory and Laboratory Memory Tests: General Function Predictors in Schizophrenia and Remitted Depression. Journal of Nervous and Mental Disease, 190, 677-682.

Fimm, B. \& Zimmermann, P. (2001). Testbatterie zur Aufmerksamkeitsüberprüfung (TAP) - Version 1.6. Herzogenrath: Psytest.

Gladsjo, J. A., Rapaport, M. H., McKinney, R., Lucas, J. A., Rabin, A., Oliver, T. et al. (1998). A neuropsychological study of panic disorder: Negative findings. Journal of Affective Disorders, 49, 123-131.

Goldberg, T. E., Gold, J. M., Greenberg, R., Griffin, S., Schulz, C., Pickar, D. et al. (1993). Contrasts between patients with affective disorders and patients with affective disorders and patients with schizophrenia on a neuropsychological test battery. American Journal of Psychiatry, 150, 1355-1362.

Helmstaedter, C., Lendt, M., \& Lux, S. (2001). Verbaler Lern- und Merkfähigkeitstest. Göttingen: Beltz Test GmbH. 
Verbal Memory and aspects of attentional control in anxiety and depressive disorders $\mid 31$

Kendall, P. C. \& Chansky, T. E. (1991). Considering cognition in anxiety-disordered children. Journal of Anxiety Disorders, 5, 167-185.

Kovacs, M. (1985). The Children's Depression Inventory (CDI). Psychopharmacology Bulletin, 21, 995-999.

Lezak, M. D. (1995). Neuropsychological Assessment. (3 ed.) New York - Oxford: Oxford University Press.

Porter, R. J., Gallagher, P., Thompson, J. M., \& Young, A. H. (2003). Neurocognitive impairment in drug-free patients with major depression. British Journal of Psychiatry, 182, 214-220.

Stark, K. D. \& Laurent, J. (2001). Joint factor analysis of the Children's Depression Inventory and the Revised Children's Minifest Anxiety Scale. Journal of Clinical Psychology, 30, $552-567$.

Stiensmeier-Pelster, J., Schürmann, M., \& Duda, K. (2000). Depressions-Inventar für Kinder und Jugendliche. (2 ed.) Göttingen: Hogrefe Verlag für Psychologie.

Swaab-Barneveld, H., Sonneville-de, L., Cohen-Kettenis, P., Gielen, A., Buitelaar, J., \& Engeland-van, H. (2000). Visual Sustained Attention in a Child Psychiatric Population. Jornal of the American Academy of Child \& Adolescent Psychiatry, 39, 651-659.

Sweeney, J. A., Wetzler, S., Stokes, P., \& Kocsis, J. (1989). Cognitive functioning in depression. Journal of Clinical Psychology, 45, 836-842.

Tabachnick, B. G. \& Fidell, L. S. (2000). Using Multivariate Statistics. (4 ed.) New York: Allyn \& Bacon.

Toren, P., Sadeh, M., Wolmer, L., Eldar, S., Koren, S., Weizman, R. et al. (2000). Neurocognitive Correlates of Anxiety Disorders in Children: A Preliminary Report. Journal of Anxiety Disorders, 14, 239-247.

Unnewehr, S., Schneider, S., \& Margraf, J. (1995). Kinder DIPS - Diagnostisches Interview bei psychischen Störungen im Kindes und Jugendalter. Heidelberg: Springer. 



\title{
The impact of age differences on impulsivity and sustained attention deficits in attention deficit/ hyperactivity disorder with and without disruptive behavior disorder: a cross-sectional study
}

\author{
T. Günther, K. Konrad, J. Jolles, B. Herpertz-Dahlmann, *
}

\section{Summary}

The aim of this study was to analyze developmental changes in impulsivity and sustained attention in children and adolescents with attention deficit/ hyperactivity disorder (ADHD) with or without disruptive behavior disorders (DBD). We compared healthy controls with patients with ADHD only and with patients with ADHD+DBD across two age groups: 8-11 years (normal controls $[\mathrm{NC}] \mathrm{n}=22 ; \mathrm{ADHD} n=31$ and $\mathrm{ADHD}+\mathrm{DBD} n=33$ ) and an adolescent group of 12-17 years (NC n=32; ADHD $n=33$ and ADHD+DBD $n=38$ ). All subjects received a standardized computerized neuropsychological assessment which comprehends a sustained attention task and a go/nogo paradigm. We wanted to analyze whether the neuropsychological deficits in the adolescent groups differ in comparison to the deficits in children with ADHD or ADHD+DBD. Children with ADHD had more attentional problems than children with $\mathrm{ADHD}+\mathrm{DBD}$ and the ADHD+DBD group was more impulsive than the ADHD group. Interestingly, we could demonstrate that the observed neuropsychological deficits and differences between NC, ADHD and ADHD+DBD in children between 8 and 11 years were not detectable with higher age. The performance of adolescents of both clinical groups was comparable with that of age and IQ matched NC. Thus, our data indicate that brain maturation processes might modulate attentional functions in ADHD and ADHD+DBD in the age range 12-17 years. 


\section{4 | Chapter 3}

\section{Introduction}

The understanding of normal brain maturation is essential for understanding neurodevelopmental disorders (Stiles, 2000; Schlaggar et al., 2002). Effective development and operation of executive function (EF) and the attentional system is essential to adaptive functioning, whether for social, academic, or vocational realms (Derryberry \& Rothbart, 1997; Kochanska, Murray, \& Coy, 1997). Cerebral development is likely to be primarily hierarchical, both within and across cerebral regions, with particular prefrontal areas reaching maturity relatively late in puberty and some regions maturing into adulthood (Anderson, Anderson, Northam, Jacobs, \& Catroppa, 2001; Gogtay et al., 2004). Maturation of executive skills is rapid during early and middle childhood and slows considerably during adolescence (Anderson et al., 2001). Adolescents have greater attentional capacity and complete tasks faster than their younger counterparts and there is a developmental spurt around age 12 for planning and problem solving skills. A period frequently associated with developmental spurts from neurophysiological (Huttenlocher \& Dabholkar, 1997) and cognitive perspectives (Levin et al., 1991; Welsh, Pennington, \& Groisser, 1991). Therefore, the study of the development of EF and the attentional system will serve to better understand the nature of particular cognitive deficits such as those seen in children and adolescents with attention deficit/ hyperactivity disorder (ADHD).

A selective review of studies on executive functioning in different childhood psychiatric disorders has shown that ADHD children have performance deficits in some EF tasks, but performances on EF tests were also deficient in other clinical groups such as oppositional defiant disorder (ODD) and conduct disorder (CD; Sergeant, Geurts, \& Oosterlaan, 2002). The go/nogo paradigm and the stop-signal task are typical tasks measuring response inhibition in ADHD (Aron \& Poldrack, 2005; Lijffijt, Kenemans, \& van Engeland, 2005). Inhibitory control is an important part of EF and an essential subdimension of impulsivity that is related to children's externalizing problems (Avila, Cuenca, Félix, Parcet, \& Miranda, 2004). There is consistent and robust evidence that children with ADHD and children with ADHD+ODD/CD seem to show both attentional and EF deficits (Pennington \& Ozonoff, 1996; Oosterlaan, Logan, \& Sergeant, 1998). Due to age dependent maturational processes of the frontal brain one can speculate that the phenotype becomes different in the course of ADHD. For instance, attention problems could be detected in different subtests dependent of the age of the participants. Children with ADHD, which were under the age of six, tended to show deficits in attention control processes, whereas older children tended to have problems in the intensity- 
and selective aspects of attention (Hanisch, Konrad, Günther, \& Herpertz-Dahlmann, 2004). A recent meta-analytic review of stopping performance concluded that children with ADHD had both, an attention deficit and an inhibitory deficit (Lijffijt et al., 2005). In this study, the attention deficits were not detectable for adults, whereas the inhibitory problems remained. In line with this, Bekker et al. (2005) report minor deficits in attention, whereas inhibitory control was obviously impaired in adults with ADHD. This suggests that an impairment of inhibitory motor control might be the core deficit in ADHD (Barkley, 1999; Quay, 1997).

Neuropsychological deficits in the attentional system and/or EF (e.g. impulsivity) are also related to Disruptive Behavior Disorders (DBD). The DBDs of the DSM-IV comprise ODD, CD and DBD-not otherwise specified (American Psychiatric Association, 1994). In this paper, the term 'DBD' will be used to refer collectively to CD and ODD. Children with ADHD and associated DBD had more serious clinical courses and poorer outcomes than children with ADHD without DBD (Biederman, Newcorn, \& Sprich, 1991; Fischer, Barkley, Smallish, $\&$ Fletcher, 2002). They had more varied, severe and stable antisocial behaviors (Fischer et al., 2002) and perform more poorly on tests of neuropsychological functioning (Lynam, 1996). According to Loeber et al. (2000) ODD, CD and antisocial personality disorder are a changing manifestation of the same disorder, with ADHD influencing the developmental progression from less serious to more serious manifestations of disruptive behavior. Children with DBD only meet not the criteria for ADHD. However, these children are likely to show elevated ADHD symptoms compared with normal children (Sergeant et al., 2002). The possible comorbidity of ADHD and DBD is a complicating factor in the identification of specific neuropsychological profiles. Due to developmental processes and the interaction between ADHD and DBD the identification of attentional and EF deficits may depend upon at which point in the developmental process the children were assessed. Thus, the comorbidity of ADHD and DBD makes is more difficult to identify specific neuropsychological profiles of a disorder. Furthermore, the association of ADHD and DBD raises the question, whether the development of attentional deficits is different to that of children with ADHD only.

In conclusion, attention and EF deficits are described for ADHD and ADHD +DBD. However, it seems that the described deficits are not specific to one clinical group. Primarily, evidence from research about neuropsychological deficits in ADHD or ADHD+DBD is based on children beneath 12 years (e.g. van Goozen et al., 2004; Halperin et al., 1990; Pennington et al., 1996), but some studies suggest that attention and EF deficits in children with ADHD 
change due to developmental aspects (e.g. Lijffijt et al., 2005; El-Sayed, Larsson, Persson, Santosh, \& Rydelius, 2003; Hanisch et al., 2004). According to Anderson (2001) there is substantial support for a stepwise model of cognitive development, rather than a gradual progression, with convergent evidence that growth spurts occur in early infancy, again around 7-10 years of age, with a final spurt during adolescence. Evidence from brain development also shows that particular brain areas develop in separate periods through the period from birth to adulthood, and that there are structures which do not develop until after the age of 20 (e.g. Gogtay et al., 2004). There is no evidence about the influence of developmental processes on attention and $\mathrm{EF}$ in relation to ADHD+DBD symptoms. Furthermore, sparse information is available about attentional disorders in adolescents with ADHD and ADHD+DBD and the change of attentional deficits due to developmental processes.

Therefore, the aim of this study is to analyze attention and inhibition differences between children and adolescents with ADHD and ADHD+DBD. Hence, we compared for the first time two age groups within each clinical group: children between 8-11 years of age and adolescents between 12-17 years of age. Due to maturational processes and in accordance with other studies (Lijffijt et al., 2005), we hypothesize that the performance of the adolescents on the sustained attention part is comparable with that of normal controls (NC), whereas the inhibitory deficit on an impulsivity related task remains. According to previous studies (Lynam, 1996), we assume that children and adolescents with ADHD+DBD show poorer performance with regard to both, sustained attention and impulsivity than patients with ADHD only.

\section{Material and methods}

\section{$\underline{\text { Subjects }}$}

A total of 64 children with ADHD (F 90.0), 71 children with the comorbid condition of ADHD and ODD/CD (F90.1; hyperkinetic conduct disorder [ADHD+DBD]), as defined by ICD-10 (World-Health-Organization, 1993) plus 54 healthy controls (NC), aged 8-17, participated in this study. Classification for all children was based on a semi-structured interview with the mother of the child (K-DIPS; Unnewehr, Schneider, \& Margraf, 1995) and developmental history. DSM-IV diagnoses were confirmed by an independent diagnosis of the clinicians. Additionally, the child-behavior-checklist (CBCL; Döpfner et al., 1998) was conducted with the ADHD and ADHD+DBD group. The score of the children on the subscale thoughtproblems was significant higher for the children in both clinical groups (Ryan-Einot-Gabriel- 
Welsch F test; $\mathrm{p}<0.05$ ). Note however, that the score of both children and adolescents is not pathological (T score $<70$ ). Both clinical groups showed an equal impairment on the attention subscale ( $\mathrm{T}$ score $>70$ ). Furthermore, the children had high T-values for delinquent behavior. Both children and adolescents with ADHD+DBD had significant higher scores than the ADHD group for delinquent and aggressive behavior. For the subscales delinquent and aggressive behavior the children and adolescent of the ADHD group and the children and adolescents of the ADHD+DBD group formed homogeneous subsets (Ryan-Einot-GabrielWelsch F test; $\mathrm{p}<0.05$ ). Exclusion criteria were IQ below 80 (WISC-III) and any kind of medication at the date of neuropsychological testing. If the children received stimulants, these were deposed 48 hours before testing.

To analyze age and age $\mathrm{x}$ group interaction effects each group was divided into a children group in the age of 8-11 years ( $\mathrm{NC} n=22$; ADHD $n=31$ and ADHD+DBD $n=33)$ and an adolescent group of 12-17 years ( $\mathrm{NC} n=32$; ADHD $n=33$ and ADHD+DBD $n=38$ ). The three diagnostic groups were not different with respect to age $\left(\mathrm{F}_{\mathrm{C}(2,83)}=2.46 ; \mathrm{ns} / \mathrm{F}_{\mathrm{A}(2,100)}=1.13\right.$; $\mathrm{ns})$, IQ $\left(\mathrm{F}_{\mathrm{C}(2,83)}=0.21 ; \mathrm{ns} / \mathrm{F}_{\mathrm{A}(2,100)}=1.08 ; \mathrm{ns}\right)$, or sex $\left(\chi_{\mathrm{C}(2)}^{2}=0.18 ; \mathrm{ns} / \chi_{\mathrm{A}(2)}^{2}=1.15 ; \mathrm{ns}\right)$. However, general IQ was significant higher in all three adolescent groups compared to the children's groups $\left(\mathrm{t}_{(187)}=3.08 ; \mathrm{p}=0.009\right)$. No difference was detected for sex distribution between children and adolescents $\left(\chi_{(1)}^{2}=0,52 ; \mathrm{ns}\right)$. Informed parental consent was obtained for all participants. The children were recruited from our in- or outpatient department of child and adolescent psychiatry. Table 1 and 2 summarizes the demographic and clinical data.

All subjects received a standardized computerized neuropsychological assessment which comprehends the following tests:

\begin{tabular}{lccccc}
\hline & a) & Controls & ADHD & ADHD + DBD & Group difference \\
\hline Age (Mean/SD) & C & $10.6 / 1.0$ & $9.9 / 1.2$ & $10.2 / 1.2$ & $\mathrm{~F}_{(2,83)}=2.46 ; \mathrm{ns}$ \\
& A & $13.7 / 1.6$ & $13.3 / 1.2$ & $13.7 / 1.8$ & $\mathrm{~F}_{(2,100)}=1.13 ; \mathrm{ns}$ \\
IQ (Mean/SD) & C & $95.9 / 11.6$ & $97.4 / 10.8$ & $95.5 / 13.1$ & $\mathrm{~F}_{(2,83)}=0.21 ; \mathrm{ns}$ \\
Sex (boy/girl) & A & $104 / 12.8$ & $100.6 / 11.7$ & $99.4 / 15.4$ & $\mathrm{~F}_{(2,100)}=1.08 ; \mathrm{ns}$ \\
& C & $19 / 3$ & $23 / 8$ & $30 / 3$ & $\chi_{(2)}^{2}=0.18 ; \mathrm{ns}$ \\
& A & $22 / 10$ & $29 / 4$ & $31 / 7$ & $\chi_{(2)}^{2}=0.15 ; \mathrm{ns}$ \\
\hline
\end{tabular}

Table 1: Demographic and clinical data for 54 normal controls $(8-11$ years $n=22 ; 12-17$ years $\mathrm{n}=32), 64$ children with ADHD (8-11 years $n=31 ; 12-17$ years $n=33)$ and 71 children with ADHD+DBD (8-11 years $n=33$; $12-17$ years $n=38)$ : ${ }^{\text {a) }} \mathrm{C}=$ children $7-11$ years $\& \mathrm{~A}=$ adolescents $12-17$ years; 


\begin{tabular}{|c|c|c|c|c|c|}
\hline$C B C L(\text { Mean } / S D)^{b)}$ & a) & $A D H D$ & $A D H D+D B D$ & Difference & Post-hoc $^{c)}$ \\
\hline \multirow[t]{2}{*}{ Social withdrawal } & $\mathrm{C}$ & $65.5 / 6.1$ & $67.2 / 6.9$ & $\mathrm{~ns}$ & \\
\hline & A & $64.3 / 8.9$ & $64.2 / 10.3$ & & \\
\hline \multirow[t]{2}{*}{ Somatic complaints } & $\mathrm{C}$ & $64.3 / 8.5$ & $61.8 / 7.9$ & ns & \\
\hline & A & $62.1 / 9.5$ & $59.3 / 7.7$ & & \\
\hline \multirow[t]{2}{*}{ Anxiety/Depression } & $\mathrm{C}$ & $68.9 / 4.7$ & $67.5 / 6.8$ & ns & \\
\hline & A & $66.2 / 7.7$ & $67.5 / 8.4$ & & \\
\hline \multirow[t]{2}{*}{ Social problems } & $\mathrm{C}$ & $65.5 / 9.3$ & $69.7 / 6.9$ & ns & \\
\hline & A & $66.4 / 12.0$ & $65.7 / 8.2$ & & \\
\hline \multirow[t]{2}{*}{ Thought problems } & $\mathrm{C}$ & $67.1 / 6.7$ & $68.1 / 7.9$ & $\mathrm{p}<0.001$ & $\mathrm{C}>\mathrm{A}$ \\
\hline & A & $55.5 / 5.3$ & $54.7 / 4.7$ & & \\
\hline \multirow[t]{2}{*}{ Attention problems } & $\mathrm{C}$ & $74.7 / 8.0$ & $75.6 / 6.2$ & ns & \\
\hline & A & $73.0 / 8.0$ & $71.9 / 7.4$ & & \\
\hline \multirow[t]{2}{*}{ Delinquent behavior } & $\mathrm{C}$ & $70.6 / 6.5$ & $74.6 / 8.6$ & $\mathrm{p}=0.001$ & $\mathrm{ADHD}+\mathrm{DBD}>\mathrm{ADHD}$ \\
\hline & A & $66.0 / 8.4$ & $72.9 / 11.7$ & & \\
\hline \multirow[t]{2}{*}{ Aggressive behavior } & $\mathrm{C}$ & $65.4 / 6.9$ & $72.9 / 9.0$ & $\mathrm{p}<0.001$ & ADHD+DBD $>$ ADHD \\
\hline & A & $65.7 / 6.6$ & $76.8 / 10.0$ & & \\
\hline
\end{tabular}

Table 2: Child Behavior Checklist T-scores for 64 children with ADHD (8-11 years $n=31 ; 12$ 17 years $n=33)$ and 71 children with $A D H D+D B D(8-11$ years $n=33 ; 12-17$ years $n=38)$ : ${ }^{\text {a) }} \mathrm{C}$ $=$ children 7-11 years \& $\mathrm{A}=$ adolescents $12-17$ years; ${ }^{\mathrm{b})}$ Child Behavior Checklist (T-scores);

${ }^{c}$ Differences between homogeneous Subsets with Ryan-Einot-Gabriel-Welsch F Test

\section{$\underline{\text { Measures }}$}

The Sustained Attention Task involved the continuous and consecutive presentation of 50 series of twelve different dot patterns (600 signals; de Sonneville, 2000). In each series, an equal number of 3-dot, 4-dot, or 5-dot patterns were presented in a pseudo-random manner. The child was instructed to push the 'yes' button with the dominant hand whenever a 4-dot pattern (target) was presented and to press the 'no' button with the non-dominant hand if the presented pattern contained 3 or 5 dots (non-targets). The dependent measures were speed, its standard deviation (SD), the score of misses (MIS) and false alarms (FA).

In the go/nogo Paradigm (Fimm \& Zimmermann, 2001), which assesses response selection/inhibition, a motor response with the dominant hand was either initiated (go) or inhibited (nogo) depending on whether an " $\mathrm{x}$ " (go) or a "+" (nogo) stimulus appeared. Visual stimuli 
appeared in a random order for a duration of $200 \mathrm{~ms}$ with a variable inter-trial interval of maximal 1600 ms. Fifty per cent of the 40 stimuli were go trials. The dependent measures were the reaction time (RT) and its standard deviation (SD), the score of misses (MIS) and false alarms (FA).

\section{$\underline{\text { Statistical analysis }}$}

The data were analyzed using SPSS 11 (SPSS Inc., 2001). The demographic and clinical characteristics were assessed by ANOVA (IQ and age) and $\chi^{2}$-Pearson (sex and medication) between the three groups. The differences on the CBCL between the four clinical groups (child ADHD, adolescent ADHD, child ADHD+DBD and adolescent ADHD.DBD) were analyzed with an ANOVA. Post-hoc differences between homogeneous clinical subsets were detected with the Ryan-Einot-Gabriel-Welsch F test. An independent samples t-test (IQ) and $\chi^{2}$-Pearson (sex) were used for within group differences. Group differences, age effects and interaction effects were evaluated using univariate analysis of covariance (ANCOVA), with the diagnostic group and age as fixed factor and neuropsychological test scores as the dependent variables. IQ was used as covariate if it correlated significantly with the dependent variable $(\mathrm{p}<.05)$. If necessary, follow-up pairwise comparisons by diagnosis were conducted to investigate specific group differences. A Hochberg's Bonferroni adjustment was made for inflated Type I error (Keselman, Cribbie, \& Holland, 2002).

\section{Results}

As IQ correlated significantly with the dependent variables speed and FA of the sustained attention task $(r>0.18 ; \mathrm{p}<0.016)$ and number of FA and MIS of the go/nogo paradigm $(r>$ $0.10 ; p<0.009)$, IQ was entered as covariate for these dependent measures.

\section{$\underline{\text { Sustained Attention }}$}

For speed, no difference was found between the NC, children with ADHD and children with ADHD+DBD $\left(\mathrm{F}_{(6,182)}=2.6 ; \mathrm{ns}\right)$. An age effect was found $\left(\mathrm{F}_{(6,182)}=37.0 ; \mathrm{p}<0.001\right)$ : all groups performed significant better with higher age $\left(\mathrm{F}_{(6,182)}=37.0 ; \mathrm{p}<0.001\right)$ and the improvement was not dependent on group classification $\left(\mathrm{F}_{(6,182)}=0.5\right.$; ns). The same profile was found for the SD of speed: no effect was found for group $\left(\mathrm{F}_{(5,183)}=2.0 ; \mathrm{ns}\right)$ and group $\mathrm{x}$ age interaction $\left(\mathrm{F}_{(5,183)}=1.3\right.$; ns $)$, but the adolescents performed better than their younger counterparts $\left(\mathrm{F}_{(5,183)}=27.6 ; \mathrm{p}<0.001\right)$. A group effect $\left(\mathrm{F}_{(6,182)}=13.6 ; \mathrm{p}<0.001\right)$ and a group $\mathrm{x}$ 
age interaction effect $\left(\mathrm{F}_{(6,182)}=7.5 ; \mathrm{p}=0.001\right)$ were found for the number of $\mathrm{FA}$ : $(1)$ children with ADHD and ADHD+DBD made more errors than NC; (2) children with ADHD+DBD made noticeable more errors than children with ADHD; (3) no significant differences could be detected in the adolescent groups in the post hoc comparisons. Note however, that the FA of NC are obvious lower than the FA in the two clinical groups (see for more details figure 1). No group $\left(\mathrm{F}_{(5,183)}=1.6 ; \mathrm{ns}\right)$, age $\left(\mathrm{F}_{(5,183)}=0.2 ; \mathrm{ns}\right)$ or interaction effect $\left(\mathrm{F}_{(5,183)}=1.4 ; \mathrm{ns}\right)$ was found for the number MIS. The results are depicted in table 3 and 4.
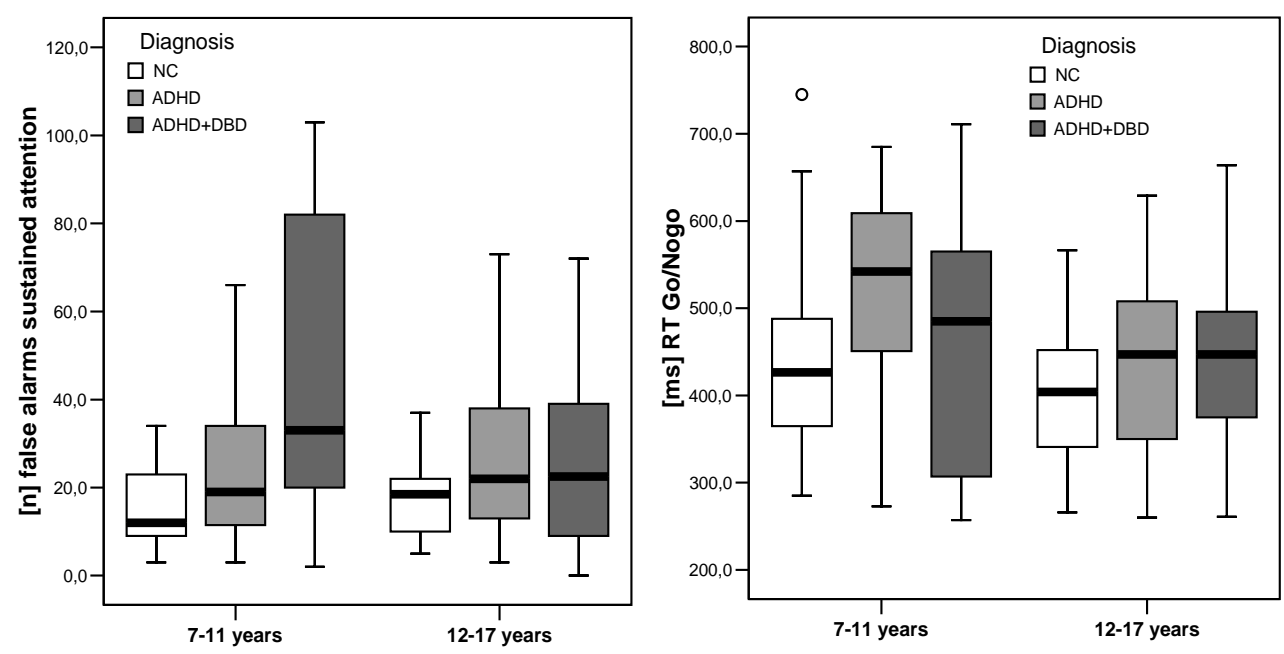

Figure 1: Number of false alarms and reaction time for children and adolescents by diagnosis for the go/nogo task. Children with ADHD+DBD $(n=33)$ made significant more false alarms than children with ADHD $(n=31)$ or $\mathrm{NC}(\mathrm{n}=22)$, whereas children with ADHD were significant slower than children with ADHD+DBD or NC. For the adolescent group no differences could be detected between NC $(n=32)$, ADHD $(n=33)$, and ADHD+DBD $(n=38)$. Note that the within-group variance in children with $\mathrm{ADHD}+\mathrm{DBD}$ is higher than in the other groups.

\section{$\underline{\text { Go/nogo }}$}

For RT and its SD a significant group $\left(\mathrm{F}_{(5,183)}>5.6 ; \mathrm{p}<0.005\right)$ and age effect $\left(\mathrm{F}_{(5,183)}>4.2 ; \mathrm{p}\right.$ $<0.041)$ were confirmed. The adolescent groups performed better than the children. Children with ADHD had slower RT than the ADHD+DBD group and NC, whereas the performance of NC and ADHD+DBD was statistically comparable. The SD of the RT for children with ADHD was significantly higher than the SD of NC, whereas no significant effects were detected between ADHD+DBD and NC or ADHD. A group $\mathrm{x}$ age interaction effect was not found $\left(\mathrm{F}_{(5,183)}<2.4 ; \mathrm{ns}\right)$ and no differences could be detected between the adolescent groups. The number of FA, a measure for impulsivity, is sensitive to group $\left(F_{(6,182)}=7.6 ; p=0.001\right)$ and age $\left(\mathrm{F}_{(6,182)}=4.6 ; \mathrm{p}=0.033\right)$. In addition, a group $\mathrm{x}$ age interaction was found $\left(\mathrm{F}_{(6,182)}=\right.$ 
5.6; $\mathrm{p}=0.005)$. Children with ADHD+DBD made significant more errors that the children with ADHD or NC. No significant difference was detected between NC and ADHD. For adolescents the significant difference between ADHD+DBD, ADHD and NC disappears (see figure 1). No significant group effect was observed for the number of $\operatorname{MIS}\left(\mathrm{F}_{(6,182)}=0.06\right.$; ns) but an age effect $\left(\mathrm{F}_{(6,182)}=5.0 ; \mathrm{p}=0.005\right)$ and a group $\mathrm{x}$ age effect $\left(\mathrm{F}_{(6,182)}=3.5 ; \mathrm{p}=0.032\right)$ were found. Adolescents performed better than children. Especially the adolescents in the ADHD+DBD group performed better than the children, whereas the variation for the NC and the group with ADHD is less (NC) or absent (ADHD).

\section{Discussion}

The goal of this study was to analyze developmental changes in impulsivity and sustained attention in children and adolescents with ADHD only and in children and adolescents with ADHD+DBD. Previous research was primarily based on children beneath 12 years and we hypothesized that deficits described in young children in inhibitory control would remain in the adolescence, whereas sustained attention deficits would disappear. Furthermore, we assumed that children and adolescents with ADHD+DBD would perform more poorly on these tasks. Therefore, we compared children with ADHD or ADHD+DBD in two different age groups on two neuropsychological tasks measuring sustained attention and inhibitory control. In agreement with previous research (e.g. Anderson et al., 2001; Pennington et al., 1996; Oosterlaan et al., 1998) we found that adolescents had greater attentional capacity and complete tasks faster than their younger counterparts and the two clinical children groups had more problems than the control children. Due to more false alarms, deficits were detected in the ADHD and ADHD+DBD group on the sustained attention task. False alarms are a parameter for impulsivity and the ADHD+DBD group made more errors than the ADHD group. In the go/nogo paradigm the ADHD group reacted slower with a higher SD. Here, the ADHD+DBD group was comparable with the NC but the ADHD+DBD group was more impulsive than NC and the ADHD group. In summary, due to slower reaction times, higher standard deviations and more errors, the ADHD group had more attentional problems than the ADHD+DBD group and the NC. This was not in agreement with our hypothesis that children with ADHD+DBD perform more poorly on all neuropsychological tasks. However, because of the higher number of false alarms on both tasks the ADHD+DBD children could be described as more impulsive than the ADHD group. 


\begin{tabular}{|c|c|c|c|c|c|c|c|}
\hline & age & $\begin{array}{c}N C \\
(n=22 / 32) \\
M(S D)\end{array}$ & $\begin{array}{c}A D H D \\
(n=31 / 33) \\
M(S D)\end{array}$ & $\begin{array}{c}A D H D+D B D \\
(n=33 / 38) \\
M(S D)\end{array}$ & $\begin{array}{c}\text { Diagnostic Group } \\
F(p)\end{array}$ & $\begin{array}{c}\text { Age Group } \\
F(p)\end{array}$ & $\begin{array}{c}\text { Diagnosis* Age } \\
F(p)\end{array}$ \\
\hline \multicolumn{8}{|l|}{ Sustained } \\
\hline Speed [sec] & $12-17$ & $11.4(3.6)$ & $11.9(3.2)$ & $11.1(2.8)$ & & & \\
\hline \multirow[t]{2}{*}{$\mathrm{SD}[\mathrm{sec}]$} & $8-11$ & $3.2(1.3)$ & $4.3(3.6)$ & $3.5(1.4)$ & $2.0(\mathrm{~ns})$ & $27.6(<0.001)$ & $1.3(\mathrm{~ns})$ \\
\hline & $12-17$ & $2(1.2)$ & $2.2(1.2)$ & $2.3(1.5)$ & & & \\
\hline \multirow[t]{2}{*}{ MIS [n] } & $8-11$ & $22(13.4)$ & $21.8(16.2)$ & $31.2(28.7)$ & $1.6(\mathrm{~ns})$ & $0.2(\mathrm{~ns})$ & $1.4(\mathrm{~ns})$ \\
\hline & $12-17$ & $26.9(16.3)$ & $20.6(15.5)$ & $23.8(24)$ & & & \\
\hline \multicolumn{8}{|l|}{ Go/Nogo } \\
\hline \multirow[t]{2}{*}{ RT [ms] } & $8-11$ & 434 (117) & $526(108)$ & 452 (139) & $5.6(0.005)$ & $8.7(0.004)$ & $2.4(\mathrm{~ns})$ \\
\hline & $12-17$ & $398(70)$ & $436(100)$ & $441(84)$ & & & \\
\hline SD [ms] & $8-11$ & $109(35)$ & $139(35)$ & $118(45)$ & $5.8(0.004)$ & $4.2(0.041)$ & $0.2(\mathrm{~ns})$ \\
\hline
\end{tabular}

Table 3: Measures of performance for sustained attention and go/nogo paradigm for 54 normal controls, 64 youngsters with ADHD and 71 youngsters with ADHD+DBD: ${ }^{\text {a) }}$, Adjusted for IQ; * $\mathrm{p}<0.05 ; * * \mathrm{p}<0.01$ 


\begin{tabular}{|c|c|c|c|c|c|c|}
\hline & $\begin{array}{c}N C \\
M(S D)\end{array}$ & $\begin{array}{l}A D H D \\
M(S D)\end{array}$ & $\begin{array}{c}A D H D+D B D \\
M(S D)\end{array}$ & $F(p)$ & $T / B^{a)}$ & Post Hoc comparisons \\
\hline \multicolumn{7}{|l|}{ Sustained } \\
\hline $\mathrm{SD}[\mathrm{sec}]$ & $3.2(1.3)$ & $4.3(3.6)$ & $3.5(1.4)$ & $1.75(\mathrm{~ns})$ & $\mathrm{B}$ & \\
\hline $\mathrm{FA}[\mathrm{n}]$ & $15(8.7)$ & $23.7(17)$ & $44.7(31)$ & $13.38(<0.001)$ & $\mathrm{T}$ & $\mathrm{NC}<\mathrm{ADHD}^{*} ; \mathrm{NC}<\mathrm{ADHD}+\mathrm{DBD}^{* *} ; \mathrm{ADHD}<\mathrm{ADHD}+\mathrm{DBD}^{* *}$ \\
\hline MIS [n] & $22(13.4)$ & $21.8(16.2)$ & $31.2(28.7)$ & $1.91(\mathrm{~ns})$ & $\mathrm{T}$ & \\
\hline $\mathrm{SD}[\mathrm{ms}]$ & $109(35)$ & $139(35)$ & $118(45)$ & $4.16(0.019)$ & $\mathrm{B}$ & $\mathrm{NC}<\mathrm{ADHD}$ \\
\hline FA [n] & $3.4(3.3)$ & $4.8(3.3)$ & $8.2(5.4)$ & $9.75(<0.001)$ & $\mathrm{T}$ & $\mathrm{NC}<\mathrm{ADHD}+\mathrm{DBD}^{* *} ; \mathrm{ADHD}<\mathrm{ADHD}+\mathrm{DBD}^{* *}$ \\
\hline MIS [n] & $1.7(2.3)$ & $1.5(3)$ & $2.4(2.4)$ & $0.00(\mathrm{~ns})$ & $\mathrm{B}$ & \\
\hline Adolescents & $\mathrm{n}=32$ & $\mathrm{n}=33$ & $\mathrm{n}=38$ & & & \\
\hline \multicolumn{7}{|l|}{ Sustained } \\
\hline Speed $[\mathrm{sec}]$ & $11.4(3.6)$ & $11.9(3.2)$ & $11.1(2.8)$ & $0.6(\mathrm{~ns})$ & B & \\
\hline RT [ms] & $398(70)$ & $436(100)$ & $441(84)$ & $2.53(\mathrm{~ns})$ & B & \\
\hline $\mathrm{SD}$ [ms] & $95(33)$ & $123(80)$ & $106(32)$ & $2.38(\mathrm{~ns})$ & B & \\
\hline FA [n] & $3.1(2.8)$ & $4.7(4.3)$ & $4.1(3.9)$ & $1.52(\mathrm{~ns})$ & $\mathrm{T}$ & \\
\hline $\operatorname{MIS}[\mathrm{n}]$ & $1(1.4)$ & $1.5(2.5)$ & $0.5(0.8)$ & $3.07(\mathrm{~ns})$ & $\mathrm{T}$ & \\
\hline
\end{tabular}

Table 4: Analysis for sustained attention and go/nogo paradigm within the two different age groups: children (8-11 years) and adolescents (12-17 years): $\mathrm{T}=$ Tamhane's Post Hoc (no equality of variances) versus $\mathrm{B}=$ Bonferroni's Post Hoc (equality of variances); ${ }^{*} \mathrm{p}<0.05 ; * * \mathrm{p}<0.01$ 
Together, this is in accordance with previous research, wherein a hyperactive/aggressive group of children was more impulsive that the pure hyperactive or pure aggressive group and the hyperactive children were most inattentive (Halperin et al., 1990). Interestingly and contrary to our expectations, we found that the neuropsychological differences between $\mathrm{NC}$, ADHD and ADHD+DBD observed in children between 8 and 11 years were not detectable with higher age. The performance of the adolescents of the two clinical groups on these tests was comparable with that of age and IQ matched NC.

As was presented in table 3 and 4 adolescents with ADHD or ADHD+DBD did not differ significantly from their coeval normal controls. This is not in accordance with previous research, wherein neuropsychological differences were found in adolescent groups (e.g. Rucklidge \& Tannock, 2002; Seidman, Biederman, Faraone, Weber, \& Ouelette, 1997). A recent study of Seidman et al. (2005) demonstrated that executive dysfunctions are correlates of ADHD regardless of age (age range in their study between 9 and 17 years). Conversely, Scheres et al. (2004) demonstrated that none of the EF deficits (e.g. interference control) in ADHD (age range between 6 and 12 years) remained after controlling for age end IQ. A recent meta-analytic review about the stop-signal paradigm concluded that the attention deficits are not detectable for adults, whereas the inhibitory problems remained (Lijffijt et al., 2005). In our study IQ was enrolled in the statistical analyzes, age was an independent variable and ADHD+DBD was added as second clinical group. In contrast to Scheres et al. (2004) we found differences in the children groups between NC, ADHD and ADHD+DBD and contrary to Seidman et al. (2005) and Lijffijt et al. (2005) the deficits in the clinical groups were not detectable in the adolescence. To explain this discrepancy, it is important to note that our adolescent groups had significant higher IQs than the children. Furthermore, our adolescent ADHD and ADHD+DBD groups had IQs around 100, whereas other studies report significant lower IQs for these groups (e.g. Scheres et al., 2004; Banaschewski et al., 2003). Due to the positive correlation between intelligence and executive functions, the higher IQ of the adolescent group might be a possible confounder resulting in better perfomance in the adolescents` groups. Thus, it can be speculated that adolescents with normal IQ are able to use strategies to perform adequately on motivational independent neuropsychological tasks. Most of the neuropsychological studies with adults or adolescents described that neuropsychological deficits are expressed across multiple cognitive domains (e.g. attention, behavioral inhibition and memory), but the results are inconsistent and some studies were not able to establish that there are neuropsychological deficits in adults (c.p. Hervey, Epstein, \& Curry, 2004). In 
addition, it has been shown that ADHD is a very heterogeneous disorder with regard to neuropsychological deficits and there is thorough evidence that about $1 / 3$ of all ADHD patients are unimpaired on the majority of neuropsychological tasks (Taylor et al., 1998; Hanisch et al., 2004). Thus, we cannot rule out that the sample examined here is not representative for all ADHD and ADHD+DBD patients. Note however, that all adolescents were carefully diagnosed according to ICD-10. The behavioral ratings of attentional problems were patholognomonic for both adolescent clinical groups (CBCL). Furthermore, delinquent and aggressive behavior was pathological for the ADHD+DBD group.

\section{$\underline{\text { Clinical implications }}$}

Inhibitory control is an important part of executive functions. Furthermore, it is an essential subdimension of impulsivity, and impulsivity, measured with laboratory instruments in young children, is related to children's externalizing problems (Avila et al., 2004). We could demonstrate that children with ADHD+DBD were more impulsive than children with ADHD or NC. According to the DSM IV ADHD, ODD and CD are independent clinical entities (American Psychiatric Association, 1994). However, ADHD and CD occur together in 30\% to 50\% of cases in both epidemiologic and clinical samples (Biederman et al., 1991). About $61 \%$ of the children with ADHD have a comorbid diagnosis and disruptive behavior (any combination with ODD or CD) is diagnosed in 44\% of the children with ADHD (August, Realmuto, MacDonald, Nugent, \& Crosby, 1996). Furthermore, severity of inattention/hyperactive ADHD symptoms is associated with aggressive and delinquent psychopathology across both parent and teacher reports (Connor et al., 2003). Thereby, these facts alone are arguments for the ICD-10 classification wherein the comorbid condition of ADHD and CD (hyperkinetic conduct disorder [HCD]) is considered as a separate disorder (World-Health-Organization, 1993). In this perspective ADHD+DBD is a distinct subtype with specific etiology, risk factors and outcome (e.g. Faraone \& Biederman, 1998; Biederman, Faraone, \& Lapey, 1992). This is in concordance with our data, wherein children with ADHD have more attentional problems and children with ADHD+DBD are more impulsive. This double dissociation is contradictory to the idea that ADHD+DBD is an additive disorder of ADHD and DBD.

\section{Limitations and Conclusion}

This study has several limitations. First, we did not include a DBD only group. Second, the cross-sectional design of our study limits generalizations and it is difficult to draw hard conclusions about causality. Third, we tried to examine a model wherein brain development is a 
central focus. But with the described neuropsychological methods it is only possible to measure brain development indirectly. Future research with direct methods, like a combination of the described tasks and brain imaging, could resolve this problem. Fourth, we did not include tasks that measure motivational processes. According to the BIS/BAS theory of Gray (1994) the Behavioral Inhibition System (BIS) inhibits behavior in response to cues of punishment or non-reward and the Behavioral Activating System (BAS) is activated by cues of reward or non-punishment. In line with this theory children with $\mathrm{CD}$ have more motivational problems (dominance of BAS over BIS) whereas children with ADHD (dysfunctional BIS) have a more EF deficits (van Goozen et al., 2004). Close to these results, the early onset, primary CD pathway characterized by Nigg (2003) describes motivational inhibition problems for children with CD with the possibility to develop comorbid ADHD. Thus, it is possible, that adolescents with ADHD+DBD differ from adolescents with ADHD on the level of motivational inhibition. Since we did not include motivational assessments, e.g. the Door Opening Test (Matthys, van Goozen, de Vries, Cohen Kettenis, \& van Engeland, 1998), it was impossible to differentiate between motivational inhibition and executive inhibition within the two clinical groups. Finally, we did not include the neighborhood socioeconomic context in our analysis. It is possible that differences between $\mathrm{ADHD}$ and ADHD+DBD are caused by different family variables between these groups. According to Ford et al. (2004)ADHD is only related to child characteristics, whereas development of DBD is strongly related to family variables. Therefore, it is possible that our differences between the ADHD and ADHD+DBD groups are confounded by socioeconomic variables.

In conclusion, and bearing these limitations foremost in mind, the present study found that children with ADHD have more attentional problems than children with ADHD+DBD and the ADHD+DBD group is more impulsive than the ADHD group. The differences between young $\mathrm{ADHD}, \mathrm{ADHD}+\mathrm{DBD}$ and $\mathrm{NC}$ on a motivational independent tasks were not detectable with higher age. The performance of adolescents with ADHD+DBD, ADHD or NC is comparable. Thus, our data indicate that brain maturation processes might modulate attentional functions in $\mathrm{ADHD}$ and $\mathrm{ADHD}+\mathrm{DBD}$ in the age range 12-17 years.

\section{References}

American Psychiatric Association (1994). Diagnostic and Statistical Manual of Mental Disorders - DSM-IV. (4 ed.) Washington D.C.: American Psychiatric Association. 
Anderson, V. (2001). Assessing executive functions in children: biological, psychological, and developmental considerations. Pediatric Rehabilitation, 4, 119-136.

Anderson, V., Anderson, P., Northam, E., Jacobs, R., \& Catroppa, C. (2001). Development of Executive Functions Through Late Childhood and Adolescence in an Australian Sample. Developmental Neuropsychology, 20, 385-406.

Aron, A. R. \& Poldrack, R. A. (2005). The cognitive neuroscience of response inhibition: relevance for genetic research in attention-deficit/hyperactivity disorder. Biological Psychiatry, 57, 1285-1292.

August, G. J., Realmuto, G. M., MacDonald, A. W., Nugent, S. M., \& Crosby, R. (1996). Prevalence of ADHD and Comorbid Disorders Among Elementary School Children Screened for Disruptive Behavior. Journal of Abnormal Child Psychology, 24, 571-595.

Avila, C., Cuenca, I., Félix, V., Parcet, M., \& Miranda, A. (2004). Measuring Impulsivity in School-Aged Boys and Examing Its Its Relationship With ADHD and ODD Ratings. Journal of Abnormal Child Psychology, 32, 295-304.

Banaschewski, T., Brandeis, D., Heinrich, H., Albrecht, B., Brunner, E., \& Rothenberger, A. (2003). Association of ADHD and conduct disorder - brain electrical evidence for the existence of a distinct subtype. Journal of Child Psychology and Psychiatry, 44, 356-376.

Barkley, R. A. (1999). Response inhibition in attention-deficit hyperactivity disorder. Mental Retardation and Developmental Disabilities Research Reviews, 5, 177-184.

Bekker, E. M., Overtoom, C. C., Kenemans, J. L., Kooij, J. J., De Noord, I., Buitelaar, J. K. et al. (2005). Stopping and changing in adults with ADHD. Psychological Medicine, 35, 807-816.

Biederman, J., Faraone, S. V., \& Lapey, K. (1992). Comorbidity of diagnosis in attention-deficit hyperactivity disorder. Child and Adolescent Psychiatric Clinics of North AMerica, 1, 335-360.

Biederman, J., Newcorn, J. H., \& Sprich, S. (1991). Comorbidity of Attention Deficit Hyperactivity Disorder With Conduct, Depressive, Anxiety, and Other Disorders. American Journal of Psychiatry, 148, 564-577.

Connor, D. F., Edwards, G., Fletcher, K., Baird, J., Barkley, R. A., \& Steingard, R. (2003). Correlates of Comorbid Psychopathology in Children With ADHD. Journal of the American Academy of Child and Adolescent Psychiatry, 42, 193-200.

de Sonneville, L. M. J. (2000). ANT 2.1 - Amsterdam Neuropsychological Tasks. Amstelveen: Sonar. 
Derryberry, D. \& Rothbart, M. K. (1997). Reactive and effortful processes in the organization of temperament. Development and Psychopathology, 9, 633-652.

Döpfner, M., Plück, J., Bölte, S., Lenz, K., Melchers, P., \& Heim, K. (1998). Elternfragebogen über das Verhalten von Kindern und Jugendlichen - 2. Auflage mit deutschen Normen. Köln: Arbeitsgruppe Deutsche Child Behavior Checklist.

El-Sayed, E., Larsson, J. O., Persson, H. E., Santosh, P. J., \& Rydelius, P. A. (2003). "Maturational lag" hypothesis of attention deficit hyperactivity disorder: an update. Acta Paediatrica, 92, 776-784.

Faraone, S. V. \& Biederman, J. (1998). Neurobiology of attention-deficit hyperactivity disorder. Biological Psychiatry, 44, 951-958.

Fimm, B. \& Zimmermann, P. (2001). Testbatterie zur Aufmerksamkeitsüberprüfung (TAP) - Version 1.6. Herzogenrath: Psytest.

Fischer, M., Barkley, R. A., Smallish, L., \& Fletcher, K. (2002). Young Adult FollowUp of Hyperactive Children: Self-Reported Psychiatric Disorders, Comorbidity, and the Role of Childhood Conduct Problems and Teen CD. Journal of Abnormal Child Psychology, 30, 463-475.

Ford, T., Goodman, R., \& Meltzer, H. (2004). The relative importance of child, family, school and neighbourhood correlates of childhood psychiatric disorder. Social Psychiatry and Psychiatric Epidemiology, 39, 487-496.

Gogtay, N., Giedd, J. N., Lusk, L., Hayashi, K. M., Greenstein, D., Vaituzis, A. C. et al. (2004). Dynamic mapping of human cortical development during childhood through early adulthood. PNAS, 101, 8174-8179.

Gray, J. A. (1994). Framework for a taxonomy of psychiatric disorders. In S.H.M.van Goozen, N. E. van de Poll, \& J. E. Sergeant (Eds.), Emotions: Essay on emotion theory (pp. 29-59). Hillsdale: Erlbaum.

Halperin, J. M., O’Brien, J. D., Newcorn, J. H., Healey, J. M., Pascualvaca, D. M., Wolf, L. E. et al. (1990). Validation of Hyperactive, Aggressive, and Mixed Hyperactive/Aggressive Childhood Disorders: A Research Note. Journal of Child Psychology and Psychiatry, 31, 455-459.

Hanisch, C., Konrad, K., Günther, T., \& Herpertz-Dahlmann, B. (2004). Age- dependent neuropsychological deficits and effects of methylphenidate in children with attentiondeficit/ hyperactivity disorder: a comparison of pre- and grade-school children. Journal of Neural Transmission, 111, 865-881. 
Hervey, A. S., Epstein, J. N., \& Curry, J. F. (2004). Neuropsychology of adults with attention-deficit/hyperactivity disorder: a meta-analytic review. Neuropsychology, 18, 485503.

Huttenlocher, P. R. \& Dabholkar, A. S. (1997). Regional differences in synaptogenesis in human cerebral cortex. The Journal of Comparative Neurology, 387, 167-178.

Keselman, H. J., Cribbie, R., \& Holland, B. (2002). Controlling the rate of Type I error over a large set of statistical tests. British Journal of Mathematical and Statistical Psychology, 55, 27-39.

Kochanska, G., Murray, K., \& Coy, K. C. (1997). Inhibitory control as a contributor to conscience in childhood: from toddler to early childhood. Child Development, 68, 490-507.

Levin, H. S., Culhane, K., Hartmann, J., Evankovich, K., Mattson, A. J., Harward, H. et al. (1991). Developmental changes in performance on tests of purported frontal lobe functioning. Developmental Neuropsychology, 7, 395.

Lijffijt, M., Kenemans, J. L., \& van Engeland, H. (2005). A Meta-Analytic Review of Stopping Performance in Attention-Deficit/ Hyperactivity Disorder: Deficient Inhibitory Control? Journal of Abnormal Psychology, 114, 216-222.

Loeber, R., Burke, J. D., Lahey, B. B., Winters, A., \& Zera, M. (2000). Oppositional defiant and conduct disorder: A review of the past 10 years, part 1. Journal of the American Academy of Child and Adolescent Psychiatry, 39, 1468-1484.

Lynam, D. R. (1996). The early identification of chronic offenders: Who is the fledgling psychopath? Psychological Bulletin, 120, 209-234.

Matthys, W., van Goozen, S. H. M., de Vries, H., Cohen Kettenis, P. T., \& van Engeland, H. (1998). The dominance of behavioral activation over behavioral inhibition in conduct disordered boys with or without attention deficit hyperactivity disorder. Journal of Child Psychology and Psychiatry, 39, 643-651.

Nigg, J. T. (2003). Response Inhibition and Disruptive Behaviors - Toward a Multiprocess Conception of Etiological Heterogeneity for ADHD Combined Type and Conduct Disorder Early-Onset Type. Annals of the New York Academy of Sciences, 1008, 170-182.

Oosterlaan, J., Logan, G. D., \& Sergeant, J. A. (1998). Response Inhibition in AD/HD, $\mathrm{CD}$, Comorbid AD/HD+CD, Anxious, and Control Children: A Meta-analysis of Studies with the Stop Task. Journal of Child Psychology and Psychiatry, 39, 411-425.

Pennington, B. F. \& Ozonoff, S. (1996). Executive functions and developmental psychopathology. Journal of Child Psychology and Psychiatry and Allied Disciplines, 37, 51-87. 
Quay, H. C. (1997). Inhibition in attention deficit hyperactivity disorder. Journal of Abnormal Child Psychology, 25, 7-13.

Rucklidge, J. J. \& Tannock, R. (2002). Neuropsychological profiles of adolescents with ADHD: effects of reading difficulties and gender. Journal of Child Psychology and Psychiatry, 43, 988-1003.

Scheres, A., Oosterlaan, J., Geurts, H., Morein Zamir, S., Meiran, N., Schut, H. et al. (2004). Executive functioning in boys with ADHD: primarily an inhibition deficit? Archives of Clinical Neuropsychology, 19, 569-594.

Schlaggar, B. L., Brown, T. T., Lugar, H. M., Visscher, K. M., Miezin, F. M., \& Petersen, S. E. (2002). Functional neuroanatomical differences between adults and school-age children in the processing of single words. Science, 296, 1476-1479.

Schuck, S. E. \& Crinella, F. M. (2005). Why children with ADHD do not have low IQs. Journal of Learning Disabilities, 38, 262-280.

Seidman, L. J., Biederman, J., \& Faraone, S. V. (2005). Impact of Gender and Age on Executive Functioning: Do Girls and Boys With and Without Attention Deficit Hyperactivity Disorder Differ Neuropsychologically in Preteen and Teenage Years? Developmental Neuropsychology, 27, 79-105.

Seidman, L. J., Biederman, J., Faraone, S. V., Weber, W., \& Ouelette, C. (1997). Toward defining a neuropsychology of attention deficit-hyperactivity disorder: performance of children and adolescents from a large clinically referred sample. Journal of Consulting and Clinical Psychology, 65, 150-160.

Sergeant, J. A., Geurts, H., \& Oosterlaan, J. (2002). How specific is a deficit of executive functioning for Attention-Deficit/Hyperactivity Disorder? Behavioural Brain Research, 130, 3-28.

SPSS Inc. (2001). Statistical Package of Social Science (Version 11) [Computer software]. SPSS Inc.

Stiles, J. (2000). Neural plasticity and cognitive development. Developmental Neuropsychology, 18, 237-272.

Taylor, E., Sergeant, J., Doepfner, M., Gunning, B., Overmeyer, S., Mobius, H. J. et al. (1998). Clinical guidelines for hyperkinetic disorder. European Society for Child and Adolescent Psychiatry. European Child and Adolescent Psychiatry, 7, 184-200.

Unnewehr, S., Schneider, S., \& Margraf, J. (1995). Kinder DIPS - Diagnostisches Interview bei psychischen Störungen im Kindes und Jugendalter. Heidelberg: Springer. 
Impulsivity and sustained attention deficits in ADHD with and without DBD | 51

van Goozen, S. H. M., Cohen Kettenis, P. T., Snoek, H., Matthys, W., SwaabBarneveld, H., \& van Engeland, H. (2004). Executive functioning in children: a comparison of hospitalised ODD and ODD/ADHD children and normal controls. Journal of Child Psychology and Psychiatry, 45, 284-292.

Welsh, M. C., Pennington, B. F., \& Groisser, D. (1991). A normative-developmental study of executive functions: a window on prefrontal function in children. Developmental Neuropsychology, 7, 149.

Willcutt, E. G., Doyle, A. E., Nigg, J. T., Faraone, S. V., \& Pennington, B. F. (2005). Validity of the Executive Function Theory of Attention-Deficit / Hyperactivity Disorder: A Meta-Analytic Review. Biological Psychiatry, 57, 1336-1346.

World-Health-Organization (1993). The ICD-10 classifications of mental and behavioral disorders: Clinical descriptions and diagnostic guidelines 1992; diagnostic criteria for research. Geneva: WHO. 

Chapter 4:

\title{
Age- dependent neuropsychological deficits and effects of methylphenidate in children with attention-deficit/ hyperactivity disorder: a comparison of pre- and grade-school children
}

\author{
C. Hanisch ${ }^{\dagger}$, K. Konrad ${ }^{\dagger}$, T. Günther, B. Herpertz-Dahlmann*
}

\section{Summary}

Objective: Pre-school and grade-school children diagnosed with attention-deficit/ hyperactivity disorder (ADHD) were compared in their performance on computerized attention tasks. Depending on the nature of the specified attention deficit, subjects were assigned to groups of cognitive subtypes. The effects of methylphenidate (MPH) were analysed depending on age and cognitive subtype. Method: The preschool group comprised 45 children aged 5-7 years; the grade-school group comprised 54 children aged 8-12 years. Children were tested on placebo and on MPH (mean dose: $0.25-0.3 \mathrm{mg} / \mathrm{kg}$ body weight) employing tasks of alertness, sustained attention, focused attention, divided attention, and a cognitive conflict task. Results: Both groups showed measurable attention deficits. While preschoolers were especially impaired in supervisory attention functions, grade-schoolers most frequently exhibited deficits in attention intensity and selectivity. Positive MPH effects were documented for sustained attention in both age-groups. Analysis of MPH effects in dependence on the type of attention impairment (supervisory functions vs. attention intensity / selectivity) revealed a positive relation between deficits in a specific attention domain and MPH effects. Conclusions: Agedependent differences in attention dysfunctions might be due to brain maturational processes. Performance on computerized attention tasks was particularly improved by MPH in children with objectified attention deficits suggesting that neuropsychological diagnostics can be useful to optimise treatment outcome.

\footnotetext{
${ }^{\dagger}$ These authors contributed equally; * Journal of Neural Transmission (2004) 111: 865-881
} 


\section{Introduction}

Attention-deficit / hyperactivity disorder (ADHD) is characterized by extensive hyperactivity, impulsiveness, and inattentiveness. Although the symptom triad must be manifest before the age of seven (DSM-IV: American Psychiatric Association, 1994; ICD-10: World Health Organization, 1993) and the peak age of onset of ADHD is between 3 and 4 years of age (Palfrey et al., 1985; Taylor et al., 1998), little research effort has been made on preschool ADHD. According to developmental models, preschool ADHD seems to be characterized by predominantly hyperactive symptoms, whereas older affected children show inattentive symptoms in addition to hyperactivity and impulsivity (Barkley et al., 1997). During adolescence and adulthood, ADHD hyperactivity has been reported to decline further while attention deficits persist in older ADHD patients (Biederman et al., 2000). Relating this change in the ADHD phenotype between childhood and adulthood to brain maturation processes, brain imaging studies suggest a shift in the locus of brain abnormalities from the midbrain in childhood to the prefrontal cortex in adulthood (Ernst et al., 1998; van Dyck et al., 2002). When tested with child-adapted neuropsychological batteries, children as young as 4 years old exhibit reliable and valid scores on attention tasks (Berger et al., 2000). An association between inhibitory dysfunction and high ADHD scores on behaviour ratings has been documented in two studies on non-clinical samples of preschool children (Sonuga-Barke, 2002; Berlin and Bohlin, 2002). ADHD preschoolers have been reported to show impaired working memory (Kalff et al., 2002), visual search and vigilance (DeWolfe et al., 1999; Byrne et al., 1998), and deficient performance of the Continuous Performance Test (Harper and Ottinger, 1992). Research on cognitive performance in school-age ADHD is far more extensive and yields inconsistent results: while sustained attention, cognitive impulsivity, and various aspects of executive control like inhibition, interference, or response-delay have been described to be deficient (Taylor et al., 1998; Konrad et al., 2000; Pennington and Ozonoff, 1996; Nigg et al., 2002), others find neither sustained nor focused attention deficits (Sergeant and van der Meere, 1990). Depending on the number of performed tasks, 30-70\% of children diagnosed with ADHD seem to exhibit attention deficits in neuropsychological tasks (Taylor, 1998).

Stimulant medication, especially methylphenidate (MPH) is the treatment of first choice for children with ADHD. In the past ten years, overall prescription of MPH has shown a threefold rise for pre-schoolers (Connor, 2002) and an eightfold rise for grade-schoolers (AACAP, 2002). The number of German children treated with MPH has increased two-and-a-half times between 1998 and 2000 (Ferber et al., 2003). For school-age ADHD, the benefits and efficacy 
of MPH have been demonstrated in more than 200 controlled studies, while only nine controlled stimulus trials have been conducted with preschoolers (Wilens and Spencer, 2000 for a review). Despite greater variability in stimulant response (Connor, 2002), positive effects on behaviour have been described for preschoolers (Efron et al., 2000; Byrne et al., 1998; Handen et al., 1999; Barkley, 1988). However, for a preschool paper-pencil-test of attention, a positive effect was achieved neither for a high dose of MPH nor for a low dose, while performance on Gordon's visual CPT (Musten et al., 1997) or on a visual and auditory vigilance test improved on MPH (Byrne et al., 1998). School-age ADHD children treated with MPH show enhanced maintenance of attention (van der Meere et al., 1995; DeSonneville et al., 1994), accuracy (Jonkman et al., 1999), working memory (Tannock et al., 1995a), or inhibition (Tannock et al., 1995b; Scheres et al., 2003). Others have found no MPH effect on the Stroop interference task (Jonkman et al., 1999), on Go/NoGo-Tasks (van der Meere et al., 1999), or on a divided attention task (DeSonneville et al., 1994). As far as doseresponse curves are concerned it has been demonstrated that attention intensity is best accelerated by higher MPH doses (Denney and Rapport, 2001), whereas executive functions are best influenced by moderate doses (Tannock et al., 1995b; Konrad et al., 2004).

Concepts of attention generally distinguish between selectivity and intensity of attention. In a task of selective attention, one has to respond to a specific stimuli constellation by giving priority to certain stimuli; whereas, intensity tasks require activation and maintenance of attention over time. In addition, a supervisory attention system (SAS) is assumed to act as a control mechanism modulating the two dimensions of selectivity and intensity (Van Zomeren and Brouwer, 1994). Figure 1 presents this theoretical framework with associated assessment paradigms. This concept is supported by clinical studies (Spikman et al., 2001) as well as by functional imaging data (Cabeza and Nyberg, 2000). The latter relate the SAS, depending on the respective task, to prefrontal predominantly dopamine mediated areas (Cabeza and Nyberg, 2000; Fan et al., 2003) and to circuits linking the basal ganglia and the orbitofrontal cortex (Castellanos, 1999). The intensity domain has been hypothesized to activate a vigilance network localized in the right prefrontal cortex and in subcortical arousal areas (Sturm et al., 2000); whereas, attention selectivity involves a broad bilateral representation also including thalamic and striatal areas (Corbetta et al., 1991). 


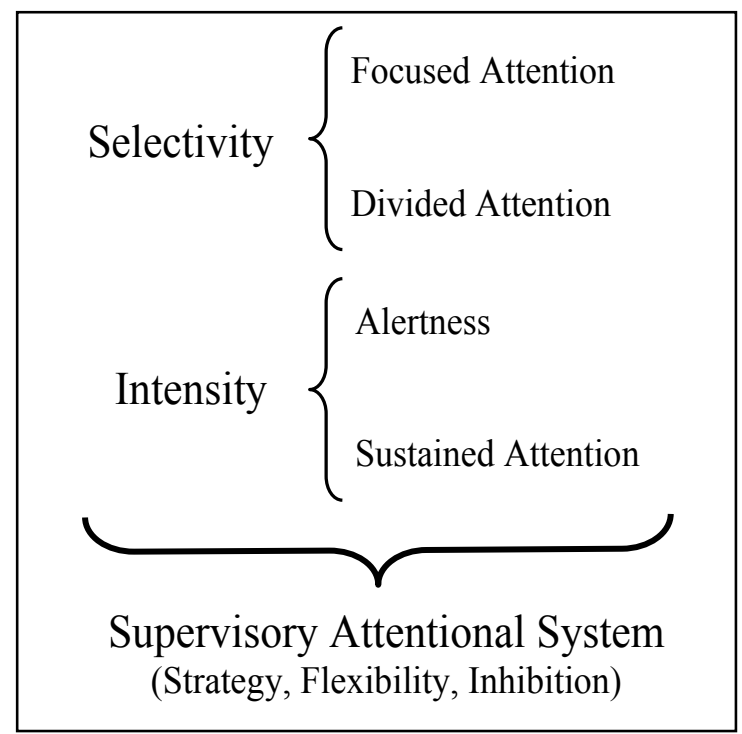

Fig. 1 A schedule of the theoretical framework of attentional functions according to Van Zomeren and Brouwer (1994).

One aim of the present paper is to compare neuropsychological performance of pre-school and grade-school children with ADHD. In concordance with the ADHD literature we anticipate attention deficits in both age groups especially in attention intensity and in the supervisory attention system. Further, in line with previous findings on ADHD we expect a number of children in each group to show normal attention performance. Brain maturation processes might result in differences in the distribution of cognitive subtypes across age groups. A second aim is to evaluate MPH effects on computerized attention tasks and compare pre-school and grade-school children again. In concordance with the literature on MPH effects in school-age ADHD, we expect improvements in both groups. Moreover, we expect differential MPH effects in dependence on the affected attention domain.

\section{Materials and Methods}

\section{Participants and selection procedure}

Two ADHD cohorts were examined. One group consisted of 45 preschool children aged 5 to 7 years (mean age $6.4 \pm 0.8$ ), the other of 54 children aged 8 to 12 years (mean age $10.7 \pm 1.7$ ). The two age-groups were termed "pre-school" and "grade-school" according to the German school system and the respective age ranges. ADHD boys and girls have been reported to differ in terms of inattentive symptoms (Biederman et al., 2002). In order to match distribution of gender and IQ between both groups, subjects of the older group were randomly drawn from a 
sample of 60 grade-school children participating in a study on MPH dosage effects (Konrad et al., 2004). Thus, the 5-7 year olds and the 8-12 year olds compared here did not differ in terms of gender distribution (Mann-Whitney-U Test, $\mathrm{p}>0.05$ ) or IQ (ANOVA, $\mathrm{p}>0.05$ ). Depending on their birth date, German children start school at age of six or seven years. The 7-year-olds were included in the study before or upon starting school. All children met the DSM-IV criteria for ADHD and were recruited from our inpatient or outpatient Department of Child and Adolescent Psychiatry. All new referrals with suspected ADHD symptoms underwent an extensive child psychiatric examination conducted by an experienced child and adolescent psychiatrist. Psychiatric classification according to DSM-IV (American Psychiatric Association, 1994) was based on a German semistructured interview of the child's parents (K-DIPS; Unnewehr et al., 1995), developmental history, playroom observation, pediatric examination, and evaluations with the Child Behavior Checklist.

Exclusion criteria were general IQ below 80 (WISC-III for school children and Kaufman Assessment Battery for Children (K-ABC) for preschoolers); any potentially confounding diagnoses such as psychosis, mania, or major depression; pervasive developmental disorders or receptive language disorders; or any kind of additional medication. Informed parental consent was obtained for all participants and the study was approved by the Medical Ethical Committee of the University Hospital of Aachen.

\section{Neuropsychological testing procedure}

Twenty two of the 45 preschool ADHD children and all of the 54 grade-school ADHD children participated in two testing sessions. Differences in group sizes for the second testing are explained by the fact that MPH is prescribed more cautiously in pre-schoolers than in gradeschoolers. Preschool children that are affected only moderately are seldom treated with stimulant medication before starting school. However, in our preschool sample severity scores of the KDIPS did not differ between the medicated pre-schoolers and those that were not medicated (ANOVA, $\mathrm{p}>0.05$ ). For children that participated in two testings, the study was conducted as a double-blind placebo-controlled medication trial. The remaining 23 preschoolers that were tested once were medication naive. The medicated children received either their morning medication or a placebo one hour before testing. Medication and placebo (lactose) were administered in identical opaque gelatin capsules in a double-blind manner. The mean dose (with standard deviations in parentheses) was $6.4 \pm 1.7 \mathrm{mg}$ for the preschoolers and $9.4 \pm$ $2.7 \mathrm{mg}$ for the grade-schoolers. Body weight doses were approximated 0.25 to $0.3 \mathrm{mg} / \mathrm{kg}$ body weight, although there is no evidence that gross body weight is predictive of response to MPH 
(Rapport and Denney, 1997). ADHD symptoms were reduced by MPH on a behavioral level in pre-schoolers (paired t-test, $\mathrm{T}=2.46, \mathrm{p}<0.04$ ) and grade-schoolers (paired t-test, $\mathrm{T}=16.89$, $\mathrm{p}<0.00$ ). The order of testings with placebo and MPH respectively was counterbalanced across subjects. Parallel versions of all attention tasks were used for the second testing in order to minimize learning effects. For the younger children, each procedure lasted about 45 minutes; for the older children, each procedure lasted approximately 60 minutes.

Grade-school children additionally participated in a third testing in which they received 0.5 $\mathrm{mg} \mathrm{MPH} / \mathrm{kg}$ body weight. Results of the higher MPH dose effects and comparison between low and high MPH dosage are reported elsewhere (Konrad et al., 2004).

All but one of the attention tasks were part of the Amsterdam Neuropsychological test battery 2.1 for children (DeSonneville, 2000). As tasks are adjusted to the abilities of the tested agerange, the two groups of children had to be tested with different versions of the same tasks. Comparability was nevertheless granted as scores were z-standardized by age-norms. Preschool children were seated on a preschool-size chair; school-aged children sat on a regular chair in front of the monitor which was positioned at eye-level. A standard mouse was used as response box, and children were trained how to use it with both hands prior to examination. All tasks started with some practice trials to ensure that the children understood the instructions.

\section{Dependent measures}

According to the theoretical framework (Fig. 1), five tasks were selected: the intensity domain was tested using a reaction time and a sustained attention task, while the attention selectivity comprised a focused attention task and a divided attention task. The SAS was accounted for by a cognitive conflict task. Dependent measures for each task comprised reaction time (RT) median, RT standard deviation, number of missings, and number of false alarms. Especially young children show high within group variances in performance scores (DeSonneville, 2000). As the Amsterdam Neuropsychological test battery 2.1 provides norm data of 108 to 330 subjects in the preschool age range we decided to compare performance of the preschool ADHD children to the norm sample rather than to a smaller healthy control group. Z-scores were computed for those dependent variables for which age norms are available: (individual score age norm mean) / age norm standard deviation. In order to reduce complexity in figures, tables, and statistical analysis, one or two variables for each task were selected that, according to the ADHD literature, reflect the tested attention domain most validly (Rubia et al., 2001; Kuntsi et al., 2001; Carlson and Mann, 2002; DeWolfe et al., 1999). 
Intensity: Baseline speed was assessed by means of a simple reaction time task as an indicator of effort (Sergeant et al., 1999) or arousal (Posner and Peterson, 1990). As ADHD subjects especially show difficulties in uniform reaction time performance (Kuntsi et al., 2001), the relevant dependent measure was the within-subject standard deviation (Std) of RTs. In the sustained attention task, children had to respond with one key to a target and with another key to non-targets. For preschoolers this test involved 20 series of twelve pictures; for grade-schoolers it comprised 50 series of twelve different dot patterns. Standard deviation of RTs and number of missings were further analyzed. Norm data was not available for the standard deviation of RTs, so z-scores were computed for the number of missings only.

Selectivity: In the focused attention task, children had to respond with the yes-key if a target was present at a specific target location and respond with the no key if the target was either not present or displayed at a different location. The preschoolers' divided attention task employed a fixed display load of four animals. A response had to be made if the target animal was present. As this task is not adapted for school-age children, divided attention in the older ADHD group was tested by a combined optic and acoustic discrimination task that is part of the Battery of Attention Examination (TAP, Zimmermann and Fimm, 1993). The relevant dependent measure for focused and divided attention was RT median.

Conflict: The preschoolers' conflict task required subjects to respond to a target and omit responding to non-targets. For the older group, this task involved shifting between compatible and incompatible response sets. The number of false alarms reflects cognitive impulsivity. It thus mirrors the ability to resolve a cognitive conflict and is regarded as the relevant measure for this domain.

\section{Statistical analysis}

Within-subject MPH effects were calculated by means of paired t-tests for focused median (FA me), divided median (DIV me), sustained standard deviation (SA std), baseline speed standard deviation (BS std), conflict false alarms (conflict), and sustained missings (SA missings). Alphalevel was adjusted to $\mathrm{p}<.008$ due to the number of comparisons used within a subject. In an additional analysis, MPH effects were compared between groups by means of oneway ANOVAs. 
60 | Chapter 4

\section{Results}

Neuropsychological deficits in pre-school and grade-school ADHD children

\begin{tabular}{|c|c|c|}
\hline & Group 5-7 & Group 8-12 \\
\hline testing on placebo & $\mathrm{n}=45$ & $\mathrm{n}=54$ \\
\hline testing on MPH & $\mathrm{n}=22$ & $\mathrm{n}=54$ \\
\hline Age at Testing: Mean (Std) & $6.0(1.8)$ & $10.7(1.7)$ \\
\hline Sex: male/ female & $40 / 5$ & $44 / 10$ \\
\hline IQ: Mean (Std) & $93.0(15.6)$ & $100.0(9.9)$ \\
\hline \multicolumn{3}{|l|}{ Comorbid disorders: } \\
\hline Oppositional Defiant & $20 \%$ & $10 \%$ \\
\hline Conduct & & $28 \%$ \\
\hline Anxiety & $14 \%$ & $13 \%$ \\
\hline Dyslexia & & $32 \%$ \\
\hline Enuresis or Encopresis & $8 \%$ & \\
\hline \multicolumn{3}{|l|}{$K-D I P S(\text { mean }, S D)^{a}:$} \\
\hline Total score (without MPH) ${ }^{a}$ & $28.1(11.8)$ & $39.5(11.2)$ \\
\hline Total score $(\mathrm{MPH})^{\mathrm{a}}$ & $17.9(10.9)$ & $14.5(3.3)$ \\
\hline Attention Deficit & $13.8(6.5)$ & $20.0(4.7)$ \\
\hline Hyperactivity & $8.8(4.4)$ & $11.1(4.8)$ \\
\hline Impulsivity & $4.3(2.5)$ & $8.4(3.6)$ \\
\hline
\end{tabular}

Table 1. Demographic data and group mean z-scores for 45 pre-school and 54 grade-school ADHD children: ${ }^{a}$ group mean of severity scores.

Table 1 shows demographic data on 45 preschool and on 54 elementary school ADHD children. Groups did not differ in respect to gender $\left(\mathrm{Z}_{\text {Mann-Whitney-U }}=1.01, \mathrm{p}=0.31\right)$ or IQ $\left(\mathrm{F}_{\text {ANOVA }}\right.$ $\mathrm{IQ}=2.98, \mathrm{p}=0.09)$. Age groups differed with respect to inattentiveness and impulsivity $\left(\mathrm{F}_{\text {ANOVA Inatt. }}=15.29, \mathrm{p}<0.00, \mathrm{~F}_{\text {ANOVA Imp. }}=18.57, \mathrm{p}<0.00\right)$ as indicated by the K-DIPS severity scores. Hyperactive symptoms were similar in both groups $\left(\mathrm{F}_{\text {ANOVA Imp. }}=3.78, \mathrm{p}=0.06\right)$. Based on the theoretical framework depicted in figure 1 we created cognitive subgroups according to individual z-scores. As a z-score above 1.5 reflects a deficit in that particular variable, subjects that showed deficits in at least one variable of the intensity or selectivity domain while the SAS was not affected were grouped as 'int + sel'. Any subject that exhibited deficits in the conflict task was assigned to the 'SAS' group. The third group was comprised of children that did not show any neuropsychological deficits and was termed 'none'. Figure 2 
depicts the distribution of the three cognitive subtypes separately for the two age groups. Table 2 shows demographic data for the three groups of cognitive subtypes, summarized across the entire age range.
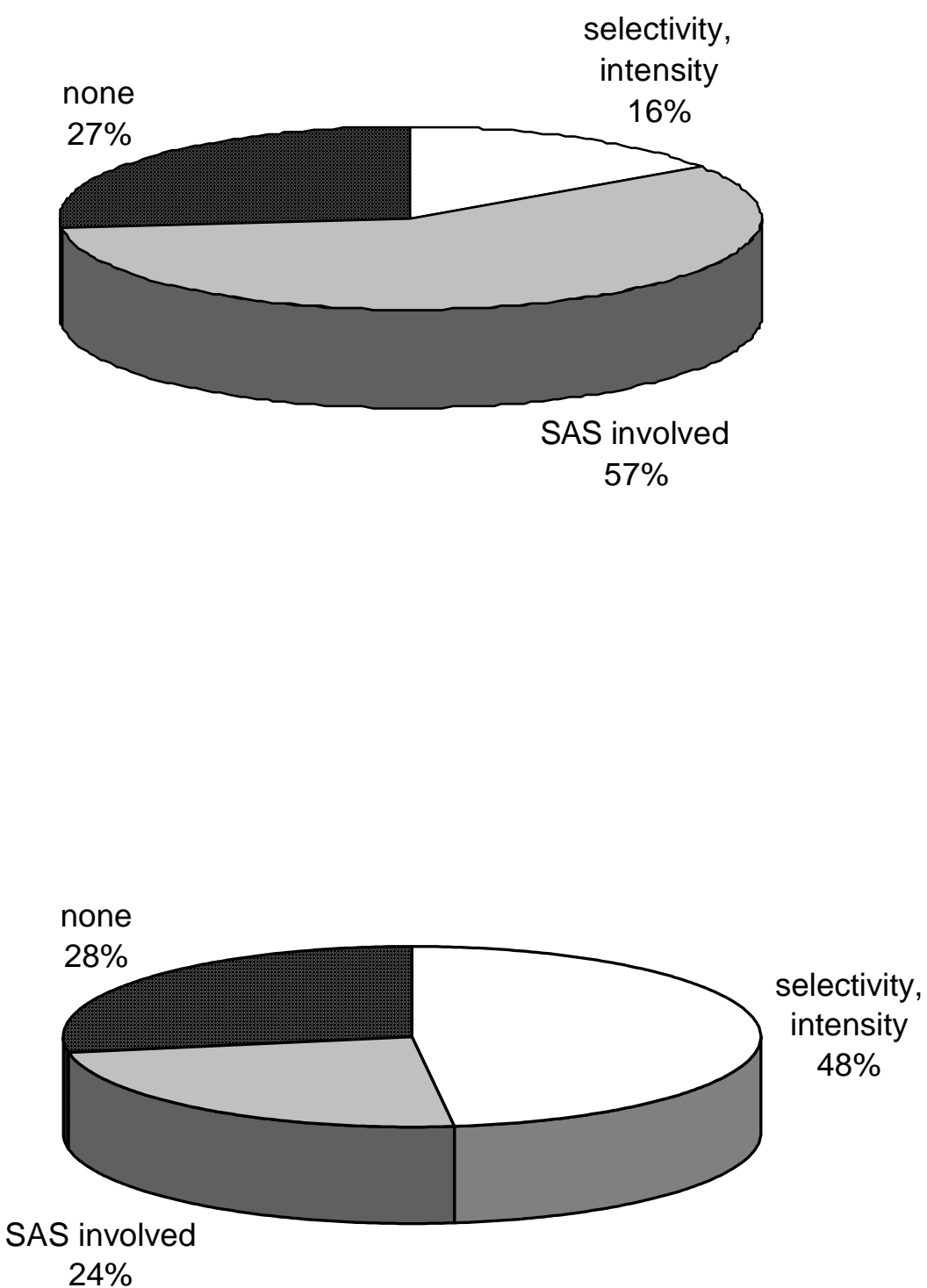

Figure 2. The number of subjects that show deficits in the respective attentional subsystem (cognitive subtype), depicted separately for young and older children. Note that $27 \%$ and $28 \%$ respectively do not exhibit any attentional deficits. 


\begin{tabular}{lccc}
\hline & int + sel & SAS & none \\
\hline$N$ & 30 & 23 & 23 \\
Age at Testing: Mean (Std) & $9.5(2.3)$ & $7.7(2.4)$ & $9.2(2.5)$ \\
IQ: Mean (Std) & $98.4(8.3)$ & $94.9(7.9)$ & $101.7(14.4)$ \\
\hline
\end{tabular}

Table. 2. Demographic data according to cognitive subtype: The 'int + sel' group is comprised of subjects that show deficits in attention intensity and/or selectivity. The 'SAS' group exhibits deficits in the supervisory attention system, and the 'none' group does not show attention deficits at all. Std = group standard deviation

MPH effects on pre-school and grade-school ADHD:

In a second step MPH effects on neuropsychological performance were compared between age groups. Figure 3 shows RT measures (group mean / group standard deviation and standard error) for placebo (left column) and MPH (right column) separately for the two age groups. Embedded figures show error rates likewise left on placebo, right on MPH. Significant MPH effects were found for the number of missings in the sustained attention task for both groups $\left(\mathrm{T}_{5-7}=3.3 \mathrm{p}_{5-7}<0.004 ; \mathrm{T}_{8-12}=3.19 \mathrm{p}_{8-12}<0.002\right)$.

\section{Cognitive subtypes and differential MPH effect:}

As MPH has been found to influence various cognitive domains differentially, we were interested in whether MPH improved neuropsychological performance in dependence on the affected cognitive domain. Due to small sample sizes for the three cognitive subtypes, both age groups were collapsed for this analysis. Despite the resulting higher variance scores, the standard deviation of baseline speed was significantly smaller on MPH than on placebo in the 'int + sel' group (BS Std: $\left.\mathrm{T}_{\text {int+sel }}=4.9 \mathrm{p}_{\mathrm{int}+\mathrm{sel}}<0.001\right)$. The 'SAS' group showed significant MPH effects for the focussed attention median (FA me: $\mathrm{T}_{\mathrm{SAS}}=3.6 \mathrm{p}_{\mathrm{SAS}}<0.002$ ), for the number of conflict false alarms (Conflict: $\left.\mathrm{T}_{\mathrm{SAS}}=3.0 \mathrm{p}_{\mathrm{SAS}}<0.007\right)$, and for the number of missings in the sustained attention task (SA missings: $\mathrm{T}_{\mathrm{SAS}}=3.7 \mathrm{p}_{\mathrm{SAS}}<0.001$ ). No significant MPH effects were found in the 'none' group. As the 'SAS' group was comprised of children that were either affected in one or two cognitive domains and thus exhibited a more severe cognitive deficit, we were interested in the relation between children's performance on the placebo testing and MPH effects. 

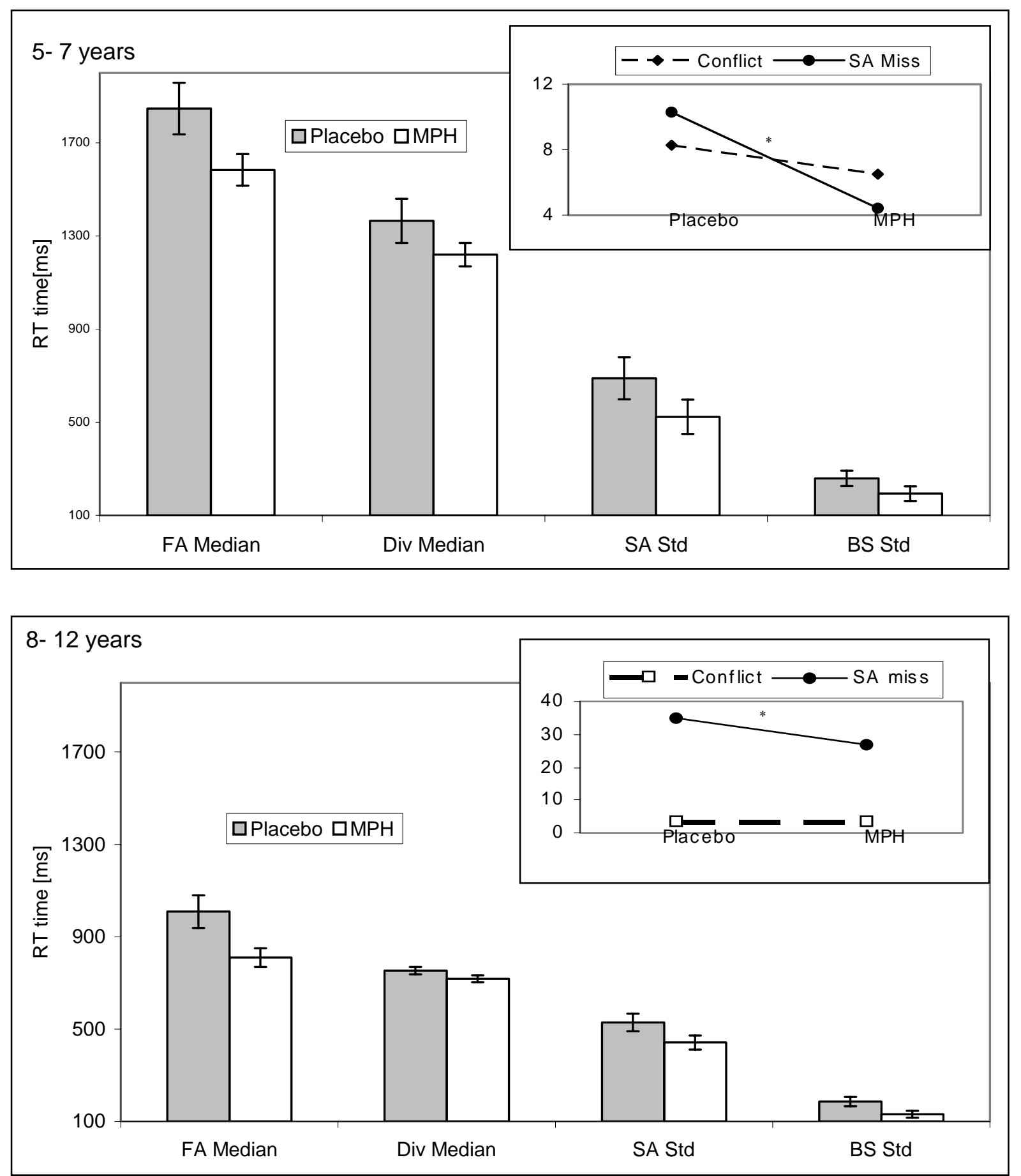

Figure 3. Comparison data for RTs and error rates for the placebo and the MPH condition. Significant effects are marked by an *. Group means of RTs for focused attention (FA) and divided attention (DIV) and group mean standard deviations of RT for sustained attention (SA) and baseline speed (BS) are shown. Group standard errors are depicted for the RT measures. Embedded figures show group means for error rates on the conflict task and the sustained attention task. Note that the number of missings in the older group exceeds the number of missings in the preschoolers due to differences in task length. Paired T-Tests revealed significant MPH effects for SA missings for both age groups $\left(\mathrm{T}_{5-7}=3,3 \mathrm{p}_{5-7}<0.004 ; \mathrm{T}_{8-12}=3.19\right.$ $\left.\mathrm{p}_{8-12}<0.002\right)$. 
64 | Chapter 4
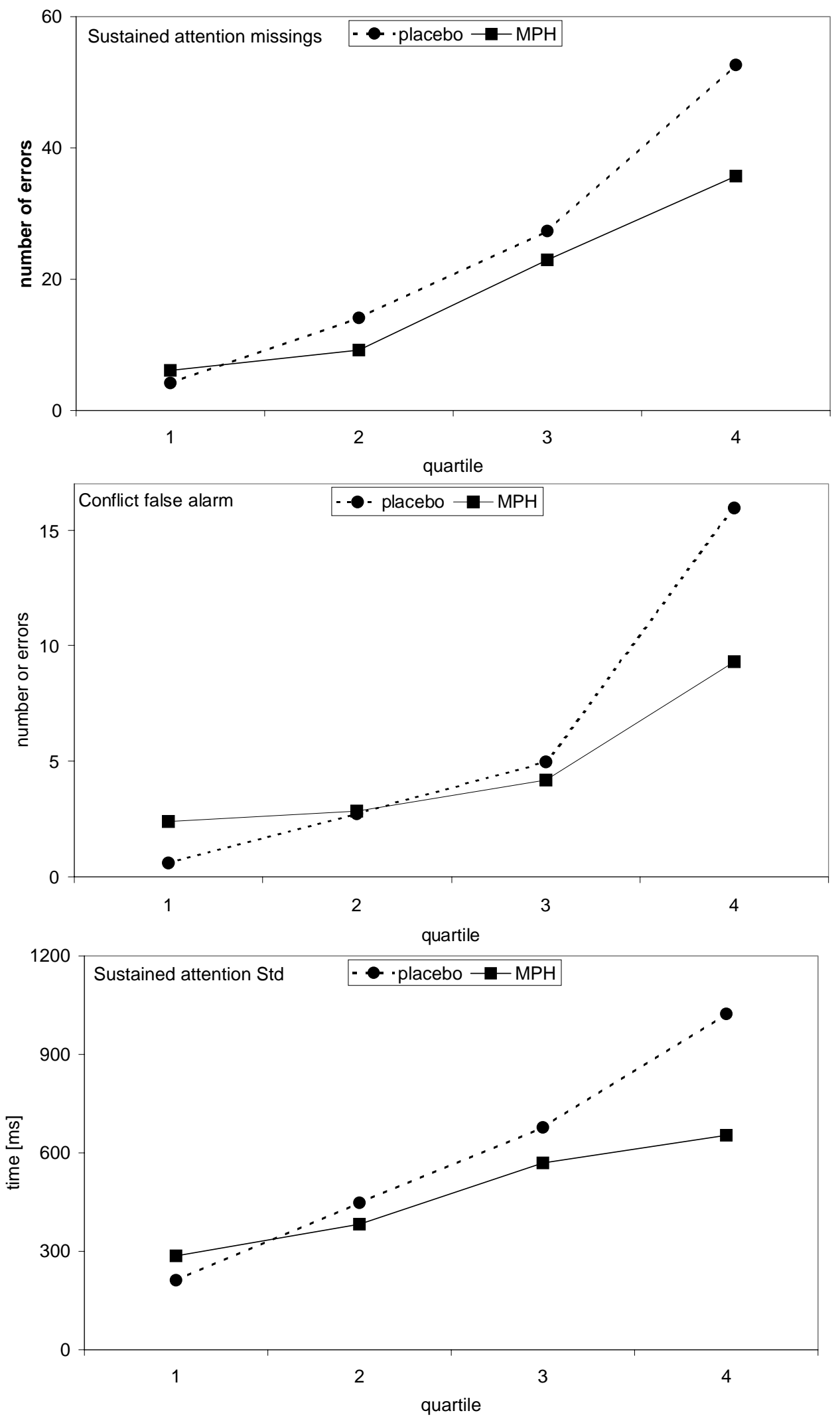

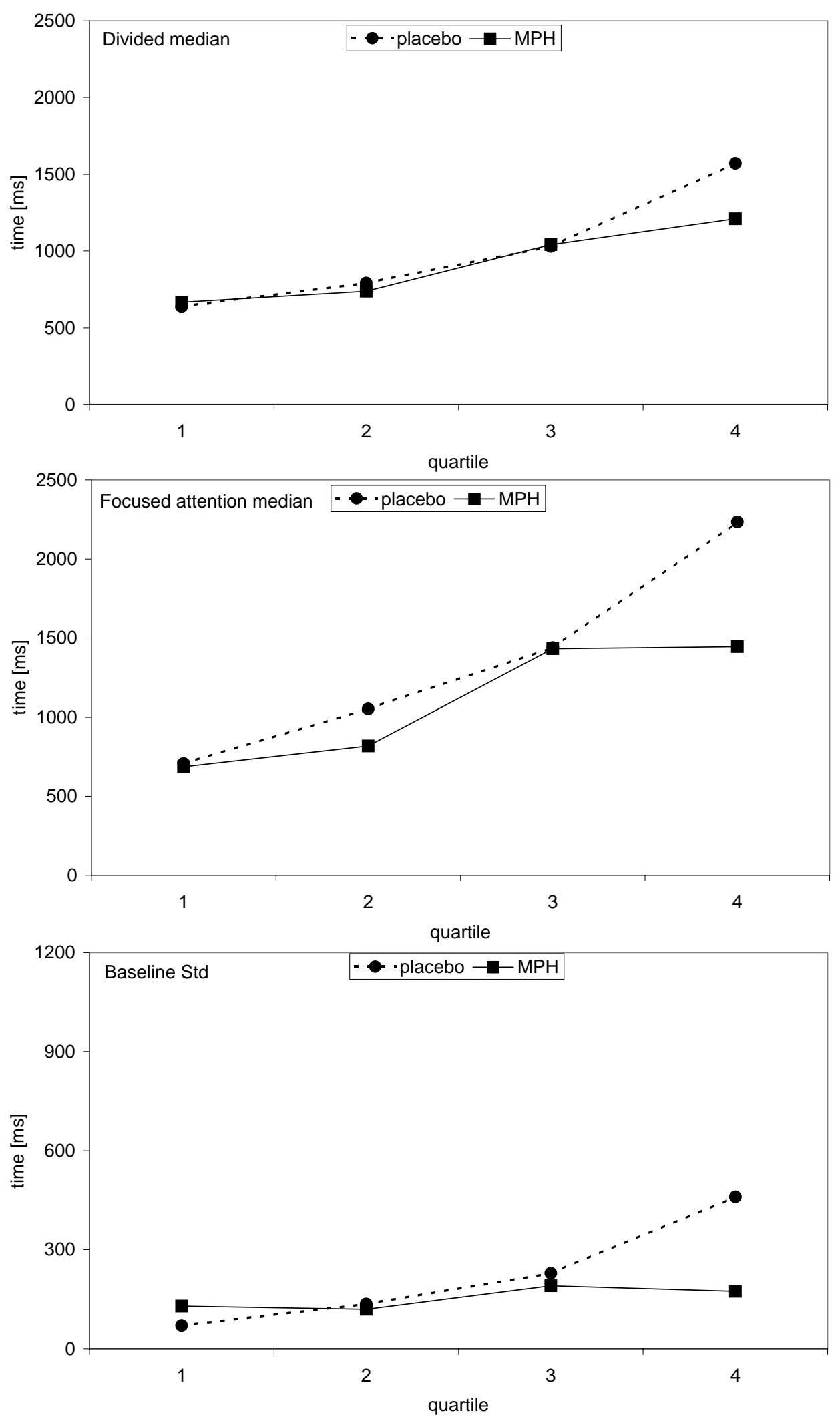

Figure 4. Performance on placebo and MPH for quartiles 1 through 4. Mean scores are calculated for each quartile and are shown separately for the placebo and the MPH testing. Std = standard deviation. 
Initial neuropsychological performance on placebo and MPH effects:

We therefore calculated rank coefficients for the dependent variables of the placebo testing. Percentage scores were computed according to the respective rank coefficient. In order to compare the MPH effects of subjects with high placebo scores (high error rates, slow RT, high standard deviation of RT = "bad" performers) with the MPH effects of those subjects with low placebo scores (low error rates, fast RT, low standard deviation of RT = "good" performers), a third group division was conducted: a rank of less than $25 \%$ (e.g. FA median percent rank of 22) assigned subjects to the ' 1 st quartile' group ("good" performers), a rank of more than $75 \%$ (e.g. FA median percent rank of 83 ) assigned subjects to ' 4 th $q u a r t i l e$ ' group. This procedure allows a comparison of various parts of the distribution of the respective variable (Sanders and Hoogenboom, 1970). As RTs and errors become smaller with increasing age, the grouping was conducted for both age groups separately. Figure 4 shows mean scores of the placebo and of the MPH testing for subjects scoring in the $1^{\text {st }}, 2^{\text {nd }}, 3^{\text {rd }}$, and $4^{\text {th }}$ quartile. The discrepancy between both scores in the ' $4^{\text {th }}$ quartile' group suggests higher MPH effects in this group than in the ' $1{ }^{\text {st }}-3^{\text {rd }}$ quartile' groups. Oneway ANOWAs comparing MPH effects between quartile groups revealed greater MPH effects for the ' 4 ' ' quartile' group for all tested variables ( $\mathrm{F}_{\text {ANOVA }}$ between 4.43 and 55.09, $\left.\mathrm{p}<0.05\right)$.

\section{Discussion}

Neuropsychological deficits in pre-school and grade-school ADHD children

Seventy-three percent of the pre-school children and seventy-two percent of the grade-school children showed deficits in at least one attention domain when tested with computerized tasks. Behavioural ratings on the other hand described the pre-school group to be less inattentive than the grade-school group. As groups showed similar scores in terms of hyperactivity symptoms, the discrepancy between parent's ratings and task performance is most likely explained by differences in demands on concentration in pre-school and grade-school children (Barkley et al., 1997). We found that among pre-schoolers the majority of subjects showed deficits in the supervisory attention system, while grade-schoolers were most frequently impaired in the selectivity and intensity domain. Regarding differences in the distribution of cognitive subtypes between age-groups, one might consider aspects of brain development as well as differences in SAS tasks. The supervisory attention system is said to involve prefrontal and striatal structures (Cabeza and Nyberg, 2000; Castellanos, 1999) which have been found to deviate in ADHD children in terms of structure (Castellanos et al., 1996; Hynd et al., 1993) and activity (Vaidya et al., 1998). The hypoactivity in frontal 
areas has been documented to worsen until adulthood (Ernst et al., 1998); whereas, striatal abnormalities seem to decrease with increasing age (van Dyck et al., 2002). Imaging data on normal brain development document massive structural changes in especially frontal areas during pre-school and grade-school years (Kanemura et al., 2003; Luciana and Nelson, 2002; Rubia et al., 2000). Our findings of differences in the supervisory attentional system between the 5-7 and the 8-12 year olds might thus be mediated by brain maturation processes. Further, differences in task demands between age groups have to be acknowledged. As stimulus presentation in the preschool conflict task is more rapid than in the grade-schoolers' task, it likely involves a stop process in addition to the actual cognitive conflict. ADHD children especially show deficient response inhibition (Konrad et al., 2000), and this disability might be measured more sensitively by the preschool conflict task. However, recent fMRI findings suggest that similar brain regions are involved in various tasks of cognitive conflict (Fan et al., 2003). All the studied conflict tasks had activation in left prefrontal areas and in the anterior cingulum in common, while behavioural data suggested distinct networks for each task. Thus, despite different task demands, it seems plausible to assume overlapping brain areas in our SAS tasks.

Approximately one third of the clinically diagnosed ADHD patients did not exhibit objectified attention deficits, which is in line with previous reports (Taylor, 1998) and suggests that the diagnosis might have predominantly been based on behavioural impulsiveness and motor hyperactivity rather than on attention problems. Although this apparently contradicts the DSM-IV specification of two distinct symptom clusters, clinical experience shows that children sitting still are generally observed as being more attentive than fidgeting children regardless of their actual attention performance. Moreover, DSM-IV or ICD-10 only require attention problems to be apparent in everyday-life and do not require below average scores on neuropsychological tests. It might further be the case that attention ratings judging attention in complex situations of school or homework measure more intrinsic aspects of attention than a highly structured one-by-one test situation. Thus, one needs to further investigate the nature of the differences between those ADHD patients with and those without objectified attention deficits in the computerized attention tests.

\section{MPH effects on pre-school and grade-school ADHD}

For both age groups, MPH improved performance in the sustained attention task, as has been reported previously (DeSonneville et al., 1994; van der Meere et al., 1995). A non-significant trend toward better performance on MPH was indicated for all tested variables. Previously 
reported differential MPH effects on various attention domains let us analyse MPH effects in dependence on cognitive subtype and thus in dependence on regions of abnormal brain functioning.

\section{Cognitive subtypes and differential MPH effect}

In concordance with those reporting MPH effects when prefrontal cortex areas are involved (Tennock et al., 1995b), we found the group with a deficient supervisory system to be positively affected by MPH in all attention domains. It must be considered that the majority of subjects in this group showed deficits not only in the supervisory system but also in the intensity and selectivity domain and was thus more severely affected. Moreover, this group was significantly younger than the other two groups. In the group exhibiting exclusively intensity and selectivity deficits, the intensity domain was improved by MPH. In the group that did not exhibit any attention deficits, MPH did not improve performance significantly. The analysis of MPH effects in dependence on affected attention system implies MPH mediated improvements only in those functions that were initially impaired. Studies dealing with MPH effects on healthy subjects yield contradictory results suggesting that medication effects on computer tasks involve various factors like age, task demands, nature of deficit or quality of performance (Vaidya et al., 1998; Moll et al., 2003). Thus, analysing the relation between medication effects and performance on the placebo testing seems rational.

\section{Initial neuropsychological performance on placebo and MPH effects}

We compared subjects scoring on the placebo testing within the fourth quartile with those in the first quartile and found that only subjects with initially high error scores and slow reaction times improved on MPH. Thus, MPH improves performance on computerized tests only in those children that show measurable attention deficits. Clinical experience shows that attention deficits are generally difficult to objectify by means of behavioural ratings, as extensive impulsivity or hyperactivity seem to bias parents' and teachers' ratings of attention performance. Thus, neuropsychological tools seem to be useful for objectifying attention deficits. However, no experimental or diagnostic paradigm has yet been found to be specific and sensitive enough to clearly differentiate between children with and without ADHD (Nigg, 2000) implicating that attention tasks can only contribute to the regular diagnostic process and can by no means replace components of this procedure.

Another study of our research group found a quadratic relation between MPH dosage and higher cognitive functions; whereas, a linear relationship between dosage and performance 
was documented for attention intensity tasks (Konrad et al., 2004). Thus, neuropsychological assessment might be not only useful for differentiating between children with and without objective attention problems before prescribing MPH but also during dosage titration. According to our results MPH dose should be moderate if children are impaired especially in the SAS domain, whereas one should consider a higher dose if attention intensity is affected most.

The National Institute for Clinical Excellence recommends prescription of MPH only in those children that show all three ADHD symptom clusters (Rey and Sawyer, 2003). Taken together, future studies are needed to clarify whether MPH titration based on neuropsychological measures or behavioral measures can produce a better longterm outcome in ADHD patients. In particular, the question whether children without any objective attention deficits should be treated at all with MPH needs further evaluation.

Different demands on concentration for pre-schoolers and grade-schoolers (Barkley et al., 1997) make it difficult to compare parents' behavioural ratings between these age groups, especially in regards to inattentive symptoms. We were therefore interested in objectifying attention deficits by means of laboratory measures. However, the validity of computerized attention tasks in terms of their transferability on everyday-life is discussed controversially. MPH effects on general behaviour are only little associated with stimulant related changes in attention functions (Van der Meere et al., 1999) and have been found to be larger for behavioural variables than for cognitive variables (Solanto, 2002, for a review). In line with these results, we previously found that behaviourally selected MPH responders did not differ from non-responders in their attentional functions (Konrad et al., 2004), suggesting that cognitive vs. behavioural improvement may be mediated by distinct neuronal processes (Solanto, 2002).

The two age groups studied here significantly differed with respect to inat-tentiveness and impulsivity. Hyperactivity scores were similar for both groups. DSM-IV provides 9 items for attention, six for hyperactivity and three for impulsivity, the latter thus being the least differentiated scale. Further, $38 \%$ of the grade-schoolers and $20 \%$ of the pre-schoolers were diagnosed with comorbid oppositional defiant or conduct disorder which has been related to high behavioural impulsivity (Moeller et al., 2001). Thus, while behavioural impulsivity scores might be influenced by differences in comorbidities between age groups, and inattentive scores might mirror differences in concentration demands, similar hyperactivity scores might reflect that both groups are still comparable in terms of ADHD severity. However, a recent study reports that ADHD children with and without comorbid oppositional defiant or conduct 
disorder differed significantly in terms of psychophysiological and neuropsychological measures and might thus represent a distinct subtype (Banaschewski et al., 2003).

In order to understand possibly deficient neuronal functioning in ADHD and to draw conclusions concerning brain maturation or functioning in these patients in dependence on age, longitudinal studies employing neuropsychological and imaging methods need to be conducted.

\section{References}

American Academy of Child and Adolescent Psychiatry (2002). Practice parameters for the use of stimulant medication in the treatment of children, adolescents and adults with ADHD. Journal of the American Academy of Child and Adolescent Psychiatry, 41 Suppl, 2649.

American Psychiatric Association (1994). Diagnostic and Statistical Manual of Mental Disorders - DSM-IV. (4 ed.) Washington D.C.: American Psychiatric Association.

Banaschewski, T., Brandeis, D., Heinrich, H., Albrecht, B., Brunner, E., \& Rothenberger, A. (2003). Association of ADHD and conduct disorder - brain electrical evidence for the existence of a distinct subtype. Journal of Child Psychology and Psychiatry, 44, 356-376.

Barkley, R. A. (1988). The effects of methylphenidate on the interactions of preschool ADHD children with their mothers. Journal of the American Academy of Child and Adolescent Psychiatry, 27, 336-341.

Barkley, R. A., Koplowitz, S., Anderson, T., \& Mc Murray, M. B. (1997). Sense of time in children with ADHD: effects of duration, distraction, and stimulant medication. Journal of the International Neuropsychological Society, 3, 359-369.

Berger, A., Jones, L., Rothbart, M. K., \& Posner, M. I. (2000). Computerized games to study the development of attention in childhood. Behavior Research Methods, Instruments, \& Computers, 32, 297-303.

Berlin, L. \& Bohlin, G. (2002). Response inhibition, hyperactivity, and conduct problems among preschool children. Journal of Clinical Child and Adolescent Psychology, 31, 242-251.

Biederman, J., Mick, E., \& Faraone, S. V. (2000). Age-dependent decline of symptoms of attention deficit hyperactivity disorder: impact of remission definition and symptom type. American Journal of Psychiatry, 157, 816-818. 
Biederman, J., Mick, E., Faraone, S. V., Braaten, E., Doyle, A., Spencer, T. et al. (2002). Influence of gender on attention deficit hyperactivity disorder in children referred to a psychiatric clinic. American Journal of Psychiatry, -36.

Byrne, J. M., Bawden, H. N., DeWolfe, N. A., \& Beattie, T. L. (1998). Clinical assessment of psychopharmacological treatment of preschoolers with ADHD. Journal of Clinical and Experimental Neuropsychology, 20, 613-627.

Cabeza, R. \& Nyberg, L. (2000). Imaging Cognition II: An Empirical Review of 275 PET and fMRI Studies. Journal of Cognitive Neuroscience, 12, 1-47.

Carlson, C. L. \& Mann, M. (2002). Sluggish cognitive tempo predicts a different pattern of impairment in the attention deficit hyperactivity disorder, predominantly inattentive type. Journal of Clinical Child and Adolescent Psychology, 31, 123-129.

Castellanos, F. X. (1999). The psychobiology of attention-deficit/ hyperactivity disorder. In H.C.Quay \& A. E. Hogan (Eds.), Handbook of Disruptive Behaviour Disorders (pp. 179-198). New York: Kluwer / Plenum.

Castellanos, F. X., Giedd, J. N., Marsh, W. L., Hamburger, S. D., Vaituzis, A. C., Dickstein, D. P. et al. (1996). Quantitative brain magnetic resonance imaging in attentiondeficit hyperactivity disorder. Archives of Genetic Psychiatry, 53, 607-616.

Connor, D. F. (2002). Preschool attention deficit hyperactivity disorder: A review of prevalence, diagnosis, neurobiology, and stimulant treatment. Journal of Developmental \& Behavioral Pediatrics, 23, 1-9.

Corbetta, M., Miezin, F. M., Dobmeyer, S., Shulman, G. L., \& Petersen, S. E. (1991). Selective and divided attention during visual discriminations of shape, color, and speed: functional anatomy by positron emission tomography. Journal of Neuroscience, 11, 2402.

de Sonneville, L. M. J. (2000). ANT 2.1 - Amsterdam Neuropsychological Tasks. Amstelveen: Sonar.

de Sonneville, L. M. J., Njiokektjien, C., \& Bos, H. (1994). Methylphenidate and information processing, part I, differentiation between responders and nonresponders; part 2, efficacy in responders. Journal of Clinical and Experimental Neuropsychology, 16, 897.

De Wolfe, N. A., Byrne, J. M., \& Bawden, H. N. (1999). Early clinical assessment of attention. Clinical Neuropsychology, 13, 458-473.

Denney, C. \& Rapport, M. D. (2001). The cognitive pharmacology of stimulants in children with ADHD. In M.V.Solanto, A. F. Arnsten, \& F. X. Castellanos (Eds.), Stimulant Drugs and ADHD: Basic and Clinical Neuroscience (pp. 283-302). New York: Oxford University Press. 
Efron, D., Jarman, F. C., \& Barker, M. J. (2000). Medium-term outcomes are comparable with short-term outcomes in children with attention deficit hyperactivity disorder treated with stimulant medication. Journal of Paediatrics and Child Health, 36, 457-461.

Ernst, M., Zametkin, A. J., Matochik, J. A., Jons, P. H., \& Cohen, R. M. (1998). DOPA decarboxylase activity in attention deficit hyperactivity disorder adults: A [fluorine18] fluorodopa positron emission tomographic study. Journal of Neurscience, 18, 5901-5907.

Fan, J., Flombaum, J. I., McCandliss, B. D., Thomas, K. M., \& Posner, M. I. (2003). Cognitive and brain consequences of conflict. Neuroimage, 18, 42-57.

Handen, B. L., Feldman, H. M., Lurier, A., \& Murray, P. J. (1999). Efficacy of methylphenidate among preschool children with developmental disabilities and ADHD. Journal of the American Academy of Child and Adolescent Psychiatry, 38, 805-812.

Harper, G. W. \& Ottinger, D. R. (1992). The performance of hyperactive and control preschoolers on a new computerized measure of visual vigilance: the Preschool Vigilance Task. Journal of Child Psychology and Psychiatry, 33, 1365-1372.

Hynd, G. W., Hern, K. L., Novey, E. S., Eliopulos, D., Marshall, R., Gonzalez, J. J. et al. (1993). Attention deficit-hyperactivity disorder and asymmetry of the caudate nucleus. Journal of Child Neurology, 8, 339-347.

Jonkman, L. M., Kemner, C., Verbaten, M. N., van Engeland, H., Kenemans, J. L., Camfferman, G. et al. (1999). Perceptual and response interference in children with attentiondeficit hyperactivity disorder, and the effects of methylphenidate. Psychophysiology, 36, 419429.

Kalff, A. C., Hendriksen, J. G., Kroes, M., Vles, J. S., Steyaert, J., Feron, F. J. et al. (2002). Neurocognitive performance of 5- and 6-year-old children who met criteria for attention deficit/hyperactivity disorder at 18 months follow-up: results from a prospective population study. Journal of Abnormal Child Psychology, 30, 589-598.

Kanemura, H., Aihara, M., Aoki, S., Araki, T., \& Nakazawa, S. (2003). Development of the prefrontal lobe in infants and children: a three-dimensional magnetic resonance volumetric study. Brain Development, 25, 195-199.

Konrad, K., Gauggel, S., Manz, A., \& Schöll, M. (2000). Inhibitory control in children with traumatic brain injury (TBI) and children with attention deficit/hyperactivity disorder (ADHD). Brain Injury, 14, 859-875.

Konrad, K., Günther, T., Hanisch, C., \& Herpertz-Dahlmann, B. (2004). Differential effects of methylphenidate on attentional functions in children with attention deficit/ hyperac- 
tivity disorder. Journal of the American Academy of Child and Adolescent Psychiatry, 43, 191-198.

Kuntsi, J., Oosterlaan, J., \& Stevenson, J. (2001). Psychological mechanisms in hyperactivity: I, response inhibition deficit, working memory impairment, delay aversion, or something else? Journal of Child Psychology and Psychiatry, 42, 199-210.

Luciana, M. \& Nelson, C. A. (2002). Assessment of neuropsychological function through use of the Cambridge Neuropsychological Testing Automated Battery: performance in 4- to 12-year-old children. Developmental Neuropsychology, 22, 595-624.

Moeller, F. G., Barratt, E. S., Dougherty, D. M., Schmitz, J. M., \& Swann, A. C. (2001). Psychiatric aspects of impulsivity. American Journal of Psychiatry, 158, 1783-1793.

Moll, G. H., Heinrich, H., \& Rothenberger, A. (2003). Methylphenidate and intracortical ecitability: opposite effects in healthy subjects and attention-deficit hyperactivity disorder. Acta Psychiatrica Scandinavica, 107, 69-72.

Musten, L. M., Firestone, P., Pisterman, S., Bennett, S., \& Mercer, J. (1997). Effects of methylphenidate on preschool children with ADHD: cognitive and behavioral functions. Journal of the American Academy of Child and Adolescent Psychiatry, 36, 1407-1415.

Nigg, J. T. (2000). On Inhibition/Disinhibition in Developmental Psychopathology: Views From Cognitive and Personality Psychology and a Working Inhibition Taxonomy. Psychological Bulletin, 126, 220-246.

Nigg, J. T., Blaskey, L. G., Huang Pollock, C. L., \& Rappley, M. D. (2002). Neuropsychological Executive Functions and DSM-IV ADHD Subtypes. Jornal of the American Academy of Child \& Adolescent Psychiatry, 41, 59-66.

Palfrey, J. S., Levine, M. D., Walker, D. K., \& Sullivan, M. (1985). The emergence of attention deficits in early childhood: a prospective study. Journal of Developmental \& Behavioral Pediatrics, 6, 339-348.

Pennington, B. F. \& Ozonoff, S. (1996). Executive functions and developmental psychopathology. Journal of Child Psychology and Psychiatry and Allied Disciplines, 37, 51-87.

Posner, M. I. \& Peterson, S. E. (1990). The attention system of the human brain. Annual review of Neuroscience, 13, 25-42.

Rapport, M. D. \& Denney, C. (1997). Titrating Methylphenidate in Children With Attention Deficit/Hyperactivity Disorder: Is Body Mass Predictive of Clinical Response. Journal of the Amarican Academy of Child and Adolescent Psychiatry, 36, 523-530.

Rey, J. M. \& Sawyer, M. G. (2003). Are psychostimulant drugs being used appropriately to treat child and adolescent disorders? British Journal of Psychiatry, 182, 284-286. 
Rubia, K., Overmeyer, S., Taylor, E., Brammer, M., Williams, S. C., Simmons, A. et al. (2000). Functional frontalisation with age: mapping neurodevelopmental trajectories with fMRI. Neuroscience and Biobehavioral Reviews, 24, 13-19.

Rubia, K., Taylor, E., Smith, A. B., Oksanen, H., Overmeyer, S., Newman, S. et al. (2001). Neuropsychological analyses of impulsiveness in childhood hyperactivity 34. Br.J.Psychiatry, 179, 138-143.

Sanders, A. F. \& Hoogenboom, W. (1970). On the effects of continuous work on performance. Acta Psychologica, 33, 414-431.

Scheres, A., Oosterlaan, J., Swanson, J., Morein Zamir, S., Meiran, N., Schut, H. et al. (2003). The effect of methylphenidate of three forms of response inhibition in boys with AD/HD. Journal of Abnormal Child Psychology, 31, 105-120.

Sergeant, J. \& Van der Meere, J. (1990). Additive factor method applied to psychopathology with special reference to childhood hyperactivity. Acta Psychologica, 74, 277-295.

Sergeant, J. A., Oosterlaan, J., \& Van der Meere, J. (1999). Information processing and energetic factors in attention deficit/ hyperactivity disorder. In H.C.Quay \& A. E. Hogan (Eds.), Handbook of Disruptive Behaviour Disorders (pp. 75-104). New York: Kluwer / Plenum.

Solanto, M. V. (2002). Dopamine dysfunction in AD/HD: integrating clinical and basic neuroscience research. Behavioural Brain Research, 130, 65-71.

Sonuga-Barke, E. J. S. (2002). Psychological heterogeneity in AD/HD--a dual pathway model of behaviour and cognition. Behavioural Brain Research, 130, 29-36.

Spikman, J. M., Kiers, H. A., Deelman, B. G., \& Van Zomeren, A. H. (2001). Construct validity of concepts of attention in healthy controls and patients with CHI. Brain and Cognition, 47, 446-460.

Sturm, W., Herrmann, M., \& Wallesch, C. W. (2000). Lehrbuch der klinischen Neuropsychologie. Lisse: Swets \& Zeitlinger.

Tannock, R., Ickowicz, A., \& Schachar, R. (1995). Differential Effects of Methylphenidate on Working Memory in ADHD Children with and without Comorbid Anxiety. The American Academy of Child and Adolescent Psychiatry, 34, 886-895.

Tannock, R., Schachar, R., \& Logan, G. D. (1995). Methylphenidate and cognitive flexibility: dissociated dose effects in hyperactive children. Journal of Abnormal Child Psychology, 23, 235-266. 
Taylor, E., Sergeant, J., Doepfner, M., Gunning, B., Overmeyer, S., Mobius, H. J. et al. (1998). Clinical guidelines for hyperkinetic disorder. European Society for Child and Adolescent Psychiatry. European Child and Adolescent Psychiatry, 7, 184-200.

Unnewehr, S., Schneider, S., \& Margraf, J. (1995). Kinder DIPS - Diagnostisches Interview bei psychischen Störungen im Kindes und Jugendalter. Heidelberg: Springer.

Vaidya, C., Austin, C., Kirkorian, G., Ridlehuber, H. W., Desmond, J. E., Glover, G. H. et al. (1998). Selective effects of methylphenidate in attention deficit hyperactivity disorder: A functional magnetic resonance study. Proceedings of the National Academy of Sciences of the United States of America, 95, 14494-14499.

Van der Meere, J. J., Shalev, R., Borger, N., \& Gross Tsur, V. (1995). Sustained attention, activation and methylphenidate in ADHD: a research note. Journal of Child Psychology and Psychiatry, 36, 697-703.

Van der Meere, J., Gunning, B., \& Stemerdink, N. (1999). The Effect of Methylphenidate and Clonidine on Response Inhibition and State Regulation in Children with ADHD. Journal of Child Psychology and Psychiatry, 40, 291-298.

Van Dyck, C. H., Quinlan, D. M., Cretella, L. M., Staley, J. K., Malison, R. T., Baldwin, R. M. et al. (2002). Unaltered dopamine transporter availability in adult attention deficit hyperactivity disorder. American Journal of Psychiatry, 159, 309-312.

Van Zomeren, A. H. \& Brouwer, W. J. (1994). Clinical Neuropsychology of Attention. New York, Oxford: Oxford University Press.

von Ferber, L., Lehmkuhl, G., Köster, I., Döpfner, M., Schubert, I., Fröhlich, J. et al. (2003). Methylphenidatgebrauch in Deutschland: Versichertenbezogene epidemiologische Studie über die Entwicklung von 1998 bis 2000. Deutsches Ärzteblatt, 100, A41/B39/C38.

Wilens, T. E. \& Spencer, T. J. (2000). The stimulants revisited. Child and Adolescent Psychiatric Clinics of North AMerica, 9, 573-603.

World-Health-Organization (1993). Tenth Revision of the International classification of diseases, chapter $V(F)$ : mental and behavioural disorders. Diagnostic criteria for research. WHO.

Zimmermann, P. \& Fimm, B. (1993). Testbatterie zur Aufmerksamkeitsüberprüfung (TAP) - Version 1.02c. Herzogenrath: Psytest. 

Chapter 5:

\title{
Differential effects of methylphenidate \\ on attentional functions in children with attention-deficit/ hyperactivity disorder
}

\author{
K. Konrad, T. Günther, C. Hanisch, B. Herpertz-Dahlmann, *
}

\section{Summary}

Objective: To examine the effects of methylphenidate on different attentional functions and behavior in children with attention-deficit/hyperactivity disorder (ADHD). Method: A total of 60 ADHD children aged between 8 and 12 years completed a randomized, double-blind, placebo-controlled, within-subject crossover trial with two doses of methylphenidate $(0.25$ and $0.5 \mathrm{mg} / \mathrm{kg}$ body weight) and placebo. A comprehensive neuropsychological test battery was applied, including tests of alertness and sustained, focused, and divided attention as well as two executive tests, the stop-signal paradigm and a visual set-shifting task. Results: A linear improvement was identified for both medication conditions in the alertness and focused and sustained attention task, but no significant improvement was found for divided attention. Quadratic trends were found for both executive tasks. Responders defined by behavior ratings did not differ from nonresponders. Conclusions: Results indicate that attentional functions are influenced differentially by methylphenidate: intensity-dimension functions are best influenced by higher doses, executive functions by moderate doses, and selectivity-dimension functions by variable doses. In addition, divergent results from behavior rating scales and from attentional paradigms emphasize that clinicians have to decide what constitutes an appropriate clinical response. A more comprehensive assessment of attention may help to find an individually optimal dose for the treatment of attentional dysfunctions. 
78 | Chapter 5

\section{Introduction}

Stimulant medication, especially methylphenidate (MPH), is the primary treatment for children with attention-deficit/hyperactivity disorder (ADHD). Over the past 10 years there has been an eightfold increase in the prescription of MPH (American Academy of Child and Adolescent Psychiatry, 2002). The benefits and efficacy of MPH have been demonstrated in more than 150 randomized control studies in school-age children. Whereas behaviorally, higher doses are known to produce greater changes than lower doses (within the therapeutic dose ranges), the dosedependent effects on attentional functions seem to be less clear (Solanto, 2002).

Concepts of attention generally distinguish between selectivity and intensity of attention. Thus, selectivity refers to the process that modulates responsiveness to specific stimuli constellations by giving priority to certain stimuli, whereas intensity describes the ability to activate and maintain attention over time. In addition to selectivity and intensity components of attention, a supervisory attentional system (SAS) is assumed to act as a control mechanism, modulating the two dimensions of selectivity and intensity (Van Zomeren and Brouwer, 1994). Figure 1 presents such a theoretical framework and possible paradigms for assessing these attentional functions. Although this conceptualization has also been criticized for its lack of specification, it nevertheless allows a classification of paradigms and is also supported by clinical studies (Spikman et al., 2001) as well as by new functional imaging data (Cabeza and Nyberg, 2000).

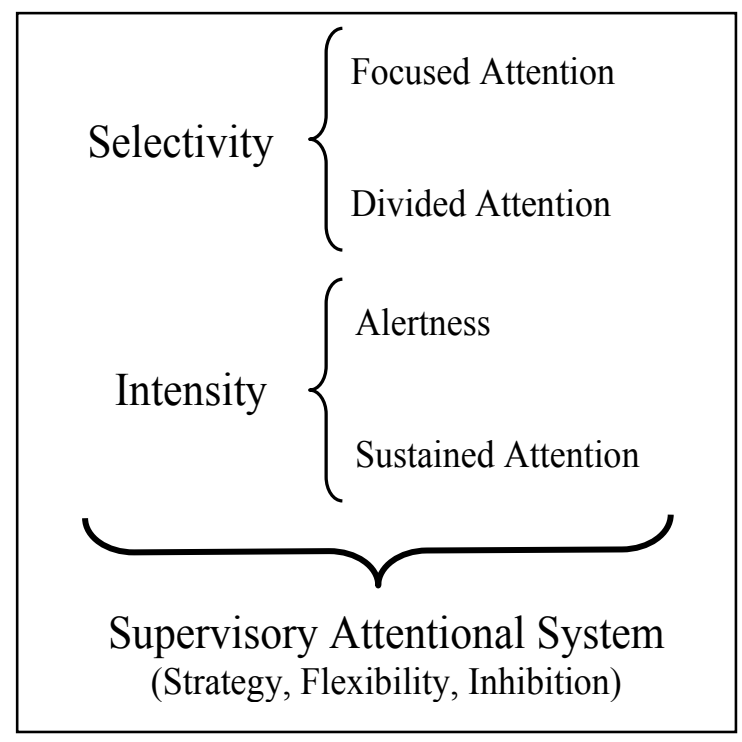

Fig. 1 A schedule of the theoretical framework of attentional functions according to Van Zomeren and Brouwer (1994). 
Until now there have been several MPH studies on cognitive performance in children with ADHD that focused on a single or a few aspects of cognitive function, such as inhibition (Van der Meere et al., 1999), working memory (Tannock et al., 1995a) or vigilance (Lousier et al., 1996). To sum up, findings have been inconsistent. For example, it has been shown that MPH improves maintenance of attention (van der Meere et al., 1995), accuracy (Jonkman et al., 1999), working memory (Tannock et al., 1995a), and inhibition (Tannock et al., 1995b), whereas other studies have found no influence on the Stroop interference task (Jonkman et al., 1999) or on go/no go tasks (van der Meere et al., 1999).

With regard to dose-dependent effects, again, divergent findings have been reported, with several studies failing to show a MPH dose effect on cognitive functions (Rapport and Kelly, 1991). When dose effects were found, unlike behavioral changes, only a few attentional functions seem to show linear improvements. This seems to be true for simple tasks of target detection, in particular for the variability of simple reaction times or sustained attention (Denney and Rapport, 2001; Douglas, 1999). However, there are also studies (e.g., on inhibition) that have shown Ushaped improvements, with reduced performance on higher doses of MPH (Tannock et al., 1995b).

To summarize, little is known about the sensitivity and specificity of levels of MPH to attention tasks, and only a limited number of studies are available so far. Although parent or teacher ratings are useful in describing general behavioral changes, they cannot provide insight into which processes are remedied by MPH. Therefore, the aim of this study was to investigate dosedependent effects on different attentional functions using a theoretically based selection of six attention paradigms. Taking the model of attention described above, it was hypothesized that attentional functions belonging to the intensity dimension are positively influenced by MPH following a linear trend, whereas MPH should have less clear effects on attentional functions of the selectivity dimension. Functions of the SAS, however, should show a U-shaped improvement with MPH use. More precisely, we hypothesized that, as demonstrated by Denney and Rapport (2001), performance in the alertness and sustained attention tasks (intensity dimension) would show linear improvement, with the best performance occurring when more MPH was administered. No directed hypotheses were stated for the focused and divided attention task (selectivity dimension), since no improvement had emerged for such tasks in previous studies (De Sonneville et al., 1994; Van der Meere et al., 1999) or discrepant findings (De Sonneville et al., 1994). For inhibitory control and set-shifting abilities (SAS), we additionally assumed a dose response on a quadratic curve as already found by Tannock et al. (1995b). 
80 | Chapter 5

\section{Method}

\section{Participants and Selection Procedure}

A total of 60 children with ADHD aged 8 to 12 years participated in this study. All the children met the DSM-IV criteria for ADHD and were recruited from our inpatient or outpatient department of child and adolescent psychiatry. All new referrals with suspected ADHD symptoms underwent an extensive child psychiatric examination conducted by an experienced child and adolescent psychiatrist. Psychiatric classification according to DSM-IV (American Psychiatric Association, 1994) was based on a German semistructured interview of the parents and the child (K-DIPS; Unnewehr et al., 1995), a parental questionnaire of ADHD symptoms (DISYPS; Döpfner and Lehmkuhl, 1998), developmental history, playroom observation, pediatric examination, evaluations with the Child Behavior Checklist (CBCL), and a German Teacher's and Parental Report on ADHD symptoms (FBB-HKS; Döpfner and Lehmkuhl, 1998). While the KDIPS interview was used to investigate general psychopathology, the DISYPS and FBB-HKS ask more specifically for ADHD items and for oppositional defiant disorder and conduct disorder as classified in DSM-IV. The number of items in the questionnaires referred to equals the number of DSM-IV items for the diagnosis. In addition, the number of DSM-IV criteria fulfilled was provided, as was a severity score for each item ranging from 0 to 3 (see also Herpertz et al., 2001). Only children without a prior history of stimulant treatment were included in the study protocol. Further exclusion criteria were general IQ below 80 (WISC-III), any potentially confounding diagnoses such as psychosis, mania, major depression, or substance abuse, and also pervasive developmental disorders, receptive language disorders, or any kind of additional medication (including selective serotonin reuptake inhibitors or anticonvulsants). Informed parental consent was obtained for all participants, and the study was approved by the Medical Ethical Committee of the University Hospital of Aachen. Table 1 summarizes the major clinical and demographic data.

As can be seen from Table 1, the sample represents a typical clinical sample with high comorbidity rates, conduct disorder being codiagnosed most frequently. Boys and ADHD children with a combined subtype of ADHD were overrepresented in comparison to girls and the inattentive-only subtype, as seen in previous studies (American Academy of Child and Adolescent Psychiatry, 1997). 


\begin{tabular}{|c|c|c|}
\hline & No. & $(\%)$ \\
\hline Males & 44 & (73) \\
\hline Combined subtype & 47 & (78) \\
\hline Inattentive only subtype & 13 & $(22)$ \\
\hline Responder & 50 & $(82)$ \\
\hline Comorbid ODD & 6 & (10) \\
\hline Comorbid CD & 18 & (30) \\
\hline Comorbid anxiety & 12 & (17) \\
\hline \multirow[t]{2}{*}{ Comorbid dyslexia } & 19 & $(32)$ \\
\hline & Mean & $(S D)$ \\
\hline Age at testing (years) & 10.8 & (1.6) \\
\hline Height (cm) & 153.5 & $(8.5)$ \\
\hline Weight (kg) & 38.6 & $(14.2)$ \\
\hline WISC-III IQ & 97.4 & $(10.7)$ \\
\hline \multicolumn{3}{|l|}{ DISYPS $^{\mathrm{a}}$} \\
\hline Attention Deficit & 22.0 & $(3.1)$ \\
\hline Hyperactivity & 10.3 & (2.9) \\
\hline Impulsivity & 8.9 & (2.3) \\
\hline ODD Behavior & 9.8 & $(4.0)$ \\
\hline CD Behavior & 3.4 & $(2.3)$ \\
\hline FBB-HKS (without medication) $^{\mathrm{a}}$ & 42.5 & $(6.1)$ \\
\hline FBB-HKS (MPH) ${ }^{\mathrm{a}}$ & 26.3 & $(5.2)$ \\
\hline \multicolumn{3}{|l|}{ CBCL (parents) } \\
\hline Externalizing $^{\mathrm{b}}$ & 68.5 & $(10.4)$ \\
\hline Internalizing $^{\mathrm{b}}$ & 67.5 & $(9.2)$ \\
\hline Inattention/Hyperactivity scale ${ }^{b}$ & 72.2 & $(10.1)$ \\
\hline
\end{tabular}

Table 1. Clinical and Demographic Features of the Sample of 60 Children With ADHD: $\mathrm{ADHD}=$ attention-deficient/hyperactivity disorder; $\mathrm{CD}=$ conduct disorder; ODD = oppositional defiant disorder; DISYPS = Diagnostic System for Psychiatric Disorders in Childhood and Adolescence; FBB-HKS = German Teacher's and Parental Report on ADHD symptoms; CBCL = Child Behavior Checklist; MPH = methylphenidate; ${ }^{a}$ Sum of severity scores; ${ }^{b} T$ scores. 
82 | Chapter 5

\section{Medication Protocol}

A double-blind, placebo-controlled, within-subject crossover design was used in which every child received each of placebo, a low dose of MPH $(0.25 \mathrm{mg} / \mathrm{kg})$, and a high dose $(0.5 \mathrm{mg} / \mathrm{kg})$ on two occasions across a 6-day period. The active medication and placebo were prepared by a study protocol physician who was not involved in the assessment. All capsules were identical opaque gelatin capsules and were administered in a double-blind manner. Capsules containing placebo (lactose) or $0.25-\mathrm{mg} / \mathrm{kg}$ or $0.5-\mathrm{mg} / \mathrm{kg}$ doses of MPH were prepared for each subject. The dose was based on the child's weight (to the nearest $2.5 \mathrm{mg}$ ), although there is no evidence that gross body weight is predictive of response to MPH (e.g., Rapport and Denney, 1997). The mean dose was $9.2 \mathrm{mg}(\mathrm{SD}=2.2)$ for the $0.25-\mathrm{mg} / \mathrm{kg}$ dose and $18.4 \mathrm{mg}(\mathrm{SD}=5.4)$ for the $0.5-\mathrm{mg} / \mathrm{kg}$ dose. The two doses were chosen based on the fact that in clinical practice children are normally administered doses of 0.5 to $1 \mathrm{mg} / \mathrm{kg}$ per day, given on two or three occasions a day. Prior to testing, all the children were given $0.3 \mathrm{mg} / \mathrm{kg}$ MPH each day for at least 1 week to ascertain tolerance. Within the 6-day protocol, the order of drug conditions was randomized, with the restriction that higher doses should never be administered after the placebo. Thus, there were 11 possible orders for the 6-day procedure as a whole, and 6 possible orders for the sequence of the three neuropsychological assessments. Children were assigned in equal numbers to each of the six orders.

Medication was administered once a day between 7 and 8 A.M.; cognitive testing began 60 minutes after medication ingestion and lasted 80 minutes. On each test three parallel versions of the computerized attentional tasks (de Sonneville, 2000) were used and the order of tasks was balanced to reduce learning and effects of fatigue. On the other 3 days, children took the capsules 60 minutes before school started and teachers rated the ADHD symptoms on the FBB-HKS during the first lessons of each day.

MPH response was defined on the basis of behavioral ratings obtained by the parents during the drug onset phase or by the teachers within the study protocol. Children were classified as responders if either their parents or teachers reported a reduction in the total ADHD symptom severity score according to the FBB-HKS of at least $30 \%$ while they were taking medication.

\section{Experimental Procedure}

Baseline Speed. Baseline speed was assessed with a simple reaction time (RT) task (de Sonneville, 2000). The child had to respond with his or her dominant hand to stimulus presence within 32 trials. The dependent measures were the median and the within-subject SD of the RTs. 
Sustained Attention. Sustained attention involved the continuous and consecutive presentation of 50 series of 12 different dot patterns (600 signals; de Sonneville, 2000). In each series, an equal number of three-, four-, or five-dot patterns were presented in a pseudorandom manner. The child was instructed to push the "yes" button with the index finger of the dominant hand whenever a four-dot pattern (target) was presented and to press the "no" button with the index finger of the nondominant hand if the pattern presented contained three or five dots (nontargets). Two types of correct responses were counted: hits on four dots and correct rejections of three- and five-dot patterns. Two types of errors were registered: misses and false alarms. As an index of speed (tempo per series), the sum score of the 12 latencies was calculated. The standard deviation of the sum scores across 50 series was taken as a measure of fluctuation in speed during task performance (tempo fluctuation).

Focused Attention. In the focused attention task, four letters were presented simultaneously and the child was instructed to respond with the yes key to one target letter, but only if this occurred on one of the relevant diagonal positions (de Sonneville, 2000). The child was told to reject any other signal ("no" response). The dependent measures were median and SD of hits and of correct rejections and number of each error types.

Divided Attention. Divided attention was a dual task that combined an optic and acoustic discrimination task (Zimmermann and Fimm, 1993). Children were asked to respond as quickly as they could whenever a square appeared and also if an alternating high and deep tone was repeated. The dependent measures were the number of misses, false alarms, median of RTs and within-subject SD.

Stop-Signal Paradigm. The go task in our stop-signal task was a choice reaction task in which an unidentified flying object (UFO) appeared to the left or right of a fixation cross (Konrad et al., 2000a,b). Children had to respond with the appropriate mouse button on a two-button response box depending on which side the UFO had appeared. They were told to inhibit their response whenever the stop-signal, a $1-\mathrm{kHz}$ tone of 500-ms duration, presented through earphones, sounded. Children were instructed to respond as quickly and accurately as possible to the UFOs and not to wait for the stop-signal. Twenty-five percent of the trials were stop trials, $75 \%$ were go trials. The stop-signal delay was set at $300 \mathrm{~ms}$ initially and then adjusted dynamically in 50-ms increments depending on the child's behavior (increasing for successful inhibition, shortening for failure). This tracking procedure converges on a stop-signal delay at which the children inhibit $50 \%$ of the time. This delay was used to calculate the stop-signal reaction time (SSRT) by subtracting the critical stop-signal delay from the mean go reaction time (for a more detailed description, see Logan et al., 1997). 
Visual Set-Shifting. The visual set-shifting task consisted of three parts (de Sonneville, 2000). The signal was a bar with a colored square. This square was liable to jump from left to right and vice versa. Depending on the color of the square after the jump, the child had to copy the movement (part 1) or was required to mirror the movement of the square (i.e., press the left key in response to a rightward movement or the right key for a leftward one; part 2). In part 3, the square might change color at any moment, upon which the child had to adjust his or her responding behavior. Parts 1 and 2 consisted of 40 trials each, and part 3 had 70 trials. The dependent measures were the number of errors as well as the median and SD of RTs separated for congruent and incongruent trials for each block.

\section{Statistical Analysis}

A multivariate repeated measure analysis of variance (MANOVA) was conducted for the attention parameters of the six paradigms. Due to computer problems, data for four children in one task in one condition were missing. As recommended by Tabachnik and Fidell (2000), these data were replaced by the average of the group per condition. Effect sizes were calculated using eta square $\left(\eta^{2}\right)$, which estimates the degree of association in the sample. In the case of significant $F$ values, post hoc comparisons and trend tests were performed to establish the presence of a linear or quadratic relationship.

\section{Results}

The MANOVA with all the dependent measures of the six attention paradigms and with the drug as the within-subject variable revealed a significant main effect for drug $\left(F_{4,236}=102.2, p<\right.$ $.001)$.

The mean scores on all the measures for the placebo condition and two dosages of MPH are summarized in Table 2, together with the results (i.e., $F$ values and probability levels) of follow-up univariate $F$ tests. As can be seen, the drug had a significant effect on the SD in the alerting task $\left(\eta^{2}=0.17\right)$, on the median $\left(\eta^{2}=0.12\right)$ and the within-subject SD of the hits $\left(\eta^{2}=0.09\right)$ in the focused attention paradigm, on the errors $\left(\eta^{2}=0.23\right)$ and the within-subject $\operatorname{SD}\left(\eta^{2}=0.11\right)$ in the sustained attention task, on the SSRT $\left(\eta^{2}=0.20\right)$ in the stop task, and on the median of the incompatible $\left(\eta^{2}=0.20\right)$ and SD $\left(\eta^{2}=0.24\right)$ of the compatible trials in the visual set-shifting task.

Post hoc analyses revealed differential dose-response effects for several parameters. For the median and SD of hits in the focused attention task, low and high doses differed significantly from placebo; however, there were no significant differences between the low and high doses in this 
task. Thus higher doses did not further improve nor did they reduce performance. Only baseline SD and total errors in the sustained attention task showed a linear dose-response with significantly better performance in the high-dose condition compared to the low-dose condition. The SSRT, the median of incompatible trials, and the SD of compatible trials in the visual set-shifting task also differed significantly in the low-versus high-dose condition, but performance was found to be worse in the high dose-condition. Con-cordantly, trend tests revealed a linear trend (i.e., for baseline SD, partial $\left.\eta^{2}=0.29\right)$, median (partial $\left.\eta^{2}=0.14\right)$, and SD (partial $\eta^{2}=0.16$ ) of hits in the focused attention task and SD (partial $\left.\eta^{2}=0.20\right)$ and total errors (partial $\left.\eta^{2}=0.35\right)$ in the sustained attention task. A quadratic relationship was found to be significant for SSRT (partial $\eta^{2}=$ 0.27 ), for median of incompatible trials (partial $\eta^{2}=0.38$ ) and SD of compatible trials (partial $\left.\eta^{2}=0.29\right)$ in the visual set-shifting task.

To test more precisely the effects of MPH on the ability to sustain attention over time, an additional MANOVA was applied with two within-subject factors, one for drug (three conditions) and one for block (five blocks), and with two dependent variables, RTs (of hits and correct rejections $)$ and sum of errors. A significant main effect for $\operatorname{drug}\left(F_{4,56}=6.3, p<.001\right)$, for block $\left(F_{8,52}=\right.$ $3.8, \mathrm{p}<.001)$, and for drug $\times$ block interaction $\left(F_{16,44}=2.6, p<.001\right)$ was revealed. Subsequent simple-effects tests and paired comparisons confirmed that while errors increased significantly over blocks in the placebo condition, this was not the case for both MPH conditions. This effect is shown in Figure 2.

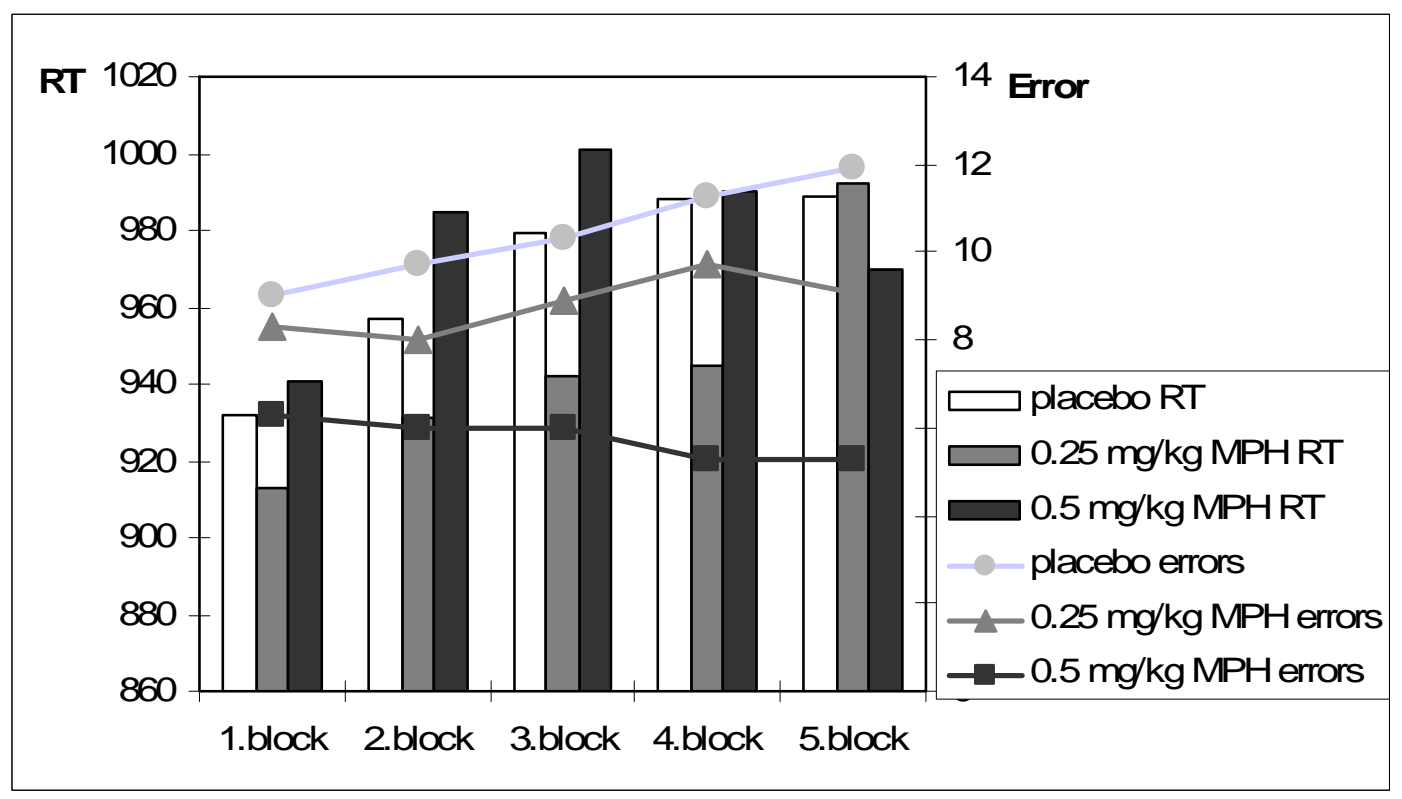

Figure 2. Methylphenidate (MPH) effects on reaction times (RT) and errors measured in a sustained attention task over five blocks. 


\begin{tabular}{lccccc}
\hline & Placebo & Low Dose & High Dose & Main Effect & \\
& & & & of Drug & \\
& Mean (SD) & Mean (SD) & Mean (SD) & $F_{2,118}$ & $p^{a}$ \\
\hline Baseline MD & $310(94)$ & $311(66)$ & $306(51)$ & 0.08 & .92 \\
Baseline SD & $193(148)$ & $136(112)$ & $101(58)$ & 11.9 & $\mathbf{. 0 0}$ \\
Focused MD hits & $926(248)$ & $834(219)$ & $855(221)$ & 7.9 & $\mathbf{. 0 0}$ \\
Focused SD hits & $367(298)$ & $352(291)$ & $249(145)$ & 5.8 & $\mathbf{. 0 0}$ \\
Focused total errors & $7.3(5.5)$ & $5.8(5.1)$ & $5.8(6.3)$ & 2.3 & .12 \\
Divided MD & $723(130)$ & $719(111)$ & $723(130)$ & 1.4 & .24 \\
Divided SD & $286(77)$ & $274(93)$ & $293(85)$ & 0.99 & .37 \\
Divided total errors & $8.5(4.0)$ & $7.8(4.2)$ & $7.6(4.4)$ & 2.4 & .10 \\
Sustained MD hits & $915(198)$ & $880(210)$ & $916(194)$ & 2.5 & .09 \\
Sustained SD hits & $486(251)$ & $403(199)$ & $398(206)$ & 7.1 & $\mathbf{. 0 0}$ \\
Sustained total errors & $57(46)$ & $40(27)$ & $27(22)$ & 17.5 & $\mathbf{. 0 0}$ \\
Sustained tempo series & $11.7(3.0)$ & $10.9(2.9)$ & $11.8(3.5)$ & 3.9 & .03 \\
Sustained tempo fluctuation & $2.9(1.7)$ & $2.8(2.0)$ & $2.6(2.3)$ & 0.66 & .50 \\
Stop-signal MRT & $772(149)$ & $765(156)$ & $757(175)$ & 0.18 & .80 \\
Stop-signal SSRT & $484(116)$ & $423(85)$ & $456(75)$ & 15.1 & $\mathbf{. 0 0}$ \\
SS-Vis part 3: MD comp & $897(208)$ & $874(224)$ & $856(330)$ & 0.65 & .50 \\
SS-Vis part 3: SD comp & $549(290)$ & $437(201)$ & $707(322)$ & 18.9 & $\mathbf{. 0 0}$ \\
SS-Vis part 3: errors comp & $7.3(5.0)$ & $6.7(6.0)$ & $5.9(5.9)$ & 2.8 & .06 \\
SS-Vis part 3: MD incomp & $939(250)$ & $784(274)$ & $902(413)$ & 7.6 & $\mathbf{. 0 0}$ \\
SS-Vis part 3: SD incomp & $538(310)$ & $446(241)$ & $501(229)$ & 4.0 & .20 \\
SS-Vis part 3: errors incomp & $9.3(6.2)$ & $7.9(6.5)$ & $7.5(5.6)$ & 3.0 & .60 \\
\hline
\end{tabular}

Table 2. Performance in All Attention Tasks Separated for Three Drug Conditions: MD = median; $\mathrm{SD}=$ standard deviation; $\mathrm{MRT}=$ mean reaction time; $\mathrm{SSRT}=$ stop-signal reaction time; $\mathrm{SS}-\mathrm{Vis}=$ visual set-shifting task. ${ }^{\mathrm{a}}$ Boldface values are significant $(\mathrm{p}<.001)$.

To facilitate comparison of the shape of the dose-response functions for the dependent measures across the different domains of attentional function, dose-response data were plotted using standard $Z$ scores (with a mean of 0 and SD of 1 ). This transformation allowed the variable to be displayed on the same scale. The $Z$ scores were calculated so that higher $Z$ scores indicated better performance. Dissociation of dose-related effects across different measures is illustrated in Figure 3, in which the mean $Z$ scores for each of the selected variables are plotted by dose. 


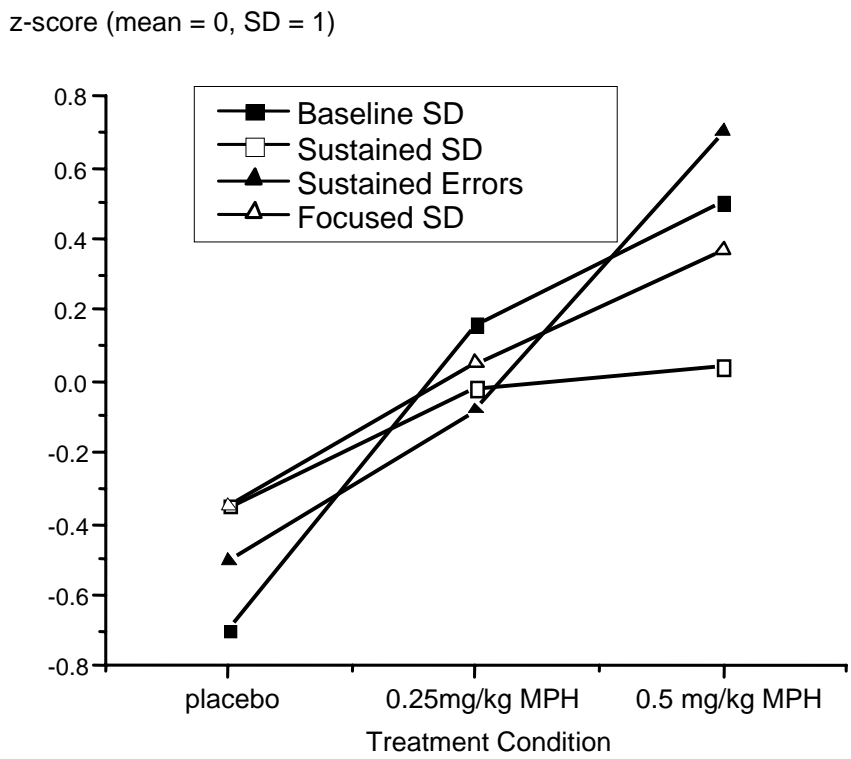

z-score $($ mean $=0, S D=1)$

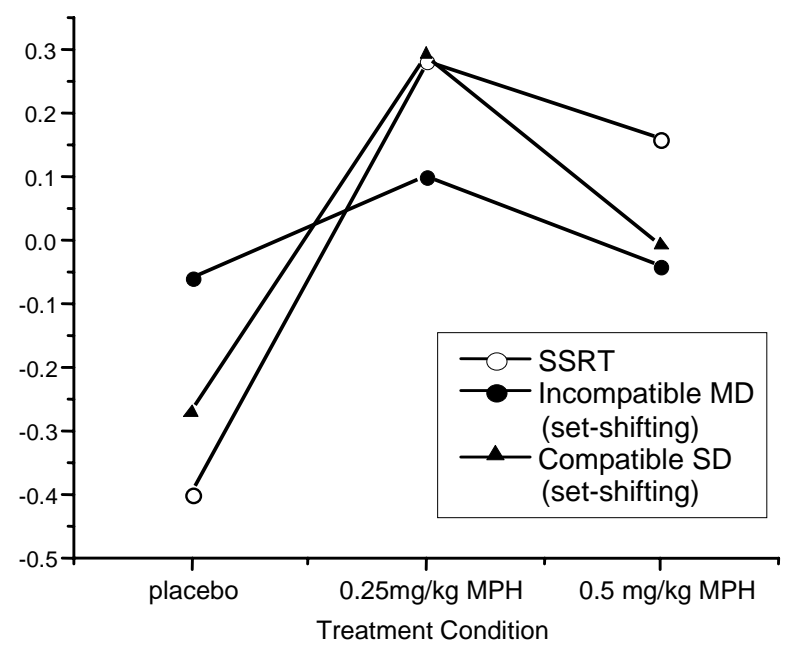

Figure 3. Dissociation of dose-related effects across different measures of attentional domains of functioning. Top: significant changes of the intensity and selectivity dimensions. Bottom: significant changes in supervisory attentional system functions. MD $=$ median; $\mathrm{MPH}=$ methylphenidate; $\mathrm{SD}=$ standard deviation; SSRT $=$ stop-signal reaction time.

Furthermore, Pearson product-moment correlations were used to examine the relationship between all dependent variables of the attentional paradigms in each condition and to control for speed-accuracy trade-off or for a general positivity effect when MPH was administered.

As the framework of attention already suggested, we found the highest correlations in the placebo condition between attentional paradigms of the same dimension-for instance, for baseline median and sustained attention tempo fluctuation: $r=0.51, \mathrm{p}<.001$ (intensity dimension), for 
focused attention median hits and divided attention total errors: $r=0.53, p<.001$ (selectivity attention), and for SSRT and visual set-shifting total errors: $r=0.54, p<.001$ (SAS). In adddition, significant correlations were found between baseline SD and at least one parameter of all other paradigms (between 0.38 and 0.57 ), indicating that general alertness seemed to influence all other attentional processes.

Similar correlation patterns were found in the low and high MPH conditions; however, for the divided attention task, a speed-accuracy trade-off (negative correlation between median and total errors) was found for both the low-dose MPH $(r=-0.4, p<.01)$ and high-dose MPH conditions $(r=-0.63, p<.001)$.

To test whether children who were behaviorally described as responders versus nonresponders also differed in their response to MPH, a MANOVA was conducted with the responder as the group factor and the drug as the repeated measure. Neither the group factor $(p=.14)$ nor the group $\times$ drug interaction $(p=.35)$ proved significant. The same analysis was performed with the $D S M-I V$ subtype as a group factor (combined versus inattentive subtype) and with comorbidities as a covariate, but again no significant differences were found.

\section{Discussion}

Our results indicated that MPH had differential effects on attentional functions. While alertness and focused and sustained attention seemed to be improved following a linear trend, inhibition and set-shifting performance were enhanced at a low dose but worsened at a moderate dose. Divided attention did not change at all. Within-subject SD in particular seemed to be a very MPHsensitive parameter across different tasks. This is in line with a recent study by Scheres et al. (2003) and might be especially interesting with regard to the fact that the variability in responding has been shown to be the variable with the highest heritability effect for ADHD (Kuntsi et al., 2001). In addition, De Sonneville et al. (1994) showed that MPH had no impact on divided attention but had the most favorable responses with regard to sustained and focused attention, especially on the within-subject variability of responses. Furthermore, our hypothesis was supported by the findings that tasks measuring the intensity dimension are more likely to be influenced in a linear manner (within a dose range of $0.5 \mathrm{mg} / \mathrm{kg} \mathrm{MPH}$ ), while SAS functions are more likely to be improved following a quadratic relationship. Thus, the results of the present study showed once more that stimulants did not have an adverse effect on executive attention or shifting abilities, since neither SSRT nor performance in the set-shifting task was worse in the two MPH conditions compared to performance in the placebo condition. However, in contrast with the results of Tannock et al. (1995b), who documented poorer inhibition at $0.9 \mathrm{mg} / \mathrm{kg} \mathrm{MPH}$, we found a 
reduction in performance for both motor inhibition and visual set-shifting at a single dose of 0.5 $\mathrm{mg} / \mathrm{kg}$ MPH. One explanation for this discrepancy might be that none of the children in our study had taken a single dose greater than $0.3 \mathrm{mg} / \mathrm{kg}$ MPH before participating in our study and therefore might have been more sensitive to adverse effects on their cognitive functions than the children in Tannock and colleagues' study. In contrast to the results of our study, Scheres et al. (2003) recently found no MPH dose effect for any of the response inhibition measures: not for the inhibition of a prepotent response, an inhibition of an ongoing response, or an interference effect. This might be explained by the fact that the highest absolute dose in that study was 20 mg MPH, while the high-dose condition $(0.5 \mathrm{mg} / \mathrm{kg} \mathrm{MPH})$ in our study ranged between 15 and $30 \mathrm{mg}$ of MPH.

For the selectivity dimension no homogeneous effects were found, whereas linear effects were found for the focused attention task and no effect for the divided attention task. The most important difference between these two tasks was that in the focused attention task, children had to distinguish between relevant and non-relevant targets, while in the divided attention task all stimuli had the same priority. Thus, it is sometimes argued that in the latter task dividing attentional resources or capacity might also require the attentional control mechanism (Sturm et al., 2000). However, it has to be taken into account that interpretation of the divided attention task was limited due to a speed-accuracy trade-off.

Another important finding was that responders did not differ from nonresponders in their attentional functions. This is in line with studies that have also shown low associations between general behavioral changes and changes in attentional functions (Van der Meere et al., 1999). Previous studies suggest the possibility that the positive effects of MPH on cognitive functions are due to facilitation of dopaminergic activity, whereas improvement in behavior ratings of hyper-activity and impulsivity may be mediated by reduction in dopaminergic stimulation in different brain regions (Solanto, 2002). This might explain different dose-response curves for cognitive and behavioral changes.

However, the fact that we did not find any group differences for children of the combined subtype compared to inattentive only, or any significant influence of comorbidities, must be considered with caution since sample sizes were small and unequal.

Taken together, the differential dose-dependent effects of MPH on attention might be due to different representation of attentional functions in the brain as well as to the complex pharmacological actions of MPH at different brain sites. Functional imaging data suggest that alerting and sustained attention seem to be localized in the frontosubcortical network of the right hemisphere (Sturm et al., 2000), while the functions of the SAS are classically associated with activity 
in the prefrontal cortex (Cabeza and Nyberg, 2000). For selectivity, a broad bilateral representation that also involves thalamic and striatal structures has to be assumed (Corbetta et al., 1991). Thus, one may speculate that attentional functions of the prefrontal cortex showed a different dose-response curve from functions of the intensity dimension. In line with this argument, the inconsistent findings for the focused and divided attention tasks might be explained as follows: in positron emission tomography studies, it was found that in a focused attention task healthy adults showed a left orbitofrontal, thalamic, caudate, and pallidal activity (Corbetta et al., 1991), whereas Madden et al. (1997) reported a more selective activation of the prefrontal cortex in a divided attention task.

Future research should focus on assessing the behavioral and cognitive effects of drugs with specific catecholamine receptor agonist and antagonist properties, not only to provide a more specific psychopharmaco-logical treatment of attentional dysfunctions in children with ADHD, but also to yield greater insight into the neurobiological etiology of the disorder itself.

\section{Limitations}

The present study investigated the effects of day-today medication on attentional functions, which might differ from dose-dependent effects in the long run. For example, discrepancies have been found between short-term MPH efficacy and long-term follow-up studies (Rapport and Denney, 2000). Furthermore, our study did not include a third MPH dose, which would have allowed additional study of dose-response curves for higher doses of MPH. In addition, there is controversy about the ecological validity of such computerized attention tasks. The nonsignificant findings for subtypes and responder types might also be due to power problems.

\section{Clinical Implications}

The results of the present study underscore the importance of monitoring multiple indices of efficacy during dosage titration, including cognitive as well as behavioral measures, and prioritizing the results to be achieved to maximize improvement in the targeted area while minimizing adverse effects in others. Clinicians have to make a decision at a more detailed level concerning which symptoms are the target for intervention and what constitutes an appropriate clinical response. The differential dose effects of MPH on attentional functions suggest that the typical clinical practice of determining the response to stimulant treatment from a single measure, such as a parent or teacher rating or a single attention task, might be insufficient. Depending on the predominant attention deficit of a child, different doses might be necessary to improve attentional functions. Thus, a more detailed assessment of attentional functions covering several compo- 
nents of attention seems to be helpful if changes in attention and not only hyperactivity are the crucial goal of treatment in children with ADHD.

\section{References}

American Academy of Child and Adolescent Psychiatry (1997). Practice Parameters for the assessment and treatment of children, adolescents and adults with ADHD. Journal of the American Academy of Child and Adolescent Psychiatry, 36, Suppl, 85-121.

American Academy of Child and Adolescent Psychiatry (2002). Practice parameters for the use of stimulant medication in the treatment of children, adolescents and adults with ADHD. Journal of the American Academy of Child and Adolescent Psychiatry, 41 Suppl, 2649.

American Psychiatric Association (1994). Diagnostic and Statistical Manual of Mental Disorders - DSM-IV. (4 ed.) Washington D.C.: American Psychiatric Association.

Cabeza, R. \& Nyberg, L. (2000). Imaging Cognition II: An Empirical Review of 275 PET and fMRI Studies. Journal of Cognitive Neuroscience, 12, 1-47.

Corbetta, M., Miezin, F. M., Dobmeyer, S., Shulman, G. L., \& Petersen, S. E. (1991). Selective and divided attention during visual discriminations of shape, color, and speed: functional anatomy by positron emission tomography. Journal of Neuroscience, 11, 2402.

de Sonneville, L. M. J. (2000). ANT 2.1 - Amsterdam Neuropsychological Tasks. Amstelveen: Sonar.

de Sonneville, L. M. J., Njiokektjien, C., \& Bos, H. (1994). Methylphenidate and information processing, part I, differentiation between responders and nonresponders; part 2, efficacy in responders. Journal of Clinical and Experimental Neuropsychology, 16, 897.

Denney, C. \& Rapport, M. D. (2001). The cognitive pharmacology of stimulants in children with ADHD. In M.V.Solanto, A. F. Arnsten, \& F. X. Castellanos (Eds.), Stimulant Drugs and ADHD: Basic and Clinical Neuroscience (pp. 283-302). New York: Oxford University Press.

Döpfner, M. \& Lehmkuhl, G. (1998). Diagnostik System für psychische Störungen im Kindes- und Jugendalter nach ICD-10 und DSM-IV. Bern: Huber Verlag.

Douglas, V. I. (1999). Cognitive control processes in attention-deficit/hy-peractivity disorder. In H.C.Quay \& A. E. Hogan (Eds.), Handbook of Disruptive Behavior Disorders (pp. 105-138). New York: Kluwer Academic / Plenum.

Herpertz, S. C., Wenning, B., Mueller, B., Qunaibi, M., Sass, H., \& HerpertzDahlmann, B. (2001). Psychophysiological responses in ADHD boys with and without con- 
duct disorder: implications for adult antisocial behavior. Journal of the American Academy of Child and Adolescent Psychiatry, 40, 1222-1230.

Jonkman, L. M., Kemner, C., Verbaten, M. N., van Engeland, H., Kenemans, J. L., Camfferman, G. et al. (1999). Perceptual and response interference in children with attentiondeficit hyperactivity disorder, and the effects of methylphenidate. Psychophysiology, 36, 419429.

Konrad, K., Gauggel, S., Manz, A., \& Schöll, M. (2000b). Inhibitory control in children with traumatic brain injury (TBI) and children with attention deficit/hyperactivity disorder (ADHD). Brain Injury, 14, 859-875.

Konrad, K., Gauggel, S., Manz, A., \& Schöll, M. (2000a). Lack of inhibition: a motivational deficit in children with attention deficit/hyperactivity disorder and children with traumatic brain injury. Neuropsychology, Development, and Cognition.Section C, Child Neuropsychology, 6, 286-296.

Kuntsi, J., Oosterlaan, J., \& Stevenson, J. (2001). Psychological mechanisms in hyperactivity: I, response inhibition deficit, working memory impairment, delay aversion, or something else? Journal of Child Psychology and Psychiatry, 42, 199-210.

Logan, G. D., Schachar, R. J., \& Tannock, R. (1997). Impulsivity and inhibitory control. Psychological Science, 8, 60-64.

Lousier, B. J., McGrath, P. J., \& Klein, R. M. (1996). Error patterns on the Continuous Performance Test in nonmedicated and medicated samples of children with and without ADHD: a meta-analytic review. Journal of Child Psychology and Psychiatry, 37, 971-987.

Madden, D. J., Turkington, T. G., Provenzale, J. M., Hawk, T. C., Hoffmann, J. M., \& Coleman, R. E. (1997). Selective and divided visual attention: age-related changes in regional cerebral blood flow measured by H2 ${ }^{15}$ O PET. Human Brain Mapping, 5, 389-409.

Rapport, M. D. \& Denney, C. B. (2000). ADHD and methylphenidate: assessment and prediction of clinical response. In L.L.Greenhill \& B. B. Osman (Eds.), Ritalin: Theory and Practice (2 ed., New York: Mary Ann Libert Inc.

Rapport, M. D. \& Kelly, K. L. (1991). Psychostimulant effects on learning and cognitive function: Findings and implications with Attention Deficit Hyperactivity Disorder. Clinical Psychology Review, 11, 61-92.

Scheres, A., Oosterlaan, J., Swanson, J., Morein Zamir, S., Meiran, N., Schut, H. et al. (2003). The effect of methylphenidate of three forms of response inhibition in boys with AD/HD. Journal of Abnormal Child Psychology, 31, 105-120. 
Solanto, M. V. (2002). Dopamine dysfunction in AD/HD: integrating clinical and basic neuroscience research. Behavioural Brain Research, 130, 65-71.

Spikman, J. M., Kiers, H. A., Deelman, B. G., \& Van Zomeren, A. H. (2001). Construct validity of concepts of attention in healthy controls and patients with CHI. Brain and Cognition, 47, 446-460.

Sturm, W., Herrmann, M., \& Wallesch, C. W. (2005). Lehrbuch der klinischen Neuropsychologie. Lisse: Swets \& Zeitlinger.

Tabachnick, B. G. \& Fidell, L. S. (2000). Using Multivariate Statistics. (4 ed.) New York: Allyn \& Bacon.

Tannock, R., Ickowicz, A., \& Schachar, R. (1995). Differential Effects of Methylphenidate on Working Memory in ADHD Children with and without Comorbid Anxiety. The American Academy of Child and Adolescent Psychiatry, 34, 886-895.

Tannock, R., Schachar, R., \& Logan, G. D. (1995). Methylphenidate and cognitive flexibility: dissociated dose effects in hyperactive children. Journal of Abnormal Child Psychology, 23, 235-266.

Unnewehr, S., Schneider, S., \& Margraf, J. (1995). Kinder DIPS - Diagnostisches Interview bei psychischen Störungen im Kindes und Jugendalter. Heidelberg: Springer.

Van der Meere, J. J., Shalev, R., Borger, N., \& Gross Tsur, V. (1995). Sustained attention, activation and methylphenidate in ADHD: a research note. Journal of Child Psychology and Psychiatry, 36, 697-703.

Van der Meere, J., Gunning, B., \& Stemerdink, N. (1999). The Effect of Methylphenidate and Clonidine on Response Inhibition and State Regulation in Children with ADHD. Journal of Child Psychology and Psychiatry, 40, 291-298.

Van Zomeren, A. H. \& Brouwer, W. J. (1994). Clinical Neuropsychology of Attention. New York, Oxford: Oxford University Press.

Zimmermann, P. \& Fimm, B. (1993). Testbatterie zur Aufmerksamkeitsüberprüfung (TAP) Version 1.02c. Herzogenrath: Psytest. 

Chapter 6:

\title{
Clinical evaluation of subjective and objective changes in motor activity and attention in children with attention-deficit/ hyperactivity disorder in a double-blind methylphenidate trial
}

\author{
K. Konrad, T. Günther, M. Heinzel Gutenbrenner, B. Herpertz-Dahlmann, *
}

\section{Summary}

The aim of this study was to determine drug-dependent effects on attention and motor activity in children with attention-deficit/hyperactivity disorder (ADHD) in a double-blind methylphenidate (MPH) trial using both subjective behavior ratings and objective measures of function. In particular, we were interested in the relationship between changes of those subjective and objective measures. A total of 44 ADHD children with the combined subtype completed a randomized, double-blind, placebo-controlled, crossover trial with 2 doses of MPH $(0.25 ; 0.5$ $\mathrm{mg} / \mathrm{kg}$ body weight) and placebo. In each condition, computerized attention tasks were performed, teacher-behavior ratings were obtained, and actigraph data were collected in both clinical and naturalistic settings. Trend tests revealed linear effects of MPH dose on actigraph data in the test session $(p=0.02)$ and at school $(p=0.001)$, as well as on sustained attention $(p<0.001)$, while inhibitory control showed a quadratic dose-response curve $(\mathrm{p}<0.001)$. Multivariate regression analyses revealed that changes of both, hyperactive-impulsive symptoms (28\%) and inattentive symptoms (23\%) could be explained by objective changes of motor activity. Thus, for clinical practice, it should be taken into account that behavior ratings of ADHD symptoms seemed to be predominantly influenced by changes of motor activity. 
96 | Chapter 6

\section{Introduction}

Stimulant medications, such as MPH, are the first choices for children with attentiondeficit/hyperactivity disorder (ADHD). Over the last 10 years, there has been an 8-fold increase in the prescription of MPH (AACAP, 2002). The benefits and efficacy of MPH have been demonstrated in more than 150 randomized, controlled studies in school-age children. For example, it has been shown that the administration of stimulant drugs brings about significant improvements in hyperactivity, inattention, and impulsivity, as measured by behavioral questionnaires filled out by parents and teachers (Greenhill et al. 2002). It produces significant reductions in activity level, as measured by truncal actometer in academic and recreational settings (Porrino et al. 1983b). In addition, stimulants improve cognitive function on laboratory measures of attention and impulsivity (de Sonneville et al. 1994; Kempton et al. 1999). However, it has recently been shown that time-action and dose-response curves for motor and cognitive effects of stimulants appear to diverge (Swanson and Volkow 2002a). Furthermore, differences in dose-response curves have been documented, showing a reduction in locomotor activity at a subclinical dose that did not produce any improvement in vigilance (Solanto 1986). A recent review concluded that effect sizes are apparently larger for behavioral (0.8-1.0) than for cognitive changes (0.6-0.8) in response to stimulants. Furthermore, it is assumed that there are differential dose effects for both behavioral and cognitive tasks of different complexities (see Solanto 2002 for a review).

Until now, only a limited number of studies have used solid-state actigraphs to determine whether the activity level of children with ADHD differed in an objective, quantitative sense from that of children without ADHD, and whether it changed while children were on stimulant medication. These actigraph instruments are acceleration-sensitive devices that might provide an accurate, reliable, and objective measure of drug-dependent effects on hyperactivity, and might test the validity of behavioral changes reported by subjective ratings of parents or teachers. Although it is known that situational and temporal factors may affect the degree to which hyperactivity is expressed, two actigraph studies have shown that children with ADHD were more active than normal children both in naturalistic (Porrino et al. 1983a) and in clinical settings (Dane et al. 2000). Dane et al. (2000) compared actigraph data collected during a clinical assessment of the predominantly inattentive and combined subtypes of ADHD. In contrast to Diagnostic and Statistical Manual of Mental Disorders, 4th edition (DSM-IV) specifications, the authors did not find differences between ADHD subtypes. Thus, the relationship between subjective and objective measures of motor activity needs to be considered with caution. 
Only a few studies have investigated dose-dependent changes on actigraph data in doubleblind medication trials (Porrino et al. 1983b). Borcherding et al. (1989) examined motor activity in 18 hyperactive boys receiving methylphenidate, dextroamphetamine (D-AMP), or placebo twice a day in an 11-week, double-blindcrossover trial. No significant differences in motor activity were found between drug doses within each drug phase across the dose ranges used (MPH: 0.45-1.25 mg/kg; D-AMP: 0.2-0.6 mg/kg, twice-daily). In a recent study, Swanson et al. (2002b) evaluated the pharmacodynamic effects of an experimental delivery of OROS MPH (bolus delivery followed by small, but increasing, MPH doses) on the activity level in laboratory classroom and playground settings. This experimental delivery of MPH was compared to a thrice-daily placebo regimen. Both deliveries of MPH produced large, significant reductions in activity and inappropriate behavior in the classroom, but the 2 MPH regimens did not differ in onset or duration of effects across the day. Interestingly, though, the MPH effects were situation-dependent, being smaller for the playground than for the classroom settings. Thus, selective effects of stimulants, dependent on the demands of the environment, were observed.

Divergent findings have also emerged with regard to objective stimulant medication effects on cognitive functions, such as attention and inhibition. For example, linear improvements have been reported for simple tasks of target detection, in particular, for the variability of simple reaction times or sustained attention (Douglas 1999; Denney and Rapport 2001); whereas changes in other cognitive functions, such as inhibition, seem to follow U-shaped curves with reduced performance on higher doses of MPH (Tannock et al. 1995; Konrad et al. 2004). In contrast to these non-homogeneous findings, higher doses of MPH are known to produce greater changes than lower doses in inattentive symptoms identified by either teacher or parent ratings within the therapeutic dose ranges (Solanto 2001). Thus, the relationship between subjective and objective measures of attention also appears to be divergent.

Although several studies have examined drug effects on either subjective or objective measures of attentional and motor functioning in children with ADHD, little is known about the relationship between these two areas of outcome measures. Studying the convergences and divergences of change in these two measures might provide a useful basis for optimizing MPH titration guidelines. Therefore, the aim of this study was to examine dose-dependent effects of MPH on motor activity and attention using both subjective behavior scales rated by teachers and objective measures, such as acti-graph data and laboratory measures of attention. We were particularly interested in the intercorrelations between these different measures. In general, we expected larger effect sizes for changes of locomotor activity than for 
98 | Chapter 6

measures of cognitive functions, along with differential dose-response curves, as has been suggested in recent reviews (Swanson and Volkow 2002a).

\section{Materials and Methods}

\section{Participants and selection procedure}

A total of 44 children with ADHD, 8-12 years of age, participated in this study. All children met DSM-IV criteria for the ADHD combined subtype and were recruited from our inpatient department of child and adolescent psychiatry. Classification according to DSM-IV (American Psychiatric Association 1994) was based on a German semistructured interview of the parents and the child (K-DIPS; Unnewehr et al. 1995), developmental history, playroom observation, pediatric examination, evaluations with the Child Behavior Checklist (CBCL), and a German teachers' and parental report on ADHD symptoms (DISYPS; Döpfner and Lehmkuhl 1998). Subtype diagnoses was based on the parental interview (K-DIPS) only; however, children were only included if they also met criteria for ADHD diagnoses in the teachers' rating scale. The exclusion criteria were: A general IQ below 80 (WISC-III), any pervasive developmental disorders or receptive language disorders, visual impairments, or any kind of additional medication (including selective serotonine reuptake inhibitors (SSRIs) or anticonvulsants). Informed parental consent was obtained for all participants, and the study was approved by the Medical Ethical Committee of the University Hospital of Aachen (Aachen, Germany). Table 1 summarizes the major clinical and demographic data.

\section{Medication protocol}

A double-blind, placebo-control, within-subject crossover design was used in which every child received each type of placebo, a low dose of MPH $(0.25 \mathrm{mg} / \mathrm{kg})$, and a high dose of MPH $(0.50 \mathrm{mg} / \mathrm{kg})$ on two occasions during a 6-day period. The active medication and placebo were prepared by a study protocol physician who was not involved in the assessment. All capsules were identical opaque gelatin capsules and administered in a double-blind manner. Capsules containing placebo (lactose), 0.25 , or $0.50 \mathrm{mg} / \mathrm{kg}$ doses of MPH were prepared for each subject. The dose was based on the child's weight (to the nearest $2.5 \mathrm{mg}$ ), although there is no evidence that gross body weight is predictive of response to MPH (e.g., Rapport and Denney 1997). The mean dose (with standard deviations in parentheses) for the 0.25 $\mathrm{mg} / \mathrm{kg}$ dose was $9.4 \mathrm{mg}$ (2.3), and the mean dose for the $0.50 \mathrm{mg} / \mathrm{kg}$ dose was $18.6 \mathrm{mg}$ (5.3). 


\begin{tabular}{|c|c|c|}
\hline & Number (n) & $(\%)$ \\
\hline Males & 37 & $(84 \%)$ \\
\hline Comorbid conduct disorder & 20 & $(45 \%)$ \\
\hline Comorbid anxiety & 6 & $(14 \%)$ \\
\hline \multirow[t]{2}{*}{ Comorbid dyslexia } & 17 & $(38 \%)$ \\
\hline & $M$ & $(S D)$ \\
\hline Age at testing (years) & 10.3 & $(1.9)$ \\
\hline Height (cm) & 149.4 & $(8.4)$ \\
\hline Weight (kg) & 36.1 & $(10.6)$ \\
\hline WISC-III IQ & 98.1 & $(11.2)$ \\
\hline \multicolumn{3}{|c|}{ Sum of ADHD symptoms (teacher rating, DISYPS (mean, SD) ${ }^{\mathrm{a}}$ : } \\
\hline Attention deficit & 7.4 & $(3.2)$ \\
\hline Hyperactivity & 6.5 & $(2.7)$ \\
\hline Impulsivity & 3.4 & $(2.4)$ \\
\hline \multicolumn{3}{|c|}{ Sum of ADHD symptoms (parent rating, DISYPS (mean, SD) ${ }^{\mathrm{a})}$ : } \\
\hline Attention deficit & 6.8 & $(2.0)$ \\
\hline Hyperactivity & 7.6 & $(2.4)$ \\
\hline Impulsivity & 3.4 & $(1.8)$ \\
\hline \multicolumn{3}{|l|}{ CBCL (parents) } \\
\hline Externalizing $^{\mathrm{b})}$ & 70.7 & $(11.2)$ \\
\hline Internalizing $^{\text {b) }}$ & 68.4 & $(10.7)$ \\
\hline
\end{tabular}

Table 1. Clinical and demographic features of the sample of 44 children with combined subtype ADHD: ADHD = attention-deficit/hyperactivity disorder; DISYPS = Diagnostic System for Psychiatric Disorders in Childhood and Adolescence; CBCL = Child Behavior Checklist.; ${ }^{a}$ Sum scores $;{ }^{b} T$ scores.

The 2 doses were chosen based on the fact that in clinical practice children are normally administered doses between 0.5 and $1.0 \mathrm{mg} / \mathrm{kg}$ per day, given 2-3 times per day.

On 3 days, all patients underwent a neuropsychological assessment 1 hour after medication was administered. On the other 3 days, children took the capsules 60 minutes before school started, and teachers made their assessments using FBB-HKS, the German behavioral rating scale for ADHD, for the first two school lessons (90 minutes) of the day. All children went 
to our hospital school and were rated by teachers who had known the child for 2 weeks without medication. Teachers were trained in behavior ratings of ADHD symptoms, and ratings were obtained in small classroom groups (4-6 children).

Prior to testing, all the children were given $0.30 \mathrm{mg} / \mathrm{kg}$ MPH each day for at least 1 week to ascertain tolerance. Within the 6-day protocol, the order of drug conditions was randomized, with the restriction that the high dose never occurred right after the placebo. Thus, there were 11 possible orders for the 6-day procedure as a whole, and the children were assigned to each of those orders in equal numbers (see Table 2).

\begin{tabular}{|c|c|c|c|c|c|c|c|}
\hline & & 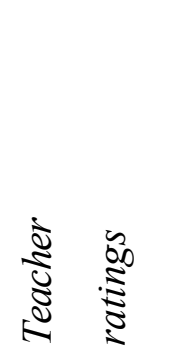 & 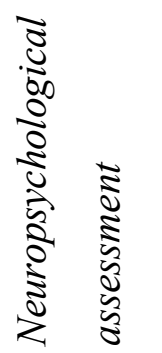 & 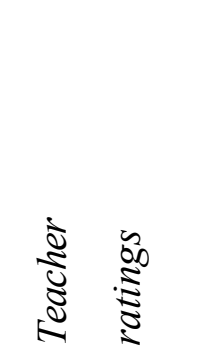 & 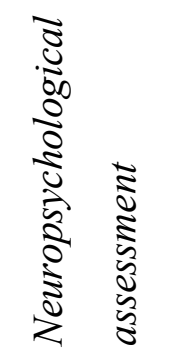 & 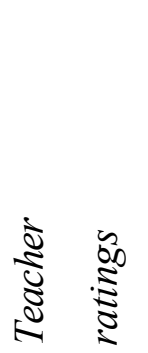 & 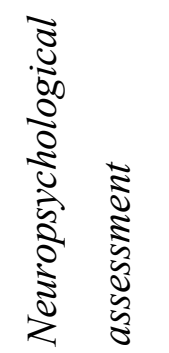 \\
\hline & $N=44$ & Monday & Tuesday & Wednesday & Thursday & Friday & Saturday \\
\hline Row 1 & $\mathrm{~N}=4$ & $P$ & $\mathrm{P}$ & low & low & high & high \\
\hline Row 2 & $\mathrm{~N}=4$ & $\mathrm{P}$ & low & high & $\mathrm{P}$ & low & high \\
\hline Row 3 & $\mathrm{~N}=4$ & $\mathrm{P}$ & low & low & high & high & $\mathrm{P}$ \\
\hline Row 4 & $\mathrm{~N}=4$ & low & $\mathrm{P}$ & $\mathrm{P}$ & low & high & high \\
\hline Row 5 & $\mathrm{~N}=4$ & low & low & high & high & $\mathrm{P}$ & $\mathrm{P}$ \\
\hline Row 6 & $\mathrm{~N}=4$ & low & high & $\mathrm{P}$ & low & high & $\mathrm{P}$ \\
\hline Row 7 & $\mathrm{~N}=4$ & low & high & high & $\mathrm{P}$ & $\mathrm{P}$ & low \\
\hline Row 8 & $\mathrm{~N}=4$ & high & $\mathrm{P}$ & low & high & $\mathrm{P}$ & low \\
\hline Row 9 & $N=4$ & high & low & $\mathrm{P}$ & $\mathrm{P}$ & low & high \\
\hline Row 10 & $\mathrm{~N}=4$ & high & high & $\mathrm{P}$ & $\mathrm{P}$ & low & low \\
\hline Row 11 & $\mathrm{~N}=4$ & high & High & $P$ & low & low & $\mathrm{p}$ \\
\hline
\end{tabular}

Table 2. Assessment schedule: $\mathrm{P}=$ Placebo, high $=$ high dose $(0.50 \mathrm{mg} / \mathrm{kg} \mathrm{MPH})$, low $=$ low dose $(0.25 \mathrm{mg} / \mathrm{kg} \mathrm{MPH})$.

\section{Dependent measures}

Teacher questionnaires. Drug effects on behavior were assessed by the German Teachers' Report on ADHD symptoms (FBB-HKS of the DISYPS; Döpfner and Lehmkuhl 1998) administered on 3 school days within 1 week. This questionnaire asks for the 18 DSM-IV criteria of $\mathrm{ADHD}$ and also provides a severity score for each item ranging from 0 to 3 (see also Her- 
pertz et al. 2001). Sum scores were calculated separately for both symptom scales (hyperactive-impulsive symptoms and inattentive symptoms). The FBB-HKS has successfully been proven to be drug-sensitive (Döpfner and Lehmkuhl 1998).

\section{Actigraph}

Children wore a tiny actigraph the size of a watch on their preferred arm (Cambridge Neurotechnology, Version 2.56, Cambridge, U.K.) throughout the 6-day period. The actiwatch measured the activity with an epoch length of 0.25 minutes. A total score of activity per hour was calculated for the first 90 minutes of each school day and for the standardized neuropsychological assessment lasting approximately 80 minutes.

\section{Attention tasks}

The neuropsychological assessment completed in our department consisted in requiring participants to perform computerized cognitive tasks. Although not all measures were used as dependent variables in this study, they served as the context in which activity was measured.

The Sustained Attention Task involved the continuous and consecutive presentation of 50 series of 12 different dot patterns (600 signals; de Sonneville 2000). In each series, an equal number of three-, four-, or five-dot patterns were presented in a pseudorandom manner. The child was instructed to push the "yes" button with the index finger of his or her dominant hand whenever a four-dot pattern (target) was presented and to press the "no" button with the index finger of the nondominant hand if the pattern presented contained three or five dots (nontargets). Reaction times, tempo fluctuation, and error rate were all registered.

The Stop-Signal Paradigm provides a valid and reliable measure of inhibitory control (Logan and Cowan 1984). We used a choice reaction task in which a "UFO" appeared to the left or right of a fixation cross (Konrad et al. 2000a,b). Children had to respond with the appropriate mouse button on a two-button response box, depending on which side the UFO had appeared on. They were told to inhibit their response whenever the stop signal (a 1$\mathrm{kHz}$ tone of $500 \mathrm{~ms}$ duration presented through earphones) sounded. Children were instructed to respond as fast and as accurately as possible to the UFOs and not to wait for the stop signal. Twenty-five percent of the trials were stop trials, while $75 \%$ were go trials. The stop-signal delay was set at $300 \mathrm{~ms}$ initially and then adjusted dynamically in 50-ms increments, dependent upon the child's ability to inhibit on the previous stop-signal trial: Lengthening for successful inhibition, shortening for failure. This tracking procedure converges on a stop- 
signal delay at which the children inhibit $50 \%$ of the time. This delay was used to calculate the stop-signal reaction time (SSRT) by subtracting the critical stop-signal delay from the mean go reaction time (MRT; for a more detailed description, see Logan et al. 1997).

\section{Statistical analysis}

$A$ multivariate repeated measure analysis of variance (MANOVA) was conducted for the objective and subjective measures of ADHD symptoms followed by univariate ANOVAs and trend tests to establish the presence of a linear or quadratic relationship between dose and dependent variables. The within-subject factor was Drug (placebo, $0.25 \mathrm{mg} / \mathrm{kg} \mathrm{MPH,} 0.50 \mathrm{mg} / \mathrm{kg}$ $\mathrm{MPH})$. Effect sizes were calculated separately for low and high doses of MPH using partial eta squared $\left(\eta^{2}\right)$, which estimates the degree of association in the sample in within-subject designs (Keppel 1991).

In order to study the influence of the objective measures on the teacher ratings, general linear mixed models were used. This multivariate regression method allows one to analyze repeated observations with dependently varying covari-ates (Brown and Prescott 1999). More specifically, the effects of actigraph scores and attention tasks on behavioral measures were evaluated as the reduction of the variance component caused by medication. This was calculated by comparing a model without any time-depending covari-ates (unconditional means model) to more complex models which contained the objective measures as time-depending covariates.

\section{Results}

The MANOVA - with teacher behavior ratings of ADHD symptoms, actigraph data, and two cognitive measures as dependent variables, and with Drug as the within-subject variablerevealed a significant main effect for Drug, $\mathrm{F}_{(12,32)}=7.0, p<0.001$.

Mean scores on all measures for the placebo condition and the two MPH dosages are summarized in Table 3, together with the results (i.e., F values and probability levels) of followup univariate F-tests and trend tests. As can be seen, the drug had a significant effect on all dependent measures. Trend tests revealed a linear trend for all dependent variables, whereas a quadratic relationship was found for SSRT.

Effect sizes for the low- and high-dose MPH conditions are summarized in Table 4. According to the classification of Cohen (1988), we found generally small to medium effect sizes for the low MPH condition and medium to large effect sizes for the high MPH dose, with the exception of SSRT measuring inhibitory control. 


\section{Correlations between dependent variables}

$A$ positive correlation between actigraph data in the school and test situation was found for all three conditions ( $\mathrm{r}=0.36$ to $0.47 ; p<0.02$ ). In addition, SSRT and errors in the Sustained Attention Task were found to be correlated only in the placebo condition $(\mathrm{r}=0.43 ; p<0.003)$ but not under medication. No significant correlations emerged between the objective measures of motor activity and the objective measures of attention. The teacher ratings of hyperactive symptoms and inattentive symptoms were, however, found to be correlated in all three conditions ( $\mathrm{r}=0.6$ to $0.7 ; p<0.001$ ).

In addition, Pearson product-moment correlations were calculated for the subjective and objective measures of drug-related changes. Changes generated by the $0.25 \mathrm{mg} / \mathrm{kg} \mathrm{MPH}$ condition were calculated by subtracting the low-dose variables from the placebo values, and changes generated by the $0.50 \mathrm{mg} / \mathrm{kg} \mathrm{MPH}$ condition represent the differences between high-dose and placebo values. Significant associations were found between the change of actigraph data collected at school and changes of teacher ratings of both inattentive and hyperactive-impulsive symptoms ( $\mathrm{r}=0.47$ to $0.62 ; p<0.001$ ). The correlation of changes of actigraph data in the test situation with changes on both teacher rating scales were only significant for the low-dose-related change ( $\mathrm{r}=0.42$ to $0.50 ; p<0.004)$, while no significant correlations emerged for the high-dose-related change. In addition, no significant correlations appeared between the change in the performance in the sustained attention or stop-signal paradigm and the change in the teacher ratings. 


\begin{tabular}{|c|c|c|c|c|c|c|c|c|}
\hline & Placebo & Low dose & High dose & \multicolumn{2}{|c|}{ Main effect of drug } & \multicolumn{3}{|l|}{ Trend } \\
\hline & $M(S D)$ & $M(S D)$ & $M(S D)$ & $F(2,42)$ & $P<$ & $F(1,42)$ & & $P$ \\
\hline \multicolumn{9}{|l|}{ Teacher ratings: } \\
\hline Hyperactive/impulsive symptoms & $10.1(6.1)$ & $8.2(6.8)$ & $6.2(6.0)$ & 5.7 & 0.006 & 11.8 & Linear & 0.001 \\
\hline ADHD total & $22.2(13.8)$ & $17.9(13.3)$ & $14.3(10.1)$ & 6.2 & 0.004 & 12.5 & Linear & 0.001 \\
\hline Activity sum score/h: School & $23,068(9942)$ & $18,253(11,060)$ & $12,746(11,893)$ & 12.8 & 0.001 & 23.3 & Linear & 0.001 \\
\hline Activity sum score/h: Test session & $6659(7207)$ & $5703(7499)$ & $3994(2643)$ & 4.5 & 0.016 & 5.4 & Linear & 0.02 \\
\hline \multicolumn{9}{|l|}{ Attention tasks: } \\
\hline Sustained attention: Total errors & $49(27)$ & $39(25)$ & $27(24)$ & 14.6 & $<0.001$ & 29.6 & Linear & $<0.001$ \\
\hline
\end{tabular}

Table 3. Behavioral and attentional measures by drug conditions: SSRT = stop signal reaction time 


$$
0.25 \mathrm{mg} / \mathrm{kg} \mathrm{MPH} \quad 0.5 \mathrm{mg} / \mathrm{kg} \mathrm{MPH}
$$

Teacher ratings:

Inattentive symptoms

0.08

Hyperactive/impulsive symptoms

0.08

ADHD total

0.09

Actigraph data:

Activity sum score/h: School

0.18

0.35

Activity sum score: Test session/h

0.10

0.12

Attention tasks:

Sustained attention: Total errors

0.15

0.41

Stop-signal task: SSRT

0.49

0.30

Table 4. Partial eta squared $\left(\eta^{2}\right)$ for dependent measures showing low and high doses separately: SSRT $=$ Stop signal reaction time.

\section{Multivariate regression analyses}

Mixed-model analyses were conducted to control for the effects of objective measures of attention and motor activity on teacher ratings of ADHD symptoms. The results of the covariance parameter estimates, which are estimates for the random effects of the model, are summarized in Table 5.

As can be seen, the changes of actigraph scores explained $27.5 \%$ of the variance of changes in the hyperactive-impulsive symptoms, while both attention tasks contributed to approximately $6 \%$ of change of the hyperactive-impulsive symptoms. A similar pattern emerged for the inattentive symptoms: Change of at-tentional performance in the Stop Signal and Sustained Attention Task explained $8 \%$ of the change in the teacher ratings, while change of locomotor activity measured by actigraph scores contributed to approximately $23 \%$ of symptom change. 


\begin{tabular}{lccc}
\hline Hyperactivity/Impulsivity & Estimate & Standard error explained by covariates \\
\hline Residual (model without covariates): & 17.8 & 3.8 & $5.6 \%$ \\
Residual (model including attention tasks as covariates): & 16.8 & 3.6 & $27.5 \%$ \\
Residual (model including actigraph scores as covariates): & 12.9 & 2.8 & $39.8 \%$ \\
Residual (model including attention tasks and actigraph scores as covariates): & 10.7 & 2.7 & \\
& & & \\
\hline Inattention & Estimate Standard error explained bycovariates \\
\hline Residual (model without covariates): & 27.4 & 5.8 & $3.0 \%$ \\
Residual (model including attention tasks as covariates) & 25.2 & 5.9 & $22.6 \%$ \\
Residual (model including actigraph scores as covariates): & 21.2 & 3.6 & $31.4 \%$ \\
Residual (model including attention tasks and actigraph scores as covariates): & 18.8 & 3.7 & \\
\hline
\end{tabular}

Table 5. Covariance parameter estimates for teacher ratings separately for hyperactive/impulsive and inattentive symptoms. 


\section{Discussion}

In accord with previous studies, our results confirm that MPH produces significant improvements on both subjective and objective measures of ADHD symptoms. Contrary to our hypothesis, we did not find generally larger effect sizes for locomotor than for cognitive changes across the board; however, differential dose-response functions were revealed. Bigger effect sizes were found for high-dose MPH than for low-dose MPH for all dependent measures, except for SSRT measuring inhibitory control. This is in agreement with other studies, which also found that inhibitory control was best influenced by low to moderate doses of MPH (Tannock et al. 1995; Konrad et al. 2004). Thus, our data concur with recent reviews (Solanto 2002) suggesting linear improvements for more simple attention tasks, such as the sustained attention task in our study, in contrast to U-shaped dose-response curves in more complex cognitive tasks, such as the Stop-Signal Task. For changes of actigraph scores, we found larger effect sizes for the school situation compared to the test session, which supports the ratedependency hypothesis (Gualtieri and Hicks 1985). As supported by our results, this hypothesis predicts that the largest effects of medication occur in situations in which the activity level is the highest. However, our results seem to contradict the results of the recent study by Swanson et al. (2002b) that found situation dependent medication effects on activity with the largest effects in the lowest level of activity (seatwork situation in the classroom). Our results also seem to contradict the results of Borcherding et al.'s study (1989) that did not find dose-dependent changes on locomotor activity. However, these differences might be explained also by different dose ranges used and/ or by a different quality of the situational context in which activity was measured. For example, our school situation comprised the nonstandardized seatwork situation as well as a small recess situation of 5 minutes. In addition, it should be considered that doses were not blinded in the study by Borcherding et al. (1989).

A significant inter-relationship was found between the sutained attention tasks and the stop task in the placebo condition; likewise, a significant relationship was found for the actigraph score in the school situation and the actigraph score in the test situation. However, no significant inter-relationship was found between attention task scores and actigraph scores. This seems to show that each of the functions (attention and motor activity) was quite consistently measured, but that each of these measures refers to different functions which are independent of one another. By contrast, in each of the 3 medication conditions (placebo, low dose, and high dose), the subjective rating scales for hyperactive-impulsive symptoms and for inattention symptoms were found to correlate highly with one another, indicating that the subjective rating scales did not differentiate adequately between the two categories of symptoms. This 
might serve as a first hint that the two areas of function could be more distinctively assessed by the use of objectives measures. Thus, further factor analysis on larger samples is needed to clarify the distinctiveness of objective measures of attention and locomotor activity. Although actigraph scores were much higher in the less-structured classroom situation than in the oneto-one test situation, actigraph scores within the two situations were generally found to be correlated, indicating that the test situation might be a clinically useful situation to observe hyperactive behavior.

Our multivariate regression analysis revealed that changes in subjective rating scales varied much more with objective changes in motor functions, compared to changes in cognitive functions. Thus, behavior ratings of inattentive symptoms also seem to be more closely related to objective measures of motor activity than to objective measures of attention. This result underlines the difficulty that, although symptom scales have been found clinically useful, symptom scales suffer from problems of bias and subjectivity. Because they do not provide operational definitions of the specific symptoms of inattention, any one form of behavior (such as being easily distracted by external stimuli) can be misinterpreted as evidence of several different symptoms. Although this result apparently seems to contradict the DSM-IV specification of the two distinct symptom clusters, it makes intuitive sense that children sitting calmly and quietly at school are rated by their teachers as concentrating better and being less distracted than are fidgeting children.

Although we did not analyze change of neural activation in this study, our results lend support to recent models which suggest that motor and cognitive functions may be mediated differently. More specifically, the different dose-response curves may result from changes in dysfunctions at different brain sites. For example, animal studies suggest that the positive effects of MPH on cognitive functions are the result of facilitation of dopaminergic activity, whereas improvement in behavior ratings of hyperactivity and impulsivity may be mediated by reduction in dopaminergic stimulation in different brain regions (Levy and Swanson 2001). This might explain the different dose-response curves for cognitive and locomotor changes.

\section{Conclusions}

Clinically, the fact that behavior ratings of inattentive symptoms seem to be more influenced by objective measures of motor activity than by objective measures of attention puts into question the typical clinical practice of determining the response to stimulant treatment using only subjective measures, such as parental or teacher ratings. Children demonstrating a 
reduction of hyperactivity while on MPH might be judged as generally improved although they might still suffer from inattentiveness. Thus, further studies are needed to clarify the question of whether the treatment of inattention in children with ADHD could be optimized by a medication-titration procedure based on either objective measures only, subjective rating scales only, or a combination of both measures.

\section{References}

American Psychiatric Association (1994). Diagnostic and Statistical Manual of Mental Disorders - DSM-IV. (4 ed.) Washington D.C.: American Psychiatric Association.

Borcherding, B. G., Keysor, C. S., Cooper, T. B., \& Rapoport, J. L. (1989). Differential effects of methylphenidate and dextroamphetamine on the motor activity level of hyperactive children. Neuropsychopharmacology, 2, 255-263.

Brown, H. \& Prescott, R. (1999). Applied Mixed Models in Medicine. Chichester: John Wiley \& Sons, Ltd.

Cohen, J. (1988). Statistical power analysis for the behavioral sciences. (2 ed.) Hillsdale: Erlbaum.

Dane, A. V., Schachar, R. J., \& Tannock, R. (2000). Does actigraphy differentiate ADHD subtypes in a clinical research setting? Journal of the Amarican Academy of Child and Adolescent Psychiatry, 39, 752-760.

de Sonneville, L. M. J. (2000). ANT 2.1 - Amsterdam Neuropsychological Tasks. Amstelveen: Sonar.

de Sonneville, L. M. J., Njiokektjien, C., \& Bos, H. (1994). Methylphenidate and information processing, part I, differentiation between responders and nonresponders; part 2, efficacy in responders. Journal of Clinical and Experimental Neuropsychology, 16, 897.

Denney, C. \& Rapport, M. D. (2001). The cognitive pharmacology of stimulants in children with ADHD. In M.V.Solanto, A. F. Arnsten, \& F. X. Castellanos (Eds.), Stimulant Drugs and ADHD: Basic and Clinical Neuroscience (pp. 283-302). New York: Oxford University Press.

Döpfner, M. \& Lehmkuhl, G. (1998). Diagnostik System für psychische Störungen im Kindes- und Jugendalter nach ICD-10 und DSM-IV. Bern: Huber Verlag.

Douglas, V. I. (1999). Cognitive control processes in attention-deficit/hy-peractivity disorder. In H.C.Quay \& A. E. Hogan (Eds.), Handbook of Disruptive Behavior Disorders (pp. 105-138). New York: Kluwer Academic / Plenum. 
Greenhill, L. L., Pliszka, S., Dulcan, M. K., Bernet, W., Arnold, V., Beitchman, J. et al. (2002). Practice Parameter for the Use of Stimulant Medications in the Treatment of Children, Adolescents, and Adults. Journal of the American Academy of Child and Adolescent Psychiatry, 41, 26S-49S.

Herpertz, S. C., Wenning, B., Mueller, B., Qunaibi, M., Sass, H., \& HerpertzDahlmann, B. (2001). Psychophysiological responses in ADHD boys with and without conduct disorder: implications for adult antisocial behavior. Journal of the American Academy of Child and Adolescent Psychiatry, 40, 1222-1230.

Kempton, S., Vance, A., Maruff, P., Luk, E., Costin, J., \& Pantelis, C. (1999). Executive function and attention deficit hyperactivity disorder: stimulant medication and better executive function performance in children. Psychological Medicine, 29, 527-538.

Keppel, G. (1991). Design and analysis. New Jersey: Prentice Hall.

Konrad, K., Gauggel, S., Manz, A., \& Schöll, M. (2000a). Inhibitory control in children with traumatic brain injury (TBI) and children with attention deficit/hyperactivity disorder (ADHD). Brain Injury, 14, 859-875.

Konrad, K., Gauggel, S., Manz, A., \& Schöll, M. (2000b). Lack of inhibition: a motivational deficit in children with attention deficit/hyperactivity disorder and children with traumatic brain injury. Neuropsychology, Development, and Cognition.Section C, Child Neuropsychology, 6, 286-296.

Konrad, K., Günther, T., Hanisch, C., \& Herpertz-Dahlmann, B. (2004). Differential effects of methylphenidate on attentional functions in children with attention deficit/ hyperactivity disorder. Journal of the American Academy of Child and Adolescent Psychiatry, 43, 191-198.

Levy, F. \& Swanson, J. M. (2001). Timing, space and ADHD: the dopamine theory revisited. Australian and New Zealand Journal of Psychiatry, 35, 504-511.

Porrino, L. J., Rapoport, J. L., Behar, D., Ismond, D. R., \& Bunney, W. E. (1983b). A naturalistic assessment of the motor activity of hyperactive boys. II. Stimulant drug effects. Archives of General Psychiatry, 40, 688-693.

Porrino, L. J., Rapoport, J. L., Behar, D., Ismond, D. R., \& Bunney, W. E. (1983a). A naturalistic assessment of the motor activity of hyperactive boys. I. Comparison with normal controls. Archives of General Psychiatry, 40, 681-687.

Rapport, M. D. \& Denney, C. (1997). Titrating Methylphenidate in Children With Attention Deficit/Hyperactivity Disorder: Is Body Mass Predictive of Clinical Response. Journal of the Amarican Academy of Child and Adolescent Psychiatry, 36, 523-530. 
Solanto, M. V. (1986). Behavioral effects of low-dose methylphenidate in childhood attention deficit disorder. Implications for a mechanism of stimulant drug action. Journal of the American Academy of Child and Adolescent Psychiatry, 25, 96-101.

Solanto, M. V., Abikoff, H., Sonuga Barke, E., Schachar, R., Logan, G. D., Wigal, T. et al. (2001). The ecological validity of delay aversion and response inhibition as measures of impulsivity in $\mathrm{AD} / \mathrm{HD}$ : a supplement to the $\mathrm{NIMH}$ multimodal treatment study of $\mathrm{AD} / \mathrm{HD}$. Journal of Abnormal Child Psychology, 29, 215-228.

Solanto, M. V. (2002). Dopamine dysfunction in AD/HD: integrating clinical and basic neuroscience research. Behavioural Brain Research, 130, 65-71.

Swanson, J., Posner, M. I., Cantwell, D., Wigal, S., Crinella, F., Filipek, P. A. et al. (1998). Attention-Deficit Hyperactivity Disorder: symptom domain, cognitive processes and neural networks. In R.Parasuraman (Ed.), The Attentive Brain (pp. 445-460). Cambridge: The MIT Press.

Swanson, J. M., Gupta, S., William, L., Agler, D., Lerner, M., \& Wigal, S. (2002). Efficacy of a New Pattern of Delivery of Methylphenidate for the Treatment of ADHD: Effects of Activity Level in the Classroom and on the Playground. Journal of the American Academy of Child and Adolescent Psychiatry, 41, 1306-1314.

Swanson, J. M. \& Volkow, N. D. (2002). Pharmacokinetic and pharmacodynamic properties of stimulants: implications for the design of new treatments for ADHD 35. Behavioural Brain Research, 130, 73-78.

Tannock, R., Schachar, R., \& Logan, G. D. (1995). Methylphenidate and cognitive flexibility: dissociated dose effects in hyperactive children. Journal of Abnormal Child Psychology, 23, 235-266.

Unnewehr, S., Schneider, S., \& Margraf, J. (1995). Kinder DIPS - Diagnostisches Interview bei psychischen Störungen im Kindes und Jugendalter. Heidelberg: Springer.

Volkow, N. D. (2002). Pharmacokinetic and pharmacodynamic properties of stimulants: implications for the design of new treatments for ADHD. Behavioral Brain Research, 130, 73-78. 

Chapter 7:

\title{
The influence of sertraline on attention and verbal memory in children and adolescents with anxiety disorders
}

\author{
T. Günther, K. Holtkamp, J. Jolles, B. Herpertz-Dahlmann \& K. Konrad *
}

\section{Summary}

This study investigated the cognitive side effects of a 6-week course of sertraline treatment on verbal memory and attention in children and adolescents. Children with various anxiety disorders (social phobia, generalized and separation anxiety disorder; $n=28$ ), aged between 8 and 17, received a standardized computerized neuropsychological assessment before treatment and another six weeks after treatment onset with sertraline (daily dose range between 25 and $100 \mathrm{mg})$. The patient group was compared to healthy controls $(\mathrm{n}=28)$, who were matched for age and IQ and were also tested twice over a six-week period. Sertraline did not have any negative effects on attentional performance $(p>0.05)$ but did increase response speed in a divided attention paradigm $(\mathrm{p}=0.02)$. By contrast, performance of the interference part of a verbal memory task decreased $(p=0.05)$. The described results also remained stable over a $12-$ week period after treatment onset. Thus, the cognitive side effects of sertraline seemed to differ slightly between pediatric patients and those described in adult patient groups, and should therefore be carefully assessed. 


\section{Introduction}

Selective serotonin reuptake inhibitors (SSRI) have become the second most prescribed psychotropic agents and represent an important therapeutic modality in the treatment of childhood psychiatric disorders (Jensen et al., 1999). Prescription rates are not only increasing among late adolescents but also among children aged between 10 and 14 (Zito et al., 2002). However, the adverse effects of these drugs are poorly investigated in children and adolescents. Very recently, serious concerns arose concerning the safety of SSRI treatment in this age group due to an increased risk of suicidal and self-harming thoughts during SSRI treatment (Roth, Boyle, Beer, Malik, \& de Bruyn, 2004). Behavioral side effects include motor restlessness and behavioral disinhibition (Damsa et al., 2004). The neuropsychological side effects of SSRI have never been systematically assessed in childhood psychiatric disorders, although animal and human studies indicate that these drugs may influence cognitive performance (Buhot, Martin, \& Segu, 2000).

Selective serotonin reuptake inhibitors (SSRI) selectively inhibit 5-HT reuptake into the presynaptic terminal resulting in an increased 5-HT concentration in the synaptic cleft (Anderson, 2004). SSRIs are effective in improving impaired cognitive functions in depressed adult patients (Ferguson, Wesnes, \& Schwartz, 2003), in subjects with Alzheimer's disease (Meltzer et al., 1998) and in improving language acquisition in autistic children (DeLong, Teague, \& Kamran, 1998). Impulsive behavior may be modified by serotonergic (5-HT) activity, with underactivity in 5-HT neurotransmission increasing impulsivity and vice versa (Bizot \& Thiebot, 1996). By contrast, animal data and lesion studies suggested that acute increases in central serotonin concentrations may impair learning abilities (Santucci, Knott, \& Haroutunian, 1996). Moreover, a single dose study with healthy adults showed that paroxetine could improve motor performance through practice, but that it decreased the ability to inhibit automatisms (Loubinoux, Pariente, Rascol, Celsis, \& Chollet, 2002). Other studies with healthy middle-aged subjects confirmed paroxetine's impairment of vigilance performance, whereas this effect was not found for sertraline (Schmitt et al., 2002).

Taken together, the results for SSRI influence on cognitive functions, like attention and memory, remain contradictory. In fact, different study designs (single application, various dosages, short-term versus long-term applications, different SSRIs) make it difficult to draw a clear picture of the cognitive side effects. However, the effects of manipulations of serotonergic activity seem to depend on the nature of the responses required, the baseline regulation of the serotonergic system and the age of the subjects, thereby differentially influencing impaired and non-impaired cognitive functions in healthy subjects and patient groups of different ages. 
During school age, cognitive dysfunctions could lead to learning difficulties and serious problems at school and consequently impair social, emotional and cognitive development. This is why the neuropsychological side effects of psychopharmacological interventions in childhood and adolescence need to be carefully assessed. Thus, our study aimed to investigate the effect of a 6-week course of sertraline treatment on verbal memory and attentional performance in children with anxiety disorders. Recently, we demonstrated that unmedicated children with anxiety disorders did not differ significantly from healthy controls in these cognitive functions (Günther, Holtkamp, Jolles, Herpertz-Dahlmann, \& Konrad, 2004). Note, however, that the sample used in the previous study did partly overlap with the sample used in the current study ( $70 \%$ of the control sample and $53 \%$ in the anxiety group). In the current study, we wanted to examine the influence of sertraline on non-impaired cognitive functions in children and adolescents treated with sertraline for clinical purposes. In 2001, when the study was designed, sertraline and fluvoxamine were the only SSRIs with proven efficacy for anxiety disorders in children and adolescents in random controlled trials (The Research Units on Pediatric Psychopharmacology Anxiety Study Group, 2001; Rynn, Siqueland, \& Rickels, 2001). In addition, there were several studies demonstrating that sertraline was rather safe in the treatment of children and adoelscents (for a review, Green, 2001).

\section{Methods}

\section{Participants and Selection Procedure}

A total of 28 children with anxiety disorders, as defined by DSM IV (American Psychiatric Association, 1994), plus 28 healthy controls, aged 8-17, participated in this study.

Prior to the study, all the children underwent an extensive psychiatric examination conducted by an experienced child psychiatrist. A further psychiatric classification was then determined on the basis of a German semi-structured interview with the parents and the child (K-DIPS; Unnewehr, Schneider, \& Margraf, 1995) performed by a second independent rater who was blind to the first rater's diagnosis. Table 1 provides demographic details.

All children of the anxiety group were inpatients at the Department of Child and Adolescent Psychiatry. In all patients, the disorder interfered significatly with the person's normal routine, academic functioning and social activities, and outpatient treatment was no longer sufficient. The primary diagnoses for hospitalization were social phobia ( $n=19$; DSM-IV: 300.23), generalized anxiety disorder $(n=4 ; 300.02)$ and separation anxiety disorder $(n=5 ; 309.21)$. In addition, other comorbid anxiety disorders were identified, like specific phobia $(n=11 ; 300.29)$, 
generalized anxiety disorder $(n=1 ; 300.02)$, panic disorder with agoraphobia $(n=3 ; 300.01)$ and without agoraphobia $(n=1 ; 300.21)$, separation anxiety disorder $(n=1 ; 309.21)$, and obsessive-compulsive disorder $(n=1 ; 300.3)$. Eleven children had no other comorbid anxiety disorder and five had more than one. Exclusion criteria were general IQ below 80 (WISC-III), any kind of psychotropic medication prior to the study and present or past diagnosis of ADHD. Affective disorders were not considered to be exclusion criteria because of the high comorbidity between anxiety and depressive disorders in children (Angold, Costello, \& Erkanli, 1999; Eley \& Stevenson, 1999). Comorbid affective disorders were dysthymic disorder ( $\mathrm{n}=1$; DSMIV: 300.4) and major depression with a recent episode of minor severity $(n=12$; DSM-IV: 296.21 ) in the anxiety group. Of the 28 patients, 11 subjects were males and 17 females.

The 28 participants in the control group (12 male, 16 females) had no history of psychiatric diagnosis. The two groups were not different with respect to sex distribution $\left(\chi_{(1)}^{2}=0.74 ; p=\right.$ $\mathrm{ns})$, age $\left(t_{(54)}=0.78 ; \mathrm{p}=\mathrm{ns}\right)$ and IQ $\left(t_{(54)}=1.48 ; \mathrm{p}=\mathrm{ns}\right)$. However, as expected, a significant difference was found on the child depression inventory (DIKJ; Stiensmeier-Pelster, Schürmann, \& Duda, 2000; Kovacs, 1985; $\left.\mathrm{F}_{(1 / 54)}=25 ; \mathrm{p}<0.001\right)$ and the state version of the German State-Trait Anxiety Inventory for Children (STAIK; Joormann \& Unnewehr, 2003; $\left.F_{(1 / 54)}=13.5 ; p=0.001\right)$. Informed parental consent was obtained for all participants and the study was approved by the Ethics Committee of the University Hospital Aachen.

\begin{tabular}{lccc}
\hline & $\begin{array}{c}\text { Controls } \\
(\mathrm{n}=28)\end{array}$ & $\begin{array}{c}\text { SSRI group } \\
(\mathrm{n}=28)\end{array}$ & Group difference \\
\hline Age $($ Mean $\pm \mathrm{SD})$ & $13.3 \pm 2.4$ & $12.8 \pm 2.3$ & $\mathrm{~ns}$ \\
IQ $($ Mean $\pm \mathrm{SD})$ & $107 \pm 9$ & $102 \pm 13$ & $\mathrm{~ns}$ \\
Sex (boy/girl) & $12 / 16$ & $11 / 17$ & $\mathrm{~ns}$ \\
\hline
\end{tabular}

Table 1. Baseline characteristics of the participants in the study

\section{Medication protocol}

The anxiety group received sertraline as part of a standardized treatment program, including parental education, single and group therapy. The daily doses of sertraline varied between 25 $\mathrm{mg}$ and $100 \mathrm{mg}$ (mean doses $=58.1 \mathrm{mg} ; \mathrm{SD}=13.7$ ). There was no difference in mean dosage between the anxiety group (mean $=58,3 \mathrm{mg} \pm 12,2 \mathrm{mg}$ ) and children with anxiety disorder and comorbid depressive disorder (mean $=57,7 \mathrm{mg} \pm 15,8 \mathrm{mg}$ ).

After six weeks a standardized psychiatric examination (including a psychopathological assessment) was conducted by a senior child psychiatrists $(\mathrm{KH})$ and all patients included in the 
current study showed a clinically relevant improvement of their anxiety symptoms compared to the baseline assessment. In addition, DIKJ scores significantly improved after 6 weeks of SSRI treatment in the patient group $\left(\mathrm{F}_{(1 / 54)}=12 ; \mathrm{p}=0.001\right)$, while no significant change was detected in the STAIK scores $\left(\mathrm{F}_{(1 / 54)}=0.41 ; \mathrm{ns}\right)$. The state version was used because state anxiety is strongly related with task performance (e.g. Kelly, 2002; Schell \& Grasha, 2000).

Twelve children with anxiety disorder were additionally examined 12 weeks after treatment onset, again with the same sertraline dose (T3) (see table 2).

All subjects received a standardized computerized neuropsychological assessment before treatment (T1) and again six weeks after treatment onset with sertraline (T2). Controls were also tested twice without medication six weeks apart. The order of the neuropsychological tests was randomized. Cognitive functions were assessed using the following tests:

\begin{tabular}{|c|c|c|c|c|c|c|}
\hline & \multirow{2}{*}{\multicolumn{2}{|c|}{$\begin{array}{l}\text { Controls }(\mathrm{n}=28) \\
\mathrm{M}(\mathrm{SD})^{\mathrm{a})}\end{array}$}} & \multirow{2}{*}{\multicolumn{2}{|c|}{$\begin{array}{c}\text { SSRI Group }(\mathrm{n}=28) \\
\text { M (SD) }\end{array}$}} & \multirow{3}{*}{$\begin{array}{c}\text { Between } \\
\text { Subject effect }\end{array}$} & \multirow{3}{*}{$\begin{array}{c}\begin{array}{c}\text { SSRI } \\
\text { effect }\end{array} \\
\mathrm{F}(\mathrm{p})\end{array}$} \\
\hline & & & & & & \\
\hline & $\mathrm{T} 1^{\mathrm{b})}$ & $\mathrm{T} 2^{\mathrm{c})}$ & $\mathrm{T} 1^{\mathrm{b})}$ & $\mathrm{T} 2^{\mathrm{c})}$ & & \\
\hline $\mathrm{DIKJ}^{\mathrm{d})}$ & $6.8(3.5)$ & $5.9(3.7)$ & $16.8(7.6)$ & $11.3(8.7)$ & $25(\mathrm{p}<0.001)$ & $12.0(p=0.001)$ \\
\hline STAIK $^{\mathrm{e})}$ & $29.1(3.4)$ & $28.1(4.2)$ & $33.8(5.5)$ & $33.6(8.8)$ & $13.5(p=0.001)$ & $0.41(\mathrm{~ns})$ \\
\hline
\end{tabular}

Table 2. Clinical characteristics of the participants in the study: ${ }^{a)}$ Mean (standard deviation), b) Assessment before treatment, ${ }^{\text {c) }}$ Assessment six weeks after treatment onset, ${ }^{\text {d) }}$ German version of the Child Depression Inventory and ${ }^{\text {e) }}$ State-Trait Anxiety Inventory (state version) for Children at $\mathrm{T} 1$.

\section{Verbal memory}

The Auditory-Verbal Learning Test (Helmstaedter, Lendt, \& Lux, 2001; Lezak, 1995) was applied with the following dependent measures:

- free recall (the score of the total words from trials 1-3),

- working memory (correct words from trial 1),

- learning curve (the difference between trial 3 and trial 1 as an acquisition rate),

- interference (trial after learning a distractive word list),

- a 30-min delayed recall trial, and

- a recognition trial.

\section{Attention}

Concepts of attention, in general, distinguish between selectivity and intensity of attention (Van Zomeren \& Brouwer, 1994) and a supervisory attentional control mechanism that modu- 
lates both the selectivity and intensity dimension (Norman \& Shallice, 1986). Different computerized attention tests were selected according to a model-oriented approach in order to get a full picture of attentional performance. Alertness was assessed with a simple reaction time (RT) task (Fimm \& Zimmermann, 2001). The child had to respond with the dominant hand to the presence of a target stimulus. The Sustained Attention Task involved the continuous and consecutive presentation of 50 series of twelve different dot patterns (600 signals; (de Sonneville, 2000). In each series, an equal number of 3, 4, or 5-dot patterns were presented in a pseudo random manner. The child was instructed to push the 'yes' button with the dominant hand whenever a 4-dot pattern (target) was shown and to press the 'no' button with the nondominant hand if the pattern contained 3 or 5 dots (non-targets). Divided Attention was a dual task which combined an visual and acoustic discrimination task (Fimm et al., 2001). Children were asked to respond as quickly as they could whenever a square appeared and if an alternating high and deep tone was repeated. One hundred stimuli were presented which contained 17 visual and 16 acoustic goal targets. In the Go/No-Go Paradigm (Fimm et al., 2001) that assesses response selection/inhibition, a motor response with the dominant hand was either initiated (go) or inhibited (no-go) depending on whether an "x" (go) or a "+" (no-go) stimulus appeared. Visual stimuli appeared in random order for a duration of $200 \mathrm{~ms}$ with a variable inter-trial interval of a maximum of $1600 \mathrm{~ms}$. Fifty percent of the 40 stimuli were go trials.

In each task the dependent measures were the reaction time (RT) and its standard deviation (SD), the number of misses and false alarms.

The high learning effects in the verbal memory and divided attention task led to parallel versions being used in the second session.

\section{Statistical analysis}

Data were analyzed using SPSS 11 (SPSS Inc., 2001). Group differences on the first measurement were analyzed using multivariate analysis of covariance (MANCOVA), with the diagnostic group as the between-subject factor and the neuropsychological test scores as the dependent variables. IQ, age or sex were included as covariates if they correlated significantly with the dependent variables $(p<0.05)$. Repeated measure group differences were evaluated using repeated measure analysis of covariance (ANCOVAR), with the diagnostic group as the independent variable, time of measurement as the within-subject factor and neuropsychological test scores as the dependent variables. The long-term effects of sertraline on the 12 patients re-examined 12 weeks after treatment onset were analyzed using the Exact Wilcoxon signed rank test for paired measurements. Results with an alpha $(\alpha) \leq 0.05$ were reported. It 
was decided not to adjust for multiple testing in order to avoid Type II errors and also to detect mild neuropsychological impairments on a more liberal level (Tabachnick \& Fidell, 2000). If significant effects were detected, an ANOVA with Post-Hoc comparisons was conducted in order to analyze whether children with comorbid depression drive the group differences at $\mathrm{T} 2$.

Indirect treatment effects might impact on neuropsychological task performance by enhancing clinical symptoms of anxiety and depressive mood. To control for those indirect effects we decided in favor of the following procedure: first, the effects of state anxiety and depressive mood were correlated with the dependent measures of the baseline assessment and second, the change of symptoms was correlated with the change of neuropsychological task performance. Significant associations were found only between depressive symptoms, their change over time and neuropsychological measures (see table 3), while this was not the case for symptoms of anxiety. Therefore, the effects of depressive symptoms (DS) and change of mood during treatment $(\mathrm{CM})$ were controlled by including two covariates: the mean depressive score of the DIKJ produced by the two measurements $(\mathrm{DS}=[\mathrm{DIKJ} 1+\mathrm{DIKJ} 2] / 2)$ and the difference between the two measures $(\mathrm{CM}=\mathrm{DIKJ} 2-\mathrm{DIKJ} 1)$.

Pearson correlations between the difference scores of the dependent measures (T1 - T2) and the dosage of sertraline were conducted to analyze dosage dependencies of the changes between baseline measures at T1 and performance at T2. All statistical tests were two-tailed to detect improvements and decrements of neuropsychological test performance under sertraline medication. 


\begin{tabular}{|c|c|c|c|c|c|c|c|c|c|c|c|c|}
\hline & \multicolumn{6}{|c|}{ Controls $(\mathrm{n}=28)$} & \multicolumn{6}{|c|}{ SSRI Group (n=28) } \\
\hline & \multicolumn{3}{|c|}{ DIKJ } & \multicolumn{3}{|c|}{ STAIK } & \multicolumn{3}{|c|}{ DIKJ } & \multicolumn{3}{|c|}{ STAIK } \\
\hline & $\mathrm{T} 1$ & $\mathrm{~T} 2$ & $\Delta_{1-2}$ & $\mathrm{~T} 1$ & $\mathrm{~T} 2$ & $\Delta_{1-2}$ & $\mathrm{~T} 1$ & $\mathrm{~T} 2$ & $\Delta_{1-2}$ & $\mathrm{~T} 1$ & $\mathrm{~T} 2$ & $\Delta_{1-2}$ \\
\hline \multicolumn{13}{|l|}{ Verbal memory } \\
\hline Free recall & -.12 & -.14 & -.18 & -.23 & .13 & -.02 & $.49 * *$ & .25 & -.05 & .29 & .26 & -.19 \\
\hline Working memory & -.14 & -.20 & -.15 & -.31 & -.03 & -.14 & .31 & .27 & -.16 & .19 & .16 & -.25 \\
\hline Learning curve & .17 & .10 & .10 & .37 & .26 & .23 & .29 & -.20 & .04 & .26 & -.05 & .06 \\
\hline Interference & .07 & -.30 & -.05 & -.18 & -.01 & -.22 & $.38 *$ & -.05 & .04 & .11 & -.10 & .16 \\
\hline Long delay recall & .07 & .03 & -.31 & -.33 & .08 & -.05 & $.38 *$ & .14 & -.13 & .12 & .17 & -.06 \\
\hline Recognition & .06 & .11 & -.31 & -.03 & .01 & -.29 & .31 & .20 & -.06 & .01 & .24 & .21 \\
\hline \multicolumn{13}{|l|}{ Alertness } \\
\hline Reaction time & -.12 & -.02 & .04 & -.17 & -.10 & .31 & $-.47 *$ & -.36 & -.05 & -.07 & -.21 & -.03 \\
\hline Standard deviation & -.24 & .14 & .11 & .29 & -.31 & -.08 & $-.58 * *$ & -.15 & -.11 & -.21 & .09 & .22 \\
\hline \multicolumn{13}{|l|}{ Sustained attention } \\
\hline Tempo & -.02 & .25 & .09 & .35 & .21 & .10 & $-.44 *$ & -.11 & $.44^{*}$ & -.21 & .03 & .30 \\
\hline Tempofluctuation & -.12 & .26 & .00 & .18 & .13 & -.15 & $-.46 *$ & -.16 & $.71 * *$ & -.19 & -.07 & .32 \\
\hline False alarms & -.16 & -.18 & -.02 & -0.2 & .01 & .00 & -.22 & -.21 & -.03 & .13 & -.19 & .11 \\
\hline Misses & .08 & .11 & -.27 & -.35 & -.34 & -.24 & $-.48 * *$ & -.29 & -.02 & -.10 & -.31 & -.04 \\
\hline
\end{tabular}




\begin{tabular}{|c|c|c|c|c|c|c|c|c|c|c|c|c|}
\hline & \multicolumn{6}{|c|}{ Controls $(\mathrm{n}=28)$} & \multicolumn{6}{|c|}{ SSRI Group $(\mathrm{n}=28)$} \\
\hline & \multicolumn{3}{|c|}{ DIKJ } & \multicolumn{3}{|c|}{ STAIK } & \multicolumn{3}{|c|}{ DIKJ } & \multicolumn{3}{|c|}{ STAIK } \\
\hline & $\mathrm{T} 1$ & $\mathrm{~T} 2$ & $\Delta_{1-2}$ & $\mathrm{~T} 1$ & $\mathrm{~T} 2$ & $\Delta_{1-2}$ & $\mathrm{~T} 1$ & $\mathrm{~T} 2$ & $\Delta_{1-2}$ & $\mathrm{~T} 1$ & $\mathrm{~T} 2$ & $\Delta_{1-2}$ \\
\hline \multicolumn{13}{|l|}{ Divided attention } \\
\hline Reaction time & .30 & .33 & .26 & -.06 & .02 & -.07 & $-.46^{*}$ & -.23 & .21 & -.21 & -.24 & .23 \\
\hline Standard deviation & .00 & .21 & .15 & .09 & .07 & -.26 & $-.44 *$ & $-.40 *$ & -.13 & -.11 & -.34 & .04 \\
\hline Misses & -.10 & -.09 & .00 & -.17 & -.02 & -.23 & -.18 & .08 & .27 & -.24 & .02 & .08 \\
\hline \multicolumn{13}{|l|}{ Go/No-Go } \\
\hline Reaction time & .04 & .35 & .22 & -.01 & .18 & -.11 & -.34 & .15 & .23 & -.17 & .11 & .10 \\
\hline Standard deviation & -.16 & .17 & .00 & -.11 & .19 & .06 & -.21 & -.14 & -.03 & -.15 & -.13 & .01 \\
\hline
\end{tabular}

Table 3. Correlation coefficients between neuropsychological task performance and self ratings of depressive and anxious symptoms, separately for different measurement points: DIKJ = German version of children's depression inventory; STAIK = State Trait Anxiety Inventory for Children. Pearson Correlation coefficients were computed between DIKJ and STAIK scores at T1 (assessment before treatment) and neuropsychological measures at T1, and for DIKJ and STAIK scores at T2 (six weeks after treatment onset) and neuropsychological measures at T2, respectively. Delta Scores $\left(\Delta_{1-2}\right)$ of DIKJ and STAIK scores were also correlated with delta scores of neuropsychological variables (difference between $\mathrm{T} 1$ and $\mathrm{T} 2)) ;{ }^{*} \mathrm{p}<0.05 ; * * \mathrm{p}<0.01$ 


\section{Results}

Generally, IQ and age for both groups correlated significantly with the dependent measures of the neuropsychological tests at T1 $(r>0.2 ; n=56 ; p<0.05)$. When controlled for age and IQ, no significant group differences between the controls and the patient group were identified in verbal memory $\left(\mathrm{F}_{(6 ; 47)}=1.62 ; \mathrm{p}=\mathrm{ns}\right)$, divided attention $\left(\mathrm{F}_{(4 ; 49)}=1.15 ; \mathrm{p}=\mathrm{ns}\right)$, sustained attention $\left(\mathrm{F}_{(4 ; 49)}=1.26 ; \mathrm{p}=\mathrm{ns}\right)$, go/no-go paradigm $\left(\mathrm{F}_{(4 ; 49)}=0.94 ; \mathrm{p}=\mathrm{ns}\right)$ and alertness task (controlled only for age; $\left.\mathrm{F}_{(2 ; 52)}=0.03 ; \mathrm{p}=\mathrm{ns}\right)$ in the multivariate comparison of the baseline measures (M1).

For descriptive purpose, correlation patterns were analysed between clinical measures of state anxiety and mood and neuropsychological variables. No significant correlation was found between the delta score $\left(\Delta_{1-2}\right)$ of the neuropsychological tests (difference between pre- [T1] and 6-week post treatment [T2]) and possible covariates, such as IQ, age and sex. Significant correlations were found between the DIKJ score and the neuropsychological dependent measures of verbal memory, alertness, sustained attention and divided attention at T1. Interestingly, the direction of correlation coefficients indicated that anxious children performed better on the neuropsychological tasks if they had higher depression scores. At T2, a significant association was found only for three of the 20 dependent measures (see table 4 ). A positive correlation was found between $\Delta_{1-2}$ of the DIKJ and $\Delta_{1-2}$ of the sustained attention task: children with higher improvement in the DIKJ showed larger enhancement of task performance. No significant correlations were found within the group of normal controls and between the STAIK and the dependent measures for the SSRI group. In addition, no correlation could be detected between the dosage of sertraline and changes of the dependent variables between $\mathrm{T} 1$ and T2 $(r<0.25 ; \mathrm{ns})$.

The analysis of the effect of sertraline medication on verbal memory revealed significant interaction between group and time for performance in the interference condition $\left(\mathrm{F}_{(1 ; 52)}=3.81\right.$; $\mathrm{p}=0.05)$. While the controls improved their performance at the second measurement $(\mathrm{T} 1-\mathrm{T} 2$ $=0.5)$, the SSRI group was more susceptible to interference $(\mathrm{T} 1-\mathrm{T} 2=-1.1)$. The mean change was higher in the group of children with comorbid depression (-1.6 in contrast to -0.5 in the group without depression), but the post-hoc comparison between the two clinical groups was not significant $(\mathrm{p}=0.113$ ) (see figure 1 ). By contrast, no significant interaction effects were found between group and time for free recall $\left(\mathrm{F}_{(1 ; 52)}=0.55 ; \mathrm{p}=\mathrm{ns}\right)$, working memory $\left(\mathrm{F}_{(1 ; 52)}=1.18 ; \mathrm{p}=\mathrm{ns}\right)$, learning curve $\left(\mathrm{F}_{(1 ; 52)}=3.16 ; \mathrm{p}=\mathrm{ns}\right)$, long delay recall $\left(\mathrm{F}_{(1 ; 52)}=\right.$ $0.1 ; \mathrm{p}=\mathrm{ns})$ and recognition $\left(\mathrm{F}_{(1 ; 52)}=0.49 ; \mathrm{p}=\mathrm{ns}\right)$. Although the performance of the control group did not change significantly with regard to working memory, learning curve, long delay 
recall and recognition in the second session, the score for the long delay recall and recognition decreased numerically in the SSRI group.

The analysis of the attention tests resulted in a significant improvement of the SSRI group in the divided attention paradigm for reaction time $\left(\mathrm{F}_{(1 ; 52)}=5.41 ; \mathrm{p}=0.024\right)$. While the control group showed a relatively stable performance at T1 and T2 (T1 - T2 =-14 ms), anxious children significantly improved their performance under SSRI medication at the second measurement $(\mathrm{T} 1-\mathrm{T} 2=36 \mathrm{~ms})$. No difference could be detected between the two clinical groups in the post-hoc comparisons; but both groups improved equally. No other significant interaction effects were detected. Table 4 summarizes the results for all neuropsychological variables separately for group and time of measurement as well as the F statistics on the interaction effects between group and time.

12 of the 28 patients were re-examined 12 weeks after treatment onset (T3). With a relatively liberal alpha level $(\alpha<0.1)$, no significant differences could be found between T2 and T3 for verbal memory, alertness, sustained attention, divided attention and go/no-go variables $(\mathrm{Z}<1.4 ; \mathrm{ns})$. At $\mathrm{T} 2$ the patients showed an improved reaction time in the divided attention task and no significant change between T2 and T3 ( $Z=0.6$; ns). Similarly, the decreased performance verbal memory interference remained stable 12 weeks after treatment onset $(Z=0.55$; ns;).

Verbal memory: Interference

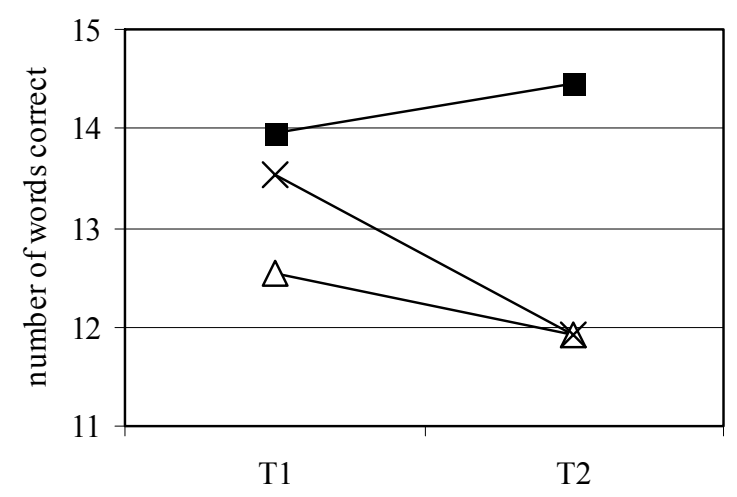

Divided Attention: Reaction time

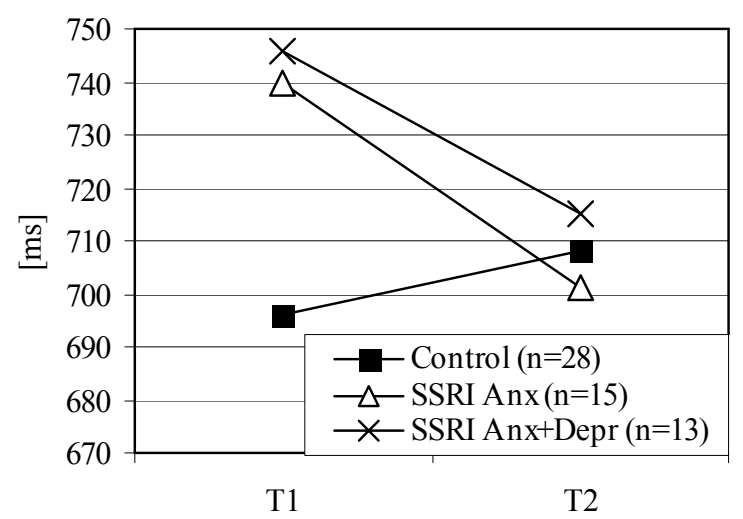

Figure 1: Verbal Memory Interference and Divided Attention Reaction Time: Comparison of the significant verbal memory and divided attention variables between controls $(n=28)$ and the SSRI group, which is divided in patients with anxiety disorder $(n=15)$ and patients with anxiety disorder with comorbid depressive disorder $(n=13)$, which were measured before treatment (T1) and six weeks after treatment onset (T2). 


\begin{tabular}{|c|c|c|c|c|c|c|}
\hline & \multirow{2}{*}{\multicolumn{2}{|c|}{$\begin{array}{c}\text { Controls }(\mathrm{n}=28) \\
\mathrm{M}(\mathrm{SD})^{\mathrm{a})}\end{array}$}} & \multirow{2}{*}{\multicolumn{2}{|c|}{$\begin{array}{c}\text { SSRI Group }(\mathrm{n}=28) \\
\text { M (SD) }\end{array}$}} & \multirow[b]{3}{*}{$F^{d)}$} & \multirow[b]{3}{*}{$\mathrm{P}$} \\
\hline & & & & & & \\
\hline & $\mathrm{T} 1^{\mathrm{b})}$ & $\mathrm{T} 2^{\mathrm{c})}$ & $\mathrm{T} 1^{\mathrm{b})}$ & $\mathrm{T} 2^{\mathrm{c})}$ & & \\
\hline \multicolumn{7}{|l|}{ Verbal memory } \\
\hline Free recall $[\mathrm{n}$ correct $]$ & $33.1(5.8)$ & $34.2(5.8)$ & $28.3(5.4)$ & $27.3(6.2)$ & 0.55 & ns \\
\hline Working memory [nc] & $8.3(2.7)$ & $8.5(2.4)$ & $6.6(2.0)$ & $6.4(2.6)$ & 1.18 & ns \\
\hline Learning curve $[\mathrm{nc}]$ & $4.8(2.0)$ & $4.8(2.0)$ & $5.2(1.5)$ & $5.4(2.6)$ & 3.16 & ns \\
\hline Interference [nc] & $14.0(1.1)$ & $14.5(0.7)$ & $13.0(2.3)$ & $11.9(2.4)$ & 3.81 & 0,05 \\
\hline Long delay recall [nc] & $14.1(1.5)$ & $13.8(1.6)$ & $13.1(2.0)$ & $12.6(2.2)$ & 0.10 & ns \\
\hline Recognition [nc] & $14.9(0.3)$ & $14.9(0.3)$ & $14.5(1.0)$ & $14.3(1.3)$ & 0.49 & ns \\
\hline \multicolumn{7}{|l|}{ Alertness } \\
\hline Reaction time $[\mathrm{ms}]$ & $245(26)$ & $243(22)$ & $248(55)$ & $248(55)$ & 0.01 & ns \\
\hline Standard deviation [ms] & 47 (19) & $56(34)$ & $48(33)$ & $52(43)$ & 0.81 & ns \\
\hline \multicolumn{7}{|l|}{ Sustained attention } \\
\hline Tempo $[\mathrm{sec}]$ & $10.9(2.7)$ & $10.1(3.0)$ & $12.4(4.0)$ & $11.2(3.9)$ & 0.43 & ns \\
\hline Tempofluctuation [sec] & $1.8(1.1)$ & $1.5(1.1)$ & $2.2(1.3)$ & $2.1(1.5)$ & 2.54 & ns \\
\hline False alarms & $20.3(13.1)$ & $11.4(9.4)$ & $16.4(12.8)$ & $10.8(13.6)$ & 0.04 & ns \\
\hline Misses & $29.6(20.4)$ & $27.1(15.5)$ & $21.2(18.0)$ & $22.1(17.1)$ & 0.01 & ns \\
\hline
\end{tabular}

\section{Divided attention}

$\begin{array}{lllllll}\text { Reaction time [ms] } & 696(69) & 708(86) & 744(104) & 708(80) & 5.41 & 0,02 \\ \text { Standard deviation [ms] } & 250(56) & 263(70) & 262(79) & 223(69) & 3.38 & \text { ns } \\ \text { False alarms } & 2.1(1.7) & 1.3(1.1) & 2.6(3.4) & 1.2(1.7) & 0.20 & \text { ns } \\ \text { Misses } & 3.3(2.1) & 2.3(2.4) & 3.0(2.5) & 2.2(2.2) & 0.11 & \text { ns }\end{array}$

\section{Go/No-Go}

$\begin{array}{lcccccc}\text { Reaction time [ms] } & 386(62) & 422(69) & 428(107) & 439(95) & 0.52 & \text { ns } \\ \text { Standard deviation [ms] } & 90(30) & 97(29) & 98(28) & 94(31) & 1.31 & \text { ns } \\ \text { False alarms } & 2.3(2.0) & 2.3(1.7) & 3.1(2.4) & 2.9(3.1) & 0.11 & \text { ns } \\ \text { Misses } & 0.7(1.0) & 0.6(0.9) & 0.6(0.8) & 1.1(2.4) & 1.52 & \text { ns }\end{array}$

Table 4. Neuropsychological performance of the control group and SSRI group, shown separately for time of assessment: ${ }^{\text {a) }}$ Mean (standard deviation), ${ }^{\text {b) }}$ Assessment before treatment, ${ }^{c}$ ) Assessment six weeks after treatment onset, ${ }^{\text {d) }}$ Adjusted for depressive symptoms and change of mood during treatment. 


\section{Discussion}

This study is the first to have examined neuropsychological side effects of sertraline treatment in a clinical group of children and adolescents over a period of 6 to 12 weeks. Depressive symptoms improved in the SSRI group, whereas no improvement was found for state markers of anxiety. Controlling for depressive symptoms and change of mood during treatment, the study showed that sertraline in dosages of between 25 and $100 \mathrm{mg}$ did not have any negative effects on attentional performance. By contrast, an increased response speed in the divided attention paradigm emerged under SSRI medication. However, performance in the interference part of the verbal memory task deteriorated and patients were more susceptible to an interference list. These effects were found to be stable even 12 weeks after treatment onset. The performance decrement was not driven by the comorbidity of depression, but was found in the patient group with and without comorbid depressive disorders. In addition, correlation patterns between neuropsychological task performance and self-rating scales of anxious and depressive symptoms confirmed that none of the significant SSRI effects on attention and memory could be primarily explained by change of state anxiety or depressive symptoms.

The results of improved attentional performance under SSRI medication, i.e. quicker reaction time in a selective attention task, are in line with several other studies (Saletu \& Grunberger, 1988) in adult subjects. Interestingly, as in our study, Schmitt et al. (2002) also found no negative effect of sertraline on vigilance performance, while paroxetine did impair vigilance performance. These differential effects on attentional functions might be explained by the fact that sertraline has an additional mild dopamine stimulating effect, which is not the case for paroxetine. So it may be speculated that the positive effects of sertraline on selective attention and the lack of a significant decline in vigilance performance may presumably be due to the concomitant effects of sertraline on dopamine activity, counteracting the negative effects of serotonin on dopamine neurotransmission. So our data suggest that this seems to be true for children and adolescents aged 8 to 17 years as well. In addition, it might be possible that the improvement in reaction time is due to clinically reduced anxiety symptoms caused by sertraline. This possibility could not be ruled out, because we only entered state anxiety in our analyses.

Although, behaviorally, it has been described that SSRIs may induce disinhibitory symptoms in children and adolescents (Damsa et al., 2004), we did not find any deterioration of inhibitory performance, e.g. in the Go/No-Go-Task. In addition, we did not find any attentional deficit (i.e. in the alerting or the vigilance system) that may correspond to the side effect of somnolence during sertraline treatment. 
Comparison between the neuropsychological side effects found in our study and the effects described for pharmacological treatment alternatives recommended for patients with anxiety disorders indicated that the cognitive outcome seemed to be more positive for sertraline. For example, benzodiazepines, which are frequently prescribed for the pharmacological management of general symptoms of anxiety (Hollister, Muller Oerlinghausen, Rickels, \& Shader, 1993), have been described as producing cognitive impairments in attention, concentration, and short-term memory (Gale \& Oakley-Browne, 2000). Side effects such as sedation (Rickels et al., 2000) and attentional problems when compared with a placebo condition (Gould, Otto, Pollack, \& Yap, 1997) were also described for buspirone, a 5-HT1A -agonist. Moreover, imipramine, a tricyclic antidepressant, exerts negative dose-response effects on reaction time performance (motor speed, motor pursuit; Gualtieri \& Evans, 1988). However, no direct conclusion on the comparative cognitive side effects of different pharmacological treatments can be drawn from the results of our study, but should rather be further addressed in future double-blind placebo controlled medication studies which directly compare the effects of different drugs.

In contrast to these positive effects of sertraline on attentional performance in pediatric patients, the effects on memory function, in particular under complex and distracting conditions (such as in the interference part), are more worrying. It is also necessary to consider that learning under distracting circumstances and distinguishing between important and unimportant information is one of the key abilities needed in school and may therefore considerably impact school performance in children and adolescents. At first glance, this result seemed to be contradictory to most of the results obtained from adult studies. For example, some studies claimed facilitation of memory consolidation (Harmer, Bhagwagar, Cowen, \& Goodwin, 2002) or no change of memory functions in healthy subjects (Schmitt, Kruizinga, \& Riedel, 2001; Siepmann, Grossmann, Muck-Weymann, \& Kirch, 2003) and adult patients (Ferguson et al., 2003; Amado-Boccara, Gougoulis, Poirier-Littré, Galinowski, \& Loo, 1995) under SSRI medication. Vythilingam et al. (2004) even demonstrated that impaired memory functions in adults with major depressive disorders were improved after treatment with the SSRI fluoxetine (e.g. verbal immediate and delayed recall), although in this study, the enhanced memory functions could also be the result of improved depressive symptomatology. However, it should be considered that SSRI effects on memory functioning might differ between children and adults due to differences in neural representation, in particular in the prefrontal cortex (HAROLD model, Cabeza, 2002)). 
In their review, Masand and Gupta (1999) summarize that memory impairment might be one of the possible side effects of SSRIs, but suggest that this is due to an initial effect of the medication and that it disappears after waiting for tolerance. In our study, however, this negative effect remained stable, even after 12 weeks of treatment. In line with this, some patients in our study reported being forgetful under SSRI medication. However, this adverse SSRI effect on memory function in our study was rather small and would not have survived on a more conservative alpha level. In addition, according to the existing norms of the AuditoryVerbal Learning Test (Helmstaedter et al., 2001) the mean test scores under sertraline in the patients group were still within the normal variation and none of the patients scored within the abnormal range of clincial signifcance (T-score under 35). Thus, the clinical impact of this performance decrement has to be carefully weighed up against the positive treatment effects of sertraline.

Taken together, this study marked a first step towards investigating the influence of SSRIs on cognition in children and adolescents. The lack of a placebo control and the open design of this study limit the conclusions that can be drawn from this report. Thus, double-blind, placebo-controlled acute and continuation studies of sertraline (and other SSRIs) in children and adolescents are much needed. Moreover, research on the role of 5-HT in neural plasticity raises questions on possible risks associated with long-term use. However, at this point, the results of our study demonstrated that sertraline with a dosage of between 25 and $100 \mathrm{mg}$ has no negative effects on attentional measures in pediatric patients, although it may negatively impact on verbal memory performance .

\section{References}

Amado-Boccara, I., Gougoulis, N., Poirier-Littré, M. F., Galinowski, A., \& Loo, H. (1995). Effects of Antidepressants on Cognitive Functions: A Review. Neuroscience and Biobehavioral Reviews, 19, 479-493.

American Psychiatric Association (1994). Diagnostic and Statistical Manual of Mental Disorders - DSM-IV. (4 ed.) Washington D.C.: American Psychiatric Association.

Anderson, G. M. (2004). Peripheral and central neurochemical effects of the selective serotonin reuptake inhibitors (SSRIs) in humans and nonhuman primates: assessing bioeffect and mechanisms of action. International Journal of Developmental Neuroscience, 22, 397404. 
Angold, A., Costello, E. J., \& Erkanli, A. (1999). Comorbidity. Journal of Child Psychology and Psychiatry, 40, 57-87.

Bizot, J. C. \& Thiebot, M. H. (1996). Impulsivity as a confounding factor in certain animal tests of cognitive function. Cognitive Brain Research, 3, 243-250.

Buhot, M. C., Martin, S., \& Segu, L. (2000). Role of serotonin in memory impairment. Annals of Medicine, 32, 210-221.

Cabeza, R. (2002). Hemispheric asymmetry reduction in older adults: the HAROLD model. Psychology and Aging, 17, 85-100.

Damsa, C., Bumb, A., Bianchi-Demicheli, F., Vidailhet, P., Sterck, R., Andreoli, A. et al. (2004). "Dopamine-dependent" side effects of selective serotonin reuptake inhibitors: a clinical review. Journal of Clinical Psychiatry, 65, 1064-1068.

de Sonneville, L. M. J. (2000). ANT 2.1 - Amsterdam Neuropsychological Tasks. Amstelveen: Sonar.

DeLong, G. R., Teague, L. A., \& Kamran, M. M. (1998). Effects of fluoxetine in young children with idiopathic autism. Developmental Medicine in Child Neurology, 40, 551562.

Eley, T. C. \& Stevenson, J. (1999). Exploring the Covariation between Anxiety and Depression Symptoms: A Genetic Analysis of the Effects of Age and Sex. Journal of Child Psychology and Psychiatry, 40, 1273-1282.

Ferguson, J. M., Wesnes, K. A., \& Schwartz, G. E. (2003). Reboxetine versus paroxetine versus placebo: effects on cognitive functioning in depressed patients. International Clinical Psychopharmacology, 18, 9-14.

Fimm, B. \& Zimmermann, P. (2001). Testbatterie zur Aufmerksamkeitsüberprüfung (TAP) - Version 1.6. Herzogenrath: Psytest.

Gale, C. \& Oakley-Browne, M. (2000). Extracts from "Clinical Evidence": Anxiety disorder. BMJ, 321, 1204-1207.

Gould, R. A., Otto, M. W., Pollack, M. H., \& Yap, L. (1997). Cognitive behavioural and pharmacological treatment of generalised anxiety disorder: a preliminary meta-analysis. Behavioural Therapy, 28, 285-305.

Green, W. H. (2001). Child and Adolescent Psychopharmacology. (3 ed.) Philadelphia: Lippincott Williams \& Wilkins.

Gualtieri, C. T. \& Evans, R. W. (1988). Motor performance in hyperactive children treated with imipramine. Perceptual and Motor Skills, 66, 763-769. 
Günther, T., Holtkamp, K., Jolles, J., Herpertz-Dahlmann, B., \& Konrad, K. (2004). Verbal memory and aspects of attentional control in children and adolescents with anxiety disorders or depressive disorders. Journal of Affective Disorders, 82, 265-269.

Harmer, C. J., Bhagwagar, Z., Cowen, P. J., \& Goodwin, G. M. (2002). Acute administration of citalopram facilitates memory consolidation in healthy volunteers. Psychopharmacology, 163, 106-110.

Helmstaedter, C., Lendt, M., \& Lux, S. (2001). Verbaler Lern- und Merkfähigkeitstest. Göttingen: Beltz Test GmbH.

Hollister, L. E., Muller Oerlinghausen, B., Rickels, K., \& Shader, R. I. (1993). Clinical use of benzodiazepines. Journal of Clinical Psychopharmacology, 13 (suppl 1), 1S-169S.

Jensen, J. B., Jessop, D. S., Harbuz, M. S., Mork, A., Sanchez, C., \& Mikkelsen, J. D. (1999). Acute and long-term treatments with the selective serotonin reuptake inhibitor citalopram modulate the HPA axis activity at different levels in male rats. Journal of Neuroendocrinology, 11, 465-471.

Joormann, J. \& Unnewehr, S. (2003). State-Trait Angstinventar für Kinder (STAIK). In J.Hoyer \& J. Margraf (Eds.), Angstdiagnostik - Grundlagen und Testverfahren (pp. 583586). Berlin: Springer.

Kelly, W. E. (2002). Anxiety and the predictoin of task duration: a preliminary analysis. Journal of Psychology, 136, 53-58.

Kovacs, M. (1985). The Children's Depression Inventory (CDI). Psychopharmacology Bulletin, 21, 995-999.

Lezak, M. D. (1995). Neuropsychological Assessment. (3 ed.) New York - Oxford: Oxford University Press.

Loubinoux, I., Pariente, J., Rascol, O., Celsis, P., \& Chollet, F. (2002). Selective serotonin reuptake inhibitor paroxetine modulates motor behavior through practice. A doubleblind, placebo-controlled, multi-dose study in healthy subjects. Neuropsycholigia, 40, 18151821.

Masand, P. S. \& Gupta, S. (1999). Selective serotonin-reuptake inhibitors: An update. Harvard Review of Psychiatry, 7, 69-84.

Meltzer, C. C., Smith, G., Dekosky, S. T., Pollock, B. G., Mathis, C. A., Moore, R. Y. et al. (1998). Serotonin in aging, late life depression and Alzheimer's disease: the merging role of functional imaging. Neuropsychopharmacology, 18, 407-430. 
Norman, D. A. \& Shallice, T. (1986). Attention to Action: Willed and Automatic Control of Behavior. In R.J.Davidson, G. E. Schwartz, \& D. Shapiro (Eds.), Consciousness and Self-Regulation (pp. 1-18). New York: Plenum Press.

Rickels, K., DeMartinis, N., García-Espaòa, F., Greenblatt, D. J., Mandos, L. A., \& Rynn, M. (2000). Imipramine and Buspirone in Treatment of Patients With Generalized Anxiety Disorders Who Are Discontinuing Long-Term Benzodiazepine Therapy. American Journal of Psychiatry, 157, 1973-1979.

Roth, D., Boyle, E., Beer, D., Malik, A., \& de Bruyn, J. (2004). Depressing research. Lancet, 363, 2087.

Rynn, M. A., Siqueland, L., \& Rickels, K. (2001). Placebo-controlled trial of sertraline in the treatment of children with generalized anxiety disorder. American Journal of Psychiatry, 158, 2008-2014.

Saletu, B. \& Grunberger, J. (1988). Drug profiling by computed electroencephalography and brain maps, with special consideration of sertraline and its psychometric effects. Journal of Clinical Psychiatry, 49, 59-71.

Santucci, A. C., Knott, P. J., \& Haroutunian, V. (1996). Excessive serotonin release, not depletion, leads to memory impairments in rats. European Journal of Pharmacology, 295, $7-17$.

Schell, K. L. \& Grasha, A. F. (2000). State anxiety, performance accuracy, and work pace in a simulated pharmacy dispensing task. Perceptual and Motor Skills, 90, 547-561.

Schmitt, J. A., Kruizinga, M. J., \& Riedel, W. J. (2001). Non-serotonergic pharmacological profiles and associated cognitive effects of serotonin reuptake inhibitors. Journal of Psychopharmacology, 15, 173-179.

Schmitt, J. A., Ramaekers, J. G., Kruizinga, M. J., van Boxtel, M. P., Vuurmann, E. F., \& Riedel, W. J. (2002). Additional dopamine reuptake inhibition attenuates vigilance impairment induced by serotonin reuptake inhibition in man. Journal of Psychopharmacology, 16, 207-214.

Siepmann, M., Grossmann, J., Muck-Weymann, M., \& Kirch, W. (2003). Effects of sertraline on autonomic and cognitive functions in healthy volunteers. Psychophamacology, 168, 293-298.

SPSS Inc. (2001). Statistical Package of Social Science (Version 11) [Computer software]. SPSS Inc.

Stiensmeier-Pelster, J., Schürmann, M., \& Duda, K. (2000). Depressions-Inventar für Kinder und Jugendliche. (2 ed.) Göttingen: Hogrefe Verlag für Psychologie. 
Tabachnick, B. G. \& Fidell, L. S. (2000). Using Multivariate Statistics. (4 ed.) New York: Allyn \& Bacon.

The Research Units on Pediatric Psychopharmacology Anxiety Study Group (2001). Fluvoxamine for the treatment of anxiety disorders in children and adolescents. New England Journal of Medicine, 344, 1279-1285.

Unnewehr, S., Schneider, S., \& Margraf, J. (1995). Kinder DIPS - Diagnostisches Interview bei psychischen Störungen im Kindes und Jugendalter. Heidelberg: Springer.

Van Zomeren, A. H. \& Brouwer, W. J. (1994). Clinical Neuropsychology of Attention. New York, Oxford: Oxford University Press.

Vythilingam, M., Vermetten, E., Anderson, G. M., Luckenbaugh, D., Anderson, E. R., Snow, J. et al. (2004). Hippocampal Volume, Memory, and Cortisol Status in Major Depressive Disorder: Effects of Treatment. Biological Psychiatry, 56, 101-112.

Zito, J. M., Safer, D. J., dosReis, S., Gardner, J. F., Soeken, K., Boles, M. et al. (2002). Rising prevalence of antidepressants among US youths. Pediatrics, 109, 721-727. 

Chapter 8:

\section{The influence of risperidone on attentional functions \\ in children and adolescents with attention deficit/ hyperactivity disorder and comorbid disruptive behavior disorder}

T. Günther, K. Konrad, J.Jolles, B. Herpertz-Dahlmann*

\section{Summary}

The aim of this study was to examine the influence of the neuroleptic agent risperidone on different attentional functions including: (1) sustained attention to examine intensity aspects of attention; (2) divided attention to detect changes in selectivity aspects of attention and (3), a Go/Nogo task to examine inhibitory control and impulsivity. Risperidone treated children $(n=23)$ with normal IQ and Attention Deficit / Hyperactivity Disorder (ADHD) and severe comorbid Disruptive Behavior Disorders (DBD) were compared with an age and IQ matched group of normal controls ( $\mathrm{NC} ; \mathrm{n}=23$ ). No influence of the risperidone medication on the three attention tasks could be detected, neither as positive enhancement nor as adverse side effects. Risperidone is useful to treat aggression in children with ADHD with comorbid severe DBD and it has no negative impact on attentional functions in dosages beneath $2.5 \mathrm{mg}$. However, additional stimulant treatment seems to be necessary to treat the attentional deficits in children with ADHD+DBD. 


\section{Introduction}

Risperidone is an atypical neuroleptic agent with combined serotonine and dopamine antagonism (Leysen et al., 1992). In child and adolescent psychiatry, risperidone is successfully used in the treatment of neuropsychiatric disorders like schizophrenia (Armenteros, Whitaker, Welikson, Stedge, \& Gorman, 1997; Grcevich, Findling, Rowane, Friedman, \& Schulz, 1996), bipolar disorder (Frazier et al., 1999; Schreier, 1998), pervasive developmental disorder (Barnard, Young, Pearson, Geddes, \& O'Brien, 2002; McCracken et al., 2002; King, Zwi, Nunn, Longworth, \& Dossetor, 2003), tic disorders and obsessive-compulsive disorder (Gilbert, Batterson, Sethuraman, \& Sallee, 2004; Scahill, Leckman, Schultz, Katsovich, \& Peterson, 2003) and disruptive behavior disorders (Barch, Sheline, Csernansky, \& Snyder, 2003; Aman, Binder, \& Turgay, 2004; Aman, Buitelaar, De Smedt, Wapenaar, \& Binder, 2005). Aggression is a common target symptom for which antipsychotics are prescribed to youths seen in psychiatric clinics (Kaplan, Simms, \& Busner, 1994) and the best evidence for the efficacy of risperidone treatment for aggression exists for autism (Arnold et al., 2003; McClellan \& Werry, 2003).

In addition, it has been suggested to use risperidone in treatment of aggressive behavior of children with Attention Deficit / Hyperactivity Disorder (ADHD) with comorbid severe Disruptive Behavior Disorders (DBD). Aggressive and disruptive behaviors are one of the core symptoms associated with DBD. The DBDs of the DSM-IV comprise Oppositional Defiant Disorder (ODD), Conduct Disorder (CD) and DBD-not otherwise specified (American Psychiatric Association, 1994). In this paper, the term 'DBD' will be used to refer collectively to $\mathrm{CD}$ and ODD. For ADHD with comorbid DBD stimulants are the treatment of first choice (Döpfner \& Lehmkuhl, 2003), but risperidone has a place in the management of children with ADHD with severe DBD if other treatments have proved unsuccessful (Morant, Mullas, Hernandez, \& Rosello, 2001; Kewley, 1999; Simeon, Milin, \& Walker, 2002). Aggression is a common target symptom for which antipsychotics are prescribed to youths seen in psychiatric clinics (Kaplan et al., 1994) and risperidone is associated with significant improvements in a high percentage of this difficult-to-treat population (Aman et al., 2004; Aman et al., 2002; Buitelaar, 2000; Buitelaar, van der Gaag, Cohen Kettenis, \& Melman, 2001; Cesena, Gonzalez Heydrich, Szigethy, Kohlenberg, \& DeMaso, 2002; Findling et al., 2000). Clinically, children with ADHD and DBD also seem to benefit from a combined treatment of stimulants and risperidone. According to Turgay et al. (2002) is the efficacy of risperidone not affected by type of disorder, level of retardation, presence/absence of ADHD, or use of stimulants. 
The most common adverse events in risperidone-treated patients are weight gain, extrapyramidal symptoms, somnolence, sedation, headache, dyspepsia, rhinitis and vomiting, (Cesena et al., 2002; Buitelaar, 2000; Buitelaar et al., 2001; Aman et al., 2004; McShane et al., 1997; Aman et al., 2002; Snyder et al., 2002). Sedative and amnestic effects of neuroleptic drugs generally occur after the first administration (Nowakowska, Chodera, \& Kus, 1999; Holland, Wesnes, \& Dietrich, 1994) and, children relative to adults seem to be particularly vulnerable to adverse effects, including sedation (McConville \& Sorter, 2004). Most evidence about the influence of risperidone on cognitive function comes from studies with healthy adults (Barrett, Bell, Watson, \& King, 2004; Allain et al., 2002) and schizophrenic patients. For patients with schizophrenia it is well documented that atypical antipsychotics have an influence on cognitive function (Keefe, Silva, Perkins, \& Lieberman, 1999), although the neurochemical basis for this effect is not well understood. For schizophrenic adults it is suggested that risperidone improves cognitive functioning (Barkic et al., 2003; Bilder et al., 2002; Brunnauer, Geiger, \& Laux, 2003) or that risperidone did not affect cognitive functioning (Liu, Chen, Chang, \& Lin, 2000). But the improvements described in these studies are related to the enhancement of the schizophrenic disorder and not to the medication per se. However, one study with ten schizophrenic patients found a negative correlation between plasma risperidone and the performance on a continuous performance test (Chen et al., 2004). Taken together, the results about the cognitive impact of risperidone are inconsistent and most studies were done with adults. Nevertheless, two studies with children between five and 12 years of age with disruptive behavior and either borderline intellectual function or mild or moderate mental retardation (IQ between 36-84 ) is available (Turgay et al., 2002; Snyder et al., 2002). They found neither evidence for improvement nor for deterioration of cognitive variables such as Sustained Attention and verbal learning (Continuous Performance Test \& California Verbal Learning Test) while participants were treated with risperidone. However, other studies reported sedative effects in adolescents with schizophrenia (Grcevich et al., 1996) and children with bipolar disorders and comorbid ADHD (Schreier, 1998). Most of the available studies with risperidone are case reports, small-open label studies, and the samples are often inhomogeneous (see Findling \& McNamara, 2004 for a review). For tic disorders, studies with greater clinical samples are available. Again, comparing risperidone and pimozide (50 children and adults; Bruggeman et al., 2001) or risperidone and clonidine (21 children and adolescents; Gaffney et al., 2002) sedation, somnolence and fatigue were reported as adverse events. 
In conclusion, risperidone is a well tolerated neuroleptic agent and has a place in the management of children with ADHD with associated severe DBD, when other treatments have proved unsuccessful. Most information about the influence of risperidone on cognitive function is based on research with schizophrenic or healthy adults. In addition, the results are inconsistent. Although for children with DBD with subaverage IQ two studies demonstrated no negative influences on cognitive functions (Turgay et al., 2002; Snyder et al., 2002), little is known about cognitive side effects in ADHD+DPD children with average IQ. Furthermore, sedation is an adverse event that is frequently associated with risperidone treatment. It could be expected, that attentional functions decline due to the sedative effects of a neuroleptic agent. Therefore, the aim of our study was to examine the influence of risperidone on different attentional systems in a sample of ADHD+DPD children with average IQ, who had not benefited sufficiently from a previous stimulant treatment.

Current concepts of attention generally distinguish between selectivity and intensity of attention. Selectivity refers to the process which modulates responsiveness to specific stimuli constellations by giving priority to certain stimuli, whereas intensity describes the ability to activate and maintain attention over time. In addition to selectivity and intensity components of attention, a supervisory attentional system (SAS) is assumed to act as a control mechanism modulating the two dimensions of selectivity and intensity (Van Zomeren \& Brouwer, 1994). Therefore, we examined for the first time the influence of risperidone on attentional functions in children with ADHD+DBD with three different attention related tasks: (1) a sustained attention task to examine intensity aspects of attention; (2) a divided attention task to detect changes in selectivity aspects of attention and (3), a Go/Nogo task to examine the inhibitory control as a measurement for impulsivity. We compared risperidone treated children with $\mathrm{ADHD}+\mathrm{DBD}$ and normal IQ with an age and IQ matched group of normal controls (NC). According to previous studies, we assumed that children with ADHD+DBD were more impulsive and that they had more attentional problems than NCs before risperidone treatment. Due to the sedative effect of risperidone, we hypothesized that the children showed an effect of cognitive slowing. Furthermore, we assume a significant improvement on aggression scales and an enhancement of the related laboratory task measuring impulsivity. 


\section{Methods}

\section{Participants and Selection Procedure}

A total of 23 children with the comorbid condition of ADHD and ODD/CD (hyperkinetic conduct disorder [ADHD+DBD]), as defined by ICD-10 (World-Health-Organization, 1993) plus 23 healthy controls, aged $8-15$, participated in this study. Prior to the study, all the children including the control group underwent an extensive psychiatric examination conducted by an experienced child psychiatrist. A further psychiatric classification was then determined on the basis of a German semi-structured interview with the parents and the child (K-DIPS; Unnewehr, Schneider, \& Margraf, 1995) performed by a second independent rater who was blind to the first rater's diagnosis. Table 1 provides participant details.

\begin{tabular}{lccc}
\hline & $\begin{array}{c}\text { Controls } \\
(\mathrm{n}=23)\end{array}$ & $\begin{array}{c}\text { ADHD+DBD } \\
(\mathrm{n}=23)\end{array}$ & Group difference \\
\hline Age $($ Mean $\pm \mathrm{SD})$ & $11.9 \pm 2.2$ & $11.9 \pm 2.1$ & $\mathrm{~ns}$ \\
IQ (Mean $\pm \mathrm{SD})$ & $96.9 \pm 10.9$ & $92.8 \pm 12.3$ & $\mathrm{~ns}$ \\
Sex (boy/girl) & $18 / 5$ & $21 / 2$ & $\mathrm{~ns}$ \\
\hline
\end{tabular}

Table 1. Baseline characteristics of the participants in the study

Exclusion criteria were general IQ below 80 (WISC-III) and any kind of neuroleptic medication prior to the study. Comorbid disorders were dysthymic disorder ( $\mathrm{n}=1$; DSM-IV: 300.4), major depression with a recent episode of minor severity (n=2; DSM-IV: 296.21) and anxiety disorders (social phobia [n=3; DSM-IV: 300.23], separation anxiety disorder [n=2;309.21]) in the ADHD+DBD group. Of the 23 patients, 21 subjects were males and 2 females. The main common characteristic of all children was a repetitive and persistent pattern of socially dysfunctional, aggressive, or defiant behavior that was sufficiently severe that school functioning and everyday-life was disturbed.

The control group (NC) was recruited from elementary and secondary schools. Out of 58 tested children 23 were matched to the ADHD+DBD group on age and IQ. The 23 participants in the NC group (18 male, 5 females) had no history of psychiatric diagnosis. The two groups were not different with respect to sex distribution $\left(\chi_{(1)}^{2}=1.52 ; \mathrm{p}=\mathrm{ns}\right)$, age $\left(t_{(44)}=0.06\right.$; $\mathrm{p}=\mathrm{ns})$ and IQ $\left(t_{(54)}=1.19 ; \mathrm{p}=\mathrm{ns}\right)$. Informed parental consent was obtained for all participants and the study was approved by the Ethics Committee of the University Hospital Aachen. 


\section{Medication protocol}

The ADHD+DBD group was recruited from our inpatient ward at the Department of Child and Adolescent Psychiatry. All children showed severe aggressive behavior and had a long history of disruptive and impulsive behaviors in different social settings. They received risperidone as part of a standardized treatment program, including parental education, single and group therapy. Risperidone was started at $0.25 \mathrm{mg} /$ day and increased on a twice-a-day schedule until a positive clinical response was obtained or side effects emerged. The daily doses varied between $1 \mathrm{mg}$ and $2.5 \mathrm{mg}$ (mean doses $=1.5 \mathrm{mg}$; $\mathrm{SD}=0.5$ ). 15 children were treated with a combination of risperidone and stimulants (methylphenidate $[n=5]$, methylphenidate HCI [n=8] and D-amphetamine [n=2]). Eight children got mono-therapy with risperidone. There was no discontinuation of the risperidone medication in any of these patients during the time of period studied. To control for the efficacy of the treatment the score of the IOWA Conners rating scale (Pelham, Milich, Murphy, \& Murphy, 1989; Collett, Ohan, $\&$ Myers, 2003) was averaged across 5 days before risperidone treatment and the last 5 days of the inpatient treatment. If the children received stimulants, these were deposed 48 hours before neuropsychological testing and during the week of rating the IOWA scale. The IOWA Conners rating scale contains two subscales, Inattention-Overactivity (IO) and Aggression (AG), each of which is five items.

All subjects received a standardized computerized neuropsychological assessment before treatment with risperidone (T1) and again four weeks after treatment onset with risperidone (T2). In order to control for retest-effects, also the normal controls were tested twice without medication four weeks apart. The order of the neuropsychological tests was randomized. Cognitive functions were assessed using the following computerized tests:

\section{Outcome measures}

The Sustained Attention Task involved the continuous and consecutive presentation of 50 series of twelve different dot patterns (600 signals; de Sonneville, 2000). In each series, an equal number of 3, 4, or 5-dot patterns were presented in a pseudo random manner. The child was instructed to push the 'yes' button with the dominant hand whenever a 4-dot pattern (target) was shown and to press the 'no' button with the non-dominant hand if the pattern contained 3 or 5 dots (non-targets). Divided Attention was a dual task which combined an visual and acoustic discrimination task (Fimm \& Zimmermann, 2001). Children were asked to respond as quickly as they could whenever a square appeared and if an alternating high and deep tone was repeated. One hundred stimuli were presented which contained 17 visual and 
16 acoustic goal targets. In the Go/Nogo Paradigm (Fimm et al., 2001) that assesses response selection/inhibition, a motor response with the dominant hand was either initiated (go) or inhibited (no-go) depending on whether an "x" (go) or a "+" (no-go) stimulus appeared. Visual stimuli appeared in random order for a duration of $200 \mathrm{~ms}$ with a variable inter-trial interval of a maximum of $1600 \mathrm{~ms}$. Fifty percent of the 40 stimuli were go trials. In each task the dependent measures were the reaction time (RT) and its standard deviation (SD), the number of misses (MIS) and false alarms (FA).

\section{Analysis}

Data were analyzed using SPSS 12 (SPSS Inc., 2003). The demographic characteristics were assessed by an independent $t$-test (IQ and age) and $\chi^{2}$-Pearson (sex distribution). Changes of the IOWA score within the risperidone group were analyzed with a paired sample $t$-test. Repeated measure group differences were evaluated using repeated measure analysis of variance (ANOVAR), with the diagnostic group as the independent variable, time of measurement as the within-subject factor and neuropsychological test scores as the dependent variables. It was decided not to adjust for multiple testing in order to avoid Type II errors and also to detect mild neuropsychological impairments on a more liberal level (Tabachnick \& Fidell, 2000).

\section{Results}

As expected, for the ADHD+DBD group the total score of the IOWA conners scale significantly decreased from $\mathrm{T} 1$ to $\mathrm{T} 2\left(\mathrm{~T} 1: \mathrm{M}=11.2( \pm 4.5), \mathrm{T} 2=8.4( \pm 2.9), t_{(22)}=3.34 ; \mathrm{p}=0.003\right)$. Significant improvement was found for both subscales of the IOWA conners scale (IO and AG: $\left(t_{(22)}>2.2 ; p<0.039\right)$. For more details see table 2 .

\begin{tabular}{lccc}
\hline & $\begin{array}{c}\mathrm{T}^{\mathrm{a}}{ }^{\mathrm{T}} \\
\mathrm{M}(\mathrm{SD})\end{array}$ & $\begin{array}{c}\mathrm{T}^{\mathrm{b})} \\
\mathrm{M}(\mathrm{SD})\end{array}$ & Group difference \\
\hline $\mathrm{IOWA}^{\mathrm{c})}$ & $11.2(4.5)$ & $8.4(2.9)$ & $\mathrm{p}=0.008$ \\
$\mathrm{IO}^{\mathrm{d})}$ & $5.9(2.7)$ & $4.3(1.9)$ & $\mathrm{p}=0.023$ \\
$\mathrm{AG}^{\mathrm{e})}$ & $5.4(2.7)$ & $4.1(1.5)$ & $\mathrm{p}=0.039$ \\
\hline
\end{tabular}

Table 2. Improvement on the IOWA Conners rating scale for the risperidone group $(n=23):{ }^{\text {a) }}$ Assessment before treatment, ${ }^{\text {b) }}$ Assessment four weeks after treatment onset, ${ }^{\text {c) }}$ IOWA Conners rating scale sum score, ${ }^{\text {d) }}$ Inattention-Overactivity (IO), ${ }^{\text {d) }}$ Aggression (AG). 
140 | Chapter 8

\section{$\underline{\text { Sustained Attention }}$}

For speed $\left(\mathrm{F}_{(1 / 44)}=0.9\right.$; ns) and number of $\mathrm{FA}\left(\mathrm{F}_{(1 / 44)}=0.97\right.$; ns $)$ no difference was found between NC and ADHD+DBD. However, both groups performed significantly better in the second measure on these two variables $\left(\mathrm{F}_{(1 / 44)}>10.28 ; \mathrm{p}<0.003\right)$. The performances for speedfluctuation $\left(\mathrm{F}_{(1 / 44)}=2.95 ; \mathrm{ns}\right)$ and number of MIS $\left(\mathrm{F}_{(1 / 44)}=0.06\right.$; ns) were comparable between both measurement points. Furthermore, the children with ADHD+DBD had a significant higher speedfluctuation $\left(\mathrm{F}_{(1 / 44)}=9.24 ; \mathrm{p}=0.004\right)$ and more number of MIS $\left(\mathrm{F}_{(1 / 44)}=5.51 ; \mathrm{p}=\right.$ 0.024) than NC. No influences of the risperidone medication were verified for any of the dependent measures for the sustained attention task $\left(\mathrm{F}_{(1 / 44)}<1.81 ; \mathrm{ns}\right)$. For details see table 3 .

\section{Divided Attention}

For all variables no difference could be detected between $\mathrm{NC}$ and $\mathrm{ADHD}+\mathrm{DBD}\left(\mathrm{F}_{(1 / 44)}<0.63\right.$; $n s)$. The results of RT and its SD did not change significantly at $\mathrm{T} 2\left(\mathrm{~F}_{(1 / 44)}<3.16\right.$; ns), whereas both error rates, $\mathrm{FA}\left(\mathrm{F}_{(1 / 44)}=7.4 ; \mathrm{p}=0.009\right)$ as well as $\operatorname{MIS}\left(\mathrm{F}_{(1 / 44)}=8.15 ; \mathrm{p}=0.007\right)$, decreased. No significant influence of the risperidone medication was detected for any of the divided attention variables $\left(\mathrm{F}_{(1 / 44)}<1.75 ; \mathrm{ns}\right)$.

\section{$\underline{\text { Go/Nogo }}$}

For RT and its SD no within $\left(\mathrm{F}_{(1 / 44)}<0.56\right.$; ns $)$ or between subject effect $\left(\mathrm{F}_{(1 / 44)}<0.84\right.$; ns $)$ could be detected. The number of MIS was comparable between the two groups $\left(\mathrm{F}_{(1 / 44)}=2.74\right.$; ns), whereas the number of FA, a measure for impulsivity, was significantly higher in the ADHD+DBD group $\left(\mathrm{F}_{(1 / 44)}=10.01 ; \mathrm{p}=0.003\right)$. Furthermore, all children had fewer MIS on the second measure $\left(\mathrm{F}_{(1 / 44)}=5.58 ; \mathrm{p}=0.023\right)$. Again, no significant influence of the risperidone medication was detected for any of the Go/Nogo variables $\left(\mathrm{F}_{(1 / 44)}<1.81\right.$; ns). 


\begin{tabular}{|c|c|c|c|c|c|c|c|}
\hline & \multicolumn{2}{|c|}{$\begin{array}{l}\text { Controls }(\mathrm{n}=23) \\
\mathrm{M}(\mathrm{SD})^{\mathrm{a})}\end{array}$} & \multicolumn{2}{|c|}{$\begin{array}{c}\text { Risperidone }(\mathrm{n}=23) \\
\mathrm{M}(\mathrm{SD})^{\mathrm{a})}\end{array}$} & \multirow{2}{*}{$\begin{array}{c}\text { Between } \\
\text { Subject effect } \\
\text { F (p) }\end{array}$} & \multirow{2}{*}{$\begin{array}{c}\text { Within } \\
\text { Subject effect } \\
\text { F (p) }\end{array}$} & \multirow{2}{*}{$\begin{array}{c}\begin{array}{c}\text { Interaction } \\
\text { (Risperidone) }\end{array} \\
\mathrm{F}(\mathrm{p})\end{array}$} \\
\hline & $\mathrm{T} 1^{\mathrm{b})}$ & $\mathrm{T} 2^{\mathrm{c})}$ & $\mathrm{T} 1^{\mathrm{b})}$ & $\mathrm{T} 2^{\mathrm{c})}$ & & & \\
\hline Speed $[\mathrm{sec}]$ & $13.7(3.9)$ & $11.7(3.4)$ & $14.1(4.2)$ & $13.3(4.4)$ & $0.90(\mathrm{~ns})$ & $10.28(\mathrm{p}=0.003)$ & $1.81(\mathrm{~ns})$ \\
\hline Speedfluctuation [sec] & $2.5(1.3)$ & $2.1(1.3)$ & $3.7(1.8)$ & $3.3(1.5)$ & $9.24(\mathrm{p}=0.004)$ & $2.95(\mathrm{~ns})$ & $0.1(\mathrm{~ns})$ \\
\hline Misses & $27.7(18.1)$ & $31.5(21.5)$ & $47.1(33.1)$ & $44.8(29.3)$ & $5.51(\mathrm{p}=0.024)$ & $0.06(\mathrm{~ns})$ & $0.87(\mathrm{~ns})$ \\
\hline \multicolumn{8}{|l|}{ Divided Attention } \\
\hline Reaction time $[\mathrm{ms}]$ & 757 (119) & $747(115)$ & $809(260)$ & $726(91)$ & $0.16(\mathrm{~ns})$ & $2.86(\mathrm{~ns})$ & $1.75(\mathrm{~ns})$ \\
\hline Standard deviation [ms] & $294(95)$ & $283(75)$ & $318(115)$ & $267(83)$ & $0.04(\mathrm{~ns})$ & $3.16(\mathrm{~ns})$ & $1.36(\mathrm{~ns})$ \\
\hline Reaction time $[\mathrm{ms}]$ & $431(81)$ & $445(67)$ & $454(120)$ & $437(105)$ & $0.08(\mathrm{~ns})$ & $0.02(\mathrm{~ns})$ & $1.81(\mathrm{~ns})$ \\
\hline Standard deviation [ms] & $112(46)$ & $113(39)$ & $120(37)$ & $127(49)$ & $0.84(\mathrm{~ns})$ & $0.56(\mathrm{~ns})$ & $0.30(\mathrm{~ns})$ \\
\hline False alarms & $3(2.8)$ & $3.1(2.7)$ & $6.2(4.6)$ & $5.6(4)$ & $10.01(p=0.003)$ & $0.18(\mathrm{~ns})$ & $0.52(\mathrm{~ns})$ \\
\hline Misses & $1(1.1)$ & $0.7(1)$ & $2(2.5)$ & $0.9(1.6)$ & $2.74(\mathrm{~ns})$ & $5.58(\mathrm{p}=0.023)$ & $0.93(\mathrm{~ns})$ \\
\hline
\end{tabular}

Table 3. Neuropsychological performance of the control group and risperidone group, shown separately for time of assessment: ${ }^{\text {a) }}$ Mean (standard deviation), ${ }^{\text {b) }}$ Assessment before treatment, ${ }^{c)}$ Assessment four weeks after treatment onset. 


\section{Discussion}

Our goal was to examine the influence of the neuroleptic agent risperidone on different attentional functions including intensity of attention, selectivity of attention and inhibitory control. We expected a cognitive slowing on different tasks and an improvement on the impulsivity related task. Previous research did not focus on cognitive adverse effects of risperidone or were either based on adults or included only children with ADHD+DBD with subaverage IQ. In concordance with previous research we found that children with ADHD+DBD show attentional deficits and that they are impulsive on laboratory tasks (e.g. van Goozen et al., 2004; Halperin et al., 1990; Hill, 2002; Lynam, 1996; Nigg, 2003; Oosterlaan, Logan, \& Sergeant, 1998; Oosterlaan \& Sergeant, 1998). Furthermore, for all tasks a decrement of errors and an enhancement of speed for the sustained attention task were detected due to the repetition of the tasks. More importantly, no influence of the risperidone medication on the neuropsychological tasks could be detected, neither as positive enhancement nor as adverse side effect.

The decrease in aggression and inattention-overactivity behavior scales under risperidone treatment in our sample is consistent with an emerging body of literature in pediatric psychopharmacology documenting the effectiveness of risperidone in the treatment of aggression in children and adolescents (e.g. Findling et al., 2004; Buitelaar et al., 2001). In addition, the children received beside risperidone a treatment program including parental education, single and group therapy. Thus, the improvement on the behavior scales could not only be interpreted in the light of risperidone treatment. Sedation could be a troublesome side effect (Buitelaar, 2000) and we assumed that sedation may affect particularly the performance in a computerized sustained attention task. It was hypothesized that the sedative effect of risperidone causes a cognitive slowing in the attentional task. However, no negative influence of the risperidone medication could be detected in our study. Nevertheless, the results are in concordance with previous research in children with subaverage IQ demonstrating that cognitive functions were not affected by risperidone treatment (Turgay et al., 2002; Snyder et al., 2002). Sedative and amnestic effects of psychotropic drugs occurred mainly after the first administrations (Nowakowska et al., 1999; Holland et al., 1994; Barrett et al., 2004) and it is possible that the sedative effects of risperidone disappear after a few weeks (Aman et al., 2002). In summary and in concordance with previous research (e.g. Findling et al., 2000; Aman et al., 2002; Frazier et al., 1999), we could demonstrate that the efficacy of risperidone to treat aggressive behavior in children is not due to the sedative effect of antipsychotics as was hypothesized by other authors (e.g. Campbell, Gonzalez, \& Silva, 1992). Furthermore, risperi- 
done produced no changes on attention variables. This is encouraged by Snyder et al. (2002) and Turgay et al. (2002). In their study with more than 100 children with subaverage IQ no deterioration of Verbal Learning Test and Continous Performance Test abilities could be detected due to risperidone treatment.

Taken together, risperidone is useful to treat impulsivity and aggression and it has no negative impact on attentional functions. Furthermore, it is not possible to enhance attentional functions or reduce impulsive behavior on laboratory tasks. Therefore, additional stimulant treatment seems to be necessary to treat the attentional deficits in children with ADHD+DBD. Aman and collegues (2004) demonstrated that the addition of stimulant and risperidone treatment causes no increase of adverse events.

Specifically, risperidone should be reserved for those children with severe aggressive behavior who failed multiple trials with other agents (Cesena et al., 2002). Risperidone should be used cautiously, because of the great range of possible side effects (Döpfner et al., 2003). Risperidone is useful in children with ADHD +DBD of early onset and it is associated with very significant improvements in this high percentage of difficult-to-treat population (Kewley, 1999), but one of the most pressing issues regarding the use of neuroleptics in young children is that little is known of the interaction between antipsychotics and the developing brain. However, the costs of caring for individuals with disruptive behavior disorders, which may include loss of productivity and costs of health care, housing, law enforcement, and security, as well as victim and family costs, are substantial (Werry, 1997).

In conclusion, the present study found that risperidone did not affect attention in children with ADHD+DBD. This interesting finding suggests that risperidone beneath a dosage of $2.5 \mathrm{mg}$ does not decrease attentional functions in children with ADHD+DBD. However, like all antipsychotics, risperidone should be used cautiously. This might be particularly true for children, whose brains are still developing. But untreated, the group of children and adolescents with ADHD+DBD have an extremely high incidence of long-term educational, psychiatric, and antisocial morbidity, and any risks associated with the use of risperidone need to be balanced against the poor prognosis of the untreated disorder in this group. 


\section{References}

Allain, H., Tessier, C., Bentué Ferrer, D., Tarral, A., Le Brenton, S., Gandon, J. M. et al. (2002). Effects of risperidone on psychometric and cognitive functions in healthy elderly volunteers. Psychophamacology, 165, 419-429.

Aman, M. G., Binder, C., \& Turgay, A. (2004). Risperidone Effects in the Presence / Absence of Psychostimulant Medicine in Children with ADHD, Other Disruptive Behavior Disorders, and Subaverage IQ. Journal of Child and Adolescent Psychopharmacology, 14, 243-254.

Aman, M., Buitelaar, J., De Smedt, G., Wapenaar, R., \& Binder, C. (2005). Pharmacotherapy of Disruptive Behavior and Item Changes on a Standardized Rating Scale: Pooled Analysis of Risperidone Effects in Children with Subaverage IQ. Journal of Child and Adolescent Psychopharmacology, 15, 220-232.

Aman, M. G., De Smedt, G., Derivan, A., Lyons, B., Findling, R. L., \& Risperidone Disruptive Behavior Study Group (2002). Double-Blind, Placebo-Controlled Study of Risperidone for the Treatment of Disruptive Behaviors in Children With Subaverage Intelligence. American Journal of Psychiatry, 159, 1337-1346.

American Psychiatric Association (1994). Diagnostic and Statistical Manual of Mental Disorders - DSM-IV. (4 ed.) Washington D.C.: American Psychiatric Association.

Armenteros, J. L., Whitaker, A. H., Welikson, M., Stedge, D. J., \& Gorman, J. (1997). Risperidone in adolescents with schizophrenia: an open pilot study. Journal of the American Academy of Child and Adolescent Psychiatry, 36, 694-700.

Arnold, L. E., Vitello, B., McDougle, C., Scahill, L., Shah, B., Gonzalez, N. M. et al. (2003). Parent-Defined Target Symptoms Respond to Risperidone in RUPP Autism Study: Customer Approach to Clinical Trials. Journal of the American Academy of Child and Adolescent Psychiatry, 42, 1443-1450.

Barch, D. M., Sheline, Y. I., Csernansky, J. G., \& Snyder, A. Z. (2003). Working Memory and Prefrontal Cortex Dysfunction: Specificity to Schizophrenia Compared with Major Depression. Biological Psychiatry, 53, 376-384.

Barkic, J., Filakovic, P., Radanovic Grguric, L., Koic, O., Laufer, D., Pozgain, I. et al. (2003). The influence of risperidone on cognitive functions in schizophrenia. Coll Antropology, 27 - Suppl 1, 111-118.

Barnard, L., Young, A. H., Pearson, J., Geddes, J., \& O'Brien, G. (2002). A systematic review of the use of atypical antipsychotics in autism. Journal of Psychopharmacology, 16, 93-101. 
Barrett, S. L., Bell, R., Watson, D., \& King, D. J. (2004). Effects of amisulpride, risperidone and chlorpromazine on auditory and visual latent inhibition, prepulse inhibition, executive function and eye movements in healthy volunteers. Journal of Psychopharmacology, 18, 156-172.

Bilder, R. M., Goldman, R. S., Volavka, J., Czobor, P., Hoptman, M., Sheitman, B. et al. (2002). Neurocognitive effects of clozapine, olanzapine, risperidone, and haloperidol in patients with chronic schizophrenia or schizoaffective disorder. American Journal of Psychiatry, 159, 1018-1028.

Bruggeman, R., van der Linden, C., Buitelaar, J. K., Gericke, G. S., Hawkridge, S. M., \& Temlett, J. A. (2001). Risperidone versus pimozide in Tourettes's disorder: a comparative double-bind parallel group study. Journal of Clinical Psychiatry, 62, 50-56.

Brunnauer, A., Geiger, E., \& Laux, G. (2003). Neuroleptics and cognition. Psychiatrische Praxis, 30 - Suppl 2, 106-109.

Buitelaar, J. K. (2000). Open-label treatment with risperidone of 26 psychiatricallyhospitalized children and adolescente with mixed diagnoses and aggressive behavior. Journal of Child and Adolescent Psychopharmacology, 10, 19-26.

Buitelaar, J. K., van der Gaag, R. J., Cohen Kettenis, P., \& Melman, C. T. (2001). A randomized controlled trial of risperidone in the treatment of aggression in hospitalized adolescents with subaverage cognitive abilities. Journal of Clinical Psychiatry, 62, 239-248.

Campbell, M., Gonzalez, N. M., \& Silva, R. R. (1992). The pharmacological treatment of conduct disorders and rage outbursts. Psychiatric Clinics of North America, 15, 69-85.

Cesena, M., Gonzalez Heydrich, J., Szigethy, E., Kohlenberg, T. M., \& DeMaso, D. R. (2002). A case series of eight aggressive young children treated with risperidone. Journal of Child and Adolescent Psychopharmacology, 12, 337-345.

Chen, P. S., Yang, Y. K., Su, S. F., Liao, Y. C., Chang, J. W., \& Yeh, T. L. (2004). Correlation between scores on Continuous Performance Test and plasma concentration for schizophrenic patients on risperidone. Psychiatry and Clinical Neurosciences, 58, 168-172.

Collett, B. R., Ohan, J. L., \& Myers, K. M. (2003). Ten-Year Review of Rating Scales. V: Scales Asessing Attention-Deficit/Hyperactivity Disorder. Journal of the Amarican Academy of Child and Adolescent Psychiatry, 42, 1015-1037.

de Sonneville, L. M. J. (2000). ANT 2.1 - Amsterdam Neuropsychological Tasks. Amstelveen: Sonar.

Döpfner, M. \& Lehmkuhl, G. (2003). Hyperkinetische Störungen (F90). In Deutsche Gesellschaft für Kinder und Jugendpsychiatrie und Psychotherapie (Ed.), Leitlinien zur Dia- 
gnostik und Therapie von psychischen Störungen im Säglings-,Kinders- und Jugendalter (2 ed., Deutscher Ärzte Verlag.

Fimm, B. \& Zimmermann, P. (2001). Testbatterie zur Aufmerksamkeitsüberprüfung (TAP) - Version 1.6. Herzogenrath: Psytest.

Findling, R. L. \& McNamara, N. K. (2004). Atypical antipsychotics in the treatment of children and adolescents: clinical applications. Journal of Clinical Psychiatry, 65 - Suppl 6, $30-44$.

Findling, R. L., McNamara, N. K., Branicky, L. A., Schluchter, M. D., Lemon, E. R. N., \& Blumer, J. L. (2000). A Double-Blind Pilot Study of Risperidone in the Treatment of Conduct Disorder. Journal of the American Academy of Child and Adolescent Psychiatry, 39, 509-516.

Frazier, J. A., Meyer, M. C., Biederman, J., Wozniak, J., Wilens, T. E., Spencer, T. J. et al. (1999). Risperidone treatment for juvenile bipolar disorder: A Retrospective Chart Review. Journal of the Amarican Academy of Child and Adolescent Psychiatry, 38, 960-965.

Gaffney, G. R., Perry, P. J., Lund, B. C., Bever Stille, K. A., Arndt, S., \& Kuperman, S. (2002). Risperidone versus clonidine in the treatment of children and adolescents with Tourette's syndrome. Journal of the Amarican Academy of Child and Adolescent Psychiatry, $41,330-336$.

Gilbert, D. L., Batterson, R., Sethuraman, G., \& Sallee, F. R. (2004). Tic Reduction With Risperidone Versus Pimozide in a Randomized, Double-Blind, Crossover Trial. Journal of the Amarican Academy of Child and Adolescent Psychiatry, 43, 206-214.

Grcevich, S. J., Findling, R. L., Rowane, W. A., Friedman, L., \& Schulz, S. C. (1996). Risperidone in the treatment of children and adolescents with schizophrenia: a retrospective study. Journal of Child and Adolescent Psychopharmacology, 6, 251-257.

Halperin, J. M., O’Brien, J. D., Newcorn, J. H., Healey, J. M., Pascualvaca, D. M., Wolf, L. E. et al. (1990). Validation of Hyperactive, Aggressive, and Mixed Hyperactive/Aggressive Childhood Disorders: A Research Note. Journal of Child Psychology and Psychiatry, 31, 455-459.

Hill, J. (2002). Biological, psychological and social processes in the conduct disorders. Journal of Child Psychology and Psychiatry, 43, 133-164.

Holland, R. L., Wesnes, K., \& Dietrich, B. (1994). Single dose human pharmacology of umespirone. European Journal of Clinical Pharmacology, 46, 461-468. 
Kaplan, S. L., Simms, R. M., \& Busner, J. (1994). Prescribing practices of outpatient child psychiatrists. Journal of the Amarican Academy of Child and Adolescent Psychiatry, 32, 577-581.

Keefe, R. S., Silva, S. G., Perkins, D. O., \& Lieberman, J. A. (1999). The effects of atypical antipsychotic drugs on neurocognitive impairment in schizophrenia: a review and meta-analysis. Schiziphrenia Bulletin, 25, 201-222.

Kewley, G. D. F. R. C. P. (1999). Risperidone in Comorbid ADHD and ODD/CD. Journal of the American Academy of Child and Adolescent Psychiatry, 38, 1327-1328.

King, B., Zwi, K., Nunn, K., Longworth, J., \& Dossetor, D. (2003). Use of risperidone in a paediatric population: an opservational study. Journal of Paediatrics and Child Health, 39, 523-527.

Leysen, J. E., Janssen, P. M. F., Gommeren, W., Wynants, J., Pauwels, P. J., \& Janssen, P. A. J. (1992). In vitro and in vivo receptor binding and effects on monoamine turnover in rat brain regions of the novel antipsychotic risperidone and ocaperidone. Molecular Pharmacology, 41, 494-508.

Liu, S. K., Chen, W. J., Chang, C. J., \& Lin, H. N. (2000). Effects of Atypical Neuroleptics on Sustained Attention Deficits in Schizophrenia: A Trial of Risperidone Versus Haloperidol. American College of Neuropsychopharmacology, 22, 311-319.

Lynam, D. R. (1996). The early identification of chronic offenders: Who is the fledgling psychopath? Psychological Bulletin, 120, 209-234.

McClellan, J. M. \& Werry, J. S. (2003). Evidence-Based Treatments in Child and Adolescent Psychiatry: An Inventory. Journal of the American Academy of Child and Adolescent Psychiatry, 42, 1388-1400.

McConville, B. J. \& Sorter, M. T. (2004). Treatment challenges and safety considerations for antpsychotic use in children and adolescents with psychoses. Journal of Clinical Psychiatry, 65, S20-S29.

McCracken, J. T., McGough, J., Shah, B., Cronin, P., Hong, D., Aman, M. G. et al. (2002). Risperidone in children with autism and serious behavioral problems. New England Journal of Medicine, 347, 314-321.

McShane, R., Keene, J., Gedling, K., Fairburn, C., Jacoby, R., \& Hope, T. (1997). Do neuroleptic drugs hasten cognitive decline in dementia? Prospective study with necropsy follow up. BMJ, 314, 266-270.

Morant, A., Mullas, F., Hernandez, S., \& Rosello, B. (2001). Pharmacological treatment with risperidone in children with behavior disorders. Rev Neurol, 33, 1-15. 
Nigg, J. T. (2003). Response Inhibition and Disruptive Behaviors - Toward a Multiprocess Conception of Etiological Heterogeneity for ADHD Combined Type and Conduct Disorder Early-Onset Type. Annals of the New York Academy of Sciences, 1008, 170-182.

Nowakowska, E., Chodera, A., \& Kus, K. (1999). Influence of olanzapine on cognitive functions and catalepsy in rats after single and chronic administration. Polish Journal of Pharmacology, 51, 295-300.

Oosterlaan, J., Logan, G. D., \& Sergeant, J. A. (1998). Response Inhibition in AD/HD, $\mathrm{CD}$, Comorbid AD/HD+CD, Anxious, and Control Children: A Meta-analysis of Studies with the Stop Task. Journal of Child Psychology and Psychiatry, 39, 411-425.

Oosterlaan, J. \& Sergeant, J. A. (1998). Response inhibition and response reengagement in attention-deficit/hyperactivity disorder, disruptive, anxious and normal children. Behavioural Brain Research, 94, 33-43.

Pelham, W. E., Milich, R., Murphy, D. A., \& Murphy, H. (1989). Normative data on hte IOWA Conners Teacher Rating Sclae. Journal of Clinical Child Psychology, 18, 259-262.

Scahill, L., Leckman, J. F., Schultz, R. T., Katsovich, L., \& Peterson, B. S. (2003). A placebo-controlled trial of risperidone in Tourette syndrome. Neurology, 60, 1130-1135.

Schreier, H. A. (1998). Risperidone for young children with mood disorders and aggressive behavior. Journal of Child and Adolescent Psychopharmacology, 8, 49-59.

Simeon, J., Milin, R., \& Walker, S. (2002). A retrospective chart review of risperidone use in treatment-resistant children and adolescents with psychiatric disorders. Progress in Neuropsychopharmacology and Biological Psychiatry, 26, 267-275.

Snyder, R., Turgay, A., Aman, M., Binder, C., Fisman, S., Carroll, A. et al. (2002). Effects of Risperidone on Conduct and Disruptive Behavior Disorders in Children With Subaverage IQs. Jornal of the American Academy of Child \& Adolescent Psychiatry, 41, 1026-1036.

SPSS Inc. (2003). SPSS (Version 12.0.1) [Computer software]. LEAD Technologies.

Tabachnick, B. G. \& Fidell, L. S. (2000). Using Multivariate Statistics. (4 ed.) New York: Allyn \& Bacon.

Turgay, A., Binder, C., Snyder, R., \& Fisman, S. (2002). Long-Term Safety and Efficacy of Risperidone for the Treatment of Disruptive Behavior Disorders With Subaverage IQs. Pediatrics, 110, e34.

Unnewehr, S., Schneider, S., \& Margraf, J. (1995). Kinder DIPS - Diagnostisches Interview bei psychischen Störungen im Kindes und Jugendalter. Heidelberg: Springer.

van Goozen, S. H. M., Cohen Kettenis, P. T., Snoek, H., Matthys, W., SwaabBarneveld, H., \& van Engeland, H. (2004). Executive functioning in children: a comparison 
of hospitalised ODD and ODD/ADHD children and normal controls. Journal of Child Psychology and Psychiatry, 45, 284-292.

Van Zomeren, A. H. \& Brouwer, W. J. (1994). Theories and Concepts of Attention. In A.H.Van Zomeren \& W. J. Brouwer (Eds.), Clinical Neuropsychology of Attention (pp. 7-38). New York, Oxford: Oxford University Press.

Werry, J. S. (1997). Severe conduct disorder - some key issues. Canadian Journal of Psychiatry, 42, 577-583.

World-Health-Organization (1993). The ICD-10 classifications of mental and behavioral disorders: Clinical descriptions and diagnostic guidelines 1992; diagnostic criteria for research. Geneva: WHO. 

Chapter 9:

Concluding Remarks 


\section{Introduction}

In order to treat children with psychiatric disorders appropriately, it is essential to understand the possible cognitive deficits that are linked to the psychiatric disorders. Furthermore, the changes of cognitive functions that are due to psychotropic treatment are an important issue for clinical practice. Therefore, the goals of this thesis were to learn more about the attentional dysfunctions in children and adolescents with psychiatric disorders and about the possible influence of psychotropics on their attentional functions. The results of the preceding chapters of this thesis contribute to our knowledge on both aspects. The thesis examined topics such as verbal memory and different aspects of attentional control in children and adolescents with anxiety or depressive disorder, attention deficit/ hyperactivity disorder (ADHD) and ADHD with comorbid disruptive behavior disorder (DBD) (chapter 2, $3 \& 4$ ). Furthermore, it addressed the influence of methylphenidate (MPH; chapter 4, 5 \& 6), sertraline (chapter 7), and risperidone (chapter 8 ) on cognitive functions in general, and particularly on attention. The following paragraphs illustrate to what extent the goals of the thesis were reached. First, they discuss neuropsychological deficits in children and adolescents with psychiatric disorders. Secondly, they present the neuropharmacological aspects of the thesis. Thirdly, they discuss the clinical implications of the results. Finally, they take a look at the implications of this study for future research.

\section{Attention Deficits in Children and Adolescents with Attention Deficit/ Hyperactivity Disorders, Disruptive Disorders and Emotional Disorders}

Until now, it remained unclear whether neurocognitive abilities are disturbed when using objective attention and memory measurements and, if so, which cognitive impairments are specifically associated with either anxiety disorders or childhood depression. This might be an important point for our understanding of the underlying cognitive impairment, as well as for the development and monitoring of a specific psychotherapeutic or psychopharmacological intervention in children with emotional disorders. The first study of this thesis (chapter 2) provides evidence for a memory impairment which was specifically associated with childhood depression, while an undisturbed attention performance was found for the anxiety and the depressed patient group. The results are similar to other studies on adult patients showing that depressive adults tend to have more problems with verbal memory (Fennig, Mottes, RicterLevin, Treves, \& Levkovitz, 2002; Goldberg et al., 1993) but do not show any deficits regarding attention-related tasks (Barch, Sheline, Csernansky, \& Snyder, 2003). Thus, the results contradict the hypothesis that memory deficits in mood disorders are the result of poor encod- 
ing caused by a deficit in attention (Sweeney, Wetzler, Stokes, \& Kocsis, 1989). In agreement with the adult literature on neurocognitive performance in patients with different kinds of anxiety disorders (e.g. Gladsjo et al., 1998), chapter 2 provides evidence that children with a social phobia or a generalized anxiety disorder do not differ from normal controls with regard to attention-related performance. Thus, the attention difficulties described in self-reports or teacher and parental ratings of anxious children are more likely caused by a bias in selective attention for emotional material (Dalgleish et al., 2003) and not by basic attentional deficits.

Evidence from research about neuropsychological deficits in ADHD or ADHD+DBD is primarily based on children under the age of 12 years (e.g. van Goozen et al., 2004; Halperin et al., 1990; Pennington \& Ozonoff, 1996) and these data suggest that attentional deficits in children with ADHD change with increasing age. Children with severe symptoms of hyperactivity-impulsivity and inattention, which were under the age of six, tend to show inhibition deficits, whereas older children with diagnosed ADHD tend to have problems in the intensityand selective parts of attention (chapter 4). However, there is no evidence regarding the influence of developmental processes on attention in relation to ADHD+DBD symptoms. Furthermore, there is very little information available about attention disorders in adolescents with ADHD and ADHD+DBD and the change of attentional deficits related to developmental processes. Therefore, chapter 3 analyzes age effects on the attentional system in children and adolescents with ADHD and ADHD+DBD. For the first time, two age groups within each clinical group were compared: children between 8-11 years of age and adolescents between 12-17 years of age. In agreement with previous research (e.g. Anderson, Anderson, Northam, Jacobs, \& Catroppa, 2001; Pennington et al., 1996; Oosterlaan, Logan, \& Sergeant, 1998) chapter 3 describes that the two clinical groups of children had more attentional problems than the control children. The ADHD group had more attentional problems than the ADHD+DBD group and the normal controls and the ADHD+DBD children could be described as more impulsive than the ADHD group. This is in accordance with previous research, wherein a group of children with combined hyperactive and aggressive behavior was more impulsive that the purely hyperactive or purely aggressive group and the hyperactive children were most inattentive (Halperin et al., 1990). Interestingly, chapter 3 demonstrates that the verified neuropsychological differences between NC, ADHD and ADHD+DBD in children between 8 and 11 years disappear in the adolescence. The performance of adolescents of the two clinical groups on these tests was comparable with that of age and IQ matched NC. 
Together, these results suggest that in-depth neuropsychological assessments with cognitive neuropsychological measures have a major contribution in the objective evaluation of attentionrelated functions in children and adolescents in a psychiatric setting. This is especially true for children and adolescents with ADHD. Behavior ratings of inattentive symptoms, for example, seem to be more influenced by objective measurements of motor activity than by objective measurements of attention. This puts into question the typical clinical practice of determining the attentional processes by only using subjective data, such as parental or teacher ratings.

\section{Cognitive Neuropharmacology}

Stimulant medication, especially MPH is the treatment of first choice for children with ADHD. More than 200 controlled studies have demonstrated the benefits and efficacy of MPH for school-age ADHD (Wilens \& Spencer, 2000) for a review). However, little is known about the sensitivity and specificity of levels of MPH to attention tasks, and only a limited number of studies are available so far. Therefore, one of the goals of this thesis was to evaluate MPH effects on computerized attention tasks with regard to different aspects: firstly, to compare MPH effects in pre-school and grade-school children (chapter 4); secondly, to investigate dosage-dependent effects on different attentional functions (chapter 5) and finally, to examine dosage-dependent effects of methylphenidate on motor activity and attention (chapter 6). Chapter 4 indicates that there is no specific difference between MPH effects in pre-school and grade school children. MPH significantly improves subjective and objective measurements of ADHD symptoms (Chapter 4, $5 \& 6$ ). Furthermore, hyperactivity is reduced in a dosagedependent manner (chapter 6), whereas MPH had differential effects on attentional functions (chapter 5). While improvement on alertness and focused and sustained attention seemed to be higher with higher dosages, inhibition and set-shifting performances were enhanced at a low dose but worsened at a moderate dose. Divided attention did not change at all. Thus, these data are in line with those presented in recent reviews (Solanto, 2002) suggesting linear improvements for more simple attention tasks in contrast to U-shaped dosage-response curves in more complex cognitive tasks. The differential dosage-dependent effects of MPH on attention might be due to a different representation of attentional functions in the brain as well as to the complex pharmacological actions of MPH at different parts of the brain.

During school age, cognitive dysfunctions could lead to learning difficulties and serious problems at school and consequently impair the patient's social, emotional and cognitive devel- 
opment. Beside the desirable enhancement of measurable attention functions of MPH in ADHD, other psychotropics are not being used to enhance or influence cognitive (dys-) functions. An example is sertraline, a selective serotonin reuptake inhibitor (SSRI), and risperidone, an atypical neuroleptic agent. Sertraline is used to treat emotional disorders like anxiety or depression (The Research Units on Pediatric Psychopharmacology Anxiety Study Group, 2001; Rynn, Siqueland, \& Rickels, 2001; Green, 2001), whereas risperidone has a place in the management of children with ADHD with severe DBD if other treatments have proven unsuccessful (Morant, Mullas, Hernandez, \& Rosello, 2001; Kewley, 1999; Simeon, Milin, \& Walker, 2002). However, the neuropsychological side effects of SSRI have never been systematically assessed in childhood psychiatric disorders, although animal and human studies indicate that these drugs may influence cognitive performance (Buhot, Martin, \& Segu, 2000). Information about the influence of risperidone on cognitive function is based on research with schizophrenic and healthy adults. The results for adults are inconsistent, but it could be that risperidone alters attention functions due to its sedative side effects (e.g. Cesena, Gonzalez Heydrich, Szigethy, Kohlenberg, \& DeMaso, 2002; Buitelaar, 2000; Buitelaar, van der Gaag, Cohen Kettenis, \& Melman, 2001; Aman, Binder, \& Turgay, 2004; McShane et al., 1997; Aman et al., 2002; Snyder et al., 2002). Furthermore, children are especially vulnerable to adverse effects, including sedation (McConville \& Sorter, 2004). This is why the neuropsychological side effects of psychotropic interventions in children and adolescents need to be carefully assessed. Thus, chapter 8 aims to study the influence of risperidone on different attentional systems. The results suggest that children with ADHD+DBD showed no change on the laboratory tests regarding impulsivity due to risperidone medication, whereas behavioral scores decreased. More importantly, the risperidone medication did not influence attention functions, neither as positive enhancement nor as an adverse side effect. Chapter 7 aimed to investigate the effect of sertraline treatment on verbal memory and attentional performance in children with anxiety disorders. The results suggest that sertraline in dosages of 25 t0 $100 \mathrm{mg}$ did not have any negative effects on attention-related performance. Although, behaviorally, it has been described that SSRIs may induce disinhibitory symptoms in children and adolescents (Damsa et al., 2004), no deterioration of inhibitory performance was found. In contrast to these positive effects of sertraline on attention performance in pediatric patients, the effects on memory function, in particular under complex and distracting conditions, are more worrying. A negative impact of sertraline on verbal memory was found. It is necessary to consider that learning under distracting circumstances and distinguishing between important and unimpor- 
tant information is one of the key abilities needed in school and may therefore have a considerable impact on school performance in children and adolescents.

\section{Clinical Implications}

The transferability of computerized attention tasks to everyday life has lead to controversial discussions. MPH effects on general behavior are not really associated with stimulant-related changes in attention functions (Van der Meere, Gunning, \& Stemerdink, 1999) and have been found to be more significant for behavioral variables than for cognitive variables (Solanto, 2002 for a review). Clinically, the fact that behavior ratings of inattentive symptoms seem to be more influenced by objective measures of motor activity than by objective measures of attention puts into question the typical clinical practice of determining the response to stimulant treatment of using only subjective measures, such as parental or teacher ratings. Children demonstrating a reduction of hyperactivity while on MPH might be considered as generally improved although they might still suffer from inattentiveness. Depending on the predominant attention deficit of a child, different dosages might be necessary to improve attention functions. Thus, it is not enough to examine the efficacy of psychotropic treatment with behavioral checklists. The results of these lists are primarily linked to hyperactivity and impulsivity. More MPH results in less hyperactive behavior and the attention functions of the child are overestimated due to its calm behavior. It is not possible to adequately measure inattention with these instruments because hyperactivity-impulsivity and inattention are two different entities. In addition, chapter 2 shows that children with anxiety disorders did not differ from normal controls with regard to laboratory attention performances, whereas self-reports or teacher and parental ratings indicated that anxious children were having attention problems. Again, the results between behavioral and laboratory measurements of inattentiveness were completely opposed. Furthermore, the results of these lists strongly depend on the judging person and judged situation. Thus, neuropsychological assessment appears to be a useful tool to measure attention in an objective way. In addition, the neuropsychological diagnostics are also relevant for disorders other than ADHD and should examine other cognitive domains like memory, executive functions, general functions (e.g. intelligence), language and visual-spatial skills (Calev, Preston, Samuel, \& Gorton, 1999).

\section{Implications for Future Research}

The results of the thesis emphasize that a neuropsychological assessment can be of added value to the psychiatric diagnostic procedure within pediatric and adolescent psychiatry. Be- 
sides identifying attention-related dysfunctions, a neuropsychological assessment can help to detect treatment efficacy or adverse side effects of psychotropic medications. However, the results of the different chapters raise new points of discussion that will influence future research.

The first point is motivation. According to the BIS/BAS theory of Gray (1994) the Behavioral Inhibition System (BIS) inhibits behavior in response to cues for punishment or non-reward and the Behavioral Activating System (BAS) is activated by cues for reward or nonpunishment. In line with this theory, children with, e.g., CD have more motivational problems (dominance of BAS over BIS) whereas children with ADHD (dysfunctional BIS) have more executive dysfunction deficits (van Goozen et al., 2004). In line with this, recent models about the development of ADHD and CD support the idea to make a distinction between (1) "reactive" (motivational) and (2) "executive" control processes (Nigg, 2003; Nigg, 2000). Nigg (2003) describes a model with different paths for children with ADHD and/or CD to explain the correlation between these two disorders. In the first (early onset, primary CD path), the children have problems with motivational inhibition and this system detects and responds to immediate contextual cues for punishment or social unfamiliarity. Several studies of children with ADHD generally failed to support the notion that there is a deficit in motivational inhibition (Nigg, 1999; Jaboni, Douglas, \& Baker, 1995), whereas motivational disinhibition in CD is well supported in behavioral and physiological data (Finn, Mazas, Justus, \& Steinmetz, 2002; O'Brian \& Frick, 1996). If socialization processes fail to compensate adequately, primary reactive problems should lead to secondary executive dysfunction, while CD would lead to possible comorbid ADHD.

The second path (executive disinhibition) begins in the toddler stage with primary weakness of the effortful control system. Several reviews have concluded that executive dysfunction is an important component in ADHD (Barkley, 1997; Pennington et al., 1996; Schachar, Tannock, \& Logan, 1993; Avila, Cuenca, Félix, Parcet, \& Miranda, 2004). As the system fails to develop normally, the regulation of reactive processes is weak, and those processes are secondarily affected. The longitudinal prediction is ADHD, with secondary problems in motivational responses. CD might develop secondarily, depending on family variables (Nigg, 2003). Thus, it is possible, that children and adolescents with ADHD+DBD differ from children and adolescents with ADHD on the motivational inhibition level. Future research, directed at different aspects of attentional control or psychotropic influences on cognition in children and adolescents, has to consider motivational aspects. 
The second point is the neighborhood socioeconomic context of the children and adolescents. It is possible that differences between clinical groups are caused by different family variables between these groups. For example, according to Ford et al. (2004) ADHD is only related to characteristics of the child, whereas development of DBD is strongly related to family variables. Therefore, it is possible that differences between ADHD and ADHD+DBD groups are compounded by socioeconomic variables. The precise interaction between neuropsychological deficits in pediatric and adolescent psychiatry and socioeconomic variables is an interesting and scarcely examined domain. Thus, future research on cognitive deficits in psychiatric disorders has to include, or to control for environmental variables like socioeconomic status.

A third factor guiding future research is the progress in the development of psychotropics. Drug development mainly focuses on monotherapy of DSM or ICD entities. This implies the possibility that some clinical targets are poorly served by this strategy. For example, the positive symptoms (delusions and hallucinations) are the clinical targets for which all current schizophrenia therapeutics were developed and for which they are most effective. Although these symptoms define the core of the DSM and ICD diagnostic constructs, it is the motivational and cognitive impairments of schizophrenia that are most associated with the profound long-term disability typically produced by the disease. One proposal for new therapeutics in schizophrenia is to dissect the DSM entity into component symptom complexes and to develop treatments for theses narrower "clinical targets", rather than try to develop a monotherapy for what is likely to be a heterogeneous disorder (Hyman \& Fenton, 2003). This implies a symptom-oriented drug development. Here, a neuropsychological assessment is one of the improved measurement tools that can be used to define new endpoints in the development of pharmacological and psychosocial therapeutics. This is especially true for the development of psychotropic drugs.

Finally, different neurotransmitter systems are associated with ADHD. MPH is a useful treatment for children with ADHD, but there are some disadvantages. Side effects, children that do not respond to $\mathrm{MPH}$, or the U-shape modification of executive functions under MPH are complicating factors. Another point is the low half time of 2-3 hours for MPH and the resulting variation of MPH plasma concentration. A possible new solution is atomoxetine. Data from clinical trials show atomoxetine to be well tolerated and effective in the treatment of ADHD in children, adolescent, and adults(Barton, 2005; Himpel, Banaschewski, Heise, \& Rothenberger, 2005; Banaschewski, Roessner, Dittmann, Santosh, \& Rothenberger, 2004; 
Michelson et al., 2004). Atomoxetine is the first non-stimulant to be approved for the treatment of ADHD and was licensed in the US in November 2002, in the UK in May 2004 and in Germany in December 2004. Both, the dopamine (DAT) and the norepinephrine transmitter system (NE) are involved in ADHD and in the treatment of ADHD (Pliszka, 2005 for a review). Atomoxetine is a highly selective inhibitor of the presynaptic noradrenaline transporter. In contrast to $\mathrm{MPH}$, atomoxetine produced a sharp increase in extracellular dopamine and norepinephrine levels in rodent frontal cortex but not in the nucleus accumbens or striatum (Bymaster et al., 2002). Furthermore, atomoxetine does not appear to have abuse potential and is associated with a benign side effect profile. However, until now there is no published data about the influence of atomoxetine on neuropsychological tasks. Therefore, future research has to evaluate to what extent attention parameters in children with ADHD change due to atomoxetine treatment. Furthermore, it is clinically important to know which ADHD children benefit from atomoxetine treatment.

\section{Conclusion}

In summary, a dedicated neuropsychological assessment can have added value in the diagnostic procedure within pediatric- and adolescent psychiatry. Firstly, this concerns the evaluation of the nature and extent of cognitive dysfunction in psychiatric diseases. The main focus of this thesis was on attention-related functions. Emotional disorders like anxiety and depressive disorder in children and adolescents appear not to be associated with a basic attention deficit, whereas children with ADHD do have attention deficits. An important factor is that the attention deficits in ADHD differ with regard to the age of the child or adolescent. Secondly, a neuropsychological assessment can be of importance in the verification of treatment effects. Thereby, not only positive effects of medication or training were evaluated, but also adverse events could be detected. In a clinically appropriate dosage, risperidone and sertraline do not influence attention functions, neither as positive enhancement nor as an adverse side effect. However, it is suggested that sertraline has a negative impact on verbal memory. The research with MPH suggests a differential dosage-dependent effect on attention-related functions. Linear improvements for more simple attention tasks are found, whereas a U-shaped doseresponse curve is suggested for more complex cognitive tasks. Taken together, the research described in this thesis suggests that a multidisciplinary approach into assessment and treatment of ADHD and related child psychiatric syndromes is of importance. Notably, the combined efforts from clinical and cognitive neuropsychology, psychopharmacology and child psychiatry have shown to be of value. 


\section{References}

Aman, M. G., Binder, C., \& Turgay, A. (2004). Risperidone Effects in the Presence / Absence of Psychostimulant Medicine in Children with ADHD, Other Disruptive Behavior Disorders, and Subaverage IQ. Journal of Child and Adolescent Psychopharmacology, 14, 243-254.

Aman, M. G., De Smedt, G., Derivan, A., Lyons, B., Findling, R. L., \& Risperidone Disruptive Behavior Study Group (2002). Double-Blind, Placebo-Controlled Study of Risperidone for the Treatment of Disruptive Behaviors in Children With Subaverage Intelligence. American Journal of Psychiatry, 159, 1337-1346.

Anderson, V., Anderson, P., Northam, E., Jacobs, R., \& Catroppa, C. (2001). Development of Executive Functions Through Late Childhood and Adolescence in an Australian Sample. Developmental Neuropsychology, 20, 385-406.

Avila, C., Cuenca, I., Félix, V., Parcet, M., \& Miranda, A. (2004). Measuring Impulsivity in School-Aged Boys and Examing Its Its Relationship With ADHD and ODD Ratings. Journal of Abnormal Child Psychology, 32, 295-304.

Banaschewski, T., Roessner, V., Dittmann, R. W., Santosh, P. J., \& Rothenberger, A. (2004). Non-stimulant medications in the treatment of ADHD. European Child and Adolescent Psychiatry, 13 Suppl 1, i102-116.

Barch, D. M., Sheline, Y. I., Csernansky, J. G., \& Snyder, A. Z. (2003). Working Memory and Prefrontal Cortex Dysfunction: Specificity to Schizophrenia Compared with Major Depression. Biological Psychiatry, 53, 376-384.

Barkley, R. A. (1997). Behavioral inhibition, sustained attention, and executive function: constructing a unified theory of ADHD. Psychological Bulletin, 121, 65-94.

Barton, J. (2005). Atomoxetine: a new pharmacotherapeutic approach in the management of attention deficit / hyperactivity disorder. Archives of Disease in Childhood, 90, i2629.

Buhot, M. C., Martin, S., \& Segu, L. (2000). Role of serotonin in memory impairment. Annals of Medicine, 32, 210-221.

Buitelaar, J. K. (2000). Open-label treatment with risperidone of 26 psychiatricallyhospitalized children and adolescente with mixed diagnoses and aggressive behavior. Journal of Child and Adolescent Psychopharmacology, 10, 19-26.

Buitelaar, J. K., van der Gaag, R. J., Cohen Kettenis, P., \& Melman, C. T. (2001). A randomized controlled trial of risperidone in the treatment of aggression in hospitalized adolescents with subaverage cognitive abilities. Journal of Clinical Psychiatry, 62, 239-248. 
Bymaster, F. P., Katner, J. S., Nelson, D. J., Hemrick-Lueke, S. K., Threlkeld, P. G., Heiligenstein, J. H. et al. (2002). Atomoxetine increases extracellular levels of norepinephrine and dopamine in prefrontal cortex of rat: a potential mechanism for efficacy in attention deficit/hyperactivity disorder. Neuropsychopharmacology, 27, 699-711.

Calev, A., Preston, T., Samuel, S., \& Gorton, G. E. (1999). Clinical Neuropsychological Assessment of Psychiatric Disorders. In A.Calev (Ed.), Assessment of Neuropsychological Functions in Psychiatric Disorders (pp. 1-32). Washington: American Psychiatric Press.

Cesena, M., Gonzalez Heydrich, J., Szigethy, E., Kohlenberg, T. M., \& DeMaso, D. R. (2002). A case series of eight aggressive young children treated with risperidone. Journal of Child and Adolescent Psychopharmacology, 12, 337-345.

Dalgleish, T., Taghavi, R., Neshat-Doost, H., Moradi, A., Canterbury, R., \& Yule, W. (2003). Patterns of processing bias for emotional information across clinical disorders: a comparison of attention, memory, and prospective cognition in children and adolescents with depression, generalized anxiety, and posttraumatic stress disorder. Journal of Clinical Child Psychology, 32, 10-21.

Damsa, C., Bumb, A., Bianchi-Demicheli, F., Vidailhet, P., Sterck, R., Andreoli, A. et al. (2004). "Dopamine-dependent" side effects of selective serotonin reuptake inhibitors: a clinical review. Journal of Clinical Psychiatry, 65, 1064-1068.

Fennig, S., Mottes, A., Ricter-Levin, G., Treves, I., \& Levkovitz, Y. (2002). Everydag Memory and Laboratory Memory Tests: General Function Predictors in Schizophrenia and Remitted Depression. Journal of Nervous and Mental Disease, 190, 677-682.

Finn, P. R., Mazas, C. A., Justus, A. N., \& Steinmetz, H. (2002). Early-onset alcoholism with conduct disorder: Go/No-Go learning deficits. working memory capacity, and personality. Alcoholism: Clinical and Experimental Research, 26, 186-206.

Ford, T., Goodman, R., \& Meltzer, H. (2004). The relative importance of child, family, school and neighbourhood correlates of childhood psychiatric disorder. Social Psychiatry and Psychiatric Epidemiology, 39, 487-496.

Gladsjo, J. A., Rapaport, M. H., McKinney, R., Lucas, J. A., Rabin, A., Oliver, T. et al. (1998). A neuropsychological study of panic disorder: Negative findings. Journal of Affective Disorders, 49, 123-131.

Goldberg, T. E., Gold, J. M., Greenberg, R., Griffin, S., Schulz, C., Pickar, D. et al. (1993). Contrasts between patients with affective disorders and patients with affective disorders and patients with schizophrenia on a neuropsychological test battery. American Journal of Psychiatry, 150, 1355-1362. 
Gray, J. A. (1994). Framework for a taxonomy of psychiatric disorders. In S.H.M.van Goozen, N. E. van de Poll, \& J. E. Sergeant (Eds.), Emotions: Essay on emotion theory (pp. 29-59). Hillsdale: Erlbaum.

Green, W. H. (2001). Child and Adolescent Psychopharmacology. (3 ed.) Philadelphia: Lippincott Williams \& Wilkins.

Halperin, J. M., O’Brien, J. D., Newcorn, J. H., Healey, J. M., Pascualvaca, D. M., Wolf, L. E. et al. (1990). Validation of Hyperactive, Aggressive, and Mixed Hyperactive/Aggressive Childhood Disorders: A Research Note. Journal of Child Psychology and Psychiatry, 31, 455-459.

Himpel, S., Banaschewski, T., Heise, C. A., \& Rothenberger, A. (2005). The safety of non-stimulant agents for the treatment of attention-deficit hyperactivity disorder. Expert Opinion in Drug Safety, 4, 311-321.

Hyman, S. E. \& Fenton, W. S. (2003). Whar are the right targets for psychopharmacology? Science, 299, 350-351.

Jaboni, F., Douglas, V. I., \& Baker, A. G. (1995). Effects of reward and response costs on inhibition in ADHD children. Journal of Abnormal Child Psychology, 104, 232-240.

Kewley, G. D. F. R. C. P. (1999). Risperidone in Comorbid ADHD and ODD/CD. Journal of the American Academy of Child and Adolescent Psychiatry, 38, 1327-1328.

McConville, B. J. \& Sorter, M. T. (2004). Treatment challenges and safety considerations for antpsychotic use in children and adolescents with psychoses. Journal of Clinical Psychiatry, 65, S20-S29.

McShane, R., Keene, J., Gedling, K., Fairburn, C., Jacoby, R., \& Hope, T. (1997). Do neuroleptic drugs hasten cognitive decline in dementia? Prospective study with necropsy follow up. $B M J, 314,266-270$.

Michelson, D., Buitelaar, J. K., Danckaerts, M., Gillberg, C., Spencer, T. J., Zuddas, A. et al. (2004). Relapse prevention in pediatric patients with ADHD treated with atomoxetine: a randomized, double-blind, placebo-controlled study. Journal of the American Academy of Child and Adolescent Psychiatry, 43, 896-904.

Morant, A., Mullas, F., Hernandez, S., \& Rosello, B. (2001). Pharmacological treatment with risperidone in children with behavior disorders. Rev Neurol, 33, 1-15.

Nigg, J. T. (1999). The ADHD response inhibition deficit as measured by the Stop Task: replication with DSM-IV combined type, extension, and qualification. Journal of Abnormal Child Psychology, 27, 391-400. 
Nigg, J. T. (2003). Response Inhibition and Disruptive Behaviors - Toward a Multiprocess Conception of Etiological Heterogeneity for ADHD Combined Type and Conduct Disorder Early-Onset Type. Annals of the New York Academy of Sciences, 1008, 170-182.

Nigg, J. T. (2000). On Inhibition/Disinhibition in Developmental Psychopathology: Views From Cognitive and Personality Psychology and a Working Inhibition Taxonomy. Psychological Bulletin, 126, 220-246.

Oosterlaan, J., Logan, G. D., \& Sergeant, J. A. (1998). Response Inhibition in AD/HD, $\mathrm{CD}$, Comorbid AD/HD+CD, Anxious, and Control Children: A Meta-analysis of Studies with the Stop Task. Journal of Child Psychology and Psychiatry, 39, 411-425.

O’Brian, B. S. \& Frick, P. J. (1996). Reward dominance: associations with anxiety, conduct problems, and psychopathology in children. Journal of Abnormal Child Psychology, 24, 223-240.

Pennington, B. F. \& Ozonoff, S. (1996). Executive functions and developmental psychopathology. Journal of Child Psychology and Psychiatry and Allied Disciplines, 37, 51-87.

Pliszka, S. (2005). The Neuropsychopharmacology of Attention-Deficit / Hyperactivity Disorder. Biological Psychiatry, 57, 1385-1390.

Rynn, M. A., Siqueland, L., \& Rickels, K. (2001). Placebo-controlled trial of sertraline in the treatment of children with generalized anxiety disorder. American Journal of Psychiatry, 158, 2008-2014.

Schachar, R., Tannock, R., \& Logan, G. D. (1993). Inhibitory control, impulsiveness, and attention deficit hyperactivity disorder. Clinical Psychology Review, 13, 721-739.

Simeon, J., Milin, R., \& Walker, S. (2002). A retrospective chart review of risperidone use in treatment-resistant children and adolescents with psychiatric disorders. Progress in Neuropsychopharmacology and Biological Psychiatry, 26, 267-275.

Snyder, R., Turgay, A., Aman, M., Binder, C., Fisman, S., Carroll, A. et al. (2002). Effects of Risperidone on Conduct and Disruptive Behavior Disorders in Children With Subaverage IQs. Jornal of the American Academy of Child \& Adolescent Psychiatry, 41, 1026-1036.

Solanto, M. V. (2002). Dopamine dysfunction in AD/HD: integrating clinical and basic neuroscience research. Behavioural Brain Research, 130, 65-71.

Sweeney, J. A., Wetzler, S., Stokes, P., \& Kocsis, J. (1989). Cognitive functioning in depression. Journal of Clinical Psychology, 45, 836-842.

The Research Units on Pediatric Psychopharmacology Anxiety Study Group (2001). Fluvoxamine for the treatment of anxiety disorders in children and adolescents. New England Journal of Medicine, 344, 1279-1285. 
164 | Chapter 9

Van der Meere, J., Gunning, B., \& Stemerdink, N. (1999). The Effect of Methylphenidate and Clonidine on Response Inhibition and State Regulation in Children with ADHD. Journal of Child Psychology and Psychiatry, 40, 291-298.

van Goozen, S. H. M., Cohen Kettenis, P. T., Snoek, H., Matthys, W., SwaabBarneveld, H., \& van Engeland, H. (2004). Executive functioning in children: a comparison of hospitalised ODD and ODD/ADHD children and normal controls. Journal of Child Psychology and Psychiatry, 45, 284-292.

Wilens, T. E. \& Spencer, T. J. (2000). The stimulants revisited. Child and Adolescent Psychiatric Clinics of North AMerica, 9, 573-603. 
Appendix:

\title{
Reliability of attention and verbal memory tests for children and adolescents
}

\author{
T. Günther, B. Herpertz-Dahlmann, K. Konrad*
}

Objective: It is especially important for the repeated measurement of neuropsychological tests, that the instruments used are a sufficiently reliable. This is a special challenge in the field of child and adolescent psychiatry, because children continuously mature and develop. Method: The research team examined the retest-reliability of a verbal memory and attention test battery in a group of 33 healthy children with a 6 week interval between assessments. Results: The examined test battery is sufficiently reliable for the age group 8- 17 years. However, despite using parallel versions for the retesting, especially young children showed significant improvements in the retests because of the exercise effect. Conclusion: Neuropsychological retest situations, e.g. to examine treatment effectiveness of a psychotropic agent, have to be interpreted more carefully with regards to younger children.

* Data and parts of the appendix were published in "Zeitschrift für Kinder- und Jugendpsychiatrie" (2005) 33: 169-179 
166 | Appendix

\section{Introduction:}

The goal of neuropsychological testing is, among other things, to validate and diagnostically investigate the child's cognitive deficits, and to document its progress (Konrad \& HerpertzDahlmann, 2004). Neuropsychological testing is not only useful for children with a confirmed cerebral lesion, but is also beneficial if the child's psychiatric disease includes cognitive deficits, e.g. attention problems. (Melchers \& Lehmkuhl, 2000). In the classification system of the World Health Organization (ICD-10; Dilling, Mombour, \& Schmidt, 1993) and the American Psychiatric Association (DSM-IV; American Psychiatric Association, 1994), for example, the existence of attention deficits is essential for diagnosing an attention deficit- / hyperactivity disorder (ADHD). A detailed neuropsychological exam makes it possible to describe in detail which aspects of the attention system are affected. Furthermore, stimulants, especially methylphenidate, are the most widely prescribed psychotropic medication for treating ADHD (Greenhill et al., 2002). Interestingly, the diverse attention parameters change differently and dosage dependently under methylphenidate (Konrad, Günther, Hanisch, \& HerpertzDahlmann, 2004). In conclusion, a neuropsychological assessment is also a useful addition to the instruments that help evaluate psychotropic treatment effectiveness in ADHD cases.

However, the evaluation of psychotropic treatment effectiveness and the resulting problems regarding the interpretation of data gained from retesting is a special challenge in the treatment of children and adolescent. Beside exercise effects in the second round of tests, it is important to consider the continuous maturation, development and age of the child (Melchers et al., 2000). Therefore, it is necessary for such repeated testing, that the neuropsychological instruments used are sufficiently reliable, so that an interpretation of care effects, side effects and follow up is possible. Some established procedures that are used for adults have already been standardized for children also (cp. Fimm \& Zimmermann, 2001a), but less data is available about the reliability and the impact of test repetitions for this age group (cp. Földényi, Giovanoli, Tagwerker-Neuenschwander, Schallberger, \& Steinhausen, 2000). Paper-pencilprocedures like e.g. the CHIPASAT (Children's Auditory Serial Addition Task) have good norms (Johnson, Roethig Johnston, \& Middleton, 1988) and show good test-retest reliabilities (up to $\mathrm{r}=.90$ ), but also have exercise effects of up to 20\% (Dyche \& Johnson, 1991). Also, computer based tests like the Conner's Continuous Performance Test II (CCPT-II; Conners, Epstein, Angold, \& Klaric, 2003), or the Gordon Continuous Performance Test (GCPT; Gordon \& Mettelman, 1988) are found to have a moderate to good test-retest reliability for children under the age of 17 . But despite the great age variance in these studies, the influence age has on the reliability of the test was not added to the analyses. This has probably resulted 
in an overestimation of the test's reliability, because the test age and the retest interval are linked to the extent of the exercise effect (Westhoff, 1989). Therefore, in case of a test repetition, age related exercise effects make it difficult to interpret test results. Currently, it is not possible to identify in a test which is used for the evaluation of an intervention (e.g. such as methylphenidate), how far the change of the test performance from the first measurement to follow-up measurements is influenced by a learning effect, or based on the effect of the medication. Thus, the goal of this study is to examine the test-retest reliability of a test regarding attention- and a verbal memory tests in healthy children after a six week interval while taking their test age into consideration. The rationale for this study is that the use of reliable instruments, which have good test-retest reliability for different ages, should make it possible to measure treatment effects of psychotropics on cognitive functions more appropriately. Because of the importance of both attention and memory functions in children with ADHD and/or behavioral problems, particular memory and attention tests were used in this study.

\section{Method}

\section{$\underline{\text { Participants }}$}

A total of 33 children and adolescents ( 15 boys / 18 girls) between the ages of 8 and 17 years $(\bar{x}=12.8 ; \mathrm{SD}=2.5)$ and of average intelligence $(\bar{x}=105 ; \mathrm{SD}=10$; HAWAIK-III; Tewes, Schallberger, \& Rossmann, 2000) participated in this study. Prior to the study, all children underwent an extensive psychiatric examination conducted by an experienced child psychiatrist. The children were then further classified on the basis of a German semi-structured interview with the parents and the child (K-DIPS; Unnewehr, Schneider, \& Margraf, 1995). All subjects received a standardized computerized neuropsychological assessment and were tested twice, without medication, six weeks apart. The order of the neuropsychological tests was randomized. Parallel versions were used for the verbal memory, divided attention and set shifting tasks.

\section{Verbal Memory}

The German version of the auditory-verbal learning test (AVLT; Helmstaedter, Lendt, \& Lux, 2001) comprises a learning list and an interference list, which each consist of 15 semantically independent words. Furthermore, a recognition list of 60 words is added. For repeated tests, there are two parallel word lists. We tested following variables: 
- Free recall (the total amount of the correctly reproduced words of the first five trials),

- Working memory (the total amount of correctly remembered words after the first trial),

- Learning curve (the difference between the remembered words of the first and the fifth trial),

- Interference (the total amount of correctly reproduced words after presenting an alternative list with 15 words),

- Delayed recall (a 30 minutes delayed recall trial) and

- Recognition (out of a list of 60 words).

\section{Attention And Executive Functions}

The advantage of computer based tasks is primarily the increased accuracy in measuring speed (Krieger, Lis, \& Meyer Lindenberg, 2004). In Germany, the "Testbatterie zur Aufmerksamkeitsüberprüfung" (TAP)" is the test battery that is used most frequently (cp. Fimm \& Zimmermann, 2001b), but the test battery “Amsterdam Neuropsychological Tasks" was especially designed for the targeted group of children (de Sonneville, 2000). Based on these two computerized test batteries, the team put together a dedicated test battery for the present study.

Alertness was assessed by using a simple reaction time (RT) task (Fimm et al., 2001b). The child had to respond to the presence of a target stimulus by using its dominant hand.

The Sustained Attention Task involved the continuous and consecutive presentation of 50 series of twelve different dot patterns (600 signals; de Sonneville, 2000). Each series presented the child with an equal number of 3,4 , or 5 dot patterns in a pseudo random manner. The child was instructed to push the 'yes' button with the dominant hand whenever a 4-dot pattern (target) was shown, and to press the 'no' button with the non-dominant hand if the pattern contained 3 or 5 dots (non-targets).

Divided Attention was a dual task which combined a visual and an acoustic discrimination task (Fimm et al., 2001b). Children were asked to respond as quickly as they could whenever a square appeared, or if an alternating high and deep tone was repeated. One hundred stimuli were presented, containing 17 visual and 16 acoustic goal targets.

In the Go/No-go Paradigm (Fimm et al., 2001b) that assesses response selection/inhibition, a motor response with the dominant hand was either initiated (go) or inhibited (no-go) depending on whether an "x" (go) or a "+" (no-go) stimulus appeared. Visual stimuli appeared in 
random order for a duration of $200 \mathrm{~ms}$ with a variable inter-trial interval of a maximum of $1600 \mathrm{~ms}$. Fifty percent of the 40 stimuli were go trials.

The Visual Set Shifting task consisted of three parts (de Sonneville, 2000). The signal was a bar with a colored square. This square would jump from left to right or vice versa. Depending on the color of the square after the jump, the child had to copy the movement (part 1), or was required to mirror the movement of the square, i.e. press the left key in response to a movement from left to right or the right key for a movement from right to left (part 2). In part 3, the square might change color at any moment, upon which the child had to adjust its response. Parts 1 and 2 consisted of 40 trials each, and part 3 had 80 trials. The dependent measures were the number of errors as well as the RTs, separated by congruent and incongruent trials for part 3. For the others tasks, the dependent measures were the reaction time (RT) and its standard deviation (SD), the number of misses (MIS) and false alarms (FA).

\section{$\underline{\text { Statistical Analysis }}$}

To check the test-retest reliability of the different tasks, the data of the first measurement was correlated with the data of the second trial (Pearson). In general, a good test has a reliability of more than .80; reliabilities of over .90 are considered high (Bortz \& Döring, 2002). To avoid a type I error, a Hochberg's Bonferroni procedure was used to correct alpha $(\alpha)$ for multiple testing (Keselman, Cribbie, \& Holland, 2002). Therefore, only correlations with an $\alpha \leq 0.003$ were considered reliable. To examine the influence of the learning-effect, a paired t-test was used. To avoid type II errors, we decided not to adjust for multiple testing here. Moreover, a $90 \%$ confidence interval was generated for the score difference between the first and the second assessment. With respect to age, the participants were divided in two groups: children between $8-12$ years of age $(n=16)$ and adolescents between $13-17$ years of age $(n=17)$. The correlations and t-tests were separately applied to each age group. Furthermore, we compared the data of the first assessment of the two groups (independent t-test). The normal distribution of the dependent measures (skewness between \pm 1 ; curtosis between \pm 3 ) and homogeneity of their variance (Levene Test) were assessed.

\section{Results}

\section{Verbal Memory}

Analyzing the entire group ( $\mathrm{n}=33$ ), we detected a significant correlation between the first (AST 1) and the second (AST2) test for four of the six variables of the AVLT ( $r>.59 ; \mathrm{p}<$ $.001)$ : free recall, working memory, interference and delayed recall. Despite using a parallel 
word list, the children performed significantly higher on the second test with regards to the free recall and interference part $\left(\mathrm{t}_{(32)}>1.87 ; \mathrm{p}<0.07\right)$. There were no improvements regarding working memory and delayed recall $\left(\mathrm{t}_{(32)}<0.93\right.$; ns). The correlations were not significant regarding the learning curve and the recognition trial $(\mathrm{r}<.49 ; \mathrm{ns})$. Due to the fact that nearly all children got the highest score on the recognition trial, almost no variance was detectable for this dependent measure (kurtosis $>10$ ).

For a detailed presentation of the results see table 1.

\section{$\underline{\text { Attention Functions }}$}

The correlation between AST1 and AST2 of RT of the alertness task (TAP) was significant $(\mathrm{r}=.63 ; \mathrm{p}<0.001)$, and did not change within the six weeks $\left(\mathrm{t}_{(32)}=0.5 ; \mathrm{ns}\right)$, whereas its SD showed no significant correlation $(r=.41$; ns; see table 1$)$. The correlations of speed $(r=.85 ; \mathrm{p}<$ $0.001)$ and speed fluctuation $(r=.88 ; \mathrm{p}<0.001)$ of the sustained attention task (ANT) were high, but the children performed significantly better on the AST2 $\left(t_{(32)}>2.4 ; p<0.01\right)$. The number of MIS correlated also significantly $(\mathrm{r}=.72 ; \mathrm{p}<0.001)$ and did not change $\left(\mathrm{t}_{(32)}=0.9\right.$; $\mathrm{ns})$, whereas the FAs showed no correlation ( $\mathrm{r}=.38$; ns). In the divided attention task (TAP) only the number of MIS showed a significant correlation $(\mathrm{r}=.61 ; \mathrm{p}<0.001)$ and the children did not improve on the AST2 $\left(\mathrm{t}_{(32)}=2 ; \mathrm{ns}\right)$. No significant results were found for RT, SD and FA. For the Go/No-go paradigm (TAP), a significant correlation was only found for RT ( $\mathrm{r}=$ $.66 ; \mathrm{p}<0.001)$, but again, the performance on the AST2 was significantly better $\left(\mathrm{t}_{(32)}=3.7 ; \mathrm{p}=\right.$ 0.001). The results for SD, MIS and FA were not significant. For the set shifting task (ANT), all dependent values showed significant correlations between AST1 and AST $2(r>.68 ; p<$ 0.001): RT for the congruent and incongruent trials and the number of errors for both conditions. Except for the number of errors of the congruent trial $\left(\mathrm{t}_{(32)}=1.3\right.$; ns), the children improved on AST2 $\left(\mathrm{t}_{(32)}>3 ; \mathrm{p}<0.005\right)$.

\section{Comparing The Reliability Between Children And Adolescents}

With respect to the effect of age, we had a group of 16 children $(\bar{x}=10.9$; SD $=1.6)$ and a group of 17 adolescents $(\bar{x}=14.6 ; \mathrm{SD}=1.6)$. Except for the parameter 'learning curve', the adolescents were significantly better than the children on all dependent measures of the verbal memory test $\left(\mathrm{t}_{(31)}>2.2 ; \mathrm{p}<0.05\right)$. This is also true for the parameters of the alertness task $\left(\mathrm{t}_{(31)}\right.$ $>2.2 ; \mathrm{p}<0.05)$ and the divided attention task $\left(\mathrm{t}_{(31)}>2.2 ; \mathrm{p}<0.05\right)$. We found significant dif- 


\begin{tabular}{|c|c|c|c|c|c|}
\hline $\mathrm{n}=33$ & $\begin{array}{l}\text { 1. } \mathrm{AST}^{\mathrm{a})} \\
\mathrm{M}(\mathrm{SD})\end{array}$ & $\begin{array}{l}\text { 2. } \mathrm{AST}^{\mathrm{a})} \\
\mathrm{M}(\mathrm{SD})\end{array}$ & $r(p)^{b)}$ & $\mathrm{t}_{(\mathrm{df}=32)}(\mathrm{p})$ & $90 \% \mathrm{KI}^{\mathrm{c}}$ \\
\hline \multicolumn{6}{|l|}{ Verbal memory } \\
\hline Free recall & $59.0(9.3)$ & $61.3(7.6)$ & $0.65(<0.001)$ & $1.87(0.07)$ & -4.5 to -0.2 \\
\hline Working memory & $7.2(2.8)$ & $8.1(2.5)$ & $0.59(<0.001)$ & $0.93(\mathrm{~ns})$ & -1.1 to -0.3 \\
\hline Learning curve & $6.6(2.4)$ & $6.6(2.5)$ & $0.49(\mathrm{~ns})$ & -- & -7.4 to 0.7 \\
\hline Interference & $13.6(1.5)$ & $14.1(1.4)$ & $0.71(<0.001)$ & $2.87(0.007)$ & -0.9 to -0.2 \\
\hline Delayed recall & $13.8(1.6)$ & $13.6(1.8)$ & $0.69(<0.001)$ & $0.90(\mathrm{~ns})$ & -0.2 to 0.6 \\
\hline Recognition & $14.8(0.6)$ & $14.8(0.4)$ & $0.28(\mathrm{~ns})$ & -- & -0.2 to 0.1 \\
\hline \multicolumn{6}{|l|}{ Alertness } \\
\hline Reaction time [ms] & $247(25)$ & $245(26)$ & $0.63(<0.001)$ & 0.5 (ns) & -4.6 to -8.5 \\
\hline Standard deviation [ms] & $55(28)$ & $60(38)$ & $0.41(\mathrm{~ns})$ & -- & -16.5 to 5.5 \\
\hline \multicolumn{6}{|l|}{ Sustained Attention } \\
\hline Speed [sec.] & $11.7(3.5)$ & $10.8(3.5)$ & $0.85(<0.001)$ & $2.7(0.01)$ & 0.4 to 1.5 \\
\hline Speed fluctuation [sec.] & $2(1.2)$ & $1.8(1.3)$ & $0.88(<0.001)$ & $2.4(0.024)$ & 0.1 to 0.4 \\
\hline False alarms & $19.1(12.6)$ & $11.1(9)$ & $0.38(\mathrm{~ns})$ & -- & 4.3 to 11.7 \\
\hline Missing & $27.2(20)$ & $25(15.2)$ & $0.72(<0.001)$ & 0.9 (ns) & -2 to 6.3 \\
\hline \multicolumn{6}{|l|}{ Divided Attention } \\
\hline Reaction time $[\mathrm{ms}]$ & $711(80)$ & $719(90)$ & $0.5(\mathrm{~ns})$ & -- & -33 to 18.1 \\
\hline Standard deviation [ms] & $262(74)$ & $273(71)$ & $0.26(\mathrm{~ns})$ & -- & -37.7 to 15.5 \\
\hline False alarms & $2.9(3.5)$ & $1.4(1.2)$ & $0.43(\mathrm{~ns})$ & -- & 2.4 to 2.6 \\
\hline Missing & $3.9(2.8)$ & $3(3.4)$ & $0.61(<0.001)$ & $2(\mathrm{~ns})$ & 1.8 to 2 \\
\hline \multicolumn{6}{|l|}{ Go/No-go } \\
\hline Reaction time $[\mathrm{ms}]$ & $389(68)$ & $426(72)$ & $0.66(<0.001)$ & $3.7(0.001)$ & -54.7 to -20.5 \\
\hline Standard deviation [ms] & $93(29)$ & $97(27)$ & $0.32(\mathrm{~ns})$ & -- & -13.7 to 6.1 \\
\hline False alarms & $2.2(1.9)$ & $2.4(1.6)$ & $0.25(\mathrm{~ns})$ & -- & -0.8 to 0.5 \\
\hline Missing & $0.8(1.1)$ & $0.6(0.9)$ & $0.22(\mathrm{~ns})$ & -- & -0.1 to 0.6 \\
\hline \multicolumn{6}{|l|}{ Set Shifting } \\
\hline RT congruent $[\mathrm{ms}]$ & $1053(451)$ & $865(254)$ & $0.9(<0.001)$ & $4.4(<0.001)$ & 115 to 261 \\
\hline RT incongruent [ms] & $1086(453)$ & $900(268)$ & $0.82(<0.001)$ & $3.8(0.001)$ & 104 to 268 \\
\hline Errors congruent & $5.9(4.3)$ & $5(5.6)$ & $0.68(<0.001)$ & $1.3(\mathrm{~ns})$ & -0.3 to 2.2 \\
\hline Errors incongruent & $6.8(5.8)$ & $4.6(5.5)$ & $0.72(<0.001)$ & $3(0.005)$ & 1 to 3.5 \\
\hline
\end{tabular}

Table 1. Comparison between first and second assessment (AST): ${ }^{a)} 1$ st \& 2nd assessment: Mean (standard deviation); b) corrected for multiple testing; ${ }^{c)} 90 \%$ - confidence interval of the difference score 
ferences regarding RT and SD for the sustained attention task $\left(\mathrm{t}_{(31)}>4.6 ; \mathrm{p}<0.001\right)$, the Go/No-go paradigm $\left(\mathrm{t}_{(31)}>2.5 ; \mathrm{p}<0.02\right)$ and the visual set shifting task $\left(\mathrm{t}_{(31)}>4.6 ; \mathrm{p}<0.001\right)$. The amount of errors did not differ between children and adolescent, both for FA and MIS $\left(\mathrm{t}_{(31)}<1.4 ; \mathrm{p}>0.05\right)$. However, the mean performances of the adolescents were better for this dependent measure, too. Interestingly, the children and adolescents profited differently from the first assessment (see table 2). With regards to the reliable dependent measures, the children showed a learning effect for 9 of the 14 tasks, whereas the adolescents only improved on RT of the Go/No-go paradigm.

\begin{tabular}{|c|c|c|c|c|c|c|}
\hline & \multicolumn{2}{|c|}{$r^{\text {a) }}$} & \multicolumn{2}{|c|}{$t(p)^{b)}$} & \multicolumn{2}{|c|}{$90 \% \mathrm{KI}^{\mathrm{c})}$} \\
\hline & $8-12$ & $13-17$ & $8-12$ & $13-17$ & $8-12$ & $13-17$ \\
\hline \multicolumn{7}{|l|}{ Verbal memory } \\
\hline Free recall & 0.58 & 0.4 & $1.7(\mathrm{~ns})$ & 0.9 (ns) & -6.8 to 0.6 & -4.2 to 1.5 \\
\hline Working memory & 0.48 & 0.53 & $0.7(\mathrm{~ns})$ & $0.6(\mathrm{~ns})$ & -1.4 to 0.6 & -1.5 to 0.7 \\
\hline Learning curve & 0.81 & -0.13 & $3(0.009)$ & $1.2(\mathrm{~ns})$ & -1.2 to -0.3 & -0.8 to 0.1 \\
\hline Interference & 0.62 & 0.72 & 0.7 (ns) & $0.58(\mathrm{~ns})$ & -0.5 to 1.1 & -0.2 to 0.5 \\
\hline \multicolumn{7}{|l|}{ Delayed recall } \\
\hline Recognition & 0.59 & 0.79 & $1.1(\mathrm{~ns})$ & $0.96(\mathrm{~ns})$ & -4.1 to 19.7 & -10 to 2.9 \\
\hline \multicolumn{7}{|l|}{ Alertness } \\
\hline Reaction time & 0.81 & 0.67 & $2.5(0.023)$ & $1.2(\mathrm{~ns})$ & 0.4 to 2.4 & -0.2 to 1.1 \\
\hline Standard deviation & 0.85 & 0.8 & $2.2(0.046)$ & $1(\mathrm{~ns})$ & 0.1 to 0.7 & -0.1 to 0.3 \\
\hline Sustained Attention & 0.81 & 0.69 & $2.1(0.053)$ & $0.8(\mathrm{~ns})$ & 1.2 to 13.3 & 2.7 to 14.2 \\
\hline \multicolumn{7}{|l|}{ Speed } \\
\hline Speed fluctuation & 0.51 & 0.41 & $1.3(\mathrm{~ns})$ & $1.7(\mathrm{~ns})$ & -0.4 to 2.8 & 0 to 1.5 \\
\hline \multicolumn{7}{|l|}{ False alarms } \\
\hline Missing & 0.85 & 0.37 & $3.6(0.003)$ & $2.1(0.054)$ & -60.2 to -20.5 & -64.3 to -5.6 \\
\hline \multicolumn{7}{|l|}{ Divided Attention } \\
\hline Reaction time & 0.92 & 0.5 & $6.5(<0.001)$ & 0.7 (ns) & 268 to 465 & -28.7 to 68.9 \\
\hline Standard deviation & 0.76 & 0.81 & $4.2(0.001)$ & 1.7 (ns) & 197 to 484 & 0.4 to 82.4 \\
\hline False alarms & 0.6 & 0.8 & $2.5(0.04)$ & 0.6 (ns) & 0.5 to 4.3 & -2 to 1 \\
\hline Missing & 0.72 & 0.74 & $3.2(0.005)$ & $1.2(\mathrm{~ns})$ & 1.5 to 5 & -0.6 to 3.1 \\
\hline
\end{tabular}

Table 2. Comparison of the reliable parameters between healthy children (8-12 years) and healthy adolescents (13-17 years): ${ }^{\text {a) }}$ Correlation between 1st and 2 nd assessment (children

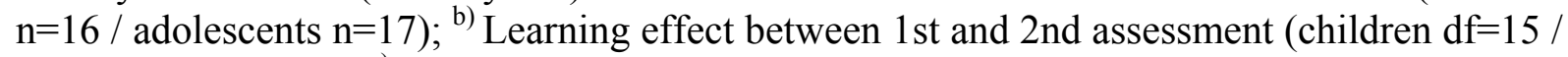
adolescents $\mathrm{df}=16) ;{ }^{\mathrm{c})} 90 \%$ - confidence interval of the difference score 


\section{Discussion}

The goal of this study was to examine the test-retest reliability for attention- and verbal memory tests in healthy children while taking their test age into consideration. We used memory and attention tests. The results indicate that the majority of the neuropsychological tests for attention- and memory functions seemed to be reliable. Furthermore, especially younger children showed a learning effect for repeated tests.

\section{$\underline{\text { Verbal Memory }}$}

In agreement with previous studies, the dependent variables of the AVLT have a good reliability for children and adolescents. According to Snow et al. (1988), the test-retest reliability of the AVLT lies between 0.38 and 0.7 for adults after one year. However, Lezak et al. (2004)describe learning effects when the test is repeated. That is why parallel lists were created for the AVLT, so that a mixture between the test-retest-and parallel test reliability emerged. A study with neurological patients and a retest interval of 8 to 12 months showed a very good reliability and a small learning effect (Helmstaedter et al., 2001). Our study was designed with a retest interval of six weeks. Four of six parameters of the verbal memory functions were interpretable and reliable. Only the interference part showed a clear learning effect for the children. In the second assessment, the children probably profited from the knowledge that the main list is asked for again after the interference list. This is an aspect of 'procedural learning'. The results of the recognition trial could not be interpreted, because nearly all children reached the maximum score (ceiling effect). In summary, the results of the study are in agreement with the study of Helmstaedter et al., so that exercise effects can be disregarded when retesting children and adolescents after a relatively short test-retest interval of 6 weeks.

\section{$\underline{\text { Attention }}$}

For the subtests of the TAP (alertness, divided attention and go/no-go), there is already a testretest reliability study by Földényi et al. (2000). A total of 94 children between the ages of seven and ten repeated the tasks with a test-retest interval of 16 to 81 days. In the research by Földényi et al. (2000) and in our study, the RT of the alertness task showed good test-retest correlations for children and adolescents and we could not detect an exercise effect. The SD value of the alertness task was not reliable in our study. Földényi et al. (2000) did not include SD in their analyses and therefore, it was not possible to compare their data to ours. It should 
be noted, however, that SD of alertness is an important variable because it is assumed that ADHDs show an increased SD compared to normal controls (Schachar, 1991).

In the Go/No-go paradigm, which is used to examine inhibition and selective attention, only the RT was reliable. The significant improvement of children and adolescents in the second assessment is due to an exercise effect. Accordingly, Földényi et al. (2000) describe the RT as being reliable and without a learning effect. Moreover, the MISs and FAs of this test are regarded as moderately reliable $(r=0.34)$. In our study, these two independent measures were analyzed separately and were not presumed to be one variable called "errors". According to our results, both parameters alone seemed not to be appropriate to make reliable statements about inhibition or the selective attention of children and adolescents.

For the divided attention task, only the number of MIS seemed to be a reliable parameter. The test-retest reliability was confirmed by the results of Földényi et al. (2000). However, they found a clear learning effect that was not replicated in our work, neither for the children nor for the adolescents. Furthermore, Földényi et al. (2000) found the RT to be moderate reliable $(\mathrm{r}=0.33)$.

The tasks of the Amsterdam neuropsychological tasks (ANT) were primarily developed for children and are standardized with relative large samples (de Sonneville, 2000), but there are no published findings about the test-retest reliability. However, in a study by (Huijbregts, de Sonneville, Licht, van Spronsen, \& Sergeant, 2002) 20 healthy control children $(\bar{x}=11.25$ years of age; $\mathrm{SD}=2.47$ ) took the sustained attention and the set shifting task from the ANT and were retested two weeks later. Based upon this data, the researchers found a good testretest reliability of the different parameters of the tests (sustained attention $r=0.82$; set shifting $r=0.53$, de Sonneville, 2003).

We were able to confirm good test-retest reliability for three variables of the sustained attention task (speed, speed fluctuation and number of MIS). This is due to the high number of stimuli (600), because a longer test and an increased amount of target stimuli results in an improved reliability (Westhoff \& Hagemeister, 1992). The group of children, however, showed a learning effect regarding the three variables despite the length of the test. This could not be detected in the adolescent group. The set shifting task, which assesses executive functions, was also reliable for RT and amount of errors. Again, the children performed significantly better on the second assessment compared to the adolescent group, although parallel forms of the test were used. 
In summary, we can draw three important conclusions regarding the attention variables: First of all, it is useful to evaluate intensity aspects of attention RT of the alertness task. Moreover, speed and number of MIS are good indicators for the sustained attention paradigm, and fluctuation of speed is a good indicator of continuously and consistently concentrated work. Regarding test repetition, it must be considered that the children work significantly faster and work speed fluctuates less in the second test. Therefore, especially the number of MIS should be used for the interpretation of test repetitions. Secondly, especially RT and the amount of MIS of the Go/No-go task are reliable parameters to appraise selective attention. Again, for the interpretation of test repetitions, the amount of MIS should be used due to the significant improvement of RT on the second test. Finally, RT and amount of errors of the set shifting task are reliable parameters. However, the results of test repetition should be interpreted with care for both errors and RT, because the children profit from the first test despite using a parallel version on the second trial.

In conclusion, the examined test battery including a verbal memory task and five different computerized attention paradigms is sufficiently reliable for the age group 8- 17 years. However, despite using parallel versions in the retest situation, especially young children showed significant improvements in the retest situation due to the exercise effect. In the adolescent group, this effect played a less important role. This interesting result suggests that neuropsychological retest situations, e.g. to examine how effective a psychotropic agent is, have to be interpreted more carefully with regards to younger children.

\section{References}

American Psychiatric Association (1994). Diagnostic and Statistical Manual of Mental Disorders - DSM-IV. (4 ed.) Washington D.C.: American Psychiatric Association.

Bortz, J. \& Döring, N. (2002). Forschungsmethoden und Evaluation für Human- und Sozialwissenschaftler. (3 ed.) Berlin: Springer.

Conners, C. K., Epstein, J. N., Angold, A., \& Klaric, J. (2003). Continuous Performance Test Performance in a normative Epidemiological Sample. Journal of Abnormal Child Psychology, 31, 555-562.

de Sonneville, L. M. J. (2000). ANT 2.1 - Amsterdam Neuropsychological Tasks. Amstelveen: Sonar. 
de Sonneville, L. M. J. (9-12-2003). Reliability of ANT: SA-Dots / SS-Vis. Ref Type: Personal Communication

Dilling, H., Mombour, W., \& Schmidt, M. H. (1993). Internationale Klassifikation psychischer Störungen: ICD-10. Bern: Verlag Hans Huber.

Dyche, G. M. \& Johnson, D. A. (1991). Development and evaluation of CHIPASAT, an attention test for children: II. Test-retest reliability and practice effect for a normal sample. Perceptual and Motor Skills, 72, 563-572.

Fimm, B. \& Zimmermann, P. (2001a). Ergänzungsmanual zur Testbatterie zur Aufmerksamkeitsprüfung (TAP) Version 1.6 - Kinder- und Jugendlichen Normen. Herzogenrath: Psytest.

Fimm, B. \& Zimmermann, P. (2001b). Testbatterie zur Aufmerksamkeitsüberprüfung (TAP) - Version 1.6. Herzogenrath: Psytest.

Földényi, M., Giovanoli, A., Tagwerker-Neuenschwander, F., Schallberger, U., \& Steinhausen, H. C. (2000). Reliabilität und Retest-Stabilität der Testleistungen von 7 - 10 jährigen Kindern in der computergestützten TAP. Zeitschrift für Neuropsychologie, 11, 1-11.

Gordon, M. \& Mettelman, B. B. (1988). The assessment of attention: 1. Standardization and reliability of a behavior-based measure. Journal of Clinical Psychology, 44, 682-690.

Greenhill, L. L., Pliszka, S., Dulcan, M. K., Bernet, W., Arnold, V., Beitchman, J. et al. (2002). Practice Parameter for the Use of Stimulant Medications in the Treatment of Children, Adolescents, and Adults. Journal of the American Academy of Child and Adolescent Psychiatry, 41, 26S-49S.

Helmstaedter, C., Lendt, M., \& Lux, S. (2001). Verbaler Lern- und Merkfähigkeitstest. Göttingen: Beltz Test GmbH.

Huijbregts, S. C. J., de Sonneville, L. M. J., Licht, R., van Spronsen, F., \& Sergeant, J. A. (2002). Short-term dietary interventions in children and adolescents with treated phenylketonuria: Effects on neuropsychological outcome of a well-controlled population. Journal of Inherited Metabolic Disease, 25, 419-430.

Johnson, D. A., Roethig Johnston, K., \& Middleton, J. (1988). Development and evaluation of an attentional test for head injured childre 1. Information processing capacity in a normal sample. Journal of Child Psychology and Psychiatry, 29, 199-208.

Keselman, H. J., Cribbie, R., \& Holland, B. (2002). Controlling the rate of Type I error over a large set of statistical tests. British Journal of Mathematical and Statistical Psychology, 55, 27-39. 
Konrad, K., Günther, T., Hanisch, C., \& Herpertz-Dahlmann, B. (2004). Differential effects of methylphenidate on attentional functions in children with attention deficit/ hyperactivity disorder. Journal of the American Academy of Child and Adolescent Psychiatry, 43, 191-198.

Konrad, K. \& Herpertz-Dahlmann, B. (2004). Neuropsychologie der Aufmerksamkeitsdefizit / Hyperaktivitätsstörung. In S.Lautenbacher \& S. Gauggel (Eds.), Neuropsychologie psychischer Störungen (pp. 387-410). Berlin: Springer.

Krieger, S., Lis, S., \& Meyer Lindenberg, A. (2004). Neuropsychologische Aspekte der Therapie mit Psychopharmaka. In S.Lautenbacher \& S. Gauggel (Eds.), Neuropsychologie psychischer Störungen (pp. 461-488). Berlin: Springer.

Lezak, M. D., Howieson, D. B., \& Loring, D. W. (2004). Neuropsychological Assessment. Oxfory: Oxford University Press.

Melchers, P. \& Lehmkuhl, G. (2000). Neuropsychologische Diagnostik im Kindesund Jugendalter. Zeitschrift für Kinder- und Jugendpsychiatrie und Psychotherapie, 28, 177187.

Schachar, R. (1991). Childhood Hyperactivity. Journal of Child Psychology and Psychiatry, 32, 155-191.

Snow, W. G., Tierney, M. C., Zorzitto, Fisher, R. H., \& Reid, D. W. (1988). One-year test-retest reliability of selected neuropsychological tests in older adults. Journal of Clinical and Experimental Neuropsychology, 12, 60.

Tewes, U., Schallberger, U., \& Rossmann, K. (2000). Hamburg Wechsler Intelligenztest für Kinder III. Göttingen: Hogrefe.

Unnewehr, S., Schneider, S., \& Margraf, J. (1995). Kinder DIPS - Diagnostisches Interview bei psychischen Störungen im Kindes und Jugendalter. Heidelberg: Springer.

Westhoff, K. (1989). Übungsabhängigkeit von Leistungen in Konzentrationstests. Diagnostica, 35, 122-130.

Westhoff, K. \& Hagemeister, C. (1992). Reliabilität von Fehlern in Konzentrationstests. Diagnostica, 38, 116-129. 

Attention plays a critical role in normal cognitive, emotional and social development. Attentional deficits could affect schooling or vocational education. Attention is, however, a broad concept. There are well-defined attentional functions or processes which need to be differentiated. For example, current concepts of attention generally distinguish between selectivity and intensity of attention. In addition, a distinction is made between so-called 'focused attention', 'selective attention', 'alertness', and 'sustained attention', whereas deficits in attentional function are thought to be related to problems in inhibitory processes which are guided by a proper functioning of prefrontal areas in the brain. The majority of studies in AttentionDeficit/Hyperactivity Disorder (ADHD) have shown that children with ADHD have attentional deficits.

Through the years, psychopharmacological approaches have proven to have beneficial effects not only on behavior but also on cognitive functions. Typically, psychotropics like methylphenidate (MPH) are used to improve attentional functions in children and adolescents. However, the literature is not unambiguous and the precise effects of MPH on cognitive functions are less clearly described. There are only a limited number of formal neuropsychological studies on cognitive deficits in disruptive behavior disorders (DBD) or emotional disorders. Furthermore, hardly any investigations exist on how the typical psychotropic agents actually impact attentional functions in children and adolescents with DBD. This is a serious problem due to the high comorbidity between the disorders and possible interaction effects.

Therefore, the aim of this thesis was to learn more about attentional dysfunctions in children and adolescents with psychiatric disorders and about the possible influence of psychotropics on attentional functions. An improvement in diagnostic processes and an objective tool to measure cognitive changes caused by psychotropics may make it possible to improve the efficacy of psychopharmacological treatment. This is why attentional functions in children and adolescents with ADHD, ADHD with comorbid DBD, anxiety disorder and depression were examined. Furthermore, the thesis investigated how the psychotropic agents typically used for the different disorders influenced cognitive functions.

The thesis consists of two parts. Part I (chapters 2 and 3) investigates neuropsychological deficits in children with ADHD, ADHD with comorbid DBD, anxiety disorder and depression. Part II (chapters 4 to 8 ) examines the influence of various psychopharmacological agents (methylphenidate, sertraline and risperidone) on attention, verbal memory and motor activity. 
Chapter 9 compiles and subsequently discusses the results described in the various chapters of the thesis.

Chapter 2 examines verbal memory and aspects of attentional control in children and adolescents with anxiety disorders or depressive disorders. It has been suggested that emotional disorders may be associated with impairments in neurocognitive functioning. However, it still remains unclear today whether neurocognitive abilities are disturbed when objective measures of attention and memory are applied and, if so, which cognitive impairments are specifically associated with either anxiety disorders or depression in childhood. Consequently, chapter 2 aimed to examine basic performance in attention and memory tasks in treatment-naïve children and adolescents with anxiety disorder or depressive disorder under drug-free conditions. A total of 34 children between 6 and 17 years of age with an anxiety disorder, 31 children with a depressive disorder, and 33 healthy controls were assessed with five different computerized attention tasks and the Auditory-Verbal Learning Test. Chapter 2 provides evidence for undisturbed attentional performance in both patient groups and a dissociation in memory functioning between anxious and depressed children. Memory impairment was found to be specifically associated with childhood depression.

The age differences for impulsivity and sustained attention deficits in ADHD with and without DBD are examined in chapter 3. Attention and executive function deficits are described for ADHD and ADHD +DBD. However, it seems that the described deficits are not specific to any one clinical group and evidence from research on neuropsychological deficits in $\mathrm{ADHD}$ or $\mathrm{ADHD}+\mathrm{DBD}$ is based primarily on children under 12 years of age. Some studies suggest that attention and executive function deficits in children with ADHD change with age, possibly due to brain development. Therefore, chapter 3 aimed to analyze attention and inhibition differences between children and adolescents with ADHD and ADHD+DBD. Two age groups within each clinical group were compared: children between 8 and 11 years of age and adolescents between 12 and 17 years of age. The results indicate that children with ADHD have more attentional problems than children with ADHD+DBD and that the ADHD+DBD group is more impulsive than the ADHD group. The differences between young ADHD, ADHD+DBD and normal controls in the used neuropsychological tasks were not detectable with higher age. The performance of adolescents with ADHD+DBD, ADHD or NC is comparable. 
Chapter 4 examines the age-dependent neuropsychological deficits and effects of MPH in children with ADHD. The neuropsychological performance of pre-school and grade-school children with ADHD was compared. Attention deficits in both age groups were expected, especially in attention intensity and in the inhibitory system. Brain maturation processes might result in differences in the distribution of cognitive subtypes across age groups. A second aim was to evaluate MPH effects on computerized attention tasks and to compare preschool and grade-school children. The pre-school group comprised 45 children aged 5-7 years; the grade-school group comprised 54 children aged 8-12 years. Children were tested on placebo and on MPH, employing tasks of alertness, sustained attention, focused attention, divided attention, and a cognitive conflict task. Both groups showed measurable attention deficits. While preschoolers were especially impaired in inhibitory functions, grade-schoolers most frequently exhibited deficits in attention intensity and selectivity. Positive MPH effects were documented for sustained attention in both age groups. Analysis of MPH effects in dependence of the type of attention impairment (supervisory functions vs. attention intensity / selectivity) revealed a positive relation between deficits in a specific attention domain and MPH effects. Age-dependent differences in attention dysfunctions might be due to brain maturational processes.

The focus of chapter 5 is on the differential effects of MPH on attentional functions in children with ADHD. Little is known about the sensitivity and specificity of levels of MPH to attention tasks, and only a limited number of studies are available. Therefore, the aim was to investigate dose-dependent effects on different attentional functions using a theoretically based selection of six attention paradigms. A total of 60 ADHD children aged between 8 and 12 years completed a randomized, double-blind, placebo-controlled, within-subject crossover trial with two doses of MPH (0.25 and $0.5 \mathrm{mg} / \mathrm{kg}$ body weight) and placebo. A neuropsychological test battery was applied, including tests of alertness and sustained, focused, and divided attention as well as two executive tests, the stop-signal paradigm and a visual set-shifting task. Results indicate that attentional functions are influenced differentially by MPH: intensity functions are best influenced by higher doses, executive functions by moderate doses, and selectivity functions by variable doses.

Chapter 6 evaluates the subjective and objective changes in motor activity and attention in children with ADHD. Although several studies have examined drug effects on either subjective or objective measures of attentional and motor functioning in children with ADHD, little is 
known about the relationship between these two areas of outcome measures. Studying the convergences and divergences of change in these two measures might provide a useful basis for optimizing MPH titration guidelines. Therefore, the aim of chapter 6 was to examine dose-dependent effects of MPH on motor activity and attention. A total of 44 ADHD children with the combined subtype completed a randomized, double-blind, placebo-controlled, crossover trial with 2 doses of MPH $(0.25 ; 0.5 \mathrm{mg} / \mathrm{kg}$ body weight $)$ and placebo. In each condition, computerized attention tasks were performed, teacher-behavior ratings obtained, and actigraph data collected, in both clinical and natural settings. The results revealed linear effects of MPH dose on actigraph data in the test session and at school as well as on sustained attention, while inhibitory control showed a quadratic dose-response curve. Multivariate regression analyses revealed that changes of both hyperactive-impulsive symptoms and inattentive symptoms could be explained by objective changes in motor activity. The results have implications for clinical practice, as the behavior ratings of ADHD symptoms appeared to be predominantly influenced by changes in motor activity.

Chapter 7 examines the influence of sertraline on attention and verbal memory in children and adolescents with anxiety disorders. Several studies demonstrate that sertraline is safe in the treatment of children and adolescents. However, their results for SSRI influence on cognitive functions, like attention and memory, remain contradictory. Thus, chapter 7 aims to investigate the effect of a 6-week course of sertraline treatment on verbal memory and attentional performance in children with anxiety disorders. Children with various anxiety disorders (social phobia, generalized and separation anxiety disorder; $n=28$ ), aged between 8 and 17 years, received a standardized computerized neuropsychological assessment before treatment and another six weeks after treatment onset with sertraline (daily dose range between 25 and $100 \mathrm{mg}$ ). The patient group was compared to healthy controls $(\mathrm{n}=28)$, who were matched for age and IQ and were also tested twice over a six-week period. Sertraline did not have any negative effects on attentional performance but did increase response speed in a divided attention paradigm. By contrast, performance in the interference part of a verbal memory task decreased. The described results also remained stable over a 12-week period after treatment onset. Thus, the cognitive side effects of sertraline seemed to differ slightly between pediatric patients and those described in adult patient groups, and should therefore be carefully assessed. 
The influence of risperidone on attentional functions in children and adolescents with ADHD and comorbid DBD is investigated in chapter 8 . Risperidone is a well tolerated neuroleptic agent and has a place in the management of children with ADHD with associated severe DBD, when other treatments have proven unsuccessful. However, little is known about cognitive side effects in ADHD+DPD children with average IQ. Therefore, the study examines the influence of risperidone on attentional functions in children with ADHD+DBD with three different attention related tasks: (1) a sustained attention task to examine intensity aspects of attention; (2) a divided attention task to detect changes in selectivity aspects of attention and (3), a Go/No-Go task to examine inhibitory control as a measurement of impulsivity. Risperidone-treated children $(n=23)$ with normal IQ and ADHD and severe comorbid DBD were compared with an age and IQ matched group of normal controls $(n=23)$. Under risperidone medication, children with ADHD+DBD improved on the inattention-overactivity and aggressive behavior scales. No influence of the risperidone medication on the three attention tasks could be detected, neither as a positive enhancement nor as adverse side effects. Risperidone is useful for treating aggression in children with ADHD with comorbid severe DBD, and it has no negative impact on attentional functions. However, additional stimulant treatment seems to be necessary to treat the attentional deficits in children with ADHD+DBD.

Chapter 9 gives some concluding remarks on the findings from the experimental research described in the thesis and on some implications. The main conclusions of the thesis are:

- Childhood depression is associated with memory impairment, whereas no attentional performance deficits are detectable for anxiety disorders and depression in pediatric patients.

- Children with ADHD have more attentional problems than children with ADHD+DBD, and children with ADHD+DBD are more impulsive than children with ADHD.

- The performance of adolescents with ADHD or ADHD+DBD in attention tasks is comparable with that of age and IQ matched normal controls.

- Children under the age of six with ADHD show deficits in attention control processes, whereas older children have problems in the intensity and selective parts of attention.

- There is no specific difference between MPH effects in pre-school or grade-school children with ADHD.

- MPH significantly improves subjective and objective measures of ADHD symptoms. Hyperactivity reduces with dose level, whereas MPH has differential effects on attentional functions. 
- Sertraline induces no deterioration of attentional performance in pediatric patients, whereas a negative impact of sertraline on verbal memory is detectable.

- Risperidone has no influence on attentional functions, neither as a positive enhancement nor as an adverse side effect.

Together, these conclusions suggest that in-depth neuropsychological assessment with cognitive neuropsychological measures has a major contribution to make to objectively evaluating attentional functions in children and adolescents in a psychiatric setting. For example, behavior ratings of inattentive symptoms are influenced more by objective measures of motor activity than by objective measures of attention. This puts into question the typical clinical practice of determining the response to stimulant treatment using only subjective measures, such as parental or teacher ratings. As a consequence, children who are less hyperactive while on MPH might be judged as generally improved while they may still suffer from inattentiveness. Depending on the predominant attentional deficit of a child, different doses might be necessary to improve attentional functions. Thus, it is not enough to examine the efficacy of psychotropic treatment with behavioral check lists: it is imperative that objective neuropsychological instruments with proven sensitivity, reliability, validity and theoretical background are used. The results of lists for behavioral observation are primarily linked to hyperactivity and impulsivity and are - generally- not very sensitive. Treatment with higher doses of MPH results in a reduction in hyperactive behavior which leads to an overestimation of the attentional functions of the child due to its calm behavior. It is not possible to measure inattention in an adequate manner with these behavioral scales because hyperactivity-impulsivity and inattention are two different entities. 